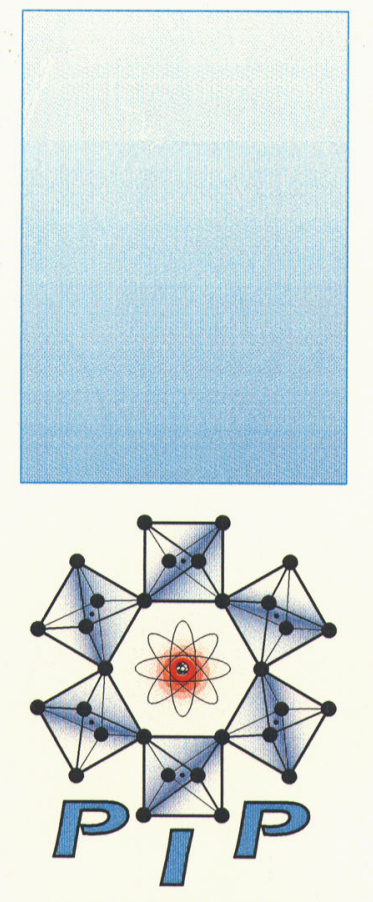

Fissile Materials Disposition Program

\title{
Design-Only Conceptual Design Report Plutonium Immobilization Plant
}

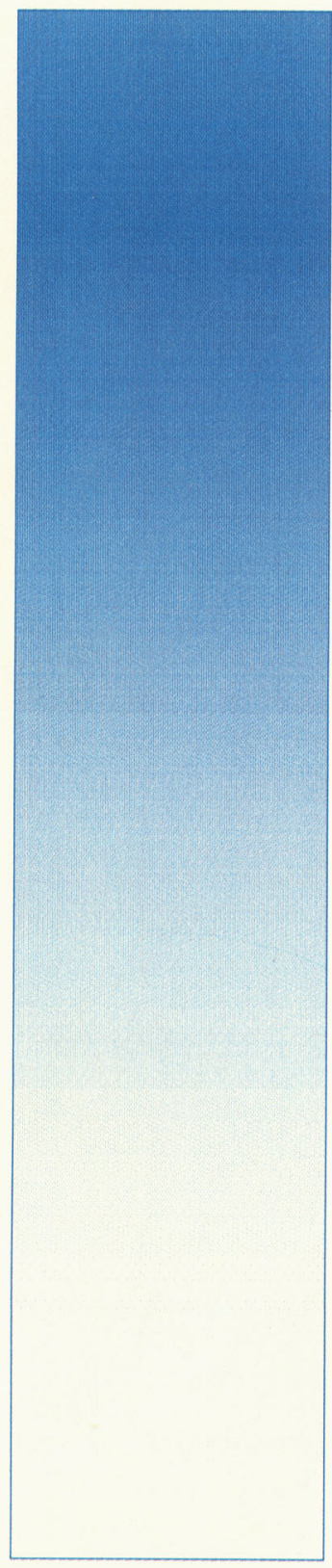

Prepared by Bechtel for

Lawrence Livermore National Laboratory

January 1999

Plutonium Immobilization Project Lawrence Livermore National Laboratory Livermore, California 94550 
UCRL-ID-131617 Rev. 1

PIP-98-I15

\title{
DISCLAIMER
}

This document was prepared as an account of work sponsored by an agency of the United States Government. Neither the United States Government nor the University of California nor any of their employees, makes any warranty, express or implied, or assumes any legal liability or responsibility for the accuracy, completeness, or usefuiness of any information, apparatus. product, or process disciosed, or represents that its use would not infringe privately owned rights. Reference herein to any specific commercial product, process, or service by trade name, trademark, manufacturer, or otherwise, does not necessarily constitute or imply its endorsement, recommendation, or favoring by the United States Government or the University of California. The views and opinions of authors expressed herein do not necessarily state or reflect those of the United States Government or the University of California, and shall not be used for advertising or product endorsement purposes.

\author{
This report has been reproduced \\ directly from the best available copy. \\ Available to DOE and DOE contractors from the \\ Office of Scientific and Technical Information \\ P.O. Box 62, Oak Ridge, TN 37831 \\ Prices availabie from $\{423 \mid 576-8401$
}

Available to the public from the

National Technical Information Service

U.S. Department of Commerce

5285 Port Royal Rd.

Springfield, VA 2216!

Work performed under the auspices of the U.S. Department of Energy by Lawrence Livermore National Laboratory under Contract W7405-ENG-48.

81047

(5) 


\section{Fissile Materials Disposition Program}

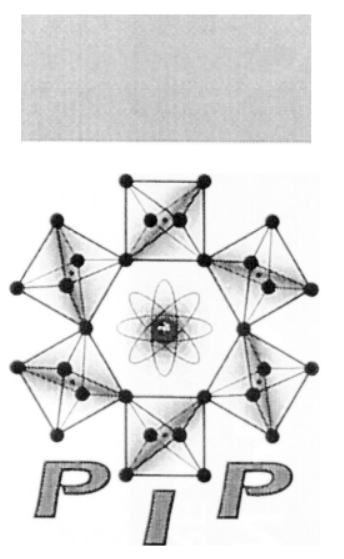

\section{Design-Only Conceptual Design Report Plutonium Immobilization Plant}

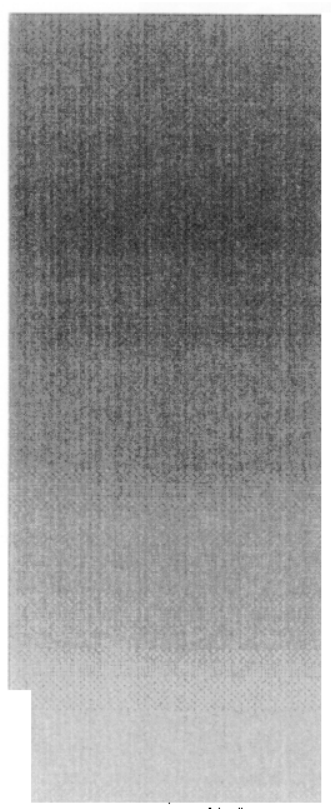

\section{Prepared by Bechtel for}

Lawrence Livermore National Laboratory

\section{January 1999}

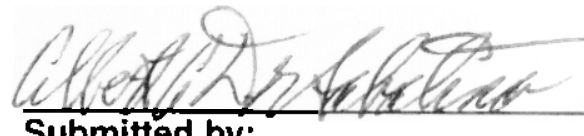

Submitted by:

Albert A. DiSabatino

Task Leader, Lawrence Livermore

National Laboratory

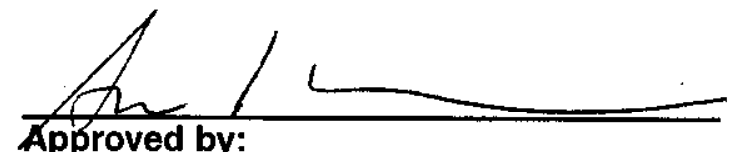

Andre Cygelman

Director, Materials and Immobilization Group, Office of Fissile Materials Disposition

Plutonium Immobilization Project

Lawrence Livermore National Laboratory Livermore, California $\mathbf{9 4 5 5 0}$ 


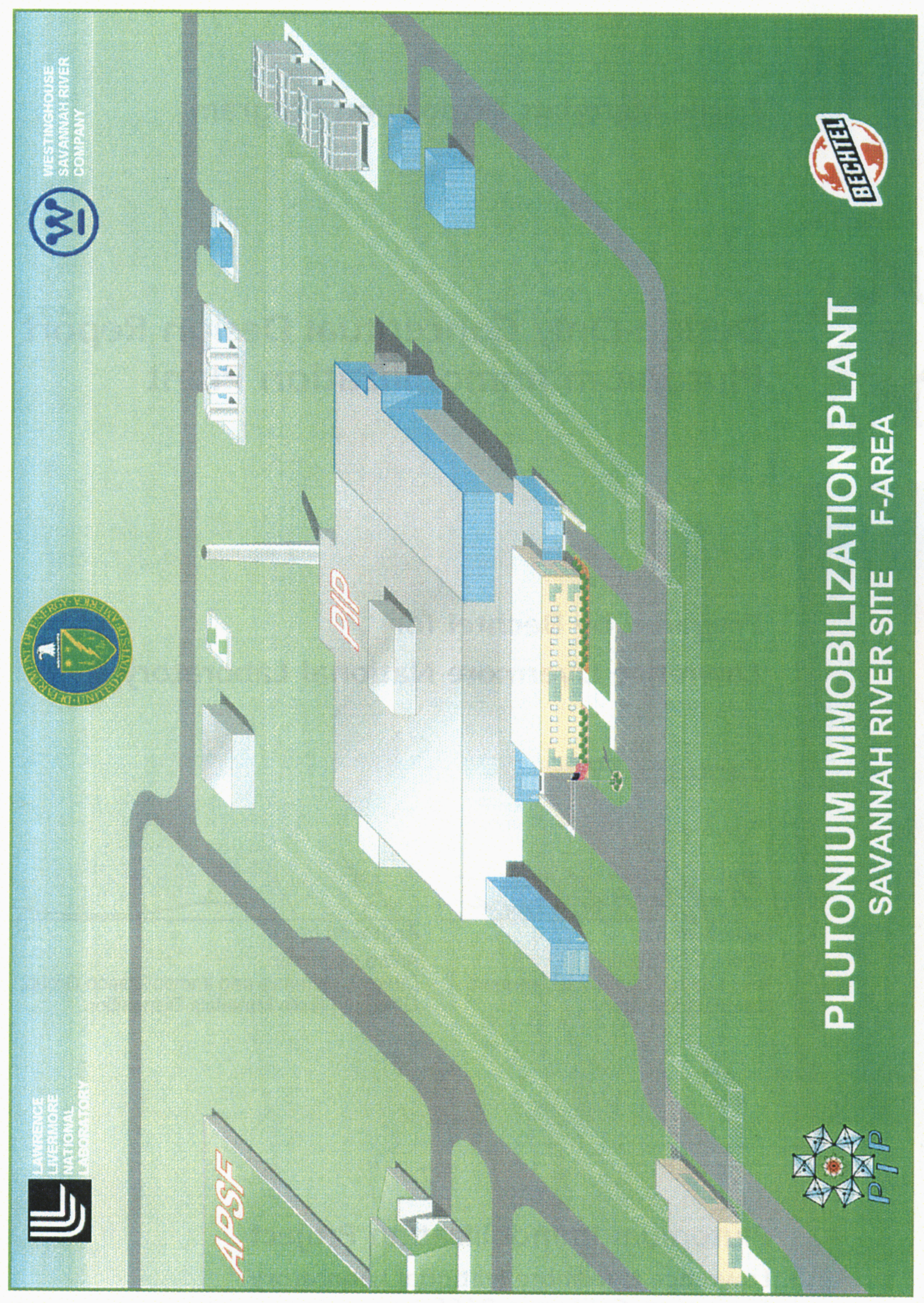




\section{DOCDR \\ PIP Approval Sheet}

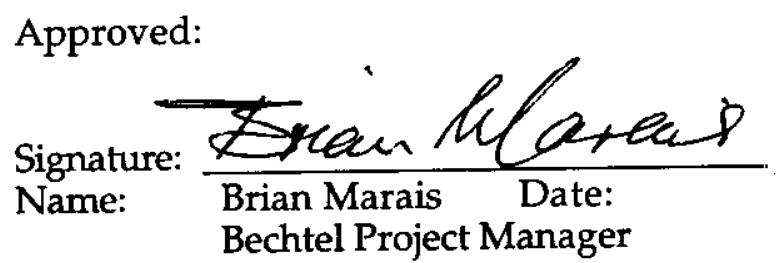

Approved:

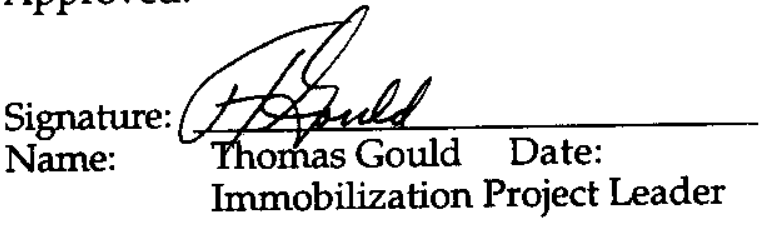

Approved:

Signature: Name:
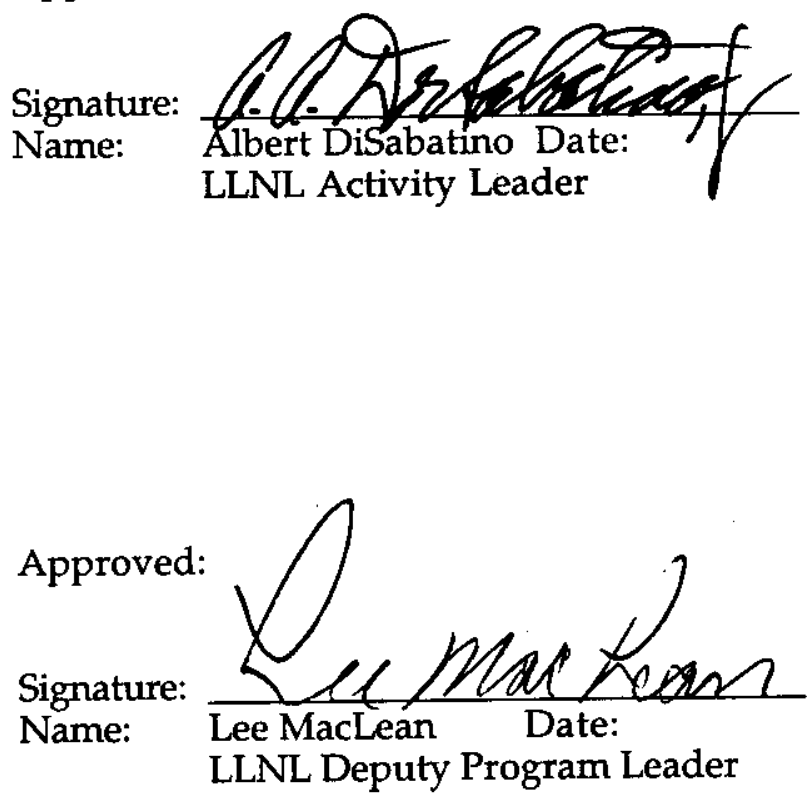



\section{Acknowledgments}

Organizations that provided major contributions to the development of this DOCDR include:

- Lawrence Livermore National Laboratory (LLNL)

- Westinghouse Savannah River Corporation (WSRC)

- Bechtel

This document was co-authored or reviewed by:

\begin{tabular}{lcclc} 
Name & Affiliation & & Name & Affiliation \\
\cline { 1 - 2 } \cline { 5 - 6 } Wilfredo Ancheta & Bechtel & & Jerry Kowsik & Bechtel \\
Guy Armantrout & LLNL & & J. D. Lee & LLNL \\
Ted Breitmayer & Bechtel & & Dan Loftus & Bechtel \\
Mark Bronson & LLNL & & Paul Maddux & WSRC \\
William Brummond & LLNL & & Brian Marais & Bechtel \\
Brian Byun & Bechtel & & Mark Mitchell & LLNL \\
Gilbert Chan & Bechtel & & Marshall Nielsen & Bechtel \\
Raymond Chiu & Bechtel & & Chan Pang & Bechtel \\
Al DiSabatino* & LLNL & & Max Pong & Bechtel \\
Joe Gilkison & WSRC & & Bill Randall & WSRC \\
Jorge Golonski & Bechtel & & Tom Severnyse & WSRC \\
Tom Gould & WSRC & & Jim Steed & WSRC \\
Leonard W. Gray & LLNL & & Danilo Tiojanco & Bechtel \\
Robert Jones & WSRC & & David Warren & Bechtel \\
Bob Kaiser & Bechtel & & Joong Yang & M. H. Chew \& \\
Tehmau Kan & LLNL & & & Associates (Bechtel) \\
John Kerns & LLNL & & Sam Young & Bechtel
\end{tabular}

* Author to whom all questions should be directed. 
UCRL-ID-131617 Rev. I

PIP-98-115 


\section{Executive Summary}

This design-only conceptual design report was prepared to support a funding request by the Department of Energy Office of Fissile Materials Disposition for engineering and design of the Plutonium Immobilization Plant, which will be used to immobilize up to 50 tonnes of surplus plutonium. The siting for the Plutonium Immobilization Plant will be determined pursuant to the site-specific Surplus Plutonium Disposition Environmental Impact Statement in a Plutonium Disposition Record of Decision in early 1999. This document reflects a new facility using the preferred technology (ceramic immobilization using the can-in-canister approach) and the preferred site (at Savannah River).

The Plutonium Immobilization Plant accepts plutonium from pit conversion and from non-pit sources and, through a ceramic immobilization process, converts the plutonium into mineral-like forms that are subsequently encapsulated within a large canister of high-level waste glass. The final immobilized product must make the plutonium as inherently unattractive and inaccessible for use in nuclear weapons as the plutonium in spent fuel from commercial reactors and must be suitable for geologic disposal.

Plutonium immobilization at the Savannah River Site uses:

- A new building, the Plutonium Immobilization Plant,* which will convert non-pit surplus plutonium to an oxide form suitable for the immobilization process, immobilize plutonium in a titanate-based ceramic form, place cans of the plutonium-ceramic forms into magazines, and load the magazines into a canister

- The existing Defense Waste Processing Facility for the pouring of high-level waste glass into the canisters

- The Actinide Packaging and Storage Facility to receive and store feed materials.

The Plutonium Immobilization Plant uses existing Savannah River Site infrastructure for analytical laboratory services, waste handling, fire protection, training, and other support utilities and services.

The Plutonium Immobilization Plant may share the disposition of the 50 tonnes of plutonium with the mixed oxide fuel/reactor disposition alternative. For this case, immobilization will process 18.2 tonnes of plutonium in 10 years. The project schedule is shown in the table below.

\footnotetext{
* Note: The Plutonium Immobilization Plant and the Actinide Packaging and Storage Facility do not currently exist. The Plutonium Immobilization Plant will be constructed adjacent to the Actinide Packaging and Storage Facility, which is currently under construction in F-Area. In the interest of readability, the present tense will be used in this document to refer to both structures. The PIP design assumes ceramic can-in-canister technology deployed at the Savannah River Site based on Departmental preferences, which are expected to be confirmed in a Record of Decision in early 1999.
} 
UCRL-1D-131617 Rev. 1

PIP-98-1 15

Project Schedule.

\begin{tabular}{|c|c|c|}
\hline \multirow[b]{2}{*}{ Activity } & \multicolumn{2}{|c|}{ Calendar month and year } \\
\hline & Beginning & End \\
\hline $\begin{array}{l}\text { Preliminary Design } \\
\text { Final Design } \\
\text { Construction and Start-up }\end{array}$ & $\begin{array}{l}10 / 99 \\
10 / 00 \\
10 / 01\end{array}$ & $\begin{array}{l}09 / 00 \\
09 / 02 \\
07 / 06\end{array}$ \\
\hline
\end{tabular}

The cost estimate of the Title I and Title II design is $\$ 69.7 \mathrm{M}$, including contingency. 


\section{Contents}

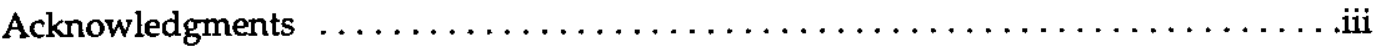

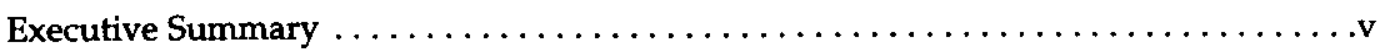

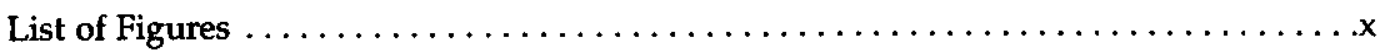

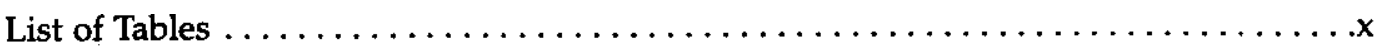

Section 1 General Description of the Project $\ldots \ldots \ldots \ldots \ldots \ldots \ldots \ldots \ldots \ldots \ldots$

1.1 Plutonium Immobilization Mission $\ldots \ldots \ldots \ldots \ldots \ldots \ldots \ldots \ldots \ldots \ldots \ldots \ldots \ldots \ldots$

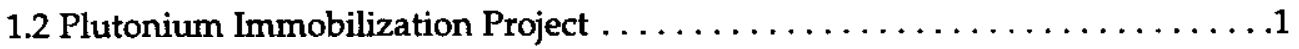

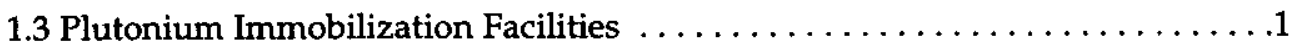

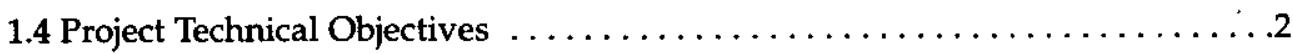

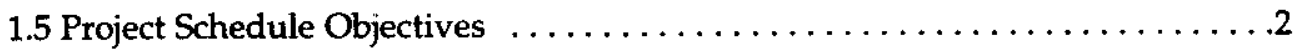

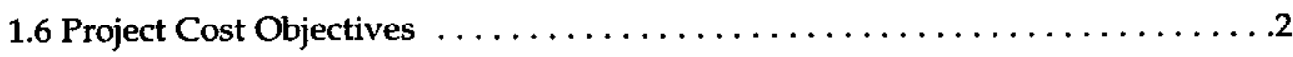

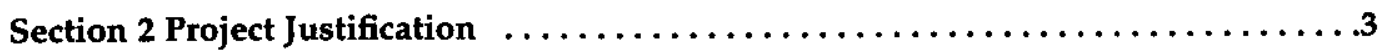

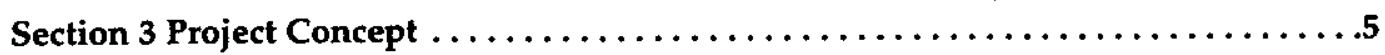

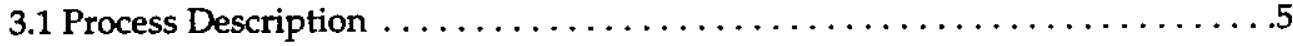

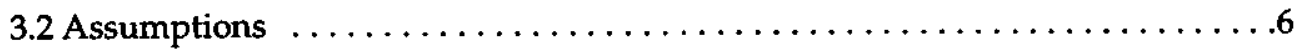

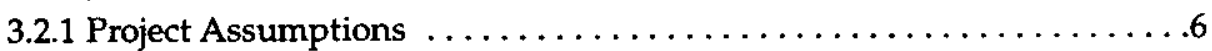

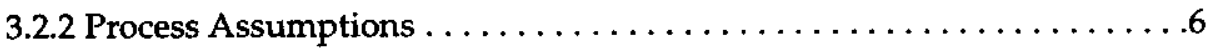

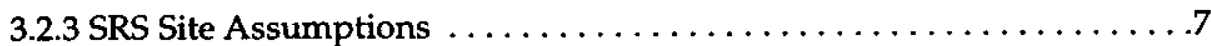

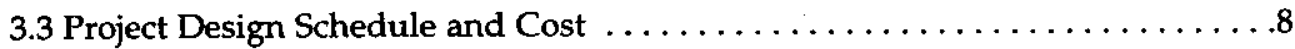

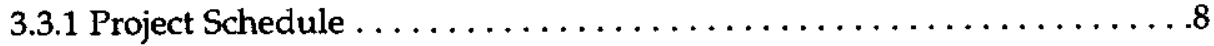

3.3.2 Project Design Cost $\ldots \ldots \ldots \ldots \ldots \ldots \ldots \ldots \ldots \ldots \ldots \ldots \ldots$

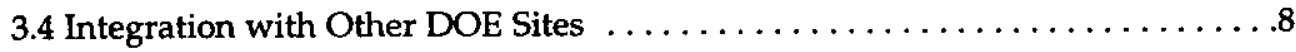

Section 4 Considerations External to the Project $\ldots \ldots \ldots \ldots \ldots \ldots \ldots \ldots \ldots \ldots$.11

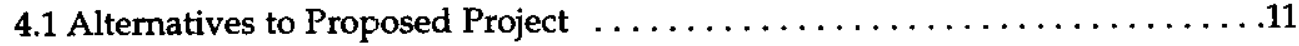

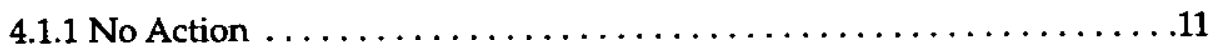

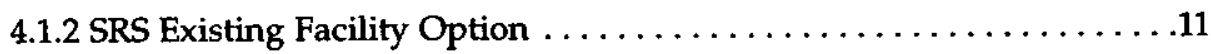

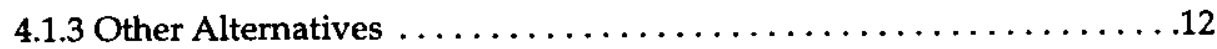

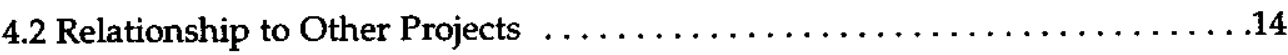

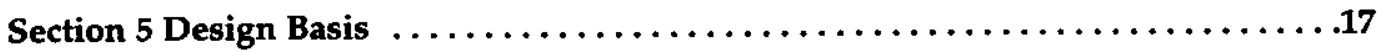

5.1 Process Description and Functional Requirements $\ldots \ldots \ldots \ldots \ldots \ldots \ldots$

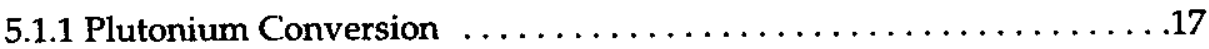

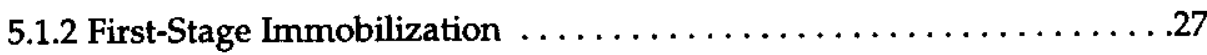

5.1 .3 Second-Stage Immobilization $\ldots \ldots \ldots \ldots \ldots \ldots \ldots \ldots \ldots \ldots \ldots \ldots$

5.1.4 International Atomic Energy Agency Accommodations . ........37

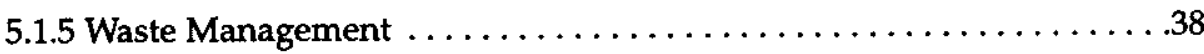

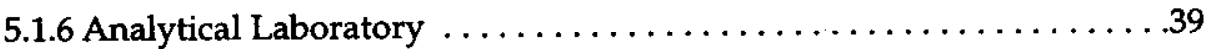

5.1 .7 Control Rooms . . . . . . . . . . . . . . . . . . . . . 41

5.1.8 Material Access Area Support Rooms/Facilities $\ldots \ldots \ldots \ldots \ldots \ldots 42$

5.1.9 Material Transport System .......................49 
5.1.10 Administrative Support Building and Foyer $\ldots \ldots \ldots \ldots \ldots . \ldots 4$

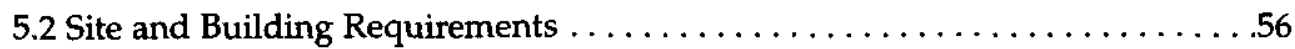

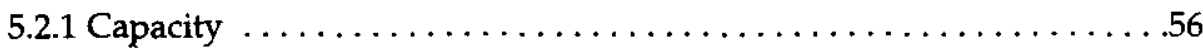

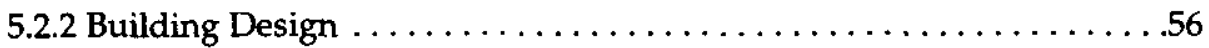

5.2 .3 Utilities and Services $\ldots \ldots \ldots \ldots \ldots \ldots \ldots \ldots \ldots \ldots \ldots \ldots \ldots$

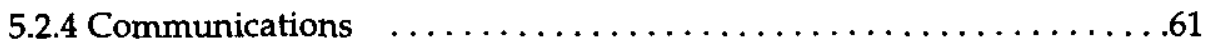

5.2 .5 Instrumentation and Control $\ldots \ldots \ldots \ldots \ldots \ldots \ldots \ldots \ldots \ldots \ldots \ldots \ldots \ldots \ldots$

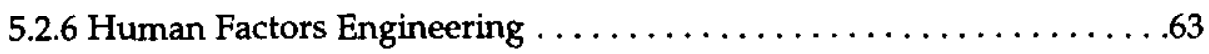

5.2.7 Safety, Radiological Control, Shielding $\ldots \ldots \ldots \ldots \ldots \ldots \ldots \ldots 6$

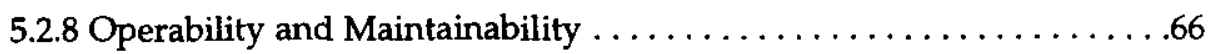

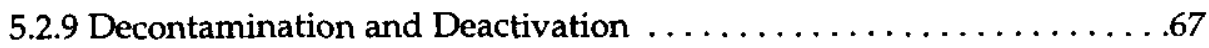

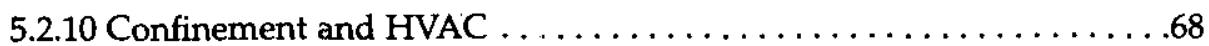

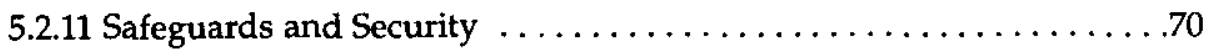

5.2.12 Environmental, Safety, and Health Monitoring $\ldots \ldots \ldots \ldots . \ldots 70$

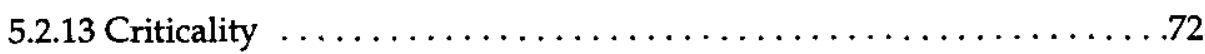

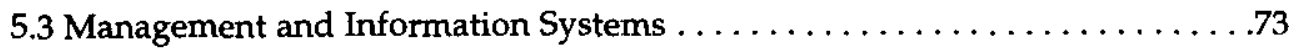

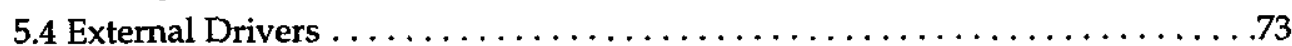

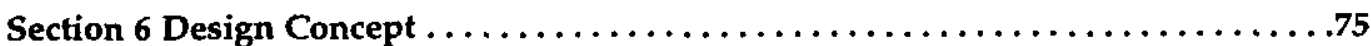

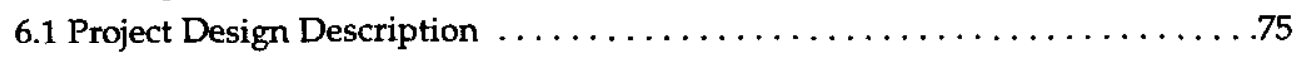

6.1.1 Process and Process Support Design Description . . . . . . . . . 75

6.1.2 Facility Systems/Elements $\ldots \ldots \ldots \ldots \ldots \ldots \ldots \ldots \ldots \ldots . \ldots \ldots$

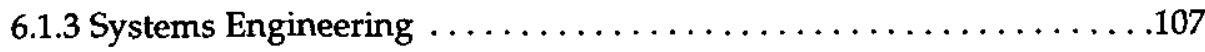

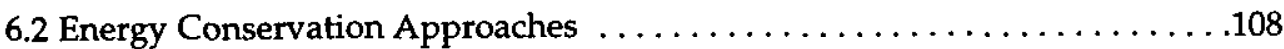

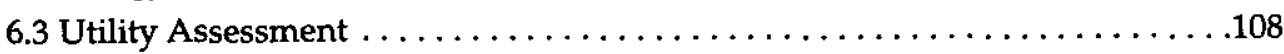

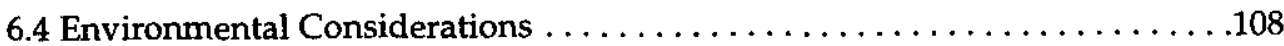

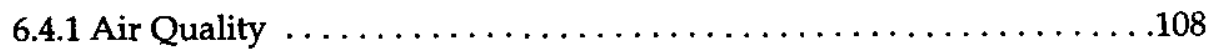

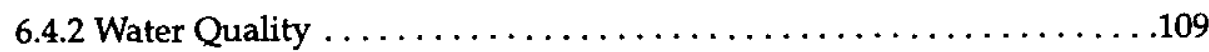

6.4.3 Waste Generation . . . . . . . . . . . . . . . . . . . . .110

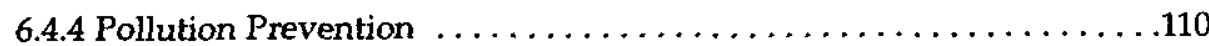

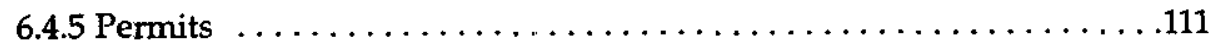

6.5 Facility and Equipment Maintenance Considerations $\ldots \ldots \ldots \ldots \ldots \ldots 11$

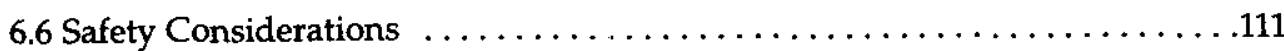

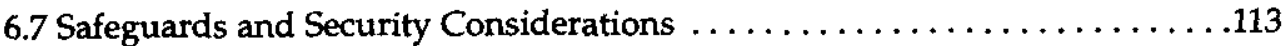

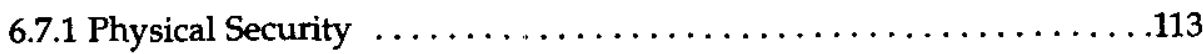

6.7.2 Material Control and Accountability ..................113

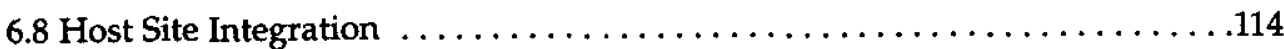

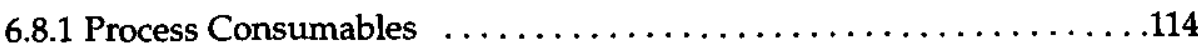

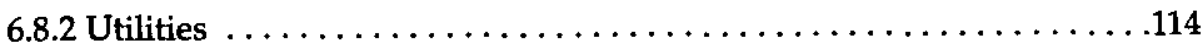

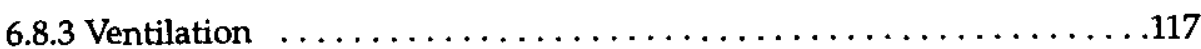

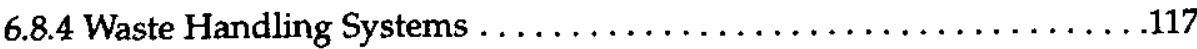

6.8 .5 Salvageable Equipment $\ldots \ldots \ldots \ldots \ldots \ldots \ldots \ldots \ldots \ldots \ldots \ldots \ldots \ldots$ 


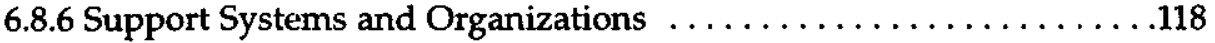

6.8.7 Host Site Integration Assumptions $\ldots \ldots \ldots \ldots \ldots \ldots \ldots \ldots \ldots$

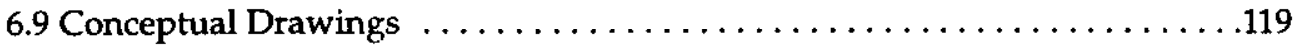

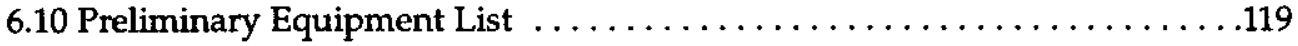

Section 7 Project Management and Implementation $\ldots \ldots \ldots \ldots \ldots \ldots \ldots \ldots \ldots \ldots$

7.1 Project Management Team and Responsibilities . . . . . . . . . . . 123

7.1.1 The DOE Office of Fissile Materials Disposition Project

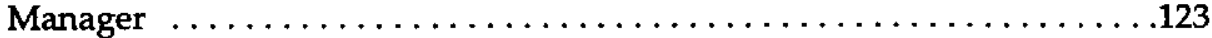

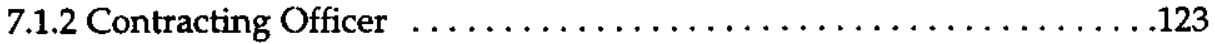

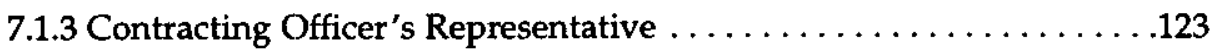

7.1.4 The Project Leader . . . . . . . . . . . . . . . . . . . . . .124

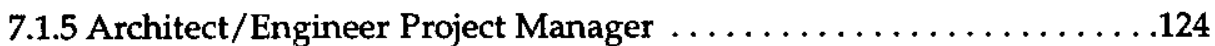

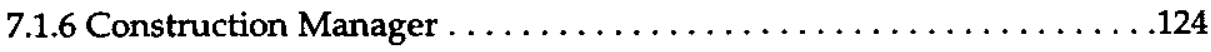

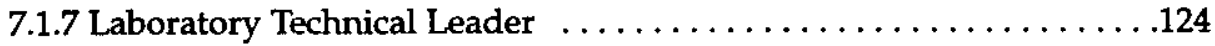

7.2 Project Management System . . . . . . . . . . . . . . . . . . . 124

7.2.1 Work Scope and Technical Baseline Management ............124

7.2.2 Cost Control . . . . . . . . . . . . . . . . . . . . . . . . . 125

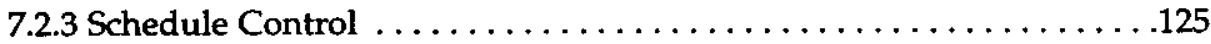

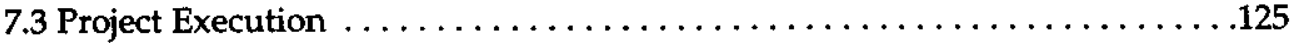

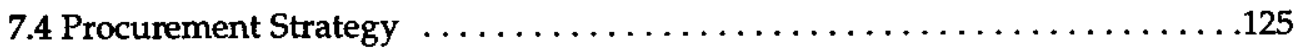

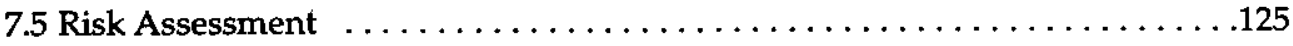

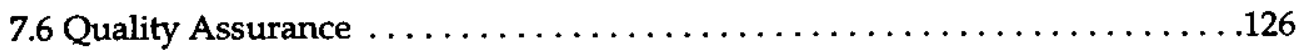

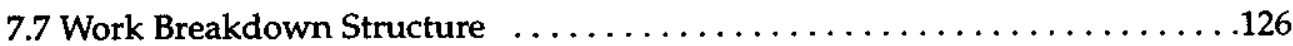

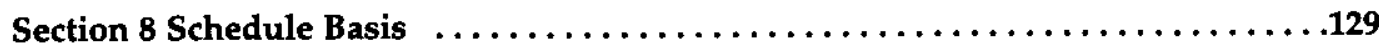

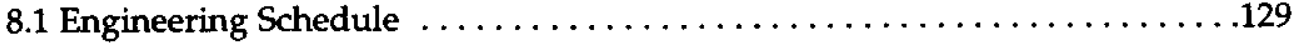

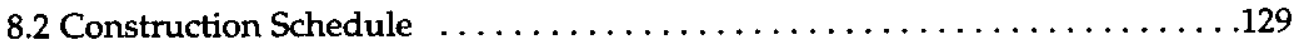

Section 9 Engineering and Life-Cycle Cost Summary $\ldots \ldots \ldots \ldots \ldots \ldots \ldots \ldots 131$

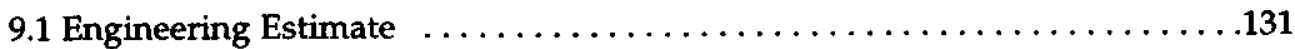

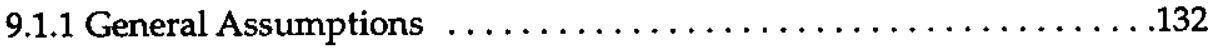

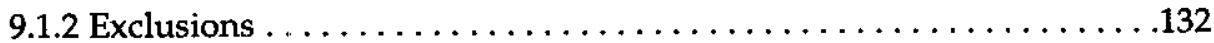

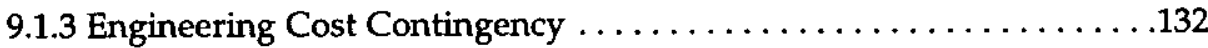

9.2 Life-Cycle Costs . . . . . . . . . . . . . . . . . . . . . . . 132

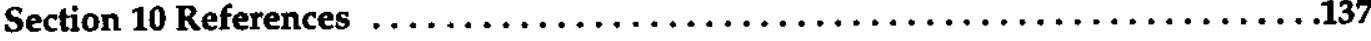

Appendix A Major Codes, Orders, Standards, and Regulations $\ldots \ldots \ldots \ldots \ldots$ A-1

Appendix B Conceptual Design Drawings $\ldots \ldots \ldots \ldots \ldots \ldots \ldots \ldots \ldots \ldots \ldots \ldots \ldots \ldots$

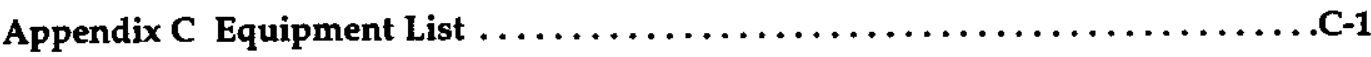

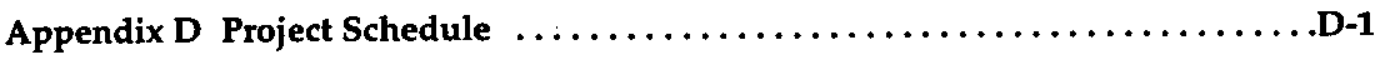

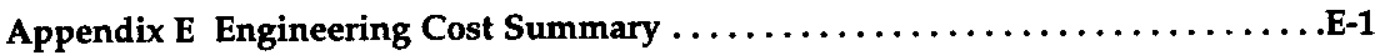

Appendix F Life Cycle Cost Estimate Summary and Bases $\ldots \ldots \ldots \ldots \ldots \ldots$ F-1

Appendix G List of Measures $\ldots \ldots \ldots \ldots \ldots \ldots \ldots \ldots \ldots \ldots \ldots \ldots \ldots \ldots \ldots \ldots \ldots \ldots \ldots$

Appendix $\mathrm{H}$ List of Acronyms and Abbreviations $\ldots \ldots \ldots \ldots \ldots \ldots \ldots \ldots \ldots \ldots$ 


\section{List of Figures}

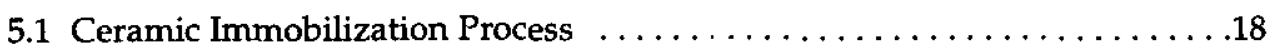

6.1 Immobilization Facility Interface Diagram $\ldots \ldots \ldots \ldots \ldots \ldots \ldots \ldots \ldots \ldots \ldots \ldots \ldots$

7.1 Plutonium Immobilization Project Proposal WBS $\ldots \ldots \ldots \ldots \ldots \ldots . \ldots \ldots$

\section{List of Tables}

3.1 Plant Project Schedule $\ldots \ldots \ldots \ldots \ldots \ldots \ldots \ldots \ldots \ldots \ldots \ldots$

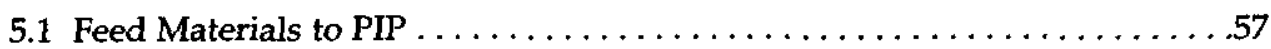

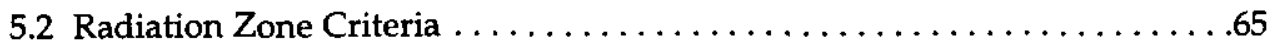

6.1 Concrete Wall Thicknesses in inches $\ldots \ldots \ldots \ldots \ldots \ldots \ldots \ldots . \ldots 9$

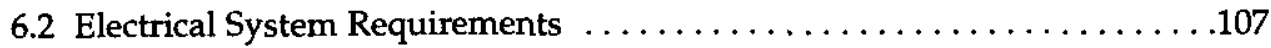

6.3 Preliminary List of Required Plutonium Facility Permits and Plans . . . . .112

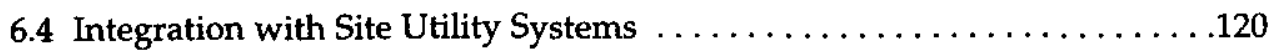

6.5 Integration of Infrastructure Support $\ldots \ldots \ldots \ldots \ldots \ldots \ldots \ldots \ldots \ldots \ldots \ldots \ldots \ldots \ldots \ldots$

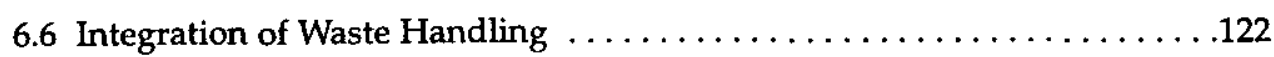

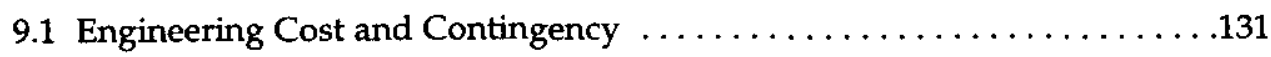

9.2 Life Cycle Cost and Contingency for Aboveground Facility . . . . . . . 135 


\section{General Description of the Project}

\subsection{Plutonium Immobilization Mission}

The Plutonium Immobilization mission is to contribute to a reduction in the global nuclear danger posed by existing surplus plutonium forms in the United States by converting weapons-usable plutonium to an immobilized form which is significantly less proliferent.

The ultimate goal of the Immobilization Project is to develop, construct, and operate facilities that will immobilize from about 18 to 50 tonnes (MT) of U.S. surplus weapons-usable plutonium materials in a manner that meets the "spent fuel standard" and is acceptable for disposal in a geologic repository.

\subsection{Plutonium Immobilization Project}

This DOCDR provides the basis for the procurement of design and engineering services for a Plutonium Immobilization Plant (PIP). The PIP would convert non-pit surplus plutonium metals to an oxide. The converted plutonium oxide, as well as other surplus plutonium oxide from DOE sites, would be converted into a ceramic material that is placed in metal cans. The cans would be loaded into magazines that are placed into a framework inside a Defense Waste Processing Facility (DWPF) canister. High-level waste (HLW) glass would then be poured into the canister at the DWPF to form a radiation barrier in the final product. The immobilized plutonium waste form (IPWF)-the cans of plutonium ceramic inside a HLW canister filled with HLW glass-is stored in the Glass Waste Storage Building (GWSB), along with the high-level waste canisters, pending geologic disposal.

The PIP is a nuclear non-reactor facility that will be designed and constructed to meet Nuclear Regulatory Commission (NRC) licensing standards and have Defense Nuclear Facilities Safety Board (DNFSB) oversight. This DOCDR is based on existing DOE orders and standards. (The DOE and the NRC are currently reviewing which NRC licensing standards will apply to the PIP.)

\subsection{Plutonium Immobilization Facilities}

The preferred siting for the PIP, a new building for plutonium conversion and immobilization, is at the Savannah River Site (SRS). The PIP uses the adjacent Actinide Packaging and Storage Facility (APSF) for feed material receipt and storage. It uses the DWPF for the pour of HLW glass. Canisters containing the HLW glass are stored in the GWSB until they are sent to the geological repository.

The general location of these structures at SRS is:

- PIP (F-Area, new)

- APSF (F-Area, new)

- DWPF (S-Area, existing)

- GWSB (S-Area, existing). 
Waste management and other necessary facility infrastructure and utility support functions required to support the primary process operations are enumerated in Section 3.2.3.

\subsection{Project Technical Objectives}

The Immobilization Project, through the deployment of an immobilization plant, will produce an immobilized form that will effectively incorporate actinides, neutron absorbers, and expected impurities and will be sufficiently flexible to accommodate available unclassified plutonium feed materials. The form will meet nonproliferation requirements and repository qualification standards.

\subsection{Project Schedule Objectives}

The Immobilization Project will design and deploy a PIP that will start production of plutonium-ceramic immobilized forms in the can-in-canister configuration not later than the year 2006. The PIP will be capable of processing up to 50 MT of surplus plutonium over a period of 10 years.

\subsection{Project Cost Objectives}

The Immobilization Project will produce an immobilized form that is cost-effective, utilizing existing facilities and capabilities to the maximum extent practical. 


\section{Project Justification}

The DOE Record of Decision for the Storage and Disposition of Weapons-Useable Fissile Material Programmatic Environmental Impact Statement, dated January 14, 1997 , announced that DOE's strategy for disposition of surplus plutonium is to pursue a dual-track approach that allows immobilization of surplus impure plutonium in a glass or ceramic matrix and burning of the surplus plutonium from retired weapons as mixed oxide (MOX) fuel in existing, domestic, commercial reactors. The capability to immobilize surplus plutonium does not presently exist.

The Plutonium Immobilization Project will provide the nation with the capability to disposition surplus plutonium and support President Clinton's Nonproliferation and Export Control Policy (September 1993), issued in response for the growing threat of nuclear proliferation. 
UCRL-ID-131617 Rev. 1

PIP-98-115 


\section{Project Concept}

The project is based on a technological approach that cost-effectively incorporates the capabilities of existing DOE facilities with a new facility for immobilizing the plutonium to meet the spent fuel standard. The technology selected, designated the can-in-canister approach, can be considered a three-stage process. In the first stage, the plutonium materials are received, treated, and converted to an acceptable form for immobilization. In the second stage, the plutonium is immobilized and packaged (canned) to meet confinement requirements. In the last stage, the packaged immobilized plutonium is prepared for placement in DWPF canisters and fixed in HLW glass. The approach uses the APSF for receipt, accountability, and storage of the incoming plutonium as well as the laboratory capabilities at the SRS. By separating the immobilization of the plutonium from the radiation barrier, existing hot-cell facilities, such as the DWPF at the SRS, can be used to add the radiation barrier.

\subsection{Process Description}

Plutonium conversion encompasses material receipt, storage, and processing of the materials to oxide feeds for the first-stage immobilization. Three different process capabilities are provided to convert metals or alloys, oxide fuel pellets, or impure oxides to oxide powder for use by first-stage immobilization. Material control and accountability (MC\&A) and storage capability are provided for the plutonium conversion process lines.

The first-stage ceramic immobilization process combines plutonium oxide with uranium oxide, ceramic precursors, and organic binders to produce 2.6 -inchdiameter-x-1-inch-thick (nominal) disk shaped forms (pucks) containing up to $10.5 \mathrm{wt} \%$ plutonium. Twenty pucks are sealed in a stainless steel can.

The ceramification process contains five basic steps. First, plutonium and uranium oxides are co-milled to about 1 micron. Second, the milled product is microblended with a ceramic precursor (including neutron absorbers). Third, to ensure flowability into a press cavity, the mixture is granulated. Fourth, the powder is pressed into "green" pucks at 2000 psi to 5000 psi. Fifth, and finally, the pucks are reactively sintered at about $1350^{\circ} \mathrm{C}$ and loaded into cans.

The second-stage immobilization places four cans of plutonium-ceramic pucks in a magazine. Seven magazines are inserted into a HLW canister and mounted on a rack inside the canister. The canister is transported to the DWPF and filled with HLW glass. The canister is stored in the GWSB until shipped to geologic respository.

A flowsheet of the key process steps is provided in Section 5, Figure 5.1. The conceptual design drawings and equipment list for the PIP are provided in Appendices B and C. 


\subsection{Assumptions}

The following section describes assumptions used to scope the project, to develop the conceptual design, and to prepare design cost estimates. Assumptions are divided into project assumptions and process-specific assumptions.

\subsubsection{Project Assumptions}

The PIP will have a 10-year production mission. The facility will process plutonium metal and oxide up to a rate of $5 \mathrm{MT}$ of plutonium per year. The actual production mission time will be optimized.

Operations will be three shifts per day, seven days per week. The PIP is assumed to operate with an availability factor of $75 \%$. Allowing normal time for maintenance, accountability, criticality control, etc., normal operations will be considered to be a 200 -day production year. Nominal throughput will therefore be $25 \mathrm{~kg}$ of plutonium per day.

The PIP is assumed to be designed, constructed, and operated with DNFSB oversight in conformance with DOE orders and NRC licensing standards. This DOCDR is based on existing DOE orders and standards and applicable codes for nuclear facilities. The DOE and the NRC are currently reviewing how and which NRC regulations will apply to the PIP.

In support of the U.S. nonproliferation policy, plutonium in the immobilization process will be made available for verification and inspection by the International Atomic Energy Agency (IAEA). Feed materials received by the PIP are unclassified.

The design life of the facility will be 20 years (including baseline operating life of 10 years).

\subsubsection{Process Assumptions}

There are two throughput scenarios: 50 and 18.2 MT of plutonium to be immobilized. Approximately 18.2 MT of plutonium coming to immobilization will be in a variety of chemical forms and will require processing to make an oxide powder acceptable with first-stage ceramification requirements. The PIP will be designed to process 50 MT of plutonium, of which $33 \mathrm{MT}$ would be relatively pure plutonium oxide powder (which will not require further processing). The disposition will be over a 10-year period. Normal maintenance and planned replacements are accounted for in the $75 \%$ plant availability factor. To reduce operator dose, the equipment will be designed for automated hands-off operation to the extent practicable. Personnel will be in the process area during maintenance activities, but, with some exceptions, will not be present during operation. 
It is also assumed that:

- Recovery of plutonium and other radioactive elements from process waste streams will be based on a value engineering analysis of the cost effectiveness of recovery versus the cost for waste disposal.

- IPNFs will have sufficient radioactive content to meet nonproliferation goals.

- The design basis for operating equipment will be $125 \%$ of the average production rate required to meet off-nominal demand for specific operations.

\subsubsection{SRS Site Assumptions}

SRS site assumptions include the following:

- The PIP will be designed and operated to the applicable existing SRS criteria, procedures, and policies.

- The PIP will be operated as part of the DOE contract with the SRS Management and Operating Contractor.

- The PIP will be designed for construction at a site near the APSF in FArea at the SRS.

- The design will use the existing SRS infrastructure to the maximum extent practicable.

- The APSF will be available for special nuclear material (SNM) receipts and storage in support of the PIP.

- The DWPF will be available to receive cans of plutonium ceramic forms assembled within canisters, pour HLW glass into the canisters, and store the IPWF in the GWSB.

Support and service facilities for the PIP include:

- Administrative buildings (Buildings 703-F and 707-F in F-Area, existing)

- Analytical laboratory (Building 772-F in F-Area, existing)

- F-Area security and entry control facility (Building 701-F in F-Area, existing)

- Central Alarm Station (CAS, Building 702-F, in F-Area, existing)

- Fire and medical stations (Building 709-F, in F-Area, existing)

- Steam boiler (D-Area, existing)

- Medical facilities (Building 704-F, in F-Area, existing).

In addition, SRS waste management facilities to support the immobilization operations include the following:

- SRS transuranic (TRU) facility (planned)

- Transuranic waste storage pad (E-Area, existing)

- Consolidated incineration facility (CIF) (Building 261-H in H-Area, existing)

- SRS hazardous/mixed waste disposal facility (planned)

- Mixed waste storage area (643-29E in E-Area, existing)

- Low-level waste (LLW) storage vault (643-7E in E-Area, existing)

- Hazardous waste storage facility (N-Area, existing)

- Effluent treatment facility (H-Area, existing)

- Radioactive liquid waste storage tanks (F-Area tank farm, existing)

- Central sanitary waste water treatment facility (C-Area, existing). 


\subsection{Project Design Schedule and Cost}

\subsubsection{Project Schedule}

The plant project schedule is summarized in Table 3.1 below.

Appendix D provides a detailed project schedule.

Table 3.1. Plant Project Schedule.

\begin{tabular}{lc}
\hline Duration Activity & (Month/Calendar Year) \\
\hline Preliminary Design (Title I) & $10 / 1999-09 / 2000$ \\
Detailed Design (Title II) & $10 / 2000-09 / 2002$ \\
Construction & $10 / 2001-03 / 2005$ \\
Permitting/Licensing & $10 / 1999-12 / 2005$ \\
Start-up & $01 / 2005-07 / 2006$ \\
Operations & $08 / 2006-07 / 2016$ \\
Decontamination and Deactivation & $09 / 2016-08 / 2019$ \\
\hline
\end{tabular}

\subsubsection{Project Design Cost}

The design cost for the PIP is estimated to be $\$ 69.7 \mathrm{M}$. This estimate includes the estimated A/E costs for Titles I and II of $\$ 55.7 \mathrm{M}$ and a $25.1 \%$ contingency of $\$ 14 \mathrm{M}$. The engineering cost summary is presented in Section 9. A rough order of magnitude (ROM) LCC estimate is also provided in Section 9.

\subsection{Integration with Other DOE Sites}

The immobilization project, and the PIP, depend on other DOE sites and programs for materials input and product output, as well as coordination with the alternative disposition technology. Surplus weapons plutonium will be dispositioned either as plutonium-ceramic forms surrounded by HLW glass using the can-in-canister option and disposal in the geological repository-the subject of this DOCDR-or as MOX fuel in a commercial reactor with subsequent burial in the geological repository as spent nuclear fuel. Depending on the technology, complexity, timing, and cost of purifying plutonium feeds to a level suitable for use in MOX fuel, DOE may decide to augment the surplus plutonium for immobilization from 18.2 to as much as $50 \mathrm{MT}$.

For either disposition option, DOE proposes to construct and operate a pit disassembly and conversion facility for converting the plutonium in the classified pit configuration to unclassified plutonium oxide for use as feed material for the MOX fuel fabrication facility or for the PIP. The preferred site for the pit disassembly and conversion facility or the MOX fuel fabrication facility is the SRS. None, some, or all of the pit oxides from the pit disassembly and conversion may come to the PIP.

In addition to the plutonium from the pits, other plutonium metals, plutonium oxides, plutonium alloys, unirradiated plutonium oxide fuel, and alloy fuel will be sent to the PIP for immobilization. These non-pit feeds will come from Hanford, Los Alamos National Laboratory (LANL), Lawrence Livermore National 
Laboratory (LLNL), Idaho National Engineering and Environmental Laboratory (INEEL), Pantex, Rocky Flats Environmental Technology Site (RFETS), and SRS. All of these materials will eventually be received and unpackaged in the APSF before transfer to the PIP.

Cans of immobilizied plutonium form will be encapsulated in HLW canisters and the resulting IPWF will eventually be shipped to the geological respository for disposal. 
UCRL-ID-131617 Rev. 1

PIP-98-115 


\section{Considerations External to the Project}

\subsection{Alternatives to Proposed Project}

Alternatives to the proposed project include:

- No Action

- Use of the 221-F Canyon Building at SRS

- Other technical, site, and facility use alternatives

\subsubsection{No Action}

Under the no-action alternative, a plutonium immobilization facility would not be constructed nor operated. Additional processing capability would have to be provided for the MOX fuel fabrication option to process unsuitable plutonium feeds. If some of the surplus plutonium could not be dispositioned because it is not technically or economically feasible to process for use as feed for the MOX fuel fabrication facility, materials would have to be stored, and President Clinton's nonproliferation and export control policy on weapons of mass destruction could not be fully implemented. In addition, substantial storage costs for these materials would continue to be incurred.

\subsubsection{SRS Existing Facility Option}

Use of the 221-F Canyon Building option would utilize, to the extent practical, existing SRS facilities to execute the PIP mission. This option was examined for its potential to minimize the construction of new site facilities. Some processing operations would be performed in the 221-F Canyon Building, which would require modifications to the Plutonium Storage Facility (PSF), New Special Recovery Facility (NSR), and areas of the first, second, and third levels of the canyon. Additional new immobilization construction would be required for parts of first-stage immobilization and canister loading.

An evaluation of the space requirements for the PIP using the 221-F facility and a factored cost estimate are presented in Plutonium Immobilization Plant Using Ceramic in Existing Facilities at the Savannah River Site, UCRL-ID-131810, September 1998. The Immobilization DOCDR New Facility Option was compared to the Environmental Impact Statement (EIS) Existing Facility Option. The process floorspace associated with each unit operation for the DOCDR New Facility Option was directly compared to that allotted for the same unit operations in the EIS Existing Facility layout. This space requirement comparison formed a basis for the factored cost estimate of the Existing Facility case.

The comparison shows that Building 221-F cannot accommodate the total immobilization process by itself, but only about $55 \%$. The remaining unit operations would be located in other existing or new facilities.

The existing facilities to be used and their proposed functions are as follows:

- Actinide Packaging and Storage Facility. For material receipt, unpackaging, accountability, and storage. 
- Building 221-F (including the New Special Recovery and Plutonium Storage Facilities). For material lag storage, FFTF fuel processing, zero-power physics reactor (ZPPR) fuel processing, conversion, oxide feed preparation, and firststage immobilization up to and including press operations.

A new building would be constructed connected to Building 221-F to house the balance of the first-stage immobilization process, can loading, can nondestructive assay (NDA), and can storage operations. This building would be a hardened, three-level facility of about $44,000 \mathrm{ft}^{2}$.

Another new building, separate from Building 221-F, would be constructed to house the canister loading operations. This building would be a $46,000 \mathrm{ft}^{2}$, hardened, two-level facility located north of Building 221-F. The location is not critical; the facility could be built anywhere within F-Area where space allows.

The 221-F facility was dropped from further consideration as an immobilization option because the existing facility option at SRS for immobilization using 221-F and requiring construction of two new structures, totalling about $90,000 \mathrm{ft}^{2}$, has a significant capital and operating cost penalty when compared to the new facility option at SRS for the PIP. Any environmental advantage this option may have had in the earlier EIS Data Call reports, when it only required retrofitting existing space in and building a small addition to $221-\mathrm{F}$, is considerable diminished by the need for $90,000 \mathrm{ft}^{2}$ of new construction.

\subsubsection{Other Alternatives}

In addition to the ceramic can-in-canister immobilization technology at either a new facility or a modified 221-F facility at SRS, five other immobilization technologies as well as two additional site and facility use alternatives are being considered for immobilization in the ongoing EIS process. Additionally, a variant of the new construction alternative at SRS that incorporates a different safeguards and security scheme is briefly discussed.

\subsubsection{Alternative Technologies}

The Department of Energy evaluated six glass and ceramic immobilization technology variants to determine the more promising ones for further development. These variants were divided into two categories: an internal radiation barrier and an external radiation barrier. The internal radiation barrier is achieved by the addition of ${ }^{137} \mathrm{Cs}$ into the immobilized form and includes four alternatives: direct vitrification, vitrification in an adjunct melter in the DWPF, direct ceramic immobilization, and electrometallurgical treatment. The external radiation barrier is achieved by placing the immobilized form in a can and, in turn, placing the can in a canister that is then filled with the HLW glass from the DWPF. These variants include the ceramic can-in-canister process and an alternative glass canin-canister immobilization process.

\section{Internal Radiation Barrier Variants}

The internal barrier or homogeneous technologies that were evaluated are as follows:

- Direct Vitrification. In this process, the plutonium feed materials are fed, along with a neutron absorber, to a first-stage melter that incorporates the 
plutonium in a borosilicate glass frit. The feed material preparation can be accomplished through either a wet or dry process, each of which has unique benefits. The frit is then blended with ${ }^{137} \mathrm{Cs}$ and clean glass frit and fed to a second-stage melter. The molten glass from the second-stage melter, containing the plutonium, the neutron absorber, and the ${ }^{137} \mathrm{Cs}$, is then poured into a DWPF type canister, sealed, and shipped for geologic disposal.

- Vitrification in an Adjunct Melter at the DWPF. This process is very similar to the direct vitrification method in that the plutonium feed materials are fed, along with a neutron absorber, to a first-stage melter that incorporates the plutonium in a borosilicate glass frit. The plutonium-containing frit is then fed to a second-stage, or adjunct, melter located adjacent to the DWPF where it is combined and melted with high level waste and additional clean frit. The molten glass from the adjunct melter is then poured into a DWPF type canister, sealed, and shipped for geologic disposal.

- Direct Ceramic Immobilization. In this process, the plutonium feed materials are converted to plutonium nitrate and blended with ceramic precursors and ${ }^{137} \mathrm{Cs}$. The blend is then calcined, hot-pressed in bellows, loaded into canisters, and shipped for geologic disposal. This process also has a wet and dry feed variant.

- Electrometallurgical Treatment. In this variant, plutonium-rich residues are shipped to the existing Argonne National Laboratory-West facilities, where the plutonium is converted to plutonium chloride, dissolved in a molten salt solution, blended with ${ }^{137} \mathrm{CsCl}$, and sorbed on zeolites. The blended, freeflowing zeolite powder is mixed with a suitable glass frit and hot-pressed to make the final immobilized form. The form is then loaded into canisters, sealed, and shipped for geologic disposal.

\section{External Radiation Barrier Variants}

The external barrier technologies that were evaluated include the ceramic canin-canister, which is the subject of this DOCDR, and an alternative glass canin-canister variant.

- Glass Can-In-Canister Immobilization. This variant is similar to the ceramic can-in-canister process except the plutonium is initially immobilized in a high melting temperature lanthanide borosilicate (LaBS) glass. Like the can-in-canister ceramic process, the excess plutonium is converted into an oxide, combined with frit and melted, and poured into metal cans that are then placed into a HLW canister. High-level waste borosilicate glass is then poured around the plutonium-LaBS-containing cans. Both glass and ceramic processes have variants for wet feed.

Evaluation of these immobilization variants resulted in the conclusion that the external barrier variants would be superior to the internal barrier variants in terms of timeliness, greater technical viability, much lower costs, and, to a lesser extent, slightly less environmental and health risks. Additionally, given the public's concern regarding water usage, potential aquifer contamination, and strong interest in waste minimization, and because the wet-feed alternatives would require larger quantities of water and generate greater amounts of wastes, the wet-feed processes were eliminated from further consideration. The level of dust production in dryfeed processes was deemed acceptable with dust control measures implemented.

In a subsequent, more detailed evaluation, the ceramic can-in-canister variant was chosen over the LaBS glass variant to be the preferred immobilization alternative for seveeral reasons. The ceramic form is more robust to extraction 
of plutonium for reuse; the form is expected to be more durable in a repository environment; the form has a significantly lower radiation source term; the form and its process offer significant potential cost savings versus glass; and the technology is more flexible and can better accommodate modifications to programmatic and technical requirements.

\subsubsection{Alternative Site and Facility Use}

The Fuels Material and Examination Facility (FMEF) at the Hanford Site was also considered for the PIP. The FMEF was evaluated as both a single and multiple occupant facility for the immobilization, pit disassembly and conversion, and MOX fuel fabrication missions. After evaluating the space requirements for the three missions, DOE concluded that the available space in the FMEF would not be sufficient to accommodate the efficient operation and maintenance of all three missions. Therefore, the FMEF siting and facility use alternatives were reduced to either a sole occupancy of the FMEF by one of the three missions or a collocation of either the pit disassembly and conversion mission or the MOX mission with immobilization in the FMEF. In former Secretary Peña's announcement in June 1997 on the selection of SRS as the preferred site for the MOX fuel fabrication facility, DOE determined that Hanford's mission is critical and should remain its top priority.

\subsubsection{Alternative Concept for a New Facility at SRS}

An alternative concept that was considered for a new facility at SRS is a facility that would be located completely underground with a 15-foot berm covering those portions of the facility that are above grade. The baseline concept is a facility located completely above ground. The impetus to locate a facility underground is primarily based on safeguards and security issues that might enhance diversion resistance and reduce operating costs. A cost-benefit comparison made for the two alternatives is documented in the preliminary draft DOCDR, PIP-98-071 for the below-ground facility, and PIP-98-081 for the aboveground concept. The aboveground facility was chosen as the baseline because it offers significant capital and life cycle cost savings over the below-ground facility.

\subsection{Relationship to Other Projects}

The PIP principally interacts with or is affected by the operation of four projects:

- The MOX fuel fabrication facility

- The pit disassembly and conversion facility

- The APSF

- The DWPF.

The pit disassembly and conversion facility produces the plutonium oxide that will be dispositioned in the PIP if DOE decides not to use it as feed for a MOX fuel fabrication facility. Therefore, the operation of the pit disassembly and conversion facility will occur in time to support a 10-year immobilization program in the PIP. 
The APSF will receive and store surplus plutonium materials prior to their introduction into the PIP. The APSF is under construction and scheduled to be in operation well before the startup of the PIP, and thus, will be available to perform this function.

The second stage of the can-in-canister immobilization process will take place within the DWPF. Coordination of operational requirements, DWPF modification to support immobilization, and construction and operating schedules will be required. 
UCRL-ID-131617 Rev. I

PIP-98-115 


\section{Design Basis}

This section provides the process description and functional requirements, site and building requirements, and process management and information systems requirements for the PIP. Appendix A lists the major codes, orders, standards, and regulations that apply to the design and construction of the PIP. Information on facilities and equipment is provided in the subsection of Section 6 that pertains to the particular process module.

The process descriptions and functional requirements are based on using the ceramic can-in-canister variant as the baseline technology for the PIP. The functional requirements are sufficiently detailed to allow for the identification and estimation of design costs for the process, the facility, and the support systems.

\subsection{Process Description and Functional Requirements}

This section describes the end-to-end ceramic immobilization process for the PIP. The process is shown in a top level block flow diagram in Figure 5.1. More detailed flow diagrams for the immobilization process as well as a detailed material balance are provided in Appendix B.

Detailed equipment requirements for each of the unit operations may be found in Appendix C. At the start of each subsection below, information is provided on where to find the relevant unit operation on the process and block flow diagrams, and its location in the attached drawings. The flow diagram numbering system is organized with respect to unit operations as defined by work breakdown structure (WBS) and process streams. The equipment list is organized with respect to each unit operation, with additional sections for equipment that does not directly apply to a particular unit operation. Thus the unit operation numbers on the flow diagrams correspond to those on the equipment list. Generally, the titles on the flow diagrams correspond to the section title on the DOCDR. The drawings are organized by their perspective and geographical portion of the plant. For the reader's convenience, process module designations and drawing numbers are listed directly following the module or service system title.

\subsubsection{Plutonium Conversion}

Plutonium conversion is the first step in the immobilization process. It encompasses material receipt, storage, and processing of the materials to oxide forms for the first-stage immobilization. The equipment for plutonium conversion will be automated to meet radiation exposure limits because of the high radiation levels of some of the plutonium feed materials. Diagram P-202, Appendix B, depicts the key process modules in conversion described below.

\subsubsection{Material Receipt and Storage}

Module 1.1, Block Flow Diagram P-202 


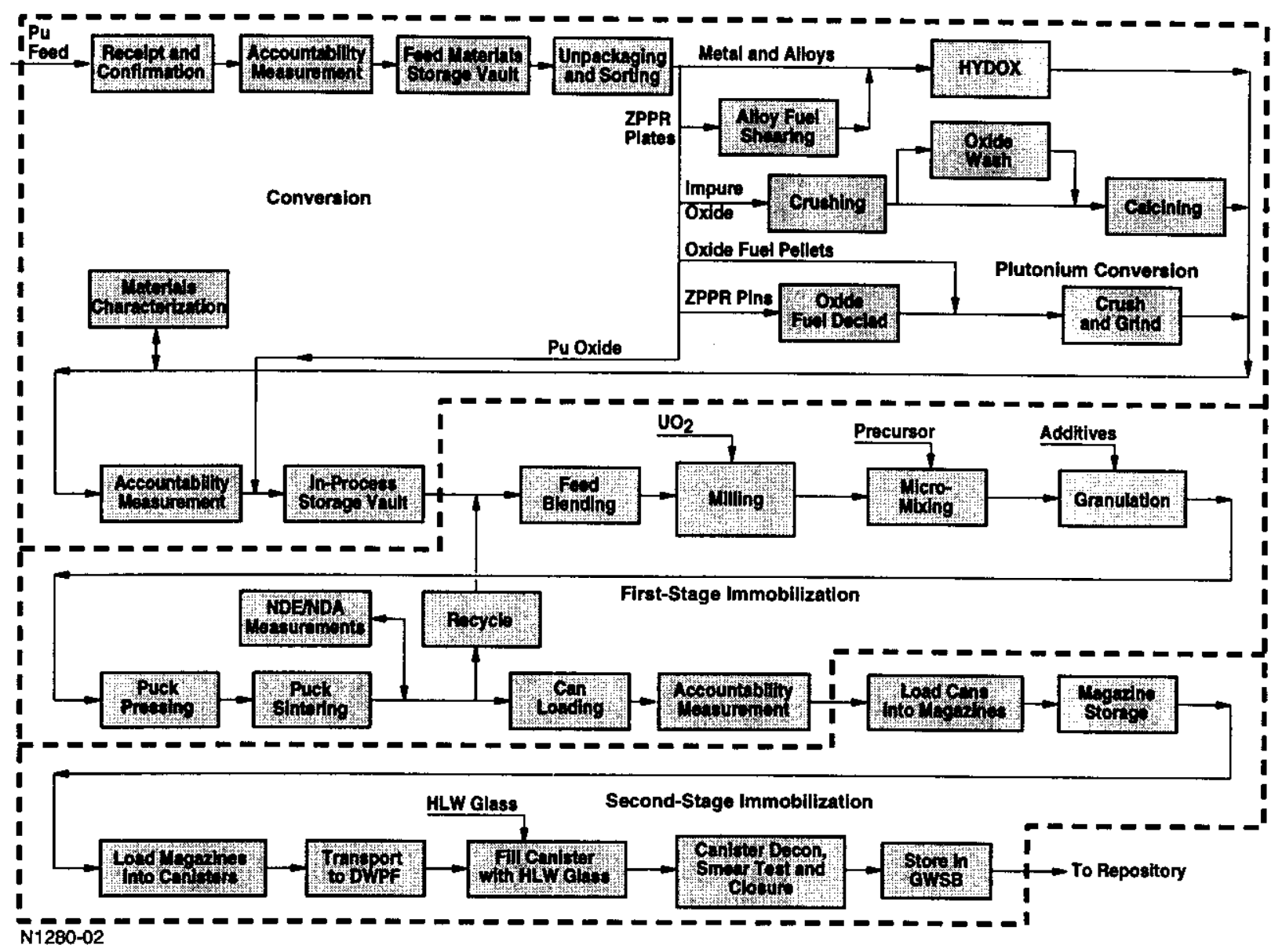

Figure 5.1. Ceramic immobilization process.

\section{Process Description}

All plutonium-bearing feed materials will be received in shipping packages at the APSF. Typical APSF procedures will be used to handle and unpackage the shipping packages. Actinide Packaging and Storage Facility capabilities will be used to perform all required material receipt and MC\&A requirements, and to store the feed materials until they are input into the immobilization process or transferred directly to lag storage at PIP.

All other process feeds, including uranium oxide and ceramic precursor materials, as well as general and maintenance supplies and equipment, will be received at the south dock of the PIP. Receipt information for the uranium oxide will be entered into the facility MC\&A database. All materials will be stored in their respective storage areas.

\section{Functional Requirements}

The APSF will provide the material receipt function for plutonium-bearing feed materials and verification that feed material is unclassified.

The PIP will provide cold chemical storage space for cold feed materials. 


\section{Utilities and Services}

Utilities required will include $120 / 208$ volts alternating current (VAC) for forklift battery charging and facility lighting. Contaminated waste will be generated if decontamination is performed. Uncontaminated waste generated will include paper, gloves, failed equipment, and cleaning supplies.

\section{Interfaces}

Interfaces will include the automatic guided vehicle (AGV) system to transport the material from the existing APSF to the PIP's lag storage or to the plutonium conversion sort glovebox. Incoming material will be entered into the PIP MC\&A system.

\subsubsection{Oxide Fuel Feed Preparation}

Module 1.2, Block Flow Diagram P-202

\section{Process Description}

Zero-power physics reactor fuel pins containing plutonium/uranium oxide will be received at the oxide fuel declad glovebox for disassembly. The objective of the disassembly is to separate the plutonium oxide pellets from the fuel pin cladding.

Each fuel pin will be declad to allow removal of the fuel pellets, which are sent to material size reduction (see Section 5.1.1.3). The metal pin cladding will be consolidated and packaged for transfer to the waste packaging area.

\section{Functional Requirements}

Remote operations will be required due to high radiation levels and the large quantities of fuel pins slated for immobilization. Gloveboxes will be provided with shielding for gamma and neutron radiation. High-efficiency particulate airfiltered (HEPA-filtered) ventilation will be required in the glovebox and the process room. The glovebox atmosphere will be recirculated nitrogen. The process area will be provided with alpha air monitoring, criticality monitoring, and a physical protection alarm system.

\section{Utilities and Services}

Utilities required will include 120/208 VAC for instruments, motors, and facility lighting. Instrument air will also be required. Cladding will be consolidated and then go to waste management and be discarded as TRU waste. Other TRU waste and low-level wastes will consist of glovebox gloves, failed equipment, windows, and filters. Uncontaminated waste generated will include paper, gloves, failed equipment, and cleaning supplies.

\section{Interfaces}

Interfaces will include the material unpackaging and sorting function, the material size reduction process, and waste management. The automated material handling inter-glovebox transport system will move material to and from this process. 


\subsubsection{Material Size Reduction}

Module 1.3, Block Flow Diagram P-202

Process Description

Fast Flux Test Facility (FFTF) fuel pellets, ZPPR oxide fuel pellets, and other materials are received from the automated transport system into the glovebox. The material is automatically weighed and placed into the crush/grind unit. After crushing/grinding, the material is transferred into a standard can in a dustless manner. Ground powder material is again weighed and removed from the glovebox by the inter-glovebox transfer system.

\section{Functional Requirements}

Crush /grind equipment will be required to reduce the size of the oxide fuel pellets and other large oxide materials into 100-micron-size powder. The processes in the glovebox will be automated and the crush/grind process will be dustless. The glovebox will include an automatic transfer system and a material weigh station. The glovebox will be provided with dry recirculated nitrogen and shielding for gamma and neutron radiation. High-efficiency particulate air-filtered ventilation will be required in the glovebox and the process room. The process area will be provided with alpha air monitoring, criticality monitoring, and a physical protection alarm system.

\section{Utilities and Services}

Utilities required will include 120/208/480 VAC for instruments, process equipment motors, and facility lighting. Plant air and instrument air will also be required. Transuranic waste and low-level wastes will consist of glovebox gloves, failed equipment, windows, and filters. Uncontaminated waste generated will include paper, gloves, failed equipment, and cleaning supplies.

Interfaces

Interfaces will include the oxide fuel feed preparation function, the material unpackaging and sorting function, the feed material MC\&A function, and waste management. The automated material handling inter-glovebox transport system will move material to and from this process.

\subsubsection{Material Unpackaging and Sorting}

Module 1.4, Block Flow Diagram P-202

Process Description

Material unpacking and sorting will receive plutonium-bearing feed materials in containment vessels (typically, 3013 or $2 \mathrm{R}$ type containers) from the PIP lag storage vault via the AGV. The containment vessels and the inner material convenience cans will be opened in a glovebox. Depending on containment vessel type, the opening operations will either involve removing mechanically attached containment vessel heads or require cutting operations to remove welded heads. 
The ZPPR alloy fuel will be received and unpackaged in this area, and then transferred to the ZPPR decladding glovebox via a clean conveyor for shearing prior to metal conversion.

Other feed materials will be removed from the cans and will be transferred via a dustless system to a standard container. The materials will be inspected and tramp materials (e.g., nuts and bolts, plastic materials) will be removed. Metallic feed materials will be transferred in standard cans to the metal conversion area.

Reusable, empty containment vessels will be reassembled, removed from the glovebox, and returned to APSF for reinstallation into shipping packages. Nonreusable containment vessels and emptied convenience cans will be removed from the glovebox and transferred to waste packaging.

\section{Functional Requirements}

The glovebox will be provided with dry recirculated nitrogen and shielding for gamma and neutron radiation. High-efficiency particulate air-filtered ventilation will be required in the glovebox and the process room. The process area will be provided with alpha air monitoring, criticality monitoring, and a physical protection alarm system.

The glovebox will include an internal automated material transfer system.

\section{Utilities and Services}

Utilities required will include 120/208/480 VAC for instruments, process equipment motors, and facility lighting. Instrument air will also be required.

Transuranic waste and low-level wastes will consist of glovebox gloves, failed equipment, windows, and filters. Uncontaminated waste generated will include paper, gloves, failed equipment, and cleaning supplies.

\section{Interfaces}

Interfaces will include the material receipt and storage function, the in-process storage vault, the metal conversion function, the metal fuel feed preparation function, the impure oxide feed preparation function, the oxide fuel feed preparation function, the material size reduction function, and waste management. The AGV transport system will supply material to these functions and the automated material handling inter-glovebox transport system will move materials from this process.

\subsubsection{Metal Fuel Feed Preparation}

Module 1.5, Block Flow Diagram P-202

\section{Process Description}

The ZPPR fuel alloy is processed to expose the actinide metals in the fuel for the hydride oxidation (HYDOX) process. The ZPPR fuel plates are sent to the ZPPR declad glovebox from material unpackaging and sorting. The can containing the plates is attached to a hood, where plates are removed and transferred to the air lock. The plates are transferred into the glovebox, weighed, and sheared. The 
sheared plates are again weighed and transferred to metal conversion via the material transfer system. The stainless steel fuel cladding recovered from metal conversion is disposed of as TRU waste.

\section{Functional Requirements}

A shearing technique will be used to expose the ZPPR alloy fuel. A just-intime process will require shearing a maximum of approximately $501-x-2-x-$ 1/8-inch-thick fuel plates into 1/4-x-2-x1/8-inch pieces in four hours. The ZPPR declad glovebox will be able to process enough ZPPR fuel to make one batch run for metal conversion $(\sim 3 \mathrm{~kg})$ every four hours.

The ZPPR declad glovebox will be able to receive ZPPR fuel from the unpackaging and sorting glovebox and to automatically take the fuel from a radioactively cold area into the radioactively hot glovebox. All operations in the glovebox will be automated.

Hydraulics located outside the glovebox will be provided for the shearing operation. The glovebox will be provided with dry nitrogen and shielding for gamma and neutron radiation. High-efficiency particulate air-filtered ventilation will be required in the glovebox and the process room. The glovebox will be provided with a recirculated nitrogen atmosphere. The process area will be provided with plant air, alpha air monitoring, criticality monitoring, and a physical protection alarm system.

\section{Utilities and Services}

Utilities required will include 120/208/480 VAC for instruments, process equipment, motors, and facility lighting. Plant air and instrument air will also be required. Stainless steel cladding will be disposed of as TRU waste. Other TRU waste and low-level wastes will consist of glovebox gloves, failed equipment, windows, and filters. Uncontaminated waste generated will include paper, gloves, failed equipment, and cleaning supplies. Hydraulic fluids will generate a hazardous waste stream.

\section{Interfaces}

Interfaces will include the material unpackaging and sorting function, the metal conversion function, and waste management. The automated material handling inter-glovebox transport system will move materials to and from this process.

\subsubsection{Metal Conversion}

Module 1.6, Block Flow Diagram P-202

\section{Process Description}

Plutonium/uranium metals and alloys are converted to an oxide powder using the HYDOX process. The feed materials for metal conversion (metals and sheared ZPPR plates) are transferred into the air lock via the overhead transport conveyor. The process receives ZPPR alloy fuel and pure and impure metals by means of an air lock connected to the conveyor. The air 
lock exchanges the conveyor nitrogen atmosphere to metal conversion argon atmosphere after pumpdown. The material is transferred into Station I of the HYDOX glovebox, where it is weighed and loaded into the hydride/nitride processing unit. After the nitriding step is complete, the material is transferred to Station III (the oxidation station) via Station II (the glovebox conveyor). In the oxidation station, the nitride is chemically converted to an oxide powder. After this process is complete, the powder is transferred by a dustless process into the standard cans designed for the plant. Lids are put on the cans, the cans are weighed, and they are transferred out of the glovebox through the air lock. Stainless steel cladding from ZPPR plates will be disposed of as TRU waste.

\section{Functional Requirements}

The process equipment will be able to process $3 \mathrm{~kg}$ of plutonium/uranium alloy fuel in a 16-hour period. The hydride/nitride processing unit and the oxide processing unit will have a heater to control the process.

The process will be provided with argon, hydrogen, nitrogen, oxygen, and cooling water for process functions. The gloveboxes will be provided with shielding for gamma and neutron radiation. High-efficiency particulate air-filtered ventilation will be required in the glovebox and process room. The glovebox will be provided with a recirculated argon atmosphere. The area will be provided with instrument air, plant air, alpha air monitoring, criticality monitoring, and a physical protection alarm system.

\section{Utilities and Services}

Utilities required will include 120/208 VAC for instruments, process equipment, furnaces, motors, and facility lighting. Cooling water will be provided for the furnaces. Process gases include nitrogen, hydrogen, argon, helium, oxygen, and air. A roughing vacuum system and instrument air will also be required. Process gases will be vented to the process off-gas system. Stainless steel cladding will be disposed of as TRU waste. Other TRU waste and low-level wastes will consist of glovebox gloves, failed equipment, windows, and filters. Uncontaminated waste generated will include paper, gloves, failed equipment, and cleaning supplies.

Interfaces

Interfaces will include the material unpackaging and sorting function, the metal fuel feed preparation function, MC\&A, and waste management. The automated material handling inter-glovebox transport system will move materials to and from this process.

\subsubsection{Impure Oxide Feed Preparation}

Module 1.7, Block Flow Diagram P-202

\section{Process Description}

Material is transferred into the impure oxide feed prep glovebox to await the determination of which process route will be taken. Some materials may need to be ground and crushed before washing. Other materials may only need to be calcined and not washed. The most stringent route would be to crush and grind the 
material, wash it, calcine it, and then transfer it out of the glovebox. Wash water is evaporated and reused, and the salts become a waste product of this line.

\section{Functional Requirements}

The function of the impure oxide feed prep glovebox is to perform a simple wash technique on impure oxides containing halides to remove the halides. The glovebox will contain equipment for the washing, filtering, and drying of oxide, as well as filtrate evaporation, salt crystallization and drying, and analytical instrumentation to determine efficiency of salt removal. The simple wash technique used at Hanford will be the baseline process. Approximately $1 \mathrm{MT}$ of plutonium has been identified for this process line. Since the amount of halide-bearing oxide material is small, this process is not automated.

A small filtrate treatment system is provided to treat wash liquids with high plutonium content. The system includes ion exchange and precipitation for plutonium removal.

The glovebox will be provided with a dry nitrogen atmosphere and shielding for gamma and neutron radiation. High-efficiency particulate air-filtered ventilation will be required in the glovebox and process room. The process area will be provided with alpha air monitoring, criticality monitoring, and a physical protection alarm system.

\section{Utilities and Services}

Utilities required will include 120/208 VAC for instruments, process equipment, furnaces, motors, and facility lighting. The only process gas is air. Instrument air will also be required. Deionized make-up wash water will be required.

Evaporated salt wastes will be disposed of as TRU waste. Other TRU waste and low-level wastes will consist of glovebox gloves, failed equipment, windows, and filters. Uncontaminated waste generated will include paper, gloves, failed equipment, and cleaning supplies.

\section{Interfaces}

Interfaces will include the material unpackaging and sorting function, the materials characterization function, $\mathrm{MC} \& \mathrm{~A}$, and waste management. The automated material handling inter-glovebox transport system will move materials to and from this process.

\subsubsection{Materials Characterization}

\section{Module 1.8, Block Flow Diagram P-202}

\section{Process Description}

The characterization of impure oxide and other feeds is done in a separated section of the impure oxide feed preparation glovebox. This glovebox section receives sample material from the impure oxide feed prep process and from other process lines handling oxide cans in the facility. Samples are put into the characterization section, analyzed by $x$-ray fluorescence, and transferred 
to the sample preparation glovebox for subsequent transfer to the analytical chemistry laboratory or MC\&A.

\section{Functional Requirements}

Compositional makeup of the oxides will be characterized to determine if this feed material is compatible with the parameters established for the ceramic form. Samples will be characterized automatically by the analysis equipment. The glovebox will be provided with a dry nitrogen atmosphere and shielding for gamma and neutron radiation. To prevent corrosion damage to the instrumentation, the glovebox section will be designed so that chemical fumes and dust from the feed preparation sections cannot enter the analytical section of the glovebox. High-efficiency particulate air-filtered ventilation will be required in the glovebox and the process room. The process area will be provided with alpha air monitoring, criticality monitoring, and a physical protection alarm system. Chemical fumes and dust from the feed preparation areas of the glovebox will be prevented from entering the analytical portion or the analytical equipment will be protected from corrosion damage and dust.

\section{Utilities and Services}

Utilities required will include 120/208 VAC for instruments, process equipment, motors, and facility lighting. The only process gas is air. Instrument air will also be required. Transuranic waste and low-level wastes will consist of glovebox gloves, failed equipment, windows, and filters. Uncontaminated waste generated will include paper, gloves, failed equipment, and cleaning supplies.

\section{Interfaces}

Interfaces will include the metal conversion function, the impure oxide feed preparation, the material size reduction function, MC\&A, and waste management. The automated material handling inter-glovebox transport system will move materials to and from this process.

\subsubsection{Material Control and Accountability}

Module 1.9, Block Flow Diagram P-202

Process Description

This glovebox performs MC\&A measurements for materials from the back-end of the plutonium conversion process and for the front-end of the first-stage immobilization process.

\section{Functional Requirements}

The MC\&A system will be capable of maintaining an accurate inventory of all SNM and other nuclear materials in the facility. The system will be computerbased and will use a combination of nondestructive assay instrumentation for SNM accounting. The system will have instrumentation for tracking all movements of materials in the facility and for real-time inventory of materials in each process area or glovebox to support personnel safety as well as to maintain good process control. 
The glovebox will be provided with a dry nitrogen atmosphere and shielding for gamma and neutron radiation. High-efficiency particulate air-filtered ventilation will be required in the glovebox and the process room. The process area will be provided with alpha air monitoring, criticality monitoring, and a physical protection alarm system.

\section{Utilities and Services}

Utilities required will include $120 / 208 \mathrm{VAC}$ for instruments, process equipment, motors, and facility lighting. Instrument air will be required. Transuranic waste and low-level wastes will consist of glovebox gloves, failed equipment, windows, and filters. Uncontaminated waste generated will include paper, gloves, failed equipment, and cleaning supplies.

Interfaces

Interfaces will include the metal conversion function, the impure oxide feed preparation, the material size reduction function, material characterization, and waste management. The automated material handling inter-glovebox transport system will move materials to and from this process.

\subsubsection{In-Process Storage Vaults/Areas}

Module 1.10, Block Flow Diagram P-202

\section{Process Description}

The various processes in the facility will have different throughput rates. In-process storage facilities (vaults or areas) are provided in selected areas of the facility to improve over-all facility efficiency and allow each process to operate at near-peak efficiency for scheduled periods of time without being idled by a slower associated process. In addition, storage facilities in some areas (e.g., the feed preparation areas) will allow materials to be inventoried so that an optimized mixture of materials is available for homogenization of feed material for the ceramic pucks. The two kinds of storage facilities (areas or vaults) are distinguished below:

- Storage areas are located in processing areas where the materials will be monitored.

- In contrast, in-process storage vaults will be in areas where the materials may be left unattended and, therefore, greater safeguards and security provisions are required.

\section{Functional Requirements}

All storage facilities (areas and vaults) will be provided with positions designed to maintain the materials segregated from all other material being stored or handled in the area. Each storage position will be designed to prevent criticality with other materials stored or being handled in the area. The storage facilities will have sufficient shielding and use remote automatically operated equipment to maintain personnel exposures as low as reasonably achievable (ALARA) and to prevent significant damage to any radiation sensitive instruments and equipment in the area. Storage vaults will also have safeguards and security features to maintain the 
materials safe and secure from theft or unauthorized diversion or sabotage by forces from outside or inside the facility.

The in-process storage vault will be an automated storage and retrieval system (AS/RS) provided with a dry nitrogen atmosphere and shielding for gamma and neutron radiation. The vault will be provided with alpha air monitoring, criticality monitoring, and physical protection alarm system.

\section{Utilities and Services}

Utilities required will include 120/208 VAC for instruments, process equipment, motors, and facility lighting. The in-process storage vault will require cooling of the nitrogen atmosphere. Instrument air will be required. Transuranic waste and low-level wastes will consist of glovebox gloves, failed equipment, windows, and filters. Uncontaminated waste generated will include paper, gloves, failed equipment, and cleaning supplies.

\section{Interfaces}

Interfaces will include the material unpackaging and sorting function, MC\&A, the first-stage immobilization ceramic feed batching function, and waste management. The automated material handling inter-glovebox transport system will move materials to and from this process.

\subsubsection{First-Stage Immobilization}

This section describes the process by which plutonium oxide is conditioned and pressed into pucks, and the pucks are sintered and then placed in stainless steel cans prior to placement into a DWPF canister. Diagram P-203, Appendix B, depicts the key process modules in first-stage immobilization described in the subsections below.

\subsubsection{Ceramic Feed Batching}

Module 2.1, Block Flow Diagram P-203

\section{Process Description}

Feed for the immobilization process includes excess plutonium materials from a wide variety of sources, including weapons production, reactor fuels, and scrap recovery operations. Although the plutonium conversion operations (Section 5.1.1) will provide feed materials similar in physical form (oxide), these feed materials will vary significantly with respect to isotopic distribution, radiation exposure levels, uranium content, and contaminant content. The feed batching process provides a "macrobatch" of uniform composition for the ceramification process to ensure that each puck produced meets acceptance specifications for product form consistency and repository waste form qualification.

Plutonium oxide from the conversion process will be introduced to the batch splitting glovebox line via the automated material handling inter-glovebox transport system. Standard cans, containing up to four kilograms of plutonium as oxide, will be charged to a mechanical sample splitter. The splitter will evenly 
distribute the oxide into a series of receipt cans which are about twice the volume of the standard transfer cans. Successive charging from a series of feed cans produces vertical layers of stratified oxide in each individual receipt can. The total plutonium inventory in the splitter glovebox, as well as the number and configuration of the receipt cans, will be determined by a detailed criticality safety analysis.

The receipt cans are capped, weighed, and then blended to a homogeneous mixture in a can tumbling or shaking device. Contents of the blended cans are sampled for chemical analysis and split into standard transfer cans, which are then transferred to the accountability glovebox for accountability assay measurement. The assayed cans are then transferred to the ceramification glovebox system or return to the batch splitting glovebox for re-blending for subsequent transfer to the in-process vault.

Due to the history and chemical makeup of candidate materials to be processed, the blend recipe will be very selective to identify feed cans that produce an acceptable blended product. Depending on shipment schedules, available inventories, and the degree of material characterization, it may not be possible to achieve a blended macrobatch that is within specification for ceramic puck production. It is estimated that up to $20 \%$ of the blended oxide may require reblending to provide acceptable feed material. This material will be assayed and returned to the in-process vault for recycle.

\section{Functional Requirements}

For radiation exposure control, can movement throughout the glovebox line will be automated with minimal personnel interaction required. Material transfers, particularly the material entry transfer and splitter charging step, will be designed to minimize dusting for radiation exposure and contamination control, material accountability, and criticality safety.

Gloveboxes will be provided with dry nitrogen and shielding for gamma and neutron radiation. High-efficiency particulate air-filtered ventilation will be required in gloveboxes and the process room. The process area will be provided with alpha air monitoring, criticality monitoring, and a physical protection alarm system.

\section{Utilities and Services}

Utilities required will include 120 VAC for instruments, small motors, and facility lighting. Compressed air will be required. Transuranic waste and low-level wastes will consist of empty cans, bag-in/bag-out bags, glovebox gloves, failed equipment, windows, and filters. Uncontaminated waste generated will include paper, gloves, failed equipment, and cleaning supplies.

\section{Interfaces}

Interfaces will include the plutonium conversion in-process storage vault, ceramification glovebox system in first-stage immobilization, and waste management. The automated material handling inter-glovebox transport system will move materials to and from this process. 


\subsubsection{Ceramification}

Module 2.2, Block Flow Diagram P-203

\section{Process Description}

The ceramification glovebox system receives the blended batches of $\mathrm{PuO}_{2}$ from the in-process vault and transfers them into an attritor mill. The required amount of $\mathrm{PuO}_{2}$ and $\mathrm{UO}_{2}$ are added, and the $\mathrm{PuO}_{2}$ and $\mathrm{UO}_{2}$ are milled to a nominal size (about 1 micron). The milled oxide is then transferred into a mixing mill along with the necessary precursors to produce a ceramic batch with the appropriate chemical composition. The milled oxides are intimately mixed with the precursors on a micron scale, after which they are transferred to the granulation station where binders are added and an agglomrated free-flowing powder of the micromixed material is formed. This free-flowing powder is then fed to an automated press. The press produces "green" (i.e., pressed, but not sintered; not a reference to the actual color) pucks that are ready for transfer to a sintering furnace.

\section{Functional Requirements}

The gloveboxes will be provided with a dry nitrogen atmosphere and shielding for gamma and neutron radiation. High-efficiency particulate air-filtered ventilation will be required in gloveboxes and process room. The process area will be provided with alpha air monitoring, criticality monitoring, and a physical protection alarm system.

\section{Utilities and Services}

The process will be provided with oleic acid and acetone for die press lubrication. Utilities required will include $480 \mathrm{~V}$ for the press, $120 \mathrm{VAC}$ for instruments, small motors, and facility lighting. Plant air will be required. Transuranic waste and low-level wastes will consist of empty cans, glovebox gloves, failed equipment, windows, and filters. Uncontaminated waste generated will include paper, gloves, failed equipment, and cleaning supplies.

\section{Interfaces}

Interfaces will include the in-process storage vault, ceramic feed batching function, the ceramic puck handling function, the recycle process, and waste management. The automated material handling inter-glovebox transport system will move materials to and from this process.

\subsubsection{Ceramic Puck Handling}

Module 2.3, Block Flow Diagram P-203

\section{Process Description}

Puck handling operations will use robotics equipment to sequentially extract compressed, unsintered pucks from a press, load and retrieve the green pucks at a weighing station, introduce the pucks for visual inspection via closed circuit television (CCTV), and place acceptable pucks in a matrix on furnace trays for transport to a sintering furnace. 
A material handling system will transport trays into the bottom-loaded sintering furnaces. The sintered pucks on furnace trays will leave the furnace at an elevated temperature.

After cooling, the sintered pucks are viewed by CCTV, weighed, and inspected. A number of pucks, based on statistical sampling, will be retrieved from in-line storage using robotics equipment for evaluation and assay using nondestructive examination and assay (NDE/NDA) procedures. The majority of trays will be sent directly from storage to the can loading operation.

\section{Functional Requirements}

Puck handling automation will be required due to the puck radiation level, the large number of pucks produced per day, and the complexity of operations that the pucks will negotiate, from initial discharge from the compaction press to final loadout into a product can.

These equipment systems will function in an inert, contaminated environment. The equipment will be designed for dustless operation to minimize the spread of contamination and to minimize the potential effects of dust and debris on the long-term operation of the automated equipment. The design will consider the effects and complexities introduced to the material handling system by the elevated temperatures of the puck leaving the furnace.

The gloveboxes will be provided with a dry nitrogen atmosphere and shielding for gamma and neutron radiation. High-efficiency particulate air-filtered ventilation will be required in the gloveboxes and process rooms. The process area will be provided with alpha air monitoring, criticality monitoring, and a physical protection alarm system.

\section{Utilities and Services}

Utilities required will include $120 \mathrm{VAC}$ for instruments, small motors, and facility lighting. Compressed air will be required. Transuranic waste and low-level wastes will consist of glovebox gloves, failed equipment, windows, and filters. Uncontaminated waste generated will include paper, gloves, failed equipment, and cleaning supplies.

Interfaces

Interfaces will include the ceramification function, sintering, can loading, NDE for process control, the recycle process, and waste management. The automated material handling inter-glovebox transport system will move materials to and from this process.

\subsubsection{Nondestructive Examination Process Control}

Module 2.4, Block Flow Diagram P-203

\section{Process Description}

The NDE module evaluates a statistically significant sampling of the sintered pucks from each batch. The evaluations include $x$-ray diffraction measurements 
on the sintered puck to verify the formation of the correct mineral phases within an acceptable range as defined in the product control model. In addition, an $x$-ray fluorescence measurement is made on the sintered puck to verify that the appropriate concentrations of neutron absorbers and the correct ceramic precursor elements are present and are in a correct ratio for the plutonium and uranium loading in the sintered puck. These data will be compared against the product control model to qualify the completed pucks for repository disposition.

\section{Functional Requirements}

The glovebox will be provided with a dry nitrogen atmosphere and shielding for gamma and neutron radiation. High-efficiency particulate air-filtered ventilation will be required in the glovebox and process room. The process area will be provided with alpha air monitoring, criticality monitoring, and a physical protection alarm system.

\section{Utilities and Services}

Utilities required will include $120 \mathrm{VAC}$ for instruments, small motors, and facility lighting. Transuranic waste and low-level wastes will consist of glovebox gloves, failed equipment, windows, and filters. Uncontaminated waste generated will include paper, gloves, failed equipment, and cleaning supplies.

\section{Interfaces}

Interfaces will include ceramic puck handling, can loading, and waste management. The automated material handling inter-glovebox transport system will move materials to and from this process.

\subsubsection{Material Control and Accountability}

Module 2.5, Block Flow Diagram P-203

\section{Process Description}

A statistical sampling of pucks from each batch of sintered pucks will be selected and measured using gamma ray spectroscopy to ascertain the plutonium loading and isotopic composition of the sintered pucks within a given batch. This concentration measurement is combined with the net weight of the pucks from a given batch to assign a plutonium inventory and to provide the material accountability information required by the SNM tracking and accountability system prior to loading the sintered pucks into the cans.

\section{Functional Requirements}

A glovebox will be provided with dry nitrogen and shielding for gamma and neutron radiation. High-efficiency particulate air-filtered ventilation will be required in the glovebox and process room. The process area will be provided with alpha air monitoring, criticality monitoring, and a physical protection alarm system. 


\section{Utilities and Services}

Utilities required will include $120 \mathrm{VAC}$ for instruments, small motors, and facility lighting. Transuranic waste and low-level wastes will consist of glovebox gloves, failed equipment, windows, and filters. Uncontaminated waste generated will include paper, gloves, failed equipment, and cleaning supplies.

\section{Interfaces}

Interfaces will include ceramic puck handling, can loading, and waste management. The automated material handling inter-glovebox transport system will move materials to and from this process.

\subsubsection{Sintering}

Module 2.6, Block Flow Diagram P-203

\section{Process Description}

The sintering operation receives the loaded trays of green pucks from the material handling system within a furnace system. Trays of pucks are bottom-loaded into the sintering furnace. The pucks are then temperature-cycled in an argon atmosphere according to process specifications to burn out any binders and to react the precursor materials with the milled actinides to form the desired mineral phases. Following cool down, the sintered pucks are ready for unloading onto transfer trays by the material handling system.

\section{Functional Requirements}

Gloveboxes will be provided with argon atmosphere and shielding for gamma and neutron radiation. High-efficiency particulate air-filtered ventilation will be required in the glovebox and process room. An off-gas system will be required to remove volatile residues from furnaces.

\section{Utilities and Services}

Utilities required will include $120 \mathrm{VAC}$ for instruments, small motors, and facility lighting. An additional $480 \mathrm{VAC}$ will be required for the sintering furnaces. The process will be provided with argon gas and cooling water for the furnaces. Transuranic waste and low-level wastes will consist of glovebox gloves, failed equipment, windows, and filters. Uncontaminated waste generated will include paper, gloves, failed equipment, and cleaning supplies.

\section{Interfaces}

Interfaces will include ceramic puck handling and waste management. The automated material handling inter-glovebox transport system will move materials to and from this process.

\subsubsection{Recycle}

Module 2.7, Block Flow Diagram P-203 
Process Description

Any off-spec materials, flashing, box sweepings, or off-spec green and sintered pucks will be recycled back into the feed batching operation or blending operation as appropriate. All materials will be size-reduced and milled to a size compatible with the selected reinsertion point. All materials to be added to the actinide stream will be milled to sizes less than 100 microns so as to be suitable for actinide milling. All green materials will be reduced to a similar size before being added to the blending operation with the milled actinides and precursors.

\section{Functional Requirements}

The glovebox will be provided with a dry nitrogen atmosphere and shielding for gamma and neutron radiation. High-efficiency particulate air-filtered ventilation will be required in the glovebox and process room.

\section{Utilities and Services}

Utilities required will include $120 \mathrm{VAC}$ for instruments, small motors, and facility lighting. Transuranic waste and low-level wastes will consist of glovebox gloves, failed equipment, windows, and filters. Uncontaminated waste generated will include paper, gloves, failed equipment, and cleaning supplies.

\section{Interfaces}

Interfaces will include ceramic puck handling, ceramic feed batching, the inprocess storage vault, and waste management. The automated material handling inter-glovebox transport system will move materials to and from this process.

\subsubsection{Can Loading}

Module 2.8, Block Flow Diagram P-203

\section{Process Description}

Trays of acceptable pucks will be transferred from the puck tray storage area to the can loading area. The automated puck product can loading system will unload individual sintered pucks from transfer trays using robotic handling equipment. The robot will place 20 sintered pucks in each puck product can.

The can will be filled with helium. Automated equipment will place a lid on the can and complete a seal weld. The welded can will then be conveyed to a smear test station to verify that the can is not contaminated, and the weld will be leaktested in a bell jar. Uncontaminated cans with acceptable welds are transferred to product NDA and, in turn, the magazine loading area.

\section{Functional Requirements}

The gloveboxes will be provided with a dry nitrogen atmosphere and shielding for gamma and neutron radiation. High-efficiency particulate air-filtered ventilation will be required in the gloveboxes and process room. 


\section{Utilities and Services}

Utilities required will include 120 VAC for welding and facility lighting. The process will be provided with helium, argon, and compressed air. Transuranic waste and low-level wastes will consist of empty cans, glovebox gloves, failed equipment, windows, and filters. Uncontaminated waste generated will include paper, gloves, failed equipment, and cleaning supplies.

\section{Interfaces}

Interfaces will include ceramic puck handling, NDE for process control, MC\&A, and waste management. The automated material handling inter-glovebox transport system will move materials to and from this process.

\subsubsection{Product NDA}

Module 2.9, Block Flow Diagram P-203

\section{Process Description}

Puck product cans will be received from the can loading area; nondestructively assayed using calorimetry, gamma isotopics, and NDA standards; and placed in a storage position until transferred to the magazine loading area by conveyer.

All movements of materials in the product NDA area will be by a remote, manually or automatically controlled, gantry crane.

\section{Functional Requirements}

The process room will be provided with shielding for gamma and neutron radiation and storage positions for assayed cans. High-efficiency particulate air-filtered ventilation will be required in process room.

\section{Utilities and Services}

Utilities required will include 120/208 VAC for instruments, process equipment, motors, and facility lighting. Instrument air will be required.

Uncontaminated waste generated will include paper, gloves, failed equipment, and cleaning supplies.

Interfaces

Interfaces will include can loading, second-stage immobilization magazine loading, puck can transport system, and waste management. The automated material handling inter-glovebox transport system will move materials to this process. The puck can transport system will move the cans to magazine loading.

\subsubsection{Second-Stage Immobilization}

In the second-stage immobilization operations, stainless steel puck cans are placed into a tubular-shaped magazine. The magazines holding four product cans are inserted and latched into place inside a DWPF canister. The DWPF 
canisters are received from an off-site vender with an internal support rack installed in the canister during canister fabrication.

The DWPF canisters with magazines are transferred from the Plutonium Immobilization Facility to the DWPF. In the DWPF, high-level waste glass is cast into the canisters to encapsulate the magazines. The glass-filled canisters are transferred from the DWPF to the existing GWSB and stored until shipped offsite to a waste repository. A flow sheet for the second-stage immobilization operations may be found in Appendix B.

\subsubsection{Can-in-Canister System}

Module 3.2, Block Flow Diagram P-204

\section{Process Description}

Product cans are received from the product can NDA area by conveyer. The cans are loaded into a magazine using robotics equipment-four cans per magazine. The cans will be secured in the magazine. The loaded magazines will be inspected, and acceptable magazine assemblies will be transferred to a shielded storage area and placed in a storage well by a remotely controlled gantry-mounted robot. Unacceptable magazine assemblies will be transferred to the off-normal storage/repair area for dispositioning.

The DWPF-type canisters used by the PIP will be fabricated with an internal rack for holding seven magazines. These canisters are received by conveyer from the clean canister storage area. The canister is positioned at the canister loading station.

The remotely controlled gantry-mounted robot will retrieve a loaded magazine from a storage well in the shielded storage area, transport the magazine to the canister loading area, insert the magazine through the head of the canister, and lock the magazine in the canister's internal rack. The assembly in the canister is inspected and acceptable assemblies and canisters are moved by conveyer to the canister temporary capping area. Unacceptable assemblies and canisters are dispositioned at the off-normal storage/repair area.

A temporary cap is installed on the canister at the canister temporary capping area. The capped canister is transferred to the loaded canister storage area, where a remotely controlled crane retrieves the canister from the conveyer and places the canister in a storage position until shipped from the facility.

\section{Functional Requirements}

Magazine loading and assembly will require remote operation due to high radiation level. The process area will be provided with shielding for gamma and neutron radiation. High-efficiency particulate air-filtered ventilation will be required in the process area. An overhead bridge-mounted robot will be required for manipulation of the magazines. An overhead bridge crane will be required for maintenance of the robotics equipment and to remove shielded storage well plugs.

Canister loading will also require remote operation due to high radiation level. The process area will be provided with compressed air for pneumatic tools, and 
shielding for gamma and neutron radiation. High-efficiency particulate air-filtered ventilation will be required in process area.

\title{
Utilities and Services
}

Utilities required will include 120/208/480 VAC for instruments, CCTV, the canister conveyor, the two overhead bridges (the robot and crane bridges), and facility lighting. Compressed air will be required for pneumatic tool operation. Wastes will consist of paper, failed equipment, and cleaning supplies.

\section{Interfaces}

Interfaces will include the puck can transport system, canister transport, and waste management. The material/cans/canisters will be entered into the plant MC\&A system.

\subsubsection{Canister Transport}

\section{Module 3.3, Block Flow Diagram P-204}

\section{Process Description}

A loaded canister is retrieved from storage by a remotely operated crane. The crane places the loaded canister into a transport cask. Canister restraints are emplaced in the cask to stabilize the canister during transport. The cask head is then installed on the cask and the cask is lowered by crane onto a transfer cart in the exit tunnel. In the truck loading bay, a crane will pick up the cask and place it on a transport vehicle. The transport vehicle, with safeguards and security protection and surveillance, moves the loaded cask to the DWPF.

\section{Functional Requirements}

Cask loading will also require remote operation due to high radiation levels. The process area in the PIP cask loading area will be provided with compressed air for pneumatic tools, and shielding for gamma and neutron radiation. High-efficiency particulate air-filtered ventilation will be required in process area.

\section{Utilities and Services}

Utilities required will include $120 / 208 / 480$ VAC for instruments, CCTV, the overhead bridge cranes in both the cask loading area and the external truck bay, the cask transporter, and facility lighting. Compressed air will be required for pneumatic tool operation. There should be no process waste. Wastes will consist of paper, failed equipment, and cleaning supplies.

\section{Interfaces}

Interfaces will include the DWPF receipt and handling, canister transport, and waste management. The canisters will be entered into the plant MC\&A system.

\subsubsection{Defense Waste Processing Facility Receipt and Handling}

\author{
Module 3.4, Block Flow Diagram P-204
}




\section{Process Description}

Casks with loaded canisters are received by transport vehicle at the DWPF dock. The casks are opened, and the canisters are transferred to the DWPF melt cell for storage. The canisters are retrieved from storage, placed under the melter pour spout, and filled with high-level waste glass. The glass-filled can-in-canister is processed through cooling, decontamination, and closure plug installation. The completed, glass-filled canister is transferred to the GWSB until final disposition.

\section{Functional Requirements}

Canister receipt at the DWPF will require a shielded lift truck for movement of the canister due to high radiation level.

\section{Utilities and Services}

Utilities required will include $120 / 208 / 480$ VAC for instruments, CCTV, the overhead bridge crane in the truck bay of the DWPF, and facility lighting. There should be no process waste. Wastes will consist of paper, failed equipment, and cleaning supplies.

\section{Interfaces}

Interfaces will include the DWPF process and waste management. The canisters will be entered into the plant MC\&A system.

\subsubsection{International Atomic Energy Agency Accommodations}

\section{Process Description}

In support of U.S. nonproliferation policy, DOE will make plutonium that is surplus to the nation's defense requirements available for verification and inspection by the IAEA, provided that no classified information is revealed. Since the PIP will be an unclassified facility, IAEA representatives are expected to be offered unrestricted access to allow the IAEA to perform inspection verification of the SNM processed in the plant. The specific details of the inspections (e.g., escort protocols and notification prior to inspection) are to be negotiated with the IAEA. Regular technical discussions between the IAEA, DOE, and the plant operator during both design and operation of the PIP will assure that the facility can accommodate IAEA requirements.

\section{Functional Requirements}

The following major elements will be provided in the facility design and operating protocols:

- A clearly identified portion of the facility for IAEA verification and surveillance activities, including record processing, calibrating and repairing instruments, and loading/unloading cameras

- Space for IAEA-supplied cameras and data recording equipment located at selected strategic locations (e.g., the plutonium storage vaults) for monitoring entry and removal of containers 
- Power and support utilities to support IAEA monitoring and surveillance equipment

- Submittal of summary material accountability data at defined points in the process and negotiated intervals

- Verifying material accounting data and appropriate containment and surveillance systems for IAEA activities such as those that will allow:

- the IAEA to witness key measurement point (KMP) transactions

- IAEA inspectors to make independent measurements at selected agreed-upon KMPs

- the IAEA to obtain independent samples prepared for IAEA analysis from the operator

- space and support systems required for IAEA containment and surveillance systems such as CCTV, video recorders, tamper-indicating seals, and selected material transfer monitoring devices

- IAEA inspector access to the facility at negotiated periods and prior notice times

- Operator assistance as required to provide appropriate samples, process data, measurements, and escorts.

\section{Utilities and Services}

Utilities required will include 120/208 VAC for instruments, CCTV, and facility lighting. There should be no process waste. Wastes will consist of paper, failed equipment, and cleaning supplies.

\section{Interfaces}

Interfaces will include the MC\&A system, all process systems, safeguards and security, and waste management.

\subsubsection{Waste Management}

\section{Process Description}

Transuranic waste will consist primarily of job control waste, metal cladding from plutonium oxide and alloy fuel elements, HEPA filters, empty cans, and failed equipment. The TRU waste, including empty containers, will be assayed prior to leaving the material access area (MAA) for MC\&A purposes and will be certified to meet the waste acceptance criteria (WAC) for the Waste Isolation Pilot Plant (WIPP). The waste will be inspected, packaged in drums or special containers, and assayed for accountability. The packages are shipped to an interim storage facility in E-Area, radiographed, certified, and transported to WIPP. Transuranic waste that does not meet the WAC will be stored in E-Area for treatment/repackaging in a future SRS TRU Waste Facility.

Small amounts of liquid TRU waste generated during decontamination or other operations will be absorbed or solidified and treated like solid TRU waste.

Larger quantities of liquid waste would be loaded into containers and shipped to the Effluent Treatment Facility in H-Area for treatment.

Low level waste will include job control waste, combustibles, filters, metal and glass. Solid LLW will be packaged in B-25 $\left(90 \mathrm{ft}^{3}\right)$ metal boxes or drums and 
transported to the SRS LLW Disposal Facility for disposal in waste vaults in E-Area. Liquid LLW would be packaged and shipped to the Effluent Treatment Facility.

Mixed LLW will include items similar to those described for LLW but including hazardous waste components. Administrative procedures will minimize generation of this waste. Mixed LLW will be transferred to the CIF adjacent to H-Area for incineration or to a future SRS Hazardous/Mixed Waste Disposal Facility for treatment/disposal.

Maintenance work may generate wastes such as lubricants, solvents, paints, coolants, and batteries. Hazardous waste will be transferred to the CIF for incineration or to a future SRS Hazardous/Mixed Waste Disposal Facility for treatment/disposal. Hazardous waste may also be shipped to an offsite commercial facility.

The nonhazardous waste generated during operations will include liquids and solids. Liquid sanitary waste will be sent to the existing sanitary sewer system in F-Area. Solid waste, such as office and shop waste, will be sent to the SRS sanitary landfill. Cooling tower blowdown and steam condensate will be treated, if necessary, and discharged to a permitted outfall.

\section{Functional Requirements}

The gloveboxes will be provided with a dry nitrogen atmosphere and shielding for gamma and neutron radiation. High-efficiency particulate air-filtered ventilation will be required in the gloveboxes and process rooms. The process area will be provided with alpha air monitoring, criticality monitoring, and a physical protection alarm system.

\section{Utilities and Services}

Utilities required will include $120 / 208$ VAC for instruments and facility lighting. Interfaces

Interfaces will include the MC\&A system, all process systems, safeguards and security, and site waste management.

\subsubsection{Analytical Laboratory}

\section{Process Description}

Analytical laboratory facilities will be provided to support operations in the PIP. A portion of these facilities will be located inside the PIP MAA and the remainder in the existing analytical laboratories in Building 772-F. This equipment will be used to support in-process control of operations in the facility and are generally considered to be destructive in nature.

Determination of plutonium mass and isotopic distribution in feed or in-process materials to support material MC\&A requirements are not analytical laboratory activities. Further, quality control inspections of the compacted (green) and sintered pucks also are outside the analytical laboratory scope. 
Analytical laboratory support for the PIP includes the following operations:

- Sample Collection. Samples of in-process materials will be collected at selected gloveboxes in the PIP. These samples will be transferred via a vacuum transfer system to a sample preparation glovebox where the samples will be put into laboratory containers. The laboratory containers will be transferred out of the glovebox via central research or equivalent type glovebox cans/ports. The samples will be taken to the analytical laboratories located in Building 772-F for analysis.

In addition, samples of ceramic precursor material, lubricants, binders, and the uranium oxide will be collected on a statistical basis. These samples will be collected in the various PIP storage areas for the materials, placed in appropriate containers, and transferred to the analytical laboratory, Building $772-\mathrm{F}$, for analysis. These samples are collected for quality assurance purposes, to assure that the materials are acceptable for use in the ceramic immobilization process.

- Oxide Wash Glovebox Analyses. Samples of impure oxides received at the impure oxide feed prep glovebox will be analyzed using $x$-ray fluorescence equipment located in the glovebox. The results of these analyses will be used to verify which materials are processed for halide removal. In addition, the "washed" solid oxide will be analyzed using the x-ray fluorescent equipment. This is done to verify acceptability for the immobilization processes prior to transferring the material to the in-process storage vault.

Building 772-F facilities will be capable of determining the physical and chemical properties of solid feed materials and of process solution taken from the impure oxide feed preparation glovebox.

Liquid samples for process control will be collected during the oxide washing process prior to filtration and calcination. These samples will be transferred to the analytical laboratory in Building 772-F via the sample preparation glovebox.

\section{Functional Requirements}

Gloveboxes will be provided with a dry nitrogen atmosphere and shielding for gamma and neutron radiation. High-efficiency particulate air-filtered ventilation will be required in the gloveboxes and process rooms. The process areas will be provided with alpha air monitoring, criticality monitoring, and a physical protection alarm system.

Equipment requirements will include $x$-ray fluorescence analytical analysis equipment, sample handling equipment, equipment/tools for collecting samples at the various process gloveboxes, equipment for transferring solid samples (from standard material transport containers to laboratory transfer cans), equipment for loading liquid samples into laboratory transfer cans, decontamination equipment, MC\&A equipment, transfer port, bagout port, and vacuum transfer system.

\section{Utilities and Services}

Utilities required will include 120/208 VAC for instruments, tooling and equipment, and facility lighting. Transuranic waste and low-level wastes will consist of glovebox gloves, failed equipment, windows, and filters. Uncontaminated waste generated will include paper, gloves, failed equipment, and cleaning supplies. 
Interfaces

Interfaces will include the MC\&A system, all process systems, and waste management.

\subsubsection{Control Rooms}

\section{Process Description}

The PIP will have a main control room and a number of strategically located local control rooms. The main control room will interface with all the local control rooms and will be capable of monitoring all operations in the facility. The main control room will in general have the capability to control (requires an enabling signal from the local control rooms) all major operations in the facility. The main control room will also provide the primary control for those facility operations and activities that affect, or involve, the facility in general, such as the movement of materials between gloveboxes in the facility via the materials transport system or AGV.

The local control rooms will be located near the modules or operations that they control. These local control rooms will provide the primary control source for controlling facility operations near their location.

\section{Functional Requirements}

The main control room will have the following functional requirements:

- MC\&A computer

- Health protection computer

- AGV control computer

- Other process control computers as determined during the design phase

- Monitors for viewing operations in the facility via CCTV

- Instrumentation for monitoring the status of all major operations in the facility

- Instrumentation, including alarms, for monitoring radiation levels in the facility, including the status of the continuous air monitors (CAMs)

- Secondary controls for all major operations in the facility (requires an enabling signal from the local control rooms)

- Office facilities for the shift supervisor.

Local control rooms will have computers and instrumentation as needed to control the specific operations under each control room's purview.

All control rooms will have facility heating, ventilation, and air conditioning (HVAC) with additional conditioning as recommended by the control instrumentation/computer manufacturers.

\section{Utilities and Services}

Utilities required will include 120/208 VAC for instruments, computers, consoles, CCTV, and facility lighting. Uninterruptible power supply (UPS) will be required for critical instruments, computers, and safety functions. Uncontaminated waste generated will include paper, failed equipment, and cleaning supplies. 


\section{Interfaces}

The main control room interfaces will include:

- All major facility operations via local area network (LAN) for secondary control

- Selected process areas via process control computers located in the room

- All local control rooms via LAN and communications lines

- All facility MC\&A operations via LAN, SRS MC\&A data system via encrypted data lines or removable storage media, IAEA area via authenticated data lines

- All facility radiation monitors, including CAMs via LAN, AGV via radio signal, materials transport system via control system, facility ventilation systems, electrical and communication systems, and waste packaging.

The local control room interfaces will include:

- Operations equipment under control room's purview via LAN

- Materials transport system via control system

- Main control room via LAN

- Facility HVAC systems

- Electrical and communications systems

- Waste packaging.

\subsubsection{Material Access Area Support Rooms/Facilities}

A number of support areas and rooms are included in the material access area and include a second floor area above the main MAA process floor. A physical description, including functional features, interfaces, and waste generated in these areas is included in the following sections.

\subsubsection{Automated Guided Vehicle Maintenance}

\section{Process Description}

A maintenance/service area for the AGVs will be provided.

\section{Functional Requirements}

Functional requirements included:

- A room sized to allow maintenance operations on one AGV while the battery on a second $A G V$ is being charged

- A standard door sized for passage of AGVs

- A battery charging station with hood to collect off-gases

- A hydraulic or mechanical lift to raise AGVs for undercarriage maintenance

- Miscellaneous tools and repair equipment and instruments as recommended by the AGV manufacturer

- Storage for tools and repair equipment/instruments. 


\section{Utilities and Services}

Utilities required will include 120/208 VAC for instruments, tooling and equipment, battery charging, and facility lighting. Uncontaminated waste generated will include paper, failed equipment, hydraulic fluids, oils, grease, and cleaning supplies.

Interfaces

The AGV maintenance room interfaces will include all major facility MAA process corridors, control rooms, and waste management.

\subsubsection{Contaminated Maintenance Room}

\section{Process Description}

A maintenance area for routine repair and service of contaminated equipment will be provided. Major or non-routine repairs may be performed in other SRS maintenance shops.

\section{Functional Requirements}

Functional requirements include:

- A room with standard door with air lock, sized for passage of the largest equipment expected to be repaired

- Work benches with hoods, tools, and instruments required for routine repairs of facility contaminated equipment

- Storage for repair tools and equipment and for inventory of frequently required spare parts

- Decontamination equipment

- Hoisting equipment (monorail or portable jib crane).

\section{Utilities and Services}

Utilities required will include 120/208 VAC for instruments, tooling and equipment, and facility lighting. Transuranic waste and low-level wastes will consist of failed equipment and parts, and decontamination wastes. Uncontaminated waste generated will include paper, failed equipment, hydraulic fluids, oils, grease, and cleaning supplies.

Interfaces

The contaminated maintenance room interfaces will include all major facility MAA process corridors, process rooms, and waste management.

\subsubsection{Electrical and Instrumentation Maintenance Room}

\section{Process Description}

A maintenance area for routine repair and service of electrical and electronic equipment and instrumentation will be provided. Major repairs or non-routine 
repairs may be performed in other SRS electrical and instrumentation (E\&I) maintenance shops.

\section{Functional Requirements}

Functional requirements include:

- A room with standard door with air lock, sized for passage of the largest equipment expected to be repaired

- Work benches with hoods, tools, and instruments required for routine repairs of facility contaminated equipment

- Storage for repair tools and equipment and for inventory of frequently required spare parts

- Decontamination equipment

- Hoisting equipment (monorail or portable jib crane).

\section{Utilities and Services}

Utilities required will include 120/208 VAC for instruments, tooling and equipment, and facility lighting. Uncontaminated waste generated will include paper, failed equipment and parts, and cleaning supplies.

Interfaces

The electrical and instrumentation maintenance room interfaces will include all major facility MAA process corridors, process rooms, and waste management.

\subsubsection{Empty Magazine and Canister Storage}

\section{Process Description}

A room will be provided for the storage and receipt inspection of empty magazines and canisters. The room will be lift-truck accessible.

\section{Functional Requirements}

Functional requirements include:

- A room with an access door sized for passage of lift trucks delivering empty magazines from the south dock

- A passage door into the magazine loading area

- A hatch for placing empty canisters onto the canister conveyer

- A storage area with capacity for about 200 magazines (2 weeks' operating supply)

- An area and equipment to allow visual and dimensional inspection of magazines at rate of seven per day and canisters at rate of one per day

- A canister storage area with capacity for 20 empty canisters (2 weeks' operating supply)

- Lifting equipment for handling canisters. 


\section{Utilities and Services}

Utilities required will include 120/208 VAC for instruments, tooling and equipment, and facility lighting. Uncontaminated waste generated will include paper, failed equipment, and cleaning supplies.

Interfaces

Interfaces will include the magazine loading area, the canister loading area, MC\&A system, and waste management.

\subsubsection{Uranium Drum Storage}

Process Description

A room will be provided for the storage of drums of uranium oxide feed materials.

\section{Functional Requirements}

The room will be located on the top level of the PIP above the ceramic processing stack and will be lift-truck accessible. An access door sized for passage of lift trucks carrying 55-gallon drums is required. The room will have space for drum storage with a capacity for 10 to 20 drums. A hood for removing drum heads is needed to allow transfer and laboratory sampling of oxide.

\section{Utilities and Services}

Utilities required will include 120/208 VAC for instruments, equipment, and facility lighting. Low level waste may be generated and will be disposed of accordingly. Uncontaminated waste generated will include paper, failed equipment, and cleaning supplies.

\section{Interfaces}

Interfaces will include the immobilization processing stack, MC\&A system, and waste management.

\subsubsection{Ceramic Precursor Storage}

\section{Process Description}

A room will be provided for the storage of drums/boxes of ceramic precursor feed materials including ceramic materials, ceramic lubricants, and binders.

\section{Functional Requirements}

The room will be located on the top level of the PIP above the ceramic processing stack and will be lift-truck accessible. An access door sized for passage of lift trucks carrying 55-gallon drums or pallets is required. The room will have space for up to 2 months' operating capacity. 


\section{Utilities and Services}

Utilities required will include 120/208 VAC for instruments, equipment, and facility lighting. Uncontaminated waste generated will include paper, failed equipment, and cleaning supplies.

\section{Interfaces}

Interfaces will include the immobilization processing stack and waste management.

\subsubsection{Cold Supply Storage}

\section{Process Description}

A room near the first-level entry location will be provided for the storage of general supplies used in the PIP MAA. The items to be stored in this area will include office supplies, recorder chart paper, miscellaneous hardware items, and other sundries that are frequently required to support operation in the facility.

\section{Functional Requirements}

A room with an access door sized for passage of lift trucks and pallets is required. The room will have storage shelves and cabinets. The room will be lifttruck accessible.

\section{Utilities and Services}

Utilities required will include $120 \mathrm{VAC}$ for facility lighting. Uncontaminated waste generated will include paper, general packing materials, card board boxes.

\section{Interfaces}

The storage room interfaces with all areas of the PIP to provide supplies.

\subsubsection{Health Protection Area}

\section{Process Description}

A room will be provided in the MAA, near the personnel entry and exit area, for health protection (HP) facilities and equipment. This area will have equipment for assessing the contamination on wipes used to survey for transferable contamination on equipment and containers being handled in the facility. The area will also be provided with portable equipment for use in monitoring the radiation levels in any area of the facility. Facilities and equipment for the decontamination of personnel will be provided. A personnel monitoring station for all personnel exiting the MAA will be provided in the hallway near the HP area. 


\section{Functional Requirements}

Functional requirements include:

- A room with an access door sized for passage of personnel and the largest equipment item in the room

- A protective clothing storage area

- A personnel decontamination area with lavatories and shower

- A "status board" for displaying the real time status of all HP-related monitors (CAMs, nuclear incident monitors [NIMs], area radiation monitors [ARMs], and fire alarms) in the PIP. This board will include both audible and visual alarms to signal unacceptable conditions detected by each monitoring device

- Contamination swipe counters

- Personnel monitoring equipment for contamination and metal detection in the hallway near the HP area

- Portable HP equipment (portable CAMs, ARMs, friskers, etc.)

- Storage facilities for portable HP equipment, instruments, and calibration sources

- Shielding requirements for walls (to be determined by ALARA analysis).

\section{Utilities and Services}

Utilities required will include $120 / 208 \mathrm{VAC}$ for instruments, equipment, and facility lighting. Low level waste will be generated from swipes and LLW water from the personnel shower and lavatory wash water. Uncontaminated waste generated will include paper, failed equipment, and cleaning supplies.

\section{Interfaces}

The HP area interfaces with all areas of the PIP to provide HP support.

\subsubsection{Contaminated Waste Water Collection System}

\section{Process Description}

A water drain system will be provided for collecting all waste water, including fire water, that is normally not contaminated, but has a potential for being contaminated. The water will be collected and monitored for contamination. Uncontaminated water will be released to an appropriate outfall. Contaminated waste water will be transferred to an appropriate existing contaminated liquid waste treatment facility at the SRS.

\section{Functional Requirements}

A room with an access door sized for passage of personnel and tanks is required, as well as shielding requirements for the walls. The room will be designed to act as secondary containment for the contents of the largest tank in the room with collection trenches and floors sloped to drains. A drain to an outfall for uncontaminated water and a pump for transferring contaminated water to a tank truck are required. 


\section{Utilities and Services}

Utilities required will include $120 \mathrm{VAC}$ for pumps and facility lighting. Storage of uncontaminated water with potential for contamination (no liquid waste generated in the area) may be required.

\section{Interfaces}

The collection system interfaces include waste management, water generating areas via piping and floor trenches and drains, the health protection decontamination shower and lavatory, and the sample preparation area.

\subsubsection{Elevators}

\section{Process Description}

Elevators for transport of personnel, equipment, and materials will be provided in locations to be determined during the design phase. The design of these elevators will include the elevator vestibules and mechanical equipment rooms.

\section{Functional Requirements}

All elevators will be designed to commercial standards. The freight elevator will be designed for cargo loads that are $125 \%$ of the maximum load expected during facility operation, including weights of lift truck, lift truck cargo, and all personnel (operating, security, and HP) accompanying the material movement.

Elevator vestibules will be sized in accordance with the elevator usage.

\section{Utilities and Services}

Utilities required will include 120/208 VAC for motors and facility lighting.

\section{Interfaces}

The elevators are part of the PIP personnel and material movement capability.

\subsubsection{Offices, Conference Room, Support Storage Areas, and Janitorial Closet}

\section{Process Description}

Rooms will be provided in the MAA for shift supervisor offices, a conference room, janitorial closet, and several support storage areas.

\section{Functional Requirements}

Offices will be furnished with standard office furniture and equipment and with telephone and data cable connections to the SRS computer LAN for each occupant of the office. Conference rooms will be sized for a minimum of $40 \mathrm{occu}$ pants and with standard conference room equipment, including telephone, connection to the SRS computer LAN, and SRS TV cable. 
A minimum of two janitorial closets-one for the radiological buffer area and one for the clean area-are required. Each janitorial closet will have storage for janitorial supplies and equipment and a sink. This sink is drained to the facility contaminated water collection system in the radiological buffer area and to the sanitary waste water system in the clean area.

\section{Utilities and Services}

Utilities required will include $120 \mathrm{VAC}$ for equipment and facility lighting. Wastes will include solid sanitary waste (miscellaneous materials, including office trash and packaging material) and liquid sanitary waste with potential for contamination (janitorial closet sink drain).

Interfaces

Interfaces will include the PIP corridors and contaminated water collection system.

\subsubsection{Material Transport System}

The PIP processing area utilizes a number of handling systems for transporting solid material during the materials receiving, processing, and shipping operations. The following section provides descriptions of the major materials handling systems associated with the facility.

\subsubsection{Overhead Inter-Glovebox/Area Transport System}

\section{Process Description}

An overhead material transport system will transport process materials as well as small tools and equipment. The transport system will be designed such that most components of the system requiring maintenance are located outside the material confinement boundary. To simplify the system design, the transfer systems will be designed to handle two types of standard cans as well as furnace and transport trays between the PIP gloveboxes and areas. All transfers of materials, tools, and equipment between the PIP gloveboxes and areas will be made using one of the cans or tray types.

The design of these transport systems will have provisions for minimizing the spread of contamination to the extent practicable. The transport systems located outside the gloveboxes will include a confinement system transport tunnel.

\section{Functional Requirements}

The following functional requirements are required for the transport system:

- Standard cans and trays for transporting materials, tools, and equipment.

- Dollies or carts designed for transporting standard cans and trays (located inside the confinement barriers.)

- Drive mechanisms located outside the confinement barrier.

- An elevating system to raise the cans/trays from the glovebox elevations to the overhead transfer tunnel elevations. 
- Docking stations for transferring the transport cans/trays between the elevating system and the overhead transport system.

- Docking stations inside the gloveboxes and areas where the transport systems will interface with other portions of the transport system (e.g., interface between the inter- and intra-glovebox transport system) and with equipment and processes within the gloveboxes.

- Confinement systems for elevating and overhead transport systems located outside gloveboxes. Some of these confinement systems will be inerted. Airlocks may be required between some transport systems and the gloveboxes.

- Shielding (as determined by ALARA analysis).

- Control systems located near the area of operation and with communication with the main control room.

- Material control and accountability equipment and instrumentation for tracking materials being transported. (Typically, these are located in the gloveboxes/areas and may be shared with the glovebox/area systems.)

\section{Utilities and Services}

Utilities required will include 120/208 VAC for motors, lighting, and equipment support. Transuranic and low level wastes will include failed equipment. Hazardous wastes may include lubricating oils and grease. The transport system's confinement will generally have a recirculating nitrogen atmosphere.

\section{Interfaces}

Interfaces will include all processing gloveboxes, an intra-glovebox transport system, storage vaults, glovebox ventilation systems, and an MC\&A system.

\subsubsection{Intra-Glovebox Transport System}

\section{Process Description}

Shorter transport systems of a similar design to the overhead interglovebox/area transport system will be used for material movements inside the gloveboxes. The type of transport system used in the gloveboxes will be determined during the design phase and will be dependent on the specific application. To the extent practicable, movement of materials, tools, and equipment in the gloveboxes will use the same can and tray designs as used by the transport systems outside the gloveboxes.

\section{Functional Requirements}

The following functional requirements are required for the intra-glovebox system:

- Standard cans and trays for transporting materials, tools, and equipment.

- Dollies or carts designed for transporting standard cans and trays (located inside the glovebox barriers).

- Drive mechanisms located outside the glovebox confinement barrier and coupled using a magnetic coupling technology or equivalent with the dollies/carts located inside the gloveboxes. 
- Docking stations inside the gloveboxes and areas where the transport systems will interface with the overhead material transport system; i.e., interface between the inter- and intra-glovebox transport systems, and with equipment and processes within the gloveboxes.

- Control systems located near the area of operation and with communication with the main control room.

- MC\&A equipment and instrumentation for tracking materials being transported. (Typically, these are located in the gloveboxes/areas and may be shared with the glovebox/area systems.)

\section{Utilities and Services}

Utilities required will include 120/208 VAC for motors, lighting, and equipment support. Transuranic and low level wastes will include failed equipment. Hazardous wastes may include lubricating oils and grease.

\section{Interfaces}

Interfaces will include an overhead inter-glovebox transport system elevating equipment, processing equipment inside the gloveboxes, glovebox ventilation systems, and an MC\&A system.

\subsubsection{Puck Can Transport System}

\section{Process Description}

A transport system for moving loaded puck cans from the product NDA area to the magazine loading area will be provided.

\section{Functional Requirements}

The transport system will be similar to the overhead transport system with the following exceptions:

- It will be designed to handle puck cans

- It will have elevating equipment to raise the cans to an overhead floor transport system

- It will not require a confinement system, but may require shielding (as determined by ALARA analysis).

\section{Utilities and Seroices}

Utilities required are similar to those described for the overhead material transport system.

\section{Interfaces}

Interfaces are generally similar to those described for the overhead material transport system. 


\subsubsection{Automated Guided Vehicles}

\section{Process Description}

Automated guided vehicles will be provided for transporting plutonium bearing materials in 3013 and $2 R$ type containers. These containers will be transported from the APSF to the PIP. Movements of these containers in the APSF will be performed using an AGV provided by the APSF project. This APSF AGV will retrieve containers with materials from the APSF vault and will deliver the containers to a portal through the APSF east exterior wall and connected to a tunnel to the PIP. An AGV provided by the PIP project will retrieve the container from the portal and deliver the container to the lag storage area in the PIP. During the tunnel movements, the AGV will pass through the entry portal connecting the tunnel to the PIP. At the lag storage vault, the AGV will place the container on a portal device that will pass the container into the vault for storage by an in-vault stacker/retriever.

The AGV will also be used to retrieve containers from the lag storage vault portal device and will deliver the containers to the sorting glovebox container entry station.

The AGV is remotely controlled from the local control, conversion and material handling, and main control rooms using a laser triangulation guidance system or something similar. It uses an AGV mounted laser to detect/follow targets located on the facility/tunnel walls.

The AGV will be commercial standard equipment that will be modified to carry the 3013 and $2 R$ containers and may be equipped with safeguards and securitymandated instrumentation. The AGV will be equipped to allow local pendanttype control.

\section{Functional Requirements}

The AGV system will:

- Use a commercially available AGV modified to meet special PIP container handling and security requirements

- Have a battery charging system (to be located in the AGV maintenance area)

- Interact with laser wall targets.

\section{Utilities and Services}

No utilities are required. Automated guided vehicle batteries are charged in the AGV maintenance room and the AGV is controlled from the control room. Hazardous wastes are generated (in the form of used batteries) by the AGV maintenance room.

\section{Interfaces}

Interfaces will include APSF, lag storage area, sorting glovebox portals (container placement and retrieval), control rooms, AGV maintenance area (including battery charging station), PIP entry portal, various PIP corridors, and the MC\&A system. 


\subsubsection{Canister Conveyer}

Process Description

A conveyer will be provided for conveying canisters sequentially from the clean canister storage area to the canister loading/capping area, and then to the loaded canister storage area.

\section{Functional Requirements}

A conveyer with capacity to move a loaded canister is required.

\section{Utilities and Services}

Utilities include 120/208 VAC for motors and support equipment. Hazardous waste is generated in the form of lubrication oils and grease.

\section{Interfaces}

Interfaces include materials handling equipment for:

- Loading canisters from the clean canister storage area

- Loading puck-filled magazines in the canister loading area

- Placing and securing a temporary canister cap in the canister capping area

- Removing canisters in the loaded canister storage area.

\subsubsection{Cask Transporter and Transport Casks}

\section{Process Description}

A cask transporter will be provided for transporting loaded canisters from the PIP to the DWPF. Design of the transporter, including casks, will comply with the requirements of DOE Order 460.1, Packaging and Transportation Safety, and WSRC Manual 19Q, Transportation Safety. The design will assume a maximum transit time of one hour to accommodate leaving the PIP and docking at the DWPF unloading facilities.

\section{Functional Requirements}

The following functional requirements are required for the AGV system:

- A tractor/trailer transport with capacity to haul three loaded canisters in transport casks from the PIP to the DWPF loading dock

- Reusable transport casks approved for onsite transportation of a loaded-canister (each cask designed for containment of one loaded canister)

- Shielding (as determined by ALARA analysis)

- Security features as specified by the cognizant SRS safeguards and security Integrating Contractor. 


\section{Utilities and Services}

Services include diesel fuel, motor oils, brake fluids, and motor coolants. Hazardous waste is generated in the form of motor oils, brake fluids, and motor coolants.

\section{Interfaces}

Interfaces include the PIP cask loading area, the DWPF cask unloading area, and the SRS security system as defined by the cognizant SRS safeguards and security Integrating Contractor.

\subsubsection{Administrative Support Building and Foyer}

A number of facility support buildings and services separate from the MAA will be provided by the PIP project.

\subsubsection{MAA Entry Control Area (Building Foyer)}

\section{Process Description}

The entry control facility (ECF) for personnel entering the PIP will be located in the foyer between the PIP MAA building and the PIP administrative support building.

\section{Functional Requirements}

The following functional requirements are required for the MAA entry control area:

- The administrative support building and foyer will be built to uniform building code (UBC) requirements

- Entry control facility equipped as directed by the cognizant safeguards and security Integrating Contractor

- X-ray fluoroscope for inspecting packages, brief cases, etc.

- Security monitoring room with equipment and instrumentation as specified by the cognizant safeguards and security Integrating Contractor

- Access to change rooms

- Access to the MAA.

\section{Utilities and Services}

Utilities will include $120 \mathrm{VAC}$ for access equipment and general facility lighting. Sanitary waste will be generated in the form of miscellaneous office-type materials.

\section{Interfaces}

Interfaces include the SRS and PIP safeguards and security systems, communications systems, and the administrative support building waste collection system. 


\subsubsection{Change Rooms}

\section{Process Description}

Men's and women's change rooms will be provided on the first level of the administrative support building and near the ECF to the PIP MAA. Each room will have rest room facilities (commodes and lavatory showers), including areas for drying, lockable (combination lock or padlock) lockers, a dressing area, storage areas for dry and wet towels, and storage areas for clean and dirty modesty clothing. The rest room facilities will be in a separate room, but accessible from the dressing and shower facilities.

\section{Functional Requirements}

The design of the change rooms will assume that $50 \%$ of the facility occupants will be of each gender. The design basis sizing of the rooms and facilities will be for $125 \%$ of the maximum number of personnel expected to occupy the PIP MAA. The design will assume that the rest room facilities will also be used by the personnel located on the first floor elevation of the main support building and will be sized accordingly.

\section{Utilities and Services}

Utilities will include 120 VAC for general facility lighting and electrical support. Both liquid and solid sanitary waste will be generated. Domestic water will be provided for shower and lavatory use as well as drinking water.

Interfaces

Interfaces include entry/exits to

- The PIP ECF

- The administrative support building dock via hand trucks or carts (for receiving and shipping laundry items)

- The public address (PA) system speakers.

\subsubsection{Other Administrative Support Building Rooms/Areas}

\section{Process Description}

Other rooms and areas in the administrative support building include:

- First- and second-floor break rooms

- Truck dock

- Receiving and storage area

- Conference room (second floor)

- Offices and cubicle office area

- Second floor restrooms

- Elevators, equipment rooms, and foyers

- Stairwells

- Support areas

- Janitor closets (one each floor). 
Functional Requirements

These areas are to be designed to UBC requirements.

\section{Utilities and Services}

Utilities will include 120 VAC for general facility lighting and electrical support. Both liquid and solid sanitary waste will be generated. Domestic water will be provided for drinking water.

Interfaces

Interfaces include other areas in the administrative complex.

\subsection{Site and Building Requirements}

Until DOE transitions its facilities to external regulation, the DNFSB is assumed to provide safety oversight for the PIP project. Accordingly, the PIP will be designed, constructed, operated, and deactivated in compliance with applicable DOE orders and with federal, state, and local laws and regulations. The PIP, at the preliminary design stage, will meet applicable NRC licensing standards.

The design life for the facility will be 20 years, which includes a planned operating life of 10 years to be followed by a decontamination and deactivation (D\&D) period of 3 years.

\subsubsection{Capacity}

The PIP is designed to immobilize $50 \mathrm{MT}$ of plutonium in a ten-year operating time period. A breakdown of plutonium feed materials is shown in Table 5.1. In addition to plutonium, the feed materials also contain about 16.6 MT of uranium and $5 \mathrm{MT}$ of impurities. Operations will be three shifts per day, seven days per week. Some process systems may have sufficient capacity to permit operating less than three shifts per day. Allowing time for maintenance, accountability shutdowns and other downtime, there will be 200 days/yr of production time. Therefore, the nominal plant throughput is $25 \mathrm{~kg} /$ day of plutonium and the annual plutonium throughput is $5000 \mathrm{~kg} / \mathrm{yr}$. This corresponds to an annual product rate of about 182 DWPF HLW glass canisters, each containing about $27.5 \mathrm{~kg}$ plutonium. For the 18.2 MT of plutonium case, about 67 DWPF HLW glass canisters, each containing about $27.5 \mathrm{~kg}$ of plutonium would be produced annually.

\subsubsection{Building Design}

The building materials, properties, and components will be designed to be consistent with a 20 -year life span for a permanent facility. The building size will be the minimum necessary space to provide for process and support functions.

The facility layout will provide separation of administrative and support personnel from operations and process activities. The layout will be based on segregation of facility functional areas in compliance with the ALARA requirements 
Table 5.1. Feed Materials to PIP.

\begin{tabular}{lc}
\hline Category & Plutonium Weight (MT) \\
\hline Plutonium oxide (clean metal and pits) & 31.8 \\
Clean oxide & 1.7 \\
Impure oxide & 6.4 \\
Uranium/plutonium oxide & 0.9 \\
Impure metal & 3.4 \\
Plutonium alloys & 1.0 \\
Oxide reactor fuel & 1.3 \\
Alloy reactor fuel & 3.5 \\
\hline Total & 50.0 \\
\hline
\end{tabular}

described in 10 CFR 835. The first level of segregation should separate process areas from nonprocess areas. Within process areas, rooms that have no radioactive material should be separated from rooms that contain radioactive material. The following guidelines will be used in the PIP layout:

- Facility functional areas will be segregated based on process flow, accessibility, shielding, and contamination control requirements.

- Rooms that are functionally and operationally alike will generally be grouped together. Where practical, rooms that require substantial shielding of the radioactive material and a minimum of manned access will be grouped in adjacent areas of the facility to increase cost effectiveness.

- Rooms with radioactive contamination potential will be co-located to help in contamination control, access control, and HVAC design.

- Components containing radioactive and potentially hazardous materials will be maintained separate from clean components.

The plant systems, structures, and components (SSCs) will be classified according to their safety-related functions. Each SSC will be evaluated in terms of its importance in protecting the safety of personnel and the public and in avoiding an unacceptable loss, in accordance with DOE Order 420.1, DOE-STD-1020-94, and DOE-STD-1021-93. The performance category to be used for determination of the natural phenomena hazard (NPH) loads in design of the SSCs will be determined per DOE-STD-1021, Section 2.5. Plant structures, systems, and components whose failure could impact the function of higher classification SSCs will be supported and anchored in a manner to recognize adverse interaction effects. The plant systems, structures, and components supports will be designed and constructed per the criteria of Westinghouse Savannah River Company (WSRC) Manual WSRC-TM-95-1, Standard No. 01060, for the appropriate performance category.

Design of foundations and retaining walls will be in accordance with the parameters developed in the geotechnical report for the plant site. In-structure floor response spectra will be developed during the design. The plant systems, structures, and components not identified in WSRC Manual WSRC-TM-95-1, Standard No. 01060, will be designed to the UBC. Building occupancies will be based on the requirements of the UBC. Means of egress from the building will conform to NFPA No. 101, Life Safety, and UBC Chapter 33. 
The facility will contain areas for radiological support functions, including a health protection area with office, a counting equipment and records storage space, an instrument storage and equipment decontamination area, and a personnel decontamination facility near the process area per DOE 6430.1A, 1300-6.6.

Men's and women's protective clothing change rooms will be provided. These rooms will be adjacent to shower facilities. Facilities for removing protective clothing and for personnel monitoring will be provided at the exit from the contamination area per DOE 6430.1A, Section 1300-6.8, and WSRC Manual 5Q, Chapter 1, Article 128. The design will provide safe storage of contaminated protective clothing to ensure that contamination does not spread beyond the storage container.

The safeguards and security features of the process building will be in accordance with DOE Orders 5632.1C and 5633.1B, DOE Manual M 5632,1C-1, and WSRC Manual 7Q. Rather than relying solely on the use of security forces, the building design will include physical barriers and activated delay systems to achieve the design basis delay time for access to the SNM in the facility by unauthorized, well-armed adversaries.

Material access areas containing SNM will be contained within a protected area. Locations within an MAA that contain unattended Category I material will be equipped with intrusion detection systems or other effective means of unauthorized access detection. Vault and vault-type rooms for SNM storage will conform to the vault construction requirements in DOE Order 6430.1A.

\subsubsection{Utilities and Services}

The following utilities and services will be required for support of the PIP operation. Existing support facilities will be used whenever possible and cost effective. Construction of new facilities will be required only when necessary to effectively support the PIP. Existing support facilities at SRS have been identified and referenced as existing in this project.

\subsubsection{Water Utilities}

Treated domestic water will be provided for general use (e.g., showers, washrooms, drinking fountains, restrooms, and emergency showers). In the main processing building, domestic water is supplied for emergency showers only.

Sanitary waste water generated from the PIP will be tied into the existing sanitary waste water treatment system at the F-Area for collection and treatment of sanitary waste. To prevent accidental contamination, sanitary facilities will not be provided in processing, material handling, and storage areas or for waste management operations.

A fire water system will be provided for supply of fire suppression water to all designated areas in the facility. The supply is from the F-Area fire main. 


\subsubsection{Fuel Utilities}

No propane or natural gas is proposed as a fuel gas in the PIP.

\subsubsection{Gas Utilities}

A clean, dry instrument and plant air system will provide facility and instrument air to operational, utility, and maintenance users.

A safe and reliable independent breathing air system will be provided for air supply to personnel performing special operational and maintenance activities in the material handling, storage, and support areas. Manifolds will be located in areas with low potential for contamination.

Recirculating nitrogen and argon systems will be used to provide inert atmosphere for process gloveboxes and the in-process storage vault. For HYDOX gloveboxes, argon is necessary to preclude the potential for $\mathrm{H}_{2}$ explosion. For the vault and other gloveboxes, nitrogen is used. Sufficient quantities of argon and nitrogen will be stored in the PIP to support the operation.

\subsubsection{Process Support Utilities}

A process cooling water system will be provided to supply demineralized cooling water to process equipment.

A chiller water system will be provided to supply chilled water to the process cooling water system and facility HVAC system.

A vacuum system will be provided for airlock transfer stations and for the air sampling stations of the radiological monitoring system.

\subsubsection{Electrical}

Electrical systems will include power systems, grounding, lighting, and lightning protection. All electrical design will conform to National Fire Protection Association (NFPA) 70-1996, National Electrical Code, American National Standards Institute (ANSI) C2 Handbook, and DOE orders.

The power system will permit increased operational integrity, flexibility, and reliability. The electrical demand at this facility will be met by providing

- Unit substations, installed in the electrical rooms of the facility, providing normal power.

- A pad-mounted substation outside the facility, providing alternate power connected to the normal low-voltage switchgear.

- Two diesel generators located at the facility, providing standby power in case of loss of both normal power busses. The alternate power will be switched on in case of loss of power from normal and standby sources.

In addition to the above, uninterruptible power supply (UPS) will be provided for all vital and critical control and monitoring functions including computers. Security and fire alarm detection systems will be provided with their own backup UPS systems. 
Normal power, supplied by two unit substations $(13.8 \mathrm{kV} / 480 \mathrm{~V})$, will consist of a high-voltage switch, indoor cast coil transformer, incoming low-voltage breaker, metering section, tie breaker, feeder breakers to motor control centers (MCCs), chillers, and distribution panels. An underground $13.8 \mathrm{kV}$ feeder from the F-Area substation will feed the unit substations. The two transformer secondary switchgears will be connected by a normally open tie breaker.

Standby power will be supplied by two diesel generators $(480 \mathrm{~V})$, one connected to each bus of the switchgear of the unit substations. One generator is adequate to maintain material confinement and supply the sintering furnaces. The two tranformers have a fan rating of $1,995 \mathrm{kVA}(1,800 \mathrm{~kW})$ each. The total connected load is $3,471 \mathrm{~kW}$ and the maximum demand is anticipated to be $2,613 \mathrm{~kW}$. Flexibility and reliability will be built in by having two busses and two generators. In case of complete loss of normal power, both generators will be started. The first one to stabilize will be connected to the load.

The generators will be seismically qualified and installed in a hardened facility adjacent to the PIP main process building. The generators will also be isolated from each other to prevent a common fire failure and provide increased operational integrity.

Standby generators will be equipped with controls that automatically activate and transfer to the busses, and will be manually deactivated on restoration of normal power. A day tank for 6 hours of operation will be provided for each generator. A large overhead or underground diesel tank will be provided to feed the day tanks, with a minimum capacity of 10,000 gallons. Class 1E (IEEE 344) is not presently invoked for the generators. If a hazard analysis indicate that it is required, Class $1 \mathrm{E}$ design standards will be built in.

An alternate power source will be a pad-mounted transformer $(13.8 \mathrm{kV} / 480 \mathrm{~V})$ located outside the facility. The transformer will tie into one of the busses of the normal switchgear. This alternate power source can be switched on in case of complete loss of both normal and standby power sources. The pad-mounted transformer will receive a $13.8 \mathrm{kV}$ overhead power feed from the F-Area substation (251-F).

Twenty percent of the lighting loads will be considered to be supplied by one standby generator during its operation. These loads will be distributed along with normal lighting loads but fed from a separate lighting panel, which will be fed from the generator during a normal power outage.

Electric power will be provided to meet material handling, material storage, gloveboxes, sintering furnaces, HVAC systems, computer systems, security and fire alarm systems, cranes and robotic equipment, elevators, and any other equipment requiring electric power. Any equipment requiring clean conditioned power will be provided with its own conditioned power supplies. The entry control facility and administration building will also be provided with power from the substations. Emergency power for safeguards and security equipment will be provided from the F-area safeguards and security emergency power system.

The lightning protection system will be designed per NFPA 780. 
The ground system will be designed to achieve a ground resistance of $10 \mathrm{ohms}$. The $15 \mathrm{kV}$ system will be resistance-grounded and the $480 \mathrm{~V}$ will be solidly grounded.

All lighting levels will be per Illuminating Engineering Society of North America (IES) handbook. Security lighting will be provided wherever required and color rendition requirements will be taken into account.

\subsubsection{Communications}

The following functions will be included in the design of PIP communications system:

- Telephone

- Public address and intercom

- Alarm

- Radio frequency transmission

- Wide area network

- Video

- Information security.

Communications at PIP will comply with DOE criteria for communications, alarms, and data processing centers. Information security will use proven hardware and software that has passed evaluations by the National Computer Security Center. Telephone specialties will be Underwriters Laboratory listed (UL-listed) or accredited by similar national organization.

Telephones will be provided in each office, the control room, all occupied areas in the process building and in general areas of the facility.

A public address system tied into F-Area PA system will be provided. Control room personnel will be able to broadcast to the process building and the other areas of building. All personnel in the facility (including process, entry control, and administration personnel) will be able to hear messages transmitted from the control room. The control room will be connected to the site-wide emergency broadcast system.

The facility will provide an adequate communications system (including voice, data, and video communications) within the facility and between outside worldwide communication centers. Linking of individual functions may be required to satisfy specific requirements for transmission speed, reliability, and security. Fiber optics systems will be considered to tie into any existing system within the complex.

\subsubsection{Instrumentation and Control}

The instrumentation and control $(1 \& C)$ system will provide the required hardware equipment and software for plant control and monitoring to ensure safe operation and efficient control during normal operation and to maintain the plant in a safe condition under accident or other abnormal conditions. 
Instrumentation and control systems required to perform a safety function will comply with SRS IEEE 344 and 323 and SRS standards. All automated or remote operations will be designed with manual back-up systems to allow operations to progress to a safe shutdown mode and to facilitate maintenance of the system and equipment. Fail-safe features will be provided for all instrumentation to maintain a safe and stable condition during any loss of power event or emergency stop activation.

The control system design will be based on a well-defined hierarchy of modular subsystems. The control and monitoring of the plant operations will be performed through a layered control systems scheme that is both functionally and physically distributed. The I\&C architecture will provide for nearly autonomous subsystems. Each subsystem will be structured into a supervisory level and a data acquisition and control level. Each I\&C subsystem will provide visual and/or audible status of system performance for both supervisory purposes and detailed operational purposes. The control panels will be logically grouped for subsystem control and monitoring. Critical components of the control systems will be provided with a UPS.

The computers for the I\&C system will be divided into classified and unclassified systems to handle the classified and unclassified data. Classified computer systems will be isolated from unclassified computer systems. The associated computers will be compatible to the transmission control protocol/Internet protocol architecture for interconnection with a LAN.

The classified computer system will consist of computers for MC\&A, process control, material handling control (AGV, stacker/retriever, and overhead conveyors), waste management, physical security, and information management. Except for the physical security computer system, the classified computer systems will be integrated and interface with a redundant communication network. The physical security computer will be isolated and independent from other computer systems and equipment. The physical security computer will be tied into the existing SRS central alarm station by buried fiber optics.

The unclassified computer system will consist of

- The environment, safety and helath (ES\&H) computer for monitoring the radiation monitoring, criticality monitoring, hazards monitoring, and fire protection systems

- The HVAC/utilities computer to control and monitor the HVAC system, utilities, and management of building energy.

In addition, the I\&C system will provide a security-classified telephone line to interface with the existing SRS MC\&A system and the IAEA computer. The data link will permit transmittal of information involved with the transfer of SNM within the plant. No data entry or modification of the data will be allowed by either the site MC\&A or the IAEA computer. The I\&C system will also provide interface to obtain MC\&A data from APSF receipt and storage functions, and sample analysis results from the existing analytical laboratory computer system.

The I\&C system equipment and software will be assessed with respect to upgrade capabilities during the design process. The development and documentation of the software will meet the requirements of the SRS E8 manual. Instrumentation and control equipment and components will be procured, to 
the extent practical, from well-established and respected commercial vendors to mitigate computer equipment obsolescent problems. Training and post-installation support service by vendors will be specified in the procurement.

\subsubsection{Human Factors Engineering}

Plant equipment interfaces with operators through various control and display devices. In order to reduce operator error and enhance safety and system performance, the principles of human factors engineering will be given consideration throughout the design process for the man-machine interfaces.

Guidelines contained in Instrument Society of America (ISA) Standard S5.3; IEEE-1023; MIL-STD-1472C, Human Engineering Design Criteria for Military Systems, Equipment, and Facilities; NUREG-0700, Guidelines for Control Room Design Review; and NUREG-2496, Human Engineering Design Considerations for CRT Generated Displays will be utilized where appropriate to assess human factor limitations in sense, motor, and cognition.

Human factor deficiency corrections will be incorporated into the design of control, alarm panel, and computer displays, and system maintainability through task analysis and software usability review. Human factors task analysis results will also be used to assist decision-making in automation and economic resource allocation.

\subsubsection{Safety, Radiological Control, Shielding}

The plant facility structures, systems, and components will be designed to accomplish the plant mission and to protect plant operating personnel and the general public and the environment from radioactive materials and other hazardous substances. All facility structures, systems, and components will be assessed and classified in a graded approach as established in DOE Order 420.1, Facility Safety.

The significance of each structure, system, and component item to safety will be assessed in accordance with DOE-STD-3009-94 and determined by the appropriate design and quality assurance requirements for procurement, fabrication, and construction.

All structures, systems, and components will be assigned a natural phenomena performance category in accordance with DOE-STD-1020-94 and DOE-STD1021-93. The plant facility will be able to accommodate any postulated initiating event that starts a design basis accident sequence and natural phenomena, plus any other events or failures directly resulting from the initiating event.

The hazards category for the facility will be determined in accordance with DOE-STD-1027-92.

All activities in the PIP will satisfy all applicable industrial safety requirements found in the following:

$\begin{array}{ll}\text { DOE Order } 420.1 & \text { Facility Safety } \\ \text { DOE Order 5480.4 } & \begin{array}{l}\text { Environmental Protection, Safety, and Health Protection } \\ \text { Standards }\end{array}\end{array}$


29 CFR 1910

R61-64

WSRC Manual 4Q

WSRC Manual 8Q
Occupational Safety and Health Standards

South Carolina Department of Health, and Conservation Regulations

Industrial Hygiene Manual

Employee Safety Manual

During the design of new facilities or modification of old facilities, optimization methods will be used to assure that occupational exposure is maintained ALARA in developing and justifying facility design and physical controls (10 CFR 835.1002 [a]).

\subsubsection{Radiation Exposure Limits}

The design of the plant facility will provide radiological protection and contamination control to maintain ALARA radiation exposures to plant personnel and the public to be consistent with the radiation protection requirements of $10 \mathrm{CFR}$ 835, Occupational Radiation Protection, and DOE Order 420.1, Facility Safety, and in compliance with WSRC Manual 5Q, Radiological Control.

The plant will be designed to minimize radiation dose-equivalent exposure of the operating personnel on site and the public off site. Design features and control procedures will be provided to minimize potential exposure or inhalation of radioactive and other hazardous material. These include use of remote-controlled automated processes to reduce the need for personnel adjacent to process enclosures.

The design objective for controlling personnel exposure from external sources of radiation in areas of continuous occupational occupancy ( 2000 hours per year) will be to maintain exposure levels below an average of 0.25 mrem per hour and as far below this average as is reasonably achievable. The design objectives for exposure rates (for potential exposure) to a radiological worker where occupancy differs from the above will be ALARA and will not exceed $20 \%$ of the applicable standards in Table 2-1 of SRS Manual 5Q, Radiological Control Manual (10 CFR 835.1002 [b]).

The design basis dose-equivalent exposure of operating personnel from all radiation sources present at the plant will not exceed 500 mrem per year per person for whole body, 3 rem per year for eye, and 10 rem per year for extremities, skin, or internal organs. The design basis whole body dose to minors, students, visitors, and the public will not exceed 100 mrem per year.

The facility design will ensure that occupied operation areas do not exceed onetenth the airborne concentration limits of 10 CFR 835 for normal operating conditions. To limit airborne contamination concentrations, the confinement and ventilation systems will be designed to ALARA standards. The design will ensure that respiratory protection is not required to meet the dose limits for normal operation.

The dose-equivalent rates from gamma and neutron will be determined in a shielding analysis in order to identify those areas where additional shielding and/or automated operations are required. A neutron qualify factor of 20 for calculating dose equivalent exposure from fast neutrons will be adopted in accordance with recommendations given by the International Committee on Radiological Protection (ICRP) in ICRP-60. 


\subsubsection{Radiological Control}

The control of radioactive material is established by a confinement system consisting of physical or ventilation barriers to prevent the uncontrolled passage of any radiation or radioactive material to the environment. The system will maintain its confinement function under all credible conditions. Measures will be taken to maintain radiation exposure ALARA through facility and equipment design and administrative control. The primary methods will be physical design features. Administrative control and procedural requirements will be used only as supplemental methods to control radiation exposure.

All operational areas of the plant will be classified by control zones that specify design requirements for controlling both personnel radiation exposures and the spread of contamination. The zone designation for each area will be consistent with its functions, accessibility, existing radiation sources, personnel occupancy, and contamination potential.

Radiation zones will be established based on the maximum whole body dose rates within a designated area. These dose rates will be used for determination of shielding thickness, separation distances, and duration of personnel occupancy. Table 5.2 defines the maximum design basis dose rates of the radiation zones.

The spread of radioactivity will be minimized by three separate confinement barriers:

- The storage container, process vessel, or glovebox

- The room surrounding the first confinement barrier, with its associated filtered exhaust system

- The building and its associated filtered exhaust system.

Contamination zones will be assigned to areas where contamination potential exists to identify the necessity for contamination control design and administrative features. These contamination zones will serve as a basis for specifying personnel decontamination facilities, ventilation air flow directions, and air lock location.

Table 5.2. Radiation Zone Criteria.

\begin{tabular}{|c|c|c|}
\hline $\begin{array}{c}\text { Radiation } \\
\text { Zone }\end{array}$ & $\begin{array}{l}\text { Design basis } \\
\text { maximum area } \\
\text { radiation dose } \\
\text { rate (mrem/hr) }\end{array}$ & Description \\
\hline $\begin{array}{l}1 \\
2 \\
3 \\
4 \\
5 \\
6 \\
7\end{array}$ & $\begin{array}{c}D \leq 0.05 \\
0.05<D \leq 0.1 \\
0.1<D \leq 0.25 \\
0.25<D \leq 5 \\
5<D \leq 100 \\
100<D \leq 500,000 \\
D>500,000\end{array}$ & $\begin{array}{l}\text { Non-rad worker, continuous occupancy } \\
\text { Administrative rad-worker, continuous occupancy } \\
\text { Rad-worker, continuous occupancy }(\leq 2000 \mathrm{hr} / \mathrm{yr}) \\
\text { Rad-worker, intermittent occupancy }(<200 \mathrm{hr} / \mathrm{yr}) \\
\text { Radiation area* } \\
\text { High radiation area* } \\
\text { Very high radiation area }\end{array}$ \\
\hline
\end{tabular}

* Requires special precautions and approvals for entry

† Entry not expected 


\subsubsection{Radiation Shielding}

An ALARA analysis will be conducted during the design phase to determine the appropriate radiation shielding required for all rooms and confinement enclosures where radiological materials are handled, processed, or stored. Exposures to occupational workers will meet the requirements defined in the above section.

Radiation shielding will be provided around the material processing, handling, and storage areas to maintain dose rates ALARA and within the radiation exposure limits for personnel in the access, support, and maintenance areas of the process. Primary shielding will be provided by the glovebox or enclosure walls. Openings (e.g., glove ports, hatches, doors, and piping) that penetrate the primary shielding will be designed to minimize radiation streaming.

Shielding materials will be selected on the basis of radiation sources, shielding efficiency, structural quality, and economy. Selection of shielding material will consider minimization of hazardous materials and/or the encasing of materials to preclude the generation of mixed waste. The designer will be aware of the limitations of the radiation shielding design methods employed as described in ANSI/ANS-6.4. The selection of material properties of all shielding materials in the analysis will be made such that the calculation results are conservative. The neutron and photon source term for process material is based on plutonium with $5 \%{ }^{241} \mathrm{Am}$ and plutonium isotopic distributions typical of ZPPR fuel and weapons-grade plutonium. Reflection configurations will be reviewed to determine the effect on the design radiation levels.

Optimization principles will be utilized in developing and justifying facility shielding design and physical controls for radiological protection. The personnel exposure design objective is to reduce the dose below the design basis requirements to ALARA consistent with 10 CFR 835.1002(a) and WSRC ESHHPT-96-0210.

For design estimating purposes, the shielding for the transparent portion of a glovebox should be assumed to consist of a layered composite shield of $1.43 \mathrm{~cm}$ safety glass $/ 11.58 \mathrm{~cm}$ plexiglass $/ 3.49 \mathrm{~cm}$ lead glass $/ 0.35 \mathrm{~cm}$ safety glass. The shielding for the opaque portion of the glovebox should consist of a layered composite shield of $0.45 \mathrm{~cm}$ steel $/ 16.19 \mathrm{~cm}$ water-extended polyester/polyethylene $/ 0.45 \mathrm{~cm}$ steel $/ 1.43 \mathrm{~cm}$ lead $/ 0.45 \mathrm{~cm}$ steel. (Refer to Radiation Exposure \& Shielding Estimates for Plutonium Immobilization Facility, Westinghouse Safety Management Solutions, Inc., Calculation N-CLC-F-00124.) Actual shielding requirements for gloveboxes will be based on ALARA analyses conducted during the design phase.

\subsubsection{Operability and Maintainability}

The plant will be designed for ease of operation and maintenance. The PIP will be designed to be comfortable and natural for humans to operate and maintain, in accordance with DOE Order 5480.19. Plant operation procedures will be developed to prevent operability problems and potential hazard consequences. To the extent possible, the equipment design will be such that:

- Plug-in module replacement will correct system failures 
- Module repairs can be performed in a shop environment

- Software diagnostics can be utilized to determine failed hardware modules

- Maintenance and troubleshooting procedures can be performed without requiring total shutdown of the plant

- The need for test and calibration is minimized.

Guidelines contained in MIL-STD-1472D, Maintainability Prediction, will be considered where appropriate. A maintenance policy that will provide the best maintainability values for the plant system and equipment will be utilized.

To the extent possible:

- All preventive maintenance will be conducted on-line, during system idle periods or the material balance inventory shutdown.

- Adequate spare part inventory and tooling will be maintained to reduce downtime delay.

- Equipment in hazardous areas will be supplied with built-in diagnostic and calibration capability. Equipment in other areas can be subject to diagnosis and calibration with portable test equipment.

- All maintenance will be conducted by contact handling.

- Residence time in hazardous areas by maintenance personnel will be minimized.

\subsubsection{Decontamination and Deactivation}

The D\&D plan for the PIP assumes that plant operations will be complete after a period of 10 years with an additional 3 years allocated for D\&D of the process building. The process building will not be demolished nor will the site be returned to greenfield conditions. Rather, the building will be decontaminated to levels that would permit unrestricted further use of the facility.

The design of the facility and the selection of materials will include features that facilitate D\&D per 10 CFR 835.1002, DOE 6430.1A Section 1300-11, and WSRC Manual 5Q, Chapter 1, Article 128. DOE Order 420.1 gives general D\&D requirements. Additional guidance is provided by DOE Order $5820.2 \mathrm{~A}$ and DOE/EV/10128-1 (The Decommissioning Handbook).

The following general principles will be employed in the design of the facility to facilitate future $D \& D$ operations:

- Areas of the facility that may become contaminated with radioactive or other hazardous materials under normal or abnormal operating conditions will incorporate measures to simplify future decontamination. Walls, ceilings, and floors in these areas will be finished with washable or strippable coverings that have been selected to withstand decontaminating agents and radiation degradation. Floors will be sloped toward drains to facilitate decontamination. Service piping, conduits, and ductwork in these areas will be minimized and will be arranged in physically separated service banks or constructed of materials that can be easily decontaminated.

- Modular, separable confinement systems will be used for radioactive and hazardous materials to minimize contamination of fixed portions of structures. Gloveboxes will be designed to be easily disconnected and removed from the process building. 
- Dimensions of process building aisles will consider movement of D\&D equipment.

- Process equipment and glovebox components potentially exposed to radioactive or hazardous materials will be constructed of materials that are easily decontaminated, will be free of cracks, crevices, or joints that could collect radioactive material, and will be smoothed or drained as necessary to prevent accumulation of material in inaccessible areas.

- Ventilation filters in potentially contaminated service will be placed as near as practical to the source of contamination to minimize contamination of ductwork.

- Process piping will be designed to minimize low points and, to the extent practical, be self-draining to minimize accumulation of radioactive or hazardous material.

During D\&D operations, a D\&D plan consistent with the requirements of DOE Order 5820.2A, Chapter V, will be developed. This plan will consider the operating history of the facility and will develop a plan for a radiological/hazardous material survey to determine the extent of cleanup effort required.

Decontamination efforts will be employed that minimize generation of wastes and atmospheric effluents. Existing ventilation and off-gas cleanup systems will be utilized where practical. Temporary enclosures or effluent treatment systems will be provided where necessary. Contaminated gloveboxes and process and support equipment will either be decontaminated in place (within the process building contaminated equipment maintenance area), or removed from the building and decontaminated in other on-site facilities. Building contamination will be reduced to previously approved de minimus levels prior to release for unrestricted use.

Wastes generated from D\&D operations will include TRU waste, low level radioactive waste, and mixed radioactive and hazardous waste. Waste treatment systems could include such operations as material compaction, liquid evaporation, filtration, ion exchange, or solidification. Minimization of TRU and mixed wastes will be a high priority. Existing SRS waste treatment facilities will be utilized to the maximum extent considered practical.

\subsubsection{Confinement and HVAC}

The HVAC function will provide the proper environmental conditions for health, safety, and comfort of personnel; for equipment protection; and, where applicable, for confinement ventilation barriers to prevent the release of airborne radioactive or other hazardous material to the environment and to minimize the spread of contamination within the facility as determined by the safety analysis. The number and arrangement of confinement zones and their design requirements will be determined by analysis. In general, the lowest pressure zone is the glovebox atmosphere. The next highest pressure zone is the processing room. The next highest pressure zone is the MAA corridors. MAA corridor pressure is to be maintained negative relative to outside atmospheric pressure. This concept is illustrated in Drawings M-213 through M-216.

Primary confinement of nuclear material is provided by the primary containment vessel or glovebox enclosures. To mitigate the consequences of an accidental release of radioactive material and to minimize the spread of contamination, 
facility design features will confine contamination to the vicinity of the radioactive source. Confinement will be achieved by ventilation control (differential pressure), by directing air from less contaminated areas toward areas of higher contamination, by HEPA or equivalent filtration, and by the use of controlled personnel traffic patterns. Contamination control will also consider compartmentalization (building, area, room), where appropriate, to further limit the extent of potential spread of contamination.

For areas of the PIP that could potentially become contaminated, a continuous airflow pattern from noncontaminated areas to potentially contaminated areas will be provided. Consideration will be given to provide separate systems for accurate temperature and humidity control areas, noncontaminated areas, potentially contaminated areas, contaminated areas, and inert glovebox atmospheres.

HVAC equipment will be designed to satisfy heating and cooling load requirements and to meet all general equipment design and selection criteria contained in the American Society of Heating, Refrigeration, and Air-Conditioning Engineers (ASHRAE) Fundamentals Handbook, ASHRAE Equipment Handbook, ASHRAE Systems Handbook, ASHRAE Applications Handbook, and ASHRAE Refrigeration Handbook.

The design of the PIP will ensure that occupied operating areas comply with DOE orders for normal operating conditions. In addition, the concept of ALARA will be used when designing confinement and ventilation systems to limit airborne contamination levels and to increase personnel protection. The design will ensure that respirators are not required to meet the dose limits for normal operations. An effective climate control system will maintain temperature and humidity at an acceptable level between personnel and the environment.

For the PIP, the following functional requirements apply:

- Primary confinement will consist of physical barriers, enclosures, gloveboxes, piping, vessels, tanks, etc. that contain plutonium, in addition to their associated ventilation system. Its principal function is to prevent the release of radioactive materials to areas other than where processing operations are normally conducted.

- An inert atmosphere, specified by process requirements, will be required in each processing glovebox.

- The supply to processing gloveboxes will be filtered by HEPA filters at the ventilation inlet to the enclosure and area confinement barriers to prevent the transport of contamination in the event of a flow reversal.

- High-efficiency particulate air filters for the glovebox exhaust will be installed on the processing gloveboxes to minimize contamination of exhaust ductwork.

- Separate exhaust ventilation system ductwork and the initial two stages of filtration will be designed for exhaust air from enclosures that confine plutonium processing.

- The design will consider the consequences of glovebox or in-duct fires on the integrity of the filters.

Because the PIP building exhaust may contain airborne radioactivity, continuous real-time effluent monitoring is required to be provided on the exhaust stack consistent with the requirements in DOE 6430.1A. 


\subsubsection{Safeguards and Security}

The safeguards and security systems in the PIP will be designed to meet the design basis threat policy for DOE programs and facilities. Features incorporated in the facility design will result in a delay time to the access to SNM in the facility by any unauthorized intruder or well-armed adversary that equals or exceeds the delay times specified by the cognizant safeguards and security Integrating Contractor. These delay times are typically defined as classified information. The design will use hardware (e.g., physical barriers and/or activated delay systems) to achieve the required delay and will not depend on the augmentation of security forces alone.

The safeguards and security systems will be designed with the following functional features:

- A perimeter intrusion detection and assessment system (PIDAS) per DOE order

- Vehicle barriers

- Entry control facilities, including instrumentation for controlling and monitoring all personnel entering or leaving the MAA

- An entry portal in the tunnel from the APSF

- Security guard stations at strategic locations in the MAA

- Security monitors and detectors (e.g., CCTVs, motion detectors) at strategic locations in the MAA

- Ventilation duct barriers

- Vault doors on all rooms where SNM is stored unattended.

The safeguards and security systems will interface with the F-Area central alarm station via secured data lines, the APSF security system, and the communications system.

\subsubsection{Environmental, Safety, and Health Monitoring}

Environment, safety, and health monitoring will include environmental monitoring and safety and radiological monitoring, as detailed below.

\subsubsection{Environmental Monitoring}

All air and water effluents and waste materials discharged from the PIP that have a potential for contamination with radioactive or hazardous components will be monitored. All monitoring plans and systems will comply with the applicable federal, state, and local laws and regulations and with the requirements defined in the applicable SRS manual. A listing of applicable regulations and requirements is provided in Appendix A.

All air discharges that have a potential for contamination will be passed through a minimum of two stages of HEPA filtration and vented though the PIP exhaust stack. This stack will have environmental monitoring equipment such as isokinetic samplers or equipment based on a shrouded probe technology. 


\subsubsection{Safety and Radiological Monitoring}

The radiological monitoring system will include air sampling and CAM equipment, personal contamination monitors (PCMs), ARMs, NIMs, and alarm and warning systems.

All monitoring equipment will provide means for calibration of the instruments to appropriate standards.

All radiation monitoring alarm and warning systems that are required to function during a loss of power will be provided with a UPS unless it has been demonstrated that the system can tolerate a temporary loss of power without losing required data. These systems are provided with standby power.

Determination of the power supply type and quantity will be based on the safety classification of the monitoring system or device.

Warning and alarm systems will be designed, installed, and tested to ensure that they can be heard in the ambient condition of the area they are intended to cover. All safety alarm systems (e.g., personnel safety alarm systems such as fire alarms or evacuation alarms) will enunciate inside and outside the facility to identify hazardous conditions to anyone inside or outside in the vicinity of the facility. The use of visual alarm devices as well as audible alarms will be evaluated. All safety alarms in high noise areas will be provided with audible and visual signaling systems. Warning, alarm, annunciator, and evacuation systems will meet the requirements of DOE 6430.1A, 1300-12.4.8 and 1300-6.5.5.

The status of all permanently located CAMs, ARMs, and NIMS will be indicated on alarm/status panels located in the central control room, the health protection laboratory, and at an emergency response area located outside the PIP facility. As a minimum, these alarm/status panels will indicate that the instruments are operating and their alarm status.

In addition to a local station alarm, radiation monitoring system signals (CAMs, alarms associated with stack monitoring systems) will have central (i.e., control room or radiation monitoring office) read-out and alarm panels that are accessible after a design basis accident (DBA) to evaluate internal conditions.

Area radiation monitors will be installed in frequently occupied locations with the potential for unexpected increase in dose rates and in locations where there is a need for local indication of dose rate prior to personnel entering remote locations per WSRC Manual 5Q, Chapter 5 Article 553 and 10 CFR 835.401 and 403. Monitors will have a local audiovisual alarm with remote alarms in the facility control room and the facility radiological control office.

Retrospective air sampling will be performed in occupied areas where, under typical conditions, an individual is likely to receive an annual intake of $2 \%$ or more of the specified annual limit of intake (ALI) values from 10 CFR 835.403. Guidance on placement of samplers, in order to comply with the SRS program, is given in WSRC Workplace Air Sampling \& Monitoring Technical Basis Manual, ESH-HPT-94-0228, Rev. 2.

Continuous air monitoring equipment will be installed in occupied areas where a person without respiratory protection is likely to be exposed to a concentration 
of radioactivity in air exceeding 0.1 derived air concentration (DAC) or where there is a need to alert potentially exposed workers to unexpected increases in the airborne radioactivity levels per 10 CFR 835.403. Continuous air monitors should be capable of measuring 1 DAC when averaged over eight hours (eight DAC-hours) under laboratory conditions. Air monitoring systems will comply with ANSI/ANS 13.1. Guidance on placement of monitors, in order to comply with the SRS program, is given in WSRC Workplace Air Sampling $\mathcal{E}$ Monitoring Technical Basis Manual, ESH-HPT-94-0228, Rev. 2.

The design will provide personnel contamination monitoring of occupational workers in work areas where radioactive materials are stored and handled. The use of devices to warn personnel of possible contamination or other hazardous material will be evaluated and such devices will be provided per DOE 6430.1A, Section 1300-6.5.3. Whole body personnel contamination monitors will be provided at the exit from all radiological buffer areas to prevent the spread of contamination as required by WSRC Manual 5Q, Articles 221 and 338 , and 10 CFR 835.404 . The background radiation dose rate at the PCMs will be designed to meet the specifications of the unit (typically less than 0.02 $\mathrm{mrem} / \mathrm{hr}$ ).

Nuclear incident monitors will be provided in accordance with the requirements of DOE Order 420.1 and ANSI/ANS-8.3 as discussed in WSRC-SCD-3. Installation will be per SRS Engineering Standard 13096. A parallel gamma radiation monitor with a recorder in the control room will be provided for each nuclear incident monitor pair or triplet.

\subsubsection{Criticality}

This project involves processing and/or handling fissionable materials and the risk of an inadvertent criticality. The design will comply with the requirements of DOE Order 420.1, Section 1.2.18.9 of the WSRC report Radiological Control Manual (5Q), and the requirements of the following ANSI/ANS standards as modified by DOE Order 420.1 regarding nuclear safety:

- ANSI/ANS-8.1-1993, R88, Nuclear Criticality Safety in Operation with Fissionable Material Outside Reactors

- ANSI/ANS-8.3-1986, Criticality Accident Alarm System

- ANSI/ANS-8.5-1986, Use of Borosilicate-Glass Raschig Rings as a Neutron Absorber in Solution of Fissile Materials

- ANSI/ANS-8.7-1975, R88, Guide for Nuclear Criticality in the Storage of Fissile Materials

- ANSI/ANS-8.10-1983,R88, Criteria for Nuclear Criticality Safety Controls in Operations with Shielding and Confinement

- ANSI/ANS-8.15-1981, R93, Nuclear Criticality Control of Special Actinide Elements

- ANSI/ANS-8.19-1984, R89, Administrative Practices for Nuclear Criticality Safety.

The quantity of ${ }^{239} \mathrm{Pu}$ containing material that will be stored in any given can, container, or containment vessel handled by the APSF or PIP will not exceed 4.50 $\mathrm{kg}(9.90 \mathrm{lbm})$. 
The design will prevent the unsafe accumulation of moderator materials, such as water, and other hydrogenated materials, such as polyethylene. The design will prevent the addition of moderator material in excess of posted limits to subcritical enclosures. The effect of moderator materials will be included in the criticality analysis.

The facility will use engineered criticality controls to preclude or minimize the potential for a criticality. Administrative controls may be used to supplement these engineered criticality controls. Criticality control will not rely on administrative procedures alone unless a practicable engineered control cannot be identified, or designed, in the facility or component of the facility.

Where there is the probability for a criticality excursion causing personnel exposures, nuclear criticality dosimeters will be provided with performance features and placement consistent with 10 CFR 835.1304.

The design of the material transport system, AGV, and all vault automated storage systems will have engineered provisions to assure that only one can or container of plutonium-bearing material can be handled at any given time, and that no plutonium-bearing can or container can be placed in a position already occupied by a container or brought into an unfavorable geometry.

\subsection{Management and Information Systems}

The management and information system will provide a centralized database of operational and administrative information to maintain historical data in nonvolatile memory and to assist plant management and operation for work schedule, quality assurance (QA) records, and maintenance logs. The management and information system will also provide functions in plant operation simulation, configuration management, data reduction, data presentation, and data archival. In addition, the management and information system will provide operator training capability and software validation functions.

The management and information system will interface with and acquire information from the supervisory level of the $I \& C$ system and will provide control functions to the I\&C system only to the extent necessary for safe and efficient plant operation.

Computers for the management and information system will use the same operating system as the supervisory-level computers for facility and process control. The operating system architecture will be of current design to provide a multi-tasking environment and will make use of layered software products. To the greatest possible degree, the software will consist of commercial vendor software packages.

\subsection{External Drivers}

Codes of Federal Regulations, DOE orders, and select standards and guidance, including construction and life safety codes applicable to the PIP are listed in Appendix A. The impact of these has been addressed in the scoping, preconceptual, and conceptual design efforts leading to this DOCDR or will be addressed in preliminary and final design or construction, as applicable. 
In addition, the design and construction of the PIP will meet applicable Codes of Federal Regulations, NRC licensing standards, and SRS standards. Canisters with immobilized plutonium cans will meet DWPF acceptance criteria and canisters with immobilized plutonium cans that are filled with HLW in the DWPF will meet the acceptance criteria for the geologic repository. 


\section{Design Concept}

This section describes the facilities and equipment that respond to the functional requirements for the PIP and provide the basis for the cost estimate. This DOCDR assumes the baseline option of a new facility at SRS using the ceramic can-in-canister technology as its basis.

The facility elements are divided into two categories: the primary process and process support design description elements, and the facility system design description elements.

\subsection{Project Design Description}

The general layout of the processing areas of the PIP is shown in Drawings L202 (First-Level Floor Plan), L-203 (Second-Level Floor Plan), and L-204 (ThirdLevel Floor Plan) as well as the sections, L-206 and L-207 in Appendix B. These drawings show the process and the process support areas. Operations are compartmentalized into rooms so that in the unlikely event of contamination occurring in one area, operations can continue in adjacent areas. Rooms are arranged to provide for efficient and logical movement of material that is to be converted, immobilized, canned, and loaded into canisters.

Plutonium is fed to the plant as oxide powders, metal, and unirradiated oxide and metallic reactor fuels. These feeds enter the building by AGV through a tunnel from the APSF. Plutonium leaves the plant by truck as canned immobilized oxide contained in $24 \times 118$-inch canisters.

Plutonium-bearing materials are processed and converted to oxide powders in shielded gloveboxes. Accountability and NDA testing are also performed in gloveboxes. Maximum use is made of remote and automated handling of plutonium bearing materials to minimize personnel exposure. An automated material transport system moves process materials between gloveboxes and an in-process storage vault. All gloveboxes have inert gas-either nitrogen or argon atmosphere-recirculated ventilation systems.

In addition to the processing of plutonium materials, gloveboxes are also provided for handling and consolidating waste materials (such as metal cladding removed from reactor fuels).

Between gloveboxes and the in-process storage vault, materials are transferred in sealed standard cans through an automated material transport system. Cans are opened only inside the gloveboxes, and empty cans are moved through the same system.

\subsubsection{Process and Process Support Design Description}

The following sections provide a description of the process and process support design. The description includes facility space usage and major equipment for the process. A more detailed equipment listing is contained in Appendix C. 


\subsubsection{Material Receipt and Storage}

Plot plan, C-201 for APSF; floor plans L-201 and L-202; sections D\&E, L-207

All plutonium-bearing materials to be processed and immobilized in the PIP are received and stored in the APSF or received in the APSF and transferred directly to lag storage in the PIP. Uranium oxide, ceramic precursor materials, and general maintenance supplies and equipment are received at the south dock of the PIP. Any plutonium-bearing materials stored at K-reactor to be immobilized are received at the APSF for transfer to the PIP.

\section{Space}

The total area in APSF used by PIP operation is $975 \mathrm{~m}^{2}\left(10,500 \mathrm{ft}^{2}\right)$. The lag storage vault in the PIP is about $51 \mathrm{~m}^{2}\left(550 \mathrm{ft}^{2}\right)$ and is located in the northwest area of the first level. A $37 \mathrm{~m}^{2}\left(400 \mathrm{ft}^{2}\right)$ clean canister storage area and $37 \mathrm{~m}^{2}\left(400 \mathrm{ft}^{2}\right)$ empty magazine storage area are located in the south side of the first level. A $56 \mathrm{~m}^{2}\left(600 \mathrm{ft}^{2}\right)$ area is provided in the first level for cold feed and supply storage. A $46 \mathrm{~m}^{2}\left(500 \mathrm{ft}^{2}\right)$ storage area is provided in the top level of the stack structure for uranium oxide and ceramic precursor storage.

\section{Equipment}

Major equipment for material receipt and storage includes confirmatory and accountability measurement equipment, a shielded forklift, an AS/RS vault, and AGVs.

\subsubsection{Oxide Fuel Feed Preparation}

Floor plan, L-202

Zero Power Physics Reactor oxide fuel pins are transported from material unpackaging and sorting in the sort glovebox to the oxide fuel decladding glovebox using a clean, dedicated conveyor.

Space

The oxide fuel decladding glovebox is $5.8 \mathrm{~m}(19 \mathrm{ft})$ long and occupies a portion of the $280 \mathrm{~m}^{2}\left(3000 \mathrm{ft}^{2}\right)$ process room in the north side of the first level. The glovebox atmosphere will be recirculated nitrogen.

\section{Equipment}

The decladding glovebox contains a decladding machine, cladding size-reduction equipment, and pellet collection and canning equipment. Glovebox operations are automated because of high radiation levels and the large quantity of fuel pins slated for immobilization.

\subsubsection{Material Size Reduction}

Floor plan, L-202

A crush and grind glovebox receives cans of oxide fuel pellets from oxide fuel feed preparation and from material unpackaging and sorting. After size reduction, the oxide is transferred via overhead conveyor to accountability. 
Space

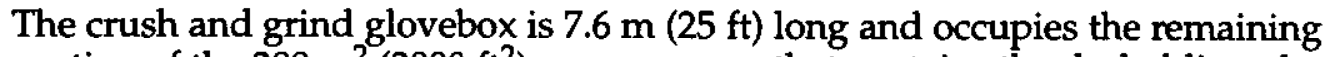
portion of the $280 \mathrm{~m}^{2}\left(3000 \mathrm{ft}^{2}\right)$ process room that contains the decladding glovebox. The glovebox atmosphere will be recirculated nitrogen.

\section{Equipment}

The crush and grind glovebox contains pellet crushing and grinding equipment and automated handling equipment.

\subsubsection{Material Unpackaging and Sorting}

Floor plan, L-202

An AGV transports cans of plutonium feed material from the APSF or the lag storage vault to the entry hood for the sort glovebox. A pick-and-place machine removes the can from the AGV and places it into the hood. Clean (contamination-free) outer cans and containers are removed and recycled or collected as scrap. The material can containing plutonium enters into the glovebox. After this material is unpacked, sorted, and transferred into a standard can (if necessary), it is transported by an overhead conveyor to a glovebox for processing or to the in-process storage vault. Empty contaminated cans are sent via the conveyor to waste handling.

Space

The sort glovebox is $13.4 \mathrm{~m}(44 \mathrm{ft})$ long and the entry hood is $1.8 \mathrm{~m}(6 \mathrm{ft})$ long. They occupy a $280 \mathrm{~m}^{2}\left(3000 \mathrm{ft}^{2}\right)$ process room in the north side of the first level. The glovebox atmosphere will be recirculated nitrogen.

\section{Equipment}

The hood contains automated can handling and outer can opening equipment. The glovebox contains automated can opening, sorting, and sampling equipment.

\subsubsection{Metal Fuel Feed Preparation}

Floor plan, L-202

A dedicated overhead clean conveyor transports ZPPR fuel plates from material unpackaging to the ZPPR decladding glovebox. After shearing, the fuel plates are canned and moved to metal conversion (HYDOX) using the overhead conveyor. Fuel cladding coming from the oxide fuel feed preparation and metal conversion operations via the overhead conveyor is consolidated in the cladding consolidation glovebox and transferred via overhead conveyor to waste handling.

Space

The ZPPR decladding and cladding consolidation gloveboxes are $15.3 \mathrm{~m}(50 \mathrm{ft})$ long and occupy a $280 \mathrm{~m}^{2}\left(3000 \mathrm{ft}^{2}\right)$ process room in the north side of the first level. The glovebox atmosphere will be recirculated nitrogen. 


\section{Equipment}

The glovebox contains decladding equipment and cladding consolidation equipment.

\subsubsection{Metal Conversion}

Floor plan, L-202

An overhead conveyor transports metal from metal fuel feed prep or material unpackaging to a HYDOX glovebox. After conversion, the oxide product from HYDOX is transported via overhead conveyor to accountability.

\section{Space}

The four HYDOX gloveboxes, each $6.1 \mathrm{~m}$ (20 ft) long, occupy a $186 \mathrm{~m}^{2}\left(2000 \mathrm{ft}^{2}\right)$ process room in the northeast corner of the first level. Each of these gloveboxes will use recirculating argon atmosphere.

\section{Equipment}

Each of these gloveboxes contains a complete HYDOX system, which includes a hydride/nitride vessel, an oxidation vessel, vacuum pumps, and supporting equipment. Instrumentation is provided to detect hydrogen leaks in the glovebox and room.

\subsubsection{Impure Oxide Feed Preparation}

Floor plan, L-202

Oxide is received from material unpackaging and sorting via the overhead conveyor. After treatment, the oxide product is transferred via overhead conveyor to materials characterization or accountability. Solid waste is transferred via conveyor to waste handling.

\section{Space}

The impure oxide feed prep glovebox is $15.3 \mathrm{~m}(50 \mathrm{ft})$ long and occupies a $130 \mathrm{~m}^{2}$ $\left(1400 \mathrm{ft}^{2}\right)$ process room on the northeast side of the first level. The glovebox atmosphere will be recirculated nitrogen.

\section{Equipment}

The glovebox is separated into a dry and wet process section. The dry section contains crushing and grinding equipment and a calcining furnace. The wet section includes the oxide washing and filtrate treatment equipment. The glovebox is Kynar-lined for corrosion resistance to chlorides. Small chemical feed tanks are located near the glovebox. Glovebox operations in the wet section will primarily be hands-on.

\subsubsection{Materials Characterization}

Floor plan, L-202 
The materials exiting the impure oxide feed preparation process will have to be analyzed for elemental content and to provide material composition data for determining batch sequencing in the feed batch step. The primary feed to characterization is impure oxide, but some HYDOX and reactor fuel oxide will also need characterization. After characterization, the oxide is transferred to accountability.

Space

The equipment for the materials characterization function is located in the impure oxide feed preparation glovebox, which has been detailed in Section 6.1.1.7 above.

\section{Equipment}

Major equipment includes sampling equipment, an x-ray fluorescence unit, and a vacuum tube transport system to collect samples.

\subsubsection{Material Control and Accountability}

Floor plan, L-202

Materials leaving the conversion process will require assaying prior to entering the immobilization process. Materials are transferred to the accountability glovebox via overhead conveyor for MC\&A measurements.

\section{Space}

The accountability glovebox is $15.3 \mathrm{~m}(50 \mathrm{ft})$ long and occupies a $93 \mathrm{~m}^{2}\left(1000 \mathrm{ft}^{2}\right)$ process room in the northwest side of the first level. The accountability room is isolated from the rest of the conversion process area by shield walls to reduce background radiation levels in the accountability measurement. The glovebox atmosphere will be recirculated nitrogen.

\section{Equipment}

The glovebox contains calorimeters, gamma spectrometers, and neutron coincidence counters. Equipment associated with the instruments is located next to the glovebox. It is anticipated that measurements made here will be totally automated.

\subsubsection{In-Process Storage Vault/Areas}

Floor plan, L-202; Section E, L-207

The in-process storage vault provides buffer storage for $\mathrm{PuO}_{2}$ powder between plutonium conversion and first-stage immobilization. At one end of the vault is an entry/security portal glovebox where the stacker-retriever interfaces with the automated can transfer conveyor. At the other end is a small vestibule for parking the stacker-retriever when it is not in use. An adjacent maintenance area for the stacker-retriever is accessible through an airlock.

Most of the vault capacity is dedicated to surge storage for plutonium oxide from plutonium conversion. However, a small portion is used for recycle material from 
first-stage immobilization. Storage racks are designed to assure criticality safety for stored material.

Space

The in-process storage vault occupies a $120 \mathrm{~m}^{2}\left(1300 \mathrm{ft}^{2}\right)$ area (including shield walls at the west end of plutonium conversion) on the first-floor

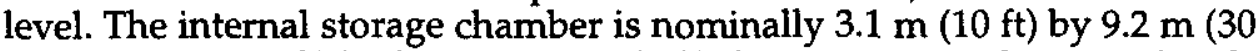

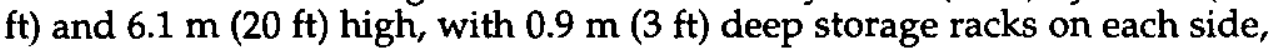
and a $1.2 \mathrm{~m}(4 \mathrm{ft})$ aisleway down the middle to accommodate a stacker/retriever. An adjacent $19 \mathrm{~m}^{2}\left(200 \mathrm{ft}^{2}\right)$ maintenance area for the stacker/retriever is accessible through an airlock. The vault has storage racks that have a 5 to 6 months' production minimum storage capacity. The vault atmosphere will be recirculated nitrogen.

\section{Equipment}

Equipment in the vault includes the portal glovebox, a pick-and-place robot, an automated storage retrieval system, storage pallets, and a bar code reader. A pair of 6-ft-long security locks and 10-ft-long entry hoods are also included.

\subsubsection{Ceramic Feed Batching}

Floor plan, L-202; Section E, L-207

An overhead conveyor transports oxide from the in-process storage vault to the batch splitting glovebox. After splitting and blending, the oxide is sampled and transferred via overhead conveyor to accountability prior to introducing the oxide to the immobilization process. Oxide batches that do not meet specifications are stored in the in-process storage vault to await reblending.

Space

The batch splitting glovebox is $6.1 \mathrm{~m}(22 \mathrm{ft})$ long, as is the blending and weighing glovebox. They occupy a $65 \mathrm{~m}^{2}\left(700 \mathrm{ft}^{2}\right)$ process room adjacent to the in-process storage vault in the first level. Both glovebox atmospheres will be recirculated nitrogen.

\section{Equipment}

The gloveboxes contain the feed splitter, can tumbler, and sampling equipment. Equipment will be automated because of high radiation levels and the large number of repetitive operations involved in puck production.

\subsubsection{Ceramification}

Floor plan, L-202, L-203, L-204; Section C, L-206

The ceramification operation is enclosed in the milling, mixing, and granulating glovebox and the puck pressing glovebox. The gloveboxes are arranged in a vertical "stack" structure in the central area of the process 
building. Material flows by gravity from the top of the stack down to the press at first level. The precursor and $\mathrm{UO}_{2}$ is fed into the glovebox through piping and airlocks. The overhead horizontal conveyor and a vertical conveyor transport the cans of blended plutonium feed from the in-process vault or accountability to the top of the glovebox stack.

\section{Space}

The stack structure is in a chamber in the middle of the PIP. The base of the chamber is $372 \mathrm{~m}^{2}\left(4000 \mathrm{ft}^{2}\right)$ and it is $12.2 \mathrm{~m}(40 \mathrm{ft})$ high to the underside of the

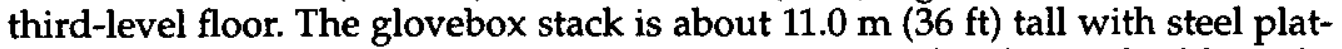
forms and stair access to the upper elevations of the glovebox. A building elevator and stairwell interface with the platform levels. The $3.7 \mathrm{~m}(12 \mathrm{ft})$ long trans$\mathrm{fer} /$ load glovebox is at top level of the stack. Below is the $2.7 \mathrm{~m} \times 6.1 \mathrm{~m}(9 \mathrm{ft} \times 20$ $\mathrm{ft})$ high mill, blend, and granulate glovebox. The $1.8 \mathrm{~m}(6 \mathrm{ft})$ long puck pressing glovebox is at the first level. A $2.4 \mathrm{~m}(8 \mathrm{ft})$ long maintenance glovebox is provided adjacent to the pressing glovebox. A $60 \mathrm{~m}^{2}\left(650 \mathrm{ft}^{2}\right)$ room space above the glovebox room is provided for storage and batching of ceramic precursor and $\mathrm{UO}_{2}$. The glovebox atmosphere will be recirculated nitrogen.

\section{Equipment}

The milling, mixing, and granulating glovebox contains the attritor mill, attritor blender, and granulator. The puck pressing glovebox contains powder feeder and press equipment. Equipment will be automated because of high radiation levels and the large number of repetitive operations involved in puck production.

\subsubsection{Ceramic Puck Handling}

Floor plan, L-202; Section C, L-206

Puck handling includes handling of green pucks between pressing and sintering, and handling of sintered pucks between sintering and can loading. Operations include puck weighing, inspection, tray loading/unloading, and tray staging/storage. Green pucks are received from pressing via a puck conveyor. The pucks are inspected, loaded on furnace trays, and moved to sintering using an overhead conveyor system. The sintered pucks are unloaded from the furnance tray, inspected, placed on transfer trays, and moved to can loading via overhead conveyor.

Space

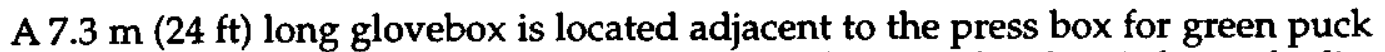

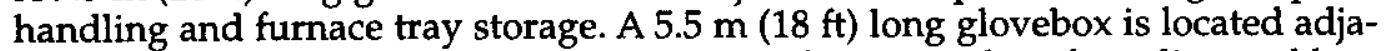
cent to each of the three sintering gloveboxes for sintered puck cooling and han-

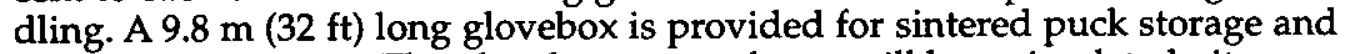
transfer tray storage. The glovebox atmospheres will be recirculated nitrogen.

\section{Equipment}

The puck handling gloveboxes contain inspection equipment, robots for puck handling, and machines for moving and stacking trays. Equipment will be automated because of high radiation levels and the large number of repetitive operations involved in puck production. 


\subsubsection{Nondestructive Examination for Process Control}

Floor plan, L-202; Section C, L-206

An NDA/NDE glovebox is provided for quality control measurements of individual pucks. A small number of sintered pucks from each batch will be sent to this glovebox via the overhead conveyor.

This glovebox also is used for MC\&A (see Section 6.1.1.15, below).

Space

The NDA/NDE glovebox is $11.6 \mathrm{~m}(38 \mathrm{ft})$ long and occupies a $70 \mathrm{~m}^{2}\left(750 \mathrm{ft}^{2}\right)$ area in the middle of a process room on the west wall of the first level. The glovebox atmosphere will be recirculated nitrogen.

\section{Equipment}

The glovebox includes an x-ray diffraction unit, an x-ray fluorescence unit, and a laser densitometer. Equipment will be automated because of high radiation levels and the large number of repetitive operations involved in puck production.

\subsubsection{Material Control and Accountability}

Floor plan, L-202; Section C, L-206

First-stage immobilization MC\&A includes accountability measurements after ceramic puck handling (Section 6.1.1.13, above) and can loading (Section 6.1.1.18, below). The accountability measurements are NDA measurements done in addition to the NDE for process control requirements. The measurements made here are performed on sintered pucks prior to their placement in cans.

Space

The NDA/NDE glovebox dimensions have been given in Section 6.1.1.14, above.

\section{Equipment}

In addition to the equipment used for NDE, the glovebox includes a gamma ray spectrometer and a calorimeter for MC\&A measurements. Equipment will be automated because of high radiation levels and the large number of repetitive operations involved in puck production.

\subsubsection{Sintering}

Floor plan, L-202

An overhead conveyor transports the furnace trays loaded with green pucks from puck handling to sintering. The trays are moved under a furnace, elevated and loaded through a bottom opening. After sintering, the furnace trays are lowered out of the furnace and moved into the adjacent cool down glovebox. 
Space

Three sintering gloveboxes, each $6.1 \mathrm{~m}(20 \mathrm{ft})$ long, occupy a $251 \mathrm{~m}^{2}\left(2700 \mathrm{ft}^{2}\right)$ area in a process room on the west end of the first level. The sintering furnaces will have argon atmospheres. The gloveboxes directly supporting the furnace gloveboxes are part of ceramic puck handling, which has been discussed earlier in Section 6.1.1.13.

\section{Equipment}

Each sintering glovebox contains two furnaces with a limited-volume cooling water system. Equipment will be automated because of high radiation levels and the large number of repetitive operations involved in puck production.

\subsubsection{Recycle}

Floor plan, L-202; Section E, L-207

An overhead conveyor transports reject material from the inspection function of ceramic puck handling glovebox to the recycle glovebox or the in-process storage vault. When the material is to be recycled, it is either already at the recycle glovebox or must be moved to the glovebox via an overhead conveyor from the in-process storage vault. The reject material is crushed for recycle and transported by overhead conveyor back to the vault or to feed batching.

Space

The recycle glovebox is $7.6 \mathrm{~m}(32 \mathrm{ft})$ long and occupies a $46 \mathrm{~m}^{2}\left(500 \mathrm{ft}^{2}\right)$ process room adjacent to the in-process storage vault in the first level. The glovebox atmosphere will be recirculated nitrogen.

\section{Equipment}

The recycle glovebox contains crushing and grinding equipment.

\subsubsection{Can Loading}

Floor plan, L-202; Section C, L-206

Ceramic pucks on transfer trays are received via an overhead conveyor. The pucks are loaded into a bagless loadout can, filled with helium, and welded shut. The cans exit the glovebox line into a hood, where a swipe and leak test is performed. A can conveyor transfers the clean cans to the product NDA area.

\section{Space}

Three parallel can loading lines are provided, each consisting of a $4.9 \mathrm{~m}(16 \mathrm{ft})$ long glovebox and a $2.4 \mathrm{~m}$. $(8 \mathrm{ft})$ long hood. The can loading occupies $170 \mathrm{~m}^{2}$ $\left(1800 \mathrm{ft}^{2}\right)$ of a process room on the west wall of the first level. The glovebox atmosphere will be recirculated nitrogen. 


\section{Equipment}

Each can loading line includes equipment for loading pucks into cans and for sealing the cans, as well as for the swipe and leak tests. Equipment will be automated because of high radiation levels and the large number of repetitive operations involved in puck production.

\subsubsection{Product NDA}

Floor plan, L-202; Section C, L-206; Section G, L-207

The product cans arrive in the NDA room via a conveyor, are nondestructively assayed, and are placed in a storage position until transferred to the magazine loading area by conveyer.

\section{Space}

The product NDA area occupies a $60 \mathrm{~m}^{2}\left(650 \mathrm{ft}^{2}\right)$ process room in the middle of the west wall at the west end of the first level. A $37 \mathrm{~m}^{2}\left(400 \mathrm{ft}^{2}\right)$ NDA instrument room located across the corridor is also provided for housing the NDA-associated equipment and computers. The accountability room is isolated from the rest of the immobilization process area by shield walls to reduce background noise in the accountability measurement.

\section{Equipment}

Major equipment in the product NDA room includes calorimeters, gamma-ray spectrometer equipment, and an overhead robotic bridge crane.

\subsubsection{Can-in-Canister System}

Floor plan, L-202; Section B, L-206; Section F, L-207

Product cans will be transferred by conveyor from the product NDA area to the magazine loading area. Four product cans will be loaded into a magazine and secured using robotics. The loaded magazines will be transferred to storage or to the off-normal storage/repair area for disposition by an overhead, telescoping bridge robot. An overhead bridge crane, on the same bridge of the overhead telescoping robot, will remove and insert the storage well plugs to provide access to the storage wells.

Each canister used in the PIP will be fabricated with an internal rack to hold seven magazines. The empty canisters will be loaded into the canister conveyor at the east end in a clean environment via an overhead monorail and moved into the canister loading station. Loaded magazines will be retrieved from the shielded storage area by the overhead telescoping bridge robot and inserted into the canister and locked in place. The filled canister will be inspected and acceptable units will be moved to the canister capping area, where temporary cap will be installed. The capped canisters will be move to the loaded canister shielded storage area to await transport to the DWPF. Units that fail inspection will be moved from the loading station via the overhead bridge crane to the off-normal storage/repair area for disposition. 
Space

The magazine loading and the shielded storage area and the off-normal storage/repair area comprise an area of about $214 \mathrm{~m}^{2}\left(2300 \mathrm{ft}^{2}\right)$ in the southwest corner of the first level. The magazine shielded storage area is a concrete form sitting on the first-level floor with penetrations into the concrete for storage wells. Each storage well has a concrete plug to cap the storage position. Magazines and canisters in the off-normal storage/repair area are worked from behind a shield wall directly east of the storage/repair area by remote manipulators.

The canister loading conveyor and the overhead monorail loading area comprise an area of about $112 \mathrm{~m}^{2}\left(1200 \mathrm{ft}^{2}\right)$ near the south wall of the PIP building.

\section{Equipment}

Major equipment in this area includes a magazine storage carousel, magazine loader, overhead bridge crane, telescoping bridge robot, and remote manipulators for magazine and canister rework.

The canister loading conveyor and the overhead monorail loading area equipment includes a lift truck, overhead monorail, canister transfer cart, canister grapple, and manipulator.

\subsubsection{Canister Transport}

Floor plan, L-202; Section G, L-207

The loaded canister is retrieved from the loaded canister storage area via a remotely operated overhead bridge crane and placed into a canister transport cask. The cask head is placed on the cask by the overhead bridge crane and the unit is moved to the cask conveyor for transport through the cask tunnel to a position below the transport truck bay.

With adequate safeguards and security in place, an overhead bridge crane in the truck bay removes the shield plug in the floor of the truck bay, retrieves the cask from the tunnel below, and places it on the transport vehicle. The vehicle then moves the cask to the DWPF. Empty casks are returned to the PIP in reverse order of this process.

Space

The cask loading area, the tunnel to the truck bay, and the truck bay itself comprise about $630 \mathrm{~m}^{2}\left(6800 \mathrm{ft}^{2}\right)$ on, below, and adjacent to the southwest corner of the PIP.

\section{Equipment}

Major equipment in this area includes the canister grapple and overhead bridge cranes, casks, and transport vehicle.

\subsubsection{DWPF Receipt and Handling}

Floor plan, L-209 
The casks are received at the DWPF dock, where they are opened, and the canisters transferred to the DWPF melt cell for storage. From this point onward the canisters are handled as part of the DWPF program.

Space

A $260 \mathrm{~m}^{2}\left(2800 \mathrm{ft}^{2}\right)$ enclosed space addition is added to the east loading dock of the DWPF for truck bay and receiving/handling functions.

\section{Equipment}

Major equipment added to the DWPF area includes the shielded lift truck, monorail hoist, canister storage rack, and overhead bridge crane.

\subsubsection{International Atomic Energy Agency Accommodations}

Floor plan, L-202

An office is provided for the use by IAEA inspectors to review records and information recorded from measurement instruments and surveillance cameras set up by the inspection agency.

\section{Space}

The floor space of the IAEA room is $19 \mathrm{~m}^{2}\left(200 \mathrm{ft}^{2}\right)$. It is located in the southeast corner area of the first level in the process building.

\section{Equipment}

Office furniture, power supply for office equipment, authenticated data lines, and UPS will be provided in or for the room.

\subsubsection{Waste Management}

Floor plan, L-202

Waste management process in the design includes waste sorting, assay, segregation, size reduction, packaging, interim storage, and equipment and waste container decontamination. Wastes generated are segregated and transferred to the existing SRS waste facilities for disposal.

Wastes generated from plutonium conversion and immobilization processes are first handled in a waste handling glovebox in their respective process areas before being transferred to the waste packaging room for final handling, certification, storage, and shipping.

\section{Space}

The plutonium conversion waste handling glovebox is $15.2 \mathrm{~m}(50 \mathrm{ft})$ long and occupies a $120 \mathrm{~m}^{2}\left(1300 \mathrm{ft}^{2}\right)$ room located in the north side of the first level. The

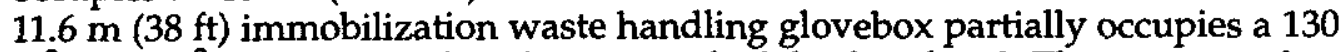
$\mathrm{m}^{2}\left(1400 \mathrm{ft}^{2}\right)$ room located in the east end of the first level. The waste packaging room is $223 \mathrm{~m}^{2}\left(2400 \mathrm{ft}^{2}\right)$ and is located in the east end of east wall of the 
first level. The room contains a $23 \mathrm{~m}^{2}\left(250 \mathrm{ft}^{2}\right)$ space for waste assay and a $33 \mathrm{~m}^{2}$ $\left(350 \mathrm{ft}^{2}\right)$ space for waste drum storage. The glovebox atmosphere will be recirculated nitrogen.

\section{Equipment}

Major equipment for waste handling includes a waste compactor, segmented gamma scanner, neutron drum counter, $\mathrm{CO}_{2}$ decontamination system (including glovebox or hood), and pallet mover.

\subsubsection{Analytical Laboratory}

Floor plan, L-202-sample preparation

The 772-F Laboratory at Savannah River will provide analytical quality control and process support capability for the PIP. Samples will be packaged in the sample preparation glovebox on the first floor level of the PIP and transported to 772-F. To meet the sampling throughput required by the PIP, additional instrumentation and glovebox and hood additions will be needed in 772-F. Because of the small sample sizes, no additional shielding requirements are anticipated. The only scope of work in the $772-\mathrm{F}$ building is the procurement and installation of equipment.

\section{Space}

The 19-ft sample preparation glovebox partially occupies a $130 \mathrm{~m}^{2}\left(1400 \mathrm{ft}^{2}\right)$ room located on the east side of the first level of the PIP. The existing 772-F analytical laboratory will be used and no space addition is needed. The glovebox atmosphere will be recirculated nitrogen.

\section{Equipment}

In addition to the sample preparation glovebox, the equipment needs in the PIP include packaging equipment, a bar code reader, and a computer. Additional analytical instrumentation and associated glovebox and hood additions will be added to the 772-F analytical laboratory. Major equipment additions include an alpha spectrometer, emission spectrometer, mass spectrometer, and uranium/plutonium assay analyzer.

\subsubsection{Control Rooms}

Floor plans, L-202, L-203

A plant central control room and various local control rooms are provided in the PIP for control and monitoring functions. The central control room is primarily used by the plant operations manager, supervisors, shift foremen, and technical engineers. Four local control rooms are strategically located throughout the plant. The process system is normally controlled by operators from control stations in the local control rooms. Control by the central control room requires a permissive from the respective local control rooms. 
Space

Several control rooms are provided for various control and monitoring functions as detailed below:

- The $93 \mathrm{~m}^{2}\left(1000 \mathrm{ft}^{2}\right)$ plant central control room is located in a clean area near the personnel entry of the first level. The central control room houses the plant central and supervisory control and the MC\&A and information system.

- A $40 \mathrm{~m}^{2}\left(450 \mathrm{ft}^{2}\right)$ conversion and material handling control room is provided for local control of the plutonium conversion process units and for control of the AGV, vault stacker/retrievers, and overhead conveyor operations. This room is at the west end of the plutonium conversion area.

- A $40 \mathrm{~m}^{2}\left(450 \mathrm{ft}^{2}\right)$ immobilization control room is provided for local control of the first-stage immobilization process units. This room is next to the conversion and material handling control room.

- A $37 \mathrm{~m}^{2}\left(400 \mathrm{ft}^{2}\right)$ NDA instrument control room on first level, directly south of the product NDA room.

- A $65 \mathrm{~m}^{2}\left(700 \mathrm{ft}^{2}\right)$ computer and instrument room is provided to house the process control computers, programmable controllers, and the associated instrument racks. This room is located on the second level.

- A $74 \mathrm{~m}^{2}\left(800 \mathrm{ft}^{2}\right)$ canister loading control room is provided for local control of the canister loading operation. This room is located on the second level adjacent to the operator gallery of the canister high bay area.

- A $37 \mathrm{~m}^{2}\left(400 \mathrm{ft}^{2}\right) \mathrm{HVAC} /$ utilities control room is provided for control of the facility HVAC and utility systems. This room is located on the second level.

- A $60 \mathrm{~m}^{2}\left(650 \mathrm{ft}^{2}\right)$ security monitoring room is provided for control and monitoring of the building security system. This room is located in the entry control facility.

\section{Equipment}

Major equipment in the control rooms includes control workstations and consoles, alarm annunciation panels, and computer equipment.

\subsubsection{Material Access Area Support Rooms/Facilities}

Floor plans, L-202, L-203, L-204; Sections L-206, L-207

A number of support areas and rooms are included in the MAA and the second floor area above the main MAA process floor. These are listed below:

- Automated guided vehicle maintenance area. For maintenance and battery charging.

- Contaminated equipment maintenance room. For routine repair and service of contaminated equipment (major repairs or nonroutine repairs may be performed in other SRS maintenance shops).

- Electrical and instrumentation maintenance room. For routine repair and service of electrical and electronic equipment and instrumentation (major repairs or nonroutine repairs may be performed in other SRS E\&I maintenance shops).

- Empty magazine and canister storage rooms. Two lift-truck accessible rooms for storage and receipt inspection of empty magazines and canisters. 
- Uranium drum storage room. For storing drums of uranium oxide feed materials.

- Ceramic precursor storage. For storing drums/boxes of ceramic precursor feed materials, ceramic lubricants, and binders.

- Cold supply storage rooms. For storing general supplies. The items to be stored in this area will include sundry items frequently required to support operation in the facility (e.g., recorder chart paper, miscellaneous hardware items). One room is on the first level and the other on the second level.

- Health protection area. For HP facilities and equipment. This area (a room near the MAA personnel entry and exit entry) will have equipment for assessing the contamination on wipes used to survey for transferable contamination on equipment and containers being handled in the facility.

- Contaminated waste water collection system. A water drain system for collecting all waste water, including fire water, that is normally not contaminated, but has a potential for being contaminated. The water will be collected and monitored for contamination. Uncontaminated water will be released to an appropriate outfall. Contaminated waste water will be transferred to an appropriate, existing contaminated liquid waste treatment facility at SRS.

- Elevators. For transport of personnel, equipment, and materials. The freight elevator shall be designed for cargo loads $125 \%$ of the maximum load expected during facility operation, including weights of lift truck, lift truck cargo, and all personnel (operating, security, and HP) accompanying the material movement.

- Other rooms. Shift supervisor offices, a conference room, janitorial closets, and several support storage areas are also supplied.

Space

The space requirements for the different MAA support rooms and facilities are listed below:

- Automated guided vehicle maintenance area. The AGV maintenance area is a room having $51 \mathrm{~m}^{2}\left(550 \mathrm{ft}^{2}\right)$ of floor space, located on the first level of the process building in the northwest corner of the first level.

- Contaminated equipment maintenance room. The contaminated equipment maintenance room is a room having $74 \mathrm{~m}^{2}\left(800 \mathrm{ft}^{2}\right)$ of floor space, located on the first level of the process building in the northwest corner of the first level.

- Electrical and instrumentation maintenance room. The E\&I maintenance room is a room having $28 \mathrm{~m}^{2}\left(300 \mathrm{ft}^{2}\right)$ of floor space, located on the first level of the process building in the southeast quadrant of the first floor.

- Empty magazine and canister storage rooms. Both lift truck accessible rooms, each with about $37 \mathrm{~m}^{2}\left(400 \mathrm{ft}^{2}\right)$ of floor space, are located on the first level of the process building in the southwest quadrant of the first floor. The access door is sized for passage of lift trucks delivering empty magazines and canisters from the south dock.

- Uranium drum storage room. The uranium drum storage room is a room having about $23 \mathrm{~m}^{2}\left(250 \mathrm{ft}^{2}\right)$ of floor space, located on the third level of the PIP, above the ceramic processing stack.

- Ceramic precursor storage. The ceramic precursor storage room is a room having about $23 \mathrm{~m}^{2}\left(250 \mathrm{ft}^{2}\right)$ of floor space, located on the third level of the PIP, above the ceramic processing stack.

- Cold supply storage rooms. Cold supplies are stored in two rooms having about of $56 \mathrm{~m}^{2}\left(600 \mathrm{ft}^{2}\right)$, located on the first level of the PIP. 
- Health protection area. The health protection area is a room having about $70 \mathrm{~m}^{2}$ $\left(750 \mathrm{ft}^{2}\right)$ of floor space, located in the southeast quadrant of the PIP is provided for HP facilities and equipment.

- Contaminated waste water collection system. The contaminated waste water collection system is in a room having about of $130 \mathrm{~m}^{2}\left(1400 \mathrm{ft}^{2}\right)$ of floor space, located in the basement of the PIP on the north wall.

\section{Equipment}

The equipment requirements for the different MAA support rooms and facilities are listed below:

- Automated guided vehicle maintenance area. Major equipment in the AGV maintenance room includes a battery charging station and a hydraulic lift.

- Contaminated equipment maintenance room. Major equipment in the contaminated maintenance room includes work benches with hoods, tools, and instruments required for routine repairs of facility contaminated equipment. There is storage here for repair tools and equipment and for inventory of frequently required spare parts, as well as for the decontamination equipment and hoisting equipment (monorail or portable jib crane). (Tools and equipment provided for the shop are to be recommended by the A/E).

- Electrical and instrumentation maintenance room. Major equipment in the E\&I maintenance room includes work benches, tools, and instruments required for routine repairs of instrumentation equipment. There is storage here for diagnostic equipment and for inventory of frequently required spare parts. (Tools and equipment provided for the shop are to be recommended by the A/E).

- Empty magazine and canister storage rooms. Area and equipment allows visual and dimensional inspection of magazines at the rate of seven per day and canisters at the rate of one per day. The canister storage area has the capacity to hold 20 empty canisters ( 2 weeks' operating supply). A monorail is provided for handling canisters.

- Uranium drum storage room. The equipment for this room includes drum handling equipment and a hood for removing drum heads to allow laboratory sampling of oxide.

- Ceramic precursor storage. Drum handling equipment is contained in the ceramic precursor storage room.

- Cold supply storage rooms. Equipment in the cold supply storage areas includes storage shelves and cabinets. The first-level room has an access door sized for passage of lift trucks and pallets.

- Health protection area. The area shall also be provided with portable equipment for use in monitoring the radiation levels in any area of the facility. Facilities and equipment for the decontamination of personnel shall be provided. A personnel monitoring station for all personnel exiting the MAA shall be provided in the hallway near the HP area.

- Contaminated waste water collection system. Equipment shall include collection tanks (capacity of tanks to be determined during the design phase) and associated piping, including sampling systems, a drain for uncontaminated water to an outfall, and a pump for transferring contaminated water to a tank truck.

- Other rooms. Offices will be furnished with standard office furniture and equipment and with telephone and data cable connections to the SRS 
computer LAN for each occupant of the office. The conference room shall be sized for a minimum of 40 occupants and with standard conference room equipment, including a telephone, connection to the SRS computer LAN, and SRS TV cable. There should be a minimum of two janitorial closets-one for the radiological buffer area and one for the clean area. Each janitorial closet shall have storage for janitorial supplies and equipment and a sink. One sink is drained to the facility contaminated water collection system (for the closet in the radiological buffer area) and the other is drained to the sanitary waste water system (for the closet in the clean area). Appropriate equipment and storage facilities in the support storage areas will be determined during the design phase.

\subsubsection{Material Transport System}

The PIP processing area utilizes a number of handling systems for transporting solid material during the materials receiving, processing, and shipping operations. The following sections provide descriptions of the major materials handling systems associated with the facility.

Overhead Inter-Glovebox/Area Transport System

An overhead material transport system, to transport materials as well as small tools and equipment, is provided. The transfer system will be designed to handle two types of standard cans as well as furnace and transport trays between the PIP gloveboxes and vaults. The transport system is located outside the gloveboxes and includes a stainless steel tunnel confinement system. It will have a recirculated nitrogen atmosphere.

\section{Intra-Glovebox Transport System}

A shorter transport system of a similar design to the above will be used for material movements inside the gloveboxes. The type of transport system used in the gloveboxes will be determined during the design phase and will be dependent on the specific application. To the extent practicable, movements of materials, tools, and equipment in the gloveboxes will use the same can and tray designs as are used by the transport systems outside the gloveboxes.

\section{Puck Can Transport System}

A transport system for moving loaded puck cans from the product NDA area to the magazine loading area is provided. The system will be similar to the overhead transport system with the following exceptions:

- The system will be designed to handle puck cans

- The system will have elevating equipment to raise the cans to an overhead floor transport system

- The transport system will not require a confinement system, but may require shielding (as determined by ALARA analysis). 


\section{Automated Guided Vehicles}

Automated guided vehicles shall be provided for transporting plutonium bearing materials in 3013 and $2 \mathrm{R}$ type containers. These containers will be transported from the APSF to the PIP. Movements of these containers in the APSF will be performed using an AGV provided by the APSF project. This APSF AGV will retrieve containers with materials from the APSF vault and will deliver the containers to a portal that goes through the APSF east exterior wall and is connected to a tunnel to the PIP. An AGV provided by the PIP project will retrieve the container from the portal and deliver the container to the lag storage area in the PIP. During tunnel movements, the AGV will pass through the entry port connecting the tunnel to the PIP. At the lag storage vault, the AGV will place the container on a portal device that will pass the container into the vault for storage by an invault stacker/retriever.

The AGV will also be used to retrieve containers from the lag storage vault portal device and will deliver the container to the sort glovebox container entry station.

The AGV is remotely controlled from the control room using a guidance system like the laser triangulation guidance system. This type of system uses an AGVmounted laser to detect/follow targets located on the facility/tunnel walls.

\section{Canister Conveyer}

A conveyer is provided for conveying canisters sequentially from the clean canister storage area to the canister loading/capping area, and then to the loaded canister shielded storage area.

\section{Lift Trucks/Pallet Handlers}

Lift trucks and pallet handlers will be used for transporting and truck unloading of large and heavy items. These lift trucks shall meet commercial standards. Lift trucks used to unload or to operate near safe secure transports (SSTs) shall be approved by the cognizant DOE Office for SSTs (Sandia National Laboratory). All lift trucks shall be battery powered. Pallet handlers will be either battery powered or manually operated, depending on their usage. The procurement/design of all lift trucks and pallet handlers shall consider the guidance of DOE-STD-1090-96, Hoisting and Rigging.

\section{Cask Transporter and Transport Casks}

A cask transporter truck will be provided for transporting loaded can-in-canister casks from the PIP to DWPF. Design of the transporter, including casks, shall comply with the requirements of DOE Order 460.1, Packaging and Transportation Safety, and WSRC Manual 19Q, Transportation Safety. The design shall assume a maximum transit time of one hour from leaving the PIP through docking at the DWPF unloading facilities. 


\subsubsection{Administrative Support Building and Foyer}

\section{Change Rooms}

Men's and women's change rooms are located in the entry control facility. Each room is $112 \mathrm{~m}^{2}\left(1200 \mathrm{ft}^{2}\right)$ and is equipped with locker storage and shower facilities.

Offices and Related Facilities

Administrative and technical support facilities are located in the administration support building. The area for administrative and support services is designed as a clean area with conventional HVAC system.

The first level of the administrative support building is designed for technical support and services. This area is $465 \mathrm{~m}^{2}\left(5000 \mathrm{ft}^{2}\right)$ and includes a maintenance shop, an E\&I shop, a break room, a supply receiving and storage area, and an open truck dock. Work benches, tools, E\&I diagnostic equipment, workshopgrade electrical power, and lighting are provided.

The second level of the administrative support building is designed for administrative support of the PIP operation. The floor space is $745 \mathrm{~m}^{2}\left(8000 \mathrm{ft}^{2}\right)$ and includes private and open offices, a conference room, a break room, and miscellaneous space for personnel services. Normal office support appliances and electrical power for office equipment are provided.

\subsubsection{Facility Systems/Elements}

\subsubsection{Site Development}

The new plutonium immobilization plant will be located inside the F-Area at SRS. The planned location will be at the northeast section of the F-area, adjacent to the APSF facility. All of the structures and buildings required for plutonium conversion, immobilization, and canister loading will be provided on site. The main process building consists of two floor levels with the main process level located at grade level and the HVAC and electrical equipment located on a second level. Transfer of material from the APSF to the PIP process will be through a below-grade connecting tunnel. Support facilities and equipment will be located outside of the PIDAS area. A new enclosed truckwell and laydown area will also be constructed at the DWPF for receipt of loaded canisters and transfer to the DWPF melt cell and HLW fill operations.

\section{Site Preparation}

Site preparation includes clearing, grubbing, and stripping the top 12 inches of soil and vegetation over an approximately $800 \mathrm{ft} \times 700 \mathrm{ft}$ area. New structures for the PIP include the following:

- Main process building (Drawings L-201 through L-207)

- Administrative support building (Drawings L-202, L-203, L-207)

- Entry control facility (Drawings L-202, L-207)

- Truck bay (Drawing L-202)

- Enclosed truck dock (Drawings L-202, L-207) 
- Open truck dock (Drawings L-202, L-207)

- Standby diesel generators (Drawings C-201, L-208)

- Electrical substation (Drawing C-201)

- Chillers (Drawing C-201)

- Chemical feed and cooling tower pumps (Drawings C-201, L-208)

- Bottled gas storage (Drawing C-201)

- Access roads and parking area (Drawing C-201, C-202).

\section{Site Grading and Storm Water Management}

The topography of the planned site slopes in a south-to-north direction with a change in elevation of about $35 \mathrm{ft}$ (see Drawing C-201). The plutonium immobilization plant will be sited to facilitate the movement of material via the underground tunnel connecting the APSF and PIP and to minimize the amount of excavation and grading required. The northern boundary of the planned site will be within $200 \mathrm{ft}$ of an existing creek. Retaining wall structures or slope stabilization features will be designed to prevent erosion by storm runoff.

Stormwater management and sediment control will be in accordance with local codes and regulations.

The minimum design level for storm water management system will be for a 25year, 6-hour storm with adequate capacity for a potential 100-year, 6-hour storm.

If the PIP facilities can be sited above the design basis flood (DBF) level in accordance with DOE-STD-1020-94, flood hazards need not be included in the design basis except that the possibility of raised ground water level must be considered.

If the PIP facility is sited below the DBF level, it will be designed to preclude the flooding of areas in the facility that contain plutonium. The design basis flood for the PIP will be established in accordance with UCRL-15910 (DOE-STD-1020). All processing and storage building structures housing plutonium and/or high level waste and the product canister storage vault will be designed to withstand the DBF.

\section{Utilities}

Electrical power, potable water, sanitary sewer, fire water, gas, chilled water, and plant and instrument air are required utility services at the PIP facility. SRS site utilities will have adequate capacity to support the additional PIP utility requirements. Connections to existing SRS site utilities are available within the vicinity of the PIP facility.

Two new electrical feeders will be routed to the PIP. One overhead feeder will be routed to a new substation on the northwest corner of the planned site to support the PIP facility. Two standby generators, located next to the new substation, will provide standby power to support critical operations. Another underground feeder will be routed into the PIP itself.

Potable and sanitary sewer systems will comply with the requirements of the Uniform Plumbing Code and ASCE-37. There will be no interconnections between stormwater systems, sanitary sewer systems, and radioactive or other hazardous material handling systems. 


\section{Paving and Surfacing}

Access roads, plant roads, parking areas, and area paving will be designed in accordance with AASHTO standards and applicable SRS requirements.

\section{Physical Protection and Security}

Physical protection of the main process building will be provided by a PIDAS and vehicle barriers. Additional protection includes vault doors and delay barriers placed at facility main entry and exit points. Entry to the main process area will be through the entry control facility at grade level.

\subsubsection{Architectural Development}

\section{Building Description}

The PIP main process building is a safety class structure for the plutonium immobilization process. All of the systems required for plutonium conversion, immobilization, and canister loading are located within a hardened concrete structure. The main process activities are located at grade level with the HVAC and electrical equipment on the second level. Support facilities and equipment are located adjacent to the main process building.

The main processing area will be located on first level at-grade. Main access to the process area will be through the entry control facility at ground level. The total square footage of this floor level is approximately $71,000 \mathrm{ft}^{2}$. Two east-west main corridors and one north-south main corridor provide separation of different process areas and facilitate the movement of materials from one process area to another.

Heating, ventilation, and air conditioning and electrical equipment will be located at the second level above the process floor with a floor area of approximately $71,000 \mathrm{ft}^{2}$. A $110-\mathrm{ft}$ exhaust stack will be located on the north side of the main process building.

The two-level administrative building $\left(16,000 \mathrm{ft}^{2}\right)$ and entry control facility $\left(4,800 \mathrm{ft}^{2}\right)$ connecting to the main process building will provide space for entry control, change rooms, restrooms, offices, and maintenance shops. Other support facilities include cooling towers, chillers, chemical feed and pumps, liquid nitrogen and argon tanks, and bottled gas storage. Standby diesel generators and an electrical substation are located on grade adjacent to the main process building.

\section{Code Basis}

Construction type is Type I (fire resistive, noncombustible construction and materials) and the area separation between occupancy is 2-hour fire resistive construction in accordance with UBC. 


\section{Code Compliance}

Nonprocess areas are fully accessible and in compliance with ANSI Standard A117.1 and the Uniform Federal Accessibility Standard, 41 CFR 101-19.6. Partitions are generally drywall type, fire-rated where required in accordance with UBC. Non-load-bearing partition framing is minimum 24-gauge galvanized metal studs.

Occupied spaces are suitably lighted and ventilated for safe habitation at all times in accordance with UBC, ASHRAE, and nuclear contamination control release requirements.

\section{Access and Egress}

The PIP building is considered a special purpose industrial facility by NFPA-101, Life Cycle Code. Access and egress requirements will be in accordance with the applicable requirement of NFPA-101.

The path of travel must be determined and meet the limitations of NFPA 101 without requiring occupants to pass from clean areas through areas of higher hazard on the way to exit.

\section{Building Envelope}

The process building envelope is insulated, watertight, and sealed sufficiently to allow maintenance of an internal negative pressure. The roof system for the support facilities consists of rigid insulation and membrane on a roof deck with galvanized metal flashing.

Penetrations through fire rated assemblies, at each floor and at shafts or vertical pipe chases, are sealed with UL-approved fire-rated material commensurate with the fire rating of the wall.

Support facilities exterior siding and windows will be designed to resist wind and tornadoes in accordance with applicable sections of ASCE 7-95.

Exterior doors at the main process building and support facilities will be designed to meet security requirements and to protect against design basis tornado missiles.

\section{Architectural Finishes}

The floors, walls, equipment, and exposed structure of the process area will be coated with a radiation resistive, decontaminable coating system or lined with stainless steel where abrasion or impact dictates more substantial finishes.

\section{Plumbing}

In the main process building, a floor trench, sump, and drain system will be installed to collect sprinkler discharge and to contain contaminated effluent. The effluent will be collected in holding tanks located in the basement pit below the process floor level. 


\section{Radiation Control}

The PIP facility will comply with the radiation protection requirements of 10 CFR 835, WRS Manual 5Q, and applicable DOE orders. Radiation shielding will be provided by reinforced concrete walls to maintain dose rates ALARA and within the allowable limits as described in 10 CFR 835.

\section{Fire Protection}

The design and construction of the PIP will comply with the design criteria of DOE orders and NFPA code. Sprinkler systems will be located in all areas of the main process building. Fire water collection tanks located in the basement level (Drawing L-1) will be provided to isolate potentially contaminated fire water.

\subsubsection{Structures}

\section{Description of Facilities}

The process building is classified as a Performance Category 3 (PC-3) reinforced concrete structure with mat foundation, exterior walls, floor slabs, and roof systems. The main process area will be located at the first floor level, which is atgrade. Heating, ventilation, and air conditioning and electrical equipment will be located above the process level on a second level. The roof of the central process stack will be at elevation $56 \mathrm{ft}$.

Seismic resistance of the structure will be provided by roof and floor concrete diaphragms with exterior and interior shear wall systems. The seismic spectra is defined in WSRC Manual WSRC-TM-95-1.

The structural framing of the process building consists of reinforced concrete roof and floor slabs supported by steel beams and column systems. The interior column grid spacing ranges from 10 to 35 feet in the north-south direction and from 10 to 30 feet in the east-west direction. The shielded storage and shipping cask area will not have any interior column due to crane travel in that area.

The exterior walls of the main process building structure are estimated at 2-ftthick for providing structural resistance to the lateral loads from NPH events and for radiation shielding. Typical interior shear walls and load bearing walls are about 2-ft-thick. Thickness of other interior walls will be determined based on specific radiation shielding, security, or fire protection requirement. Interior partition walls will be concrete. Metal stud walls may be possible in the office area. Based on the WSRC study, NMP-PLS 980056, Radiological Control and Criticality Requirements for the Plutonium Immobilization Plant, the walls in the PIP must have minimum thicknesses for shielding purposes. The walls shown in the layouts for the PIP (Appendix B), have thickness dimensions shown in Table 6.1. Wall thicknesses either meet or exceed the WSRC requirements based on shielding or structural requirements.

The water table at the planned site is estimated at about $55 \mathrm{ft}$ below grade level. The lowest foundation of the main process building is located at elevation $-26 \mathrm{ft}$ so as to remain above the existing groundwater table even with seasonal fluctuations. 
Table 6.1. Concrete Wall Thicknesses (as shield) in Inches.

\begin{tabular}{lccccc}
\hline Room/Location & N & S & E & W & Ceiling \\
\hline Lag storage vault & 30 & 30 & 30 & 30 & 24 \\
Accountability & 12 & 12 & 12 & 18 & 24 \\
Weighing (adjacent batch splitting) & 24 & 12 & 0 & 18 & 24 \\
Batch splitter & 48 & 12 & 0 & 12 & 24 \\
In-process vault & 48 & 48 & 48 & 48 & 24 \\
Recycle & 12 & 48 & 0 & 12 & 24 \\
ZPPR operations & 12 & 12 & 12 & 24 & 24 \\
Impure oxide feed preparations & 12 & 12 & 12 & 12 & 24 \\
Waste handling (oxide prep) & 12 & 12 & 12 & 12 & 24 \\
HYDROX lines (four modules) & 12 & 12 & 24 & 12 & 24 \\
Packaged waste storage & 12 & 12 & 12 & 12 & 24 \\
Waste packaging & 24 & 12 & 12 & 12 & 24 \\
Waste handling (disassembly) & 24 & 12 & 12 & 12 & 24 \\
Sample preparation (near disassembly) & 24 & 12 & 12 & 18 & 24 \\
Green puck weigh \& inspect & 24 & 12 & 12 & 24 & 24 \\
Green puck storage & 24 & 12 & 12 & 24 & 24 \\
Furnaces (1 of 3 sets) & 24 & 12 & 12 & 24 & 24 \\
Sintered puck cool \& store & 24 & 12 & 12 & 24 & 24 \\
Sintered puck weigh \& inspect & 24 & 12 & 12 & 24 & 24 \\
NDANDE & 24 & 12 & 12 & 24 & 24 \\
Can loading \& leak/smear (three units) & 24 & 12 & 12 & 24 & 24 \\
Sintered puck storage & 24 & 12 & 12 & 24 & 24 \\
Product NDA & 36 & 36 & 24 & 36 & 24 \\
Loaded cask/canister storage & 48 & 48 & 48 & 48 & 24 \\
Shielded storage & 48 & 48 & 48 & 48 & 24 \\
Magazine loading & 36 & 48 & 48 & 48 & 24 \\
Canister capping \& loading & 48 & 48 & 48 & 48 & 24 \\
Blend/mill/granulate, 2nd level & 36 & 12 & 12 & 12 & 24 \\
Transfer/load, 3rd level & 36 & 12 & 12 & 12 & 24 \\
Central control room & 0 & 0 & 0 & 0 & 24 \\
Conversion/control room & 18 & 12 & 18 & 18 & 24 \\
Immobilization control room & 12 & 18 & 18 & 18 & 24 \\
Canister loading control room & 12 & 12 & 24 & 48 & 24 \\
Health protection, etc. & 18 & 0 & 0 & 0 & 24 \\
Vault entry hoods, north central corridor & 12 & 12 & 12 & 0 & 24 \\
AGV charge maintenance & 12 & 18 & 30 & 12 & 24 \\
Contaminated equipment maintenance & 18 & 18 & 18 & 18 & 24 \\
\hline
\end{tabular}

\section{Support Buildings and Facilities}

The entry control facility, administrative support building, and canister truck bay, which are located adjacent to the PIP building, will be designed as PC-2 facilities. The canister truck bay is functionally connected to the main process building by an underground tunnel but may be structurally isolated from the main process building. Structural framing for the PC-2 buildings will consist of steel beams, girders, and columns. Metal siding and a metal roof deck are provided as are a concrete floor slab with metal decking and perimeter concrete foundation. Braced frames and moment resisting frames will be designed for lateral load resistance.

Cooling towers, chillers, pumps, liquid nitrogen and argon tanks, bottled gas storage, standby diesel generators, and an electrical substation are located on grade in the immediate vicinity of the main process building. 


\section{Tunnel}

The tunnel connecting the APSF and PIP main process building will be designed for loads from vehicular traffic on access roads in addition to the PC- $3 \mathrm{NPH}$ design requirements.

\section{Structural Requirements}

The PIP main process building, classified as PC-3, will be designed in accordance with DOE Order 420.1 and associated DOE NPH-related guidance standards, WSRC manual WSRC-TM-95-1, applicable building codes, and standards for the design of DOE nonreactor facilities.

Design for natural phenomena hazards (including wind, tornado, flood and earthquake) will be in accordance with DOE-1020 for the main process building. The main process building, loads, loading combinations, and design requirements will be in accordance with ACI 349 for concrete and AISC N690 for steel structures.

The administrative building, entry control facility, canister truck bay, and DWPF addition will be designed as PC-2 structures in accordance with SRS Manual WSRC-TM-95-1 and applicable DOE-STD-1020 requirements. Steel structures will be designed in accordance with AISC Design Specifications and Manual of Steel Construction. Concrete design will conform with ACI-318 requirements.

\section{Geotechnical Investigation}

A geotechnical investigation will be conducted to obtain engineering evaluation of the soil conditions, design soil properties, and foundation design recommendations. The geotechnical investigation effort will consist of reviewing existing data; performing field explorations, laboratory analyses, geotechnical analyses, and engineering evaluations; and providing a summary of the investigation, including recommendations for foundation design. Data should include soilbearing pressures for foundations, lateral soil pressures and distribution for below-grade walls and retaining walls, differential settlements, static and dynamic soil properties, and various design parameters for seismic and soilstructure interaction analyses. Additional field exploration may be required to determine soft zone layers if encountered during the initial field investigation.

\section{Seismic Design and Qualification of Systems and Components}

Nonstructural systems and components of the PIP facility will require seismic design and qualification. Components requiring seismic design and qualification include foundations, supports, and bracings (for piping, conduit, ducting, mechanical and electrical equipment, control systems, and architectural elements such as suspended ceilings, lighting panels, access floors, windows, and wall panels).

Components in the main process building will be evaluated for design basis earthquake in accordance with DOE-STD-1020. For PC-2 facilities, the components will be designed to UBC or standard building code (SBC) requirements. For PC-0 through PC-3, a graded approach shall be used. Each SSC shall be designed to the respective requirement for its PC level as defined in WSRC-TM-95-1. 


\subsubsection{HVAC and Confinement Zones}

Confinement of radioactive materials in the PIP is achieved by a combination of primary confinement structures, (i.e., process enclosures), secondary confinement structures, the ventilation system, and the process building. Areas in the PIP processing building are divided into three confinement zones. Process enclosures (Zone I enclosures) are gloveboxes, conveyors, and process vaults that normally contain radioactive materials, and are surrounded by the secondary confinement structures (Zone II areas), including operating and maintenance spaces for gloveboxes. The HVAC system operates to maintain negative pressures in the Zone I enclosures with respect to the Zone II areas; the HVAC system maintains negative pressures in Zone II areas with respect to the surrounding Zone III areas. Zone III areas consist of office space, corridors, and the health physics area located on the southeast corner of the main processing floor of the PIP. The Zone III areas are also maintained at a negative pressure with respect to the outside environment to ensure that the potential radioactive release is confined within the PIP.

There are three separate HVAC systems to serve the PIP. One system provides the glovebox exhaust. Another system provides ventilation to the process building, i.e., the MAA. A third, smaller, systern provides the necessary heating and cooling for comfort of personnel in the ECF and administrative support building. The process building HVAC system also serves to control the spread of airborne contamination in the process building.

The treated air is provided in the main processing area into Zone III areas, i.e., corridors and clean office areas located in the southeast corner of the main processing area. The differential pressure of -0.1 in water gauge is maintained in all Zone III areas to minimize the potential airborne contamination leakage to the environment. Zone II areas, mainly the operating and maintenance spaces for gloveboxes and canister loading and storage areas, are maintained at a design pressure of -0.5 in water gauge. Because of higher potential for contamination, the required air change in Zone II areas is $50 \%$ higher than in Zone III areas; a total of 12 air changes in an hour is designed for Zone II areas in comparison to a total of 6 air changes in Zone III areas. This is consistent with the zone control requirements at SRS.

\section{Glovebox Exhaust System}

Zone I enclosures (e.g., gloveboxes and overhead conveyors) and the in-process vault are, in general, inerted with nitrogen gas. Argon is used in lieu of nitrogen to maintain an inert atmosphere for the HYDOX and sintering gloveboxes. Highefficiency particulate air filters located on the supply side and on the exhaust side of gloveboxes ensure that the airborne contaminants are confined within. The nitrogen or argon glovebox inerted atmosphere is maintained and purified through recirculation. The system capacity is sized to maintain a flow velocity of 5 feet per minute (fpm) at the largest cross sectional area of the gloveboxes. This is to keep the typical 5-micron-aerodynamic-equivalent-diameter (AED) plutonium oxide particulate airborne inside the enclosures. The glovebox pressure is maintained at -1 in water gauge relative to the room pressure.

The exhaust system equipment is designed to maintain a minimum pressure of -1.0 in water gauge and to make 30 air changes in an hour in Zone I areas in case of a loss of inerting atmosphere or during maintenance activities. 
The total required flow rate for the Zone I exhaust is $17,000 \mathrm{cfm}$ during maintinance or a loss of inserted atmosphere. Two redundant trains of Zone I HEPA filter plena and exhaust fans with a combined capacity of $18,000 \mathrm{cfm}$ (i.e., each fan and the HEPA filter plenum is designed for a flow rate of $9,000 \mathrm{cfm}$ ) are located on the second floor of the processing building of the PIP. Each exhaust filter plena contains two stages of HEPA filters. Exhaust fans will route flow to the 110-ft-tall stack.

\section{Process Building HVAC System}

The HVAC system serving the Process Building is designed as a once-through system utilizing $100 \%$ outside air. The system is designed for 1,530 tons cooling, $16,900,000 \mathrm{Btu} / \mathrm{hr}$ heating and 270,000 cfm supply air flow to maintain the indoor design temperature of $74^{\circ} \mathrm{F}$. Major equipment consists of seven air handling units and ten exhaust HEPA filter trains. Air handling units (AHUs) are sized for $45,000 \mathrm{cfm}$ each and are located in the mechanical room on the second floor of the Process Building. Normally, six units are operating and one unit is on standby. The air handling unit consists of roughing filters, high efficiency filters, cooling coil, heating coil and a 60 -hp supply fan motor with variable frequency driver (VFD).

A total of 10 exhaust HEPA filter trains are provided for building exhaust. Normally, nine trains are operating and one train is on standby. Each HEPA filter train contains prefilters, two stages of HEPA filters, a demister, and isolation dampers. Each train is sized for 30,000 cfm capacity using a 6-cell-wide and 5cell-high side-access bag-in/bag-out type filter housing. One exhaust fan is provided for each HEPA filter train and is equipped with a 75-hp fan motor and VFD. Exhaust air flow rate out of the HEPA filter train can be varied by modulating the VFD as necessary to maintain the design negative pressure in the building. A common fire suppression exhaust air plenum with water sprays is provided for the Zone II/III exhaust filter trains. High-efficiency particulate air filter trains are designed for in-place testing of each stage of filters. Any one of the filter trains can be isolated from the rest of the system for testing or filter change. An isokinetic sampling system is provided for stack exhaust effluent monitoring.

Tornado protection damplers, designed to close automatically during tornado conditions, are provided at all the outside air intakes on the exterior walls and exhaust air opening of the building to the exhaust stack.

\section{Conventional HVAC System}

A separate conventional HVAC system serves the ECF and the Administrative Support Building. The system is designed for 135 tons cooling, 1,354,000 Btu/hr heating and $22,000 \mathrm{cfm}$ supply air to maintain the indoor design temperature of $74^{\circ} \mathrm{F}$. The system consists of two $50 \%$ capacity air handling units and two $50 \%$ capacity exhaust fans. Supply air flow rate is based on approximately $1 \mathrm{cfm} / \mathrm{ft}^{2}$ for personnel comfort. The conventional HVAC system is designed to maintain a negative pressure to ensure inflow; however, the pressure is positive with respect to the Zone III areas in the PIP. 


\subsubsection{Safety Support Systems}

The conceptual design of the PIP SSCs did not include a safety analysis in accordance with DOE 5480.23. However, initial estimates of the potential for radioactive consequences were performed to assess broadly whether a single failure criterion, including redundancy and separation, was required for public health and safety. This may be significant for the capital cost estimate because safety-class systems and components must comply with DOE 6430.1A.

Two significant operational accidents were considered in the initial estimate. The first is an explosion, either deflagration or detonation, involving hydrogen. The second is a compartment fire with the potential for radioactive release.

Because the structural and shielding requirements drive the structural design to thick concrete walls, separation between fire areas is assured to preclude fire propagation. In addition, wet-pipe sprinklers proposed in the design minimize the potential for radioactive release from a compartment fire. Finally, the ignition temperature of plutonium metal depends on the specific surface area; the ignition temperature drops drastically as the particle size of plutonium metal decreases (refer to DOE-HDBK-3010-94). With the exception of HYDOX operations, the potential for pyrophoric combustion of plutonium is very low because the ignition temperature is typically significantly higher than the ambient temperature for most operations. Along with inert atmospheres, inert powders will be used to suppress fire inside the primary containment.

\subsubsection{Utility and Process Support Systems}

\section{Argon Recirculation System}

The purpose of the argon purification system is to maintain an inert atmosphere in the HYDOX processing gloveboxes and the sintering furnace gloveboxes. Oxygen, nitrogen, and water vapor content are minimized.

The argon gas purification unit will be a stand-alone, self-contained system located on the second floor above the gloveboxes (e.g., a DriTrain unit). There will be a total of four units with a capacity of $400 \mathrm{cfm}$ each. This is sufficient to maintain the flow velocity of $5 \mathrm{fpm}$, which is slightly larger than the settling velocity of plutonium oxide particulate at the largest cross-sectional area. Two are for the HYDOX operations and two are for the sintering. Each operations purification unit consists of a blower, catalytic oxygen removal unit, regenerable desiccant-type or molecular sieve water drier, nitrogen removal unit, and a HEPA filter. The system includes pressure regulators, alarms, and distribution piping. The purification unit requires vacuum for desiccant drier regeneration, and regeneration gas for oxygen removal.

\section{Nitrogen Recirculation System}

Similar to the argon recirculation system, nitrogen recirculation systems are located on the second floor of the PIP above the gloveboxes. There are eight selfcontained units with a capacity of $400 \mathrm{cfm}$ each to circulate nitrogen in the vault, the conversion and immobilization gloveboxes, and the material transport containment tunnels. This is sufficient to maintain the flow velocity of $5 \mathrm{fpm}$, which 
is slightly larger than the settling velocity of plutonium oxide particulate at the largest cross-sectional area. The purification units consist of a blower, catalytic oxygen removal unit, regenerable desiccant-type or molecular sieve water drier, and a HEPA filter. The system includes pressure regulators, alarms, and distribution piping.

\section{Process Cooling Water System}

The process cooling water system provides deionized water for cooling to process equipment located on the main floor of the PIP. The system is pressurized to prevent spread of contamination.

The process cooling water system consists of a heat exchanger, which rejects heat to the chilled water system; a circulating pump; a small volume reservoir; and discharge filters, piping, and instrumentation. The system design parameters are to be determined.

\section{Chilled Water System}

A chilled water system serves the Process Building, the ECF, and process cooling water system. The system is a closed loop recirculation system designed for primary to secondary distribution. The chilled water system for the PIP facility is sized for 4,000 gpm chilled water supply based on 1,680 tons of cooling load. Major equipment consists of four 450-ton water cooled chillers, four primary pumps, four secondary pumps, an expansion tank, distributing piping, and controls.

\section{Cooling Tower System}

The cooling tower system is the ultimate heat sink for the chilled water system and the process cooling water system.

The cooling tower system consists of four 450-ton cooling towers, a tower basin, four 1,350 gpm circulation pumps, a pH adjustment system, multimedia filter beds for makeup water, a chemical injection package unit (for corrosion inhibitor), controls, instrumentation, and distribution piping.

\section{Fire Suppression System}

The fire suppression system will protect the PIP from compartment fires and minimize the fire damage. It consists of wet-pipe sprinklers, hydrants, and an alarm system that feeds into the central alarm station in the plant central control room.

The actuation temperature and the response time index of the sprinklers are $165^{\circ} \mathrm{F}$ and $300(\mathrm{ft}-\mathrm{s})^{1 / 2}$, respectively. Anticipated fire hazard in the PIP is low; therefore, the sprinkler system is based on the Ordinary Hazard Group 2 requirement in NFPA 13.

In addition, a fire water collection system is provided to collect potentially contaminated water discharged from sprinklers. These tanks are located at elevation $-22 \mathrm{ft}$, one level below the main processing floor. For fires in the primary containment, see Section 6.1.2.5. 


\section{Plant and Instrument Air System}

The plant and instrument air system provides plant air and instrument air to users at the PIP. This system consists of compressors and an air purification system. Two $100 \%$ capacity compressors are proposed to supply the required volume of air; one of these is on standby.

Both compressors are included in package units that include aftercoolers. The air purification system consists of regenerative air dryers, particulate filters, and air receivers. These components are also specified as a package. The compressed air system is split into an instrument air supply and a plant air supply. The plant air supply is subjected to back pressure regulation, which shuts off plant air supply when system pressure falls.

\section{Breathing Air System}

The purpose of the breathing air system is to provide clean, properly humidified air for consumption by personnel while conducting decontamination or maintenance tasks.

Compressed air meeting Compressed Gas Association Grade D breathing air specifications is supplied from breathing air compressors with backup bottled gas.

\section{Potable Water System}

The purpose of the potable water system is to supply cold and hot potable water.

The existing potable water system is extended to the PIP. This water line is split into hot and cold potable water distribution systems. Potable cold and hot water are provided to restrooms, change rooms, the decontamination room, and janitors' fixtures. Potable cold water is provided to the deionized water system. The supply of potable hot water is provided by local electric hot water heaters. All potable water fixtures are fitted with vacuum breakers.

\subsubsection{Instrumentation and Control}

The I\&C system includes all instrumentation and control elements necessary for monitoring and control of the PIP operations. The I\&C design concept is based on an integrated distributed system to provide operators control over the plant from central, local, or field area with high efficiency and reliability.

An I\&C system functional block diagram is shown in Drawing E-2 (Appendix B). The PIP facility systems are monitored and controlled by the following control subsystems, each with a distinct process function:

- MC\&A

- Plutonium conversion

- First-stage immobilization

- Canister loading

- Waste management

- Material handling

- Information management 
- Physical security

- ES\&H

- HVAC and utilities.

\section{Control-Systems Architecture}

The distributed I\&C system is hierarchically configured with a central control level, supervisory control level, local control level, and data acquisition level. A conceptual control-systems architecture illustrating the control and computer configuration of the PIP is shown in Drawing E-203 (Appendix B).

The data acquisition level consists of input/output (I/O) multiplexing modules, field interface devices, and front-end microprocessors to condition process data from field devices and interface control commands to process hardware. The process unit is equipped with a field monitoring station for system development and testing, operational check-out, maintenance, and trouble-shooting.

The local control level at the gloveboxes is comprised of programmable logic controllers (PLCs) and process computers providing local operation of the process and material handling operations. The local control interfaces with the field I/O controllers, performs calculations and logical operations, and accepts and processes commands from supervisory control. It has all necessary computational capability and control algorithms for direct control of process units and is capable of standalone operation in the event of a failure in the data communications network. The process unit is normally controlled by operators from local control panels and consoles in local control rooms that are strategically located throughout the plant.

The supervisory control level at the local control rooms performs overall supervisory functions for the process systems. The supervisory control monitors the process status and material transactions, and provides coordination and issuance of control permissive to local control stations. The supervisory control has the capability to override local control (provided it is enabled by local control). It also performs complex process optimization calculations, alarm reporting, and events logging.

The plant central control level at the main control room performs all top level plant operation functions and provides a centralized data base and storage capability for data distributed to the MC\&A system. The central control has the capability to monitor and override control of process systems, but requires a permissive signal from the local control room. The control stations for the supervisory and central control levels are located in a plant central control room.

The data communications layer of the distributed control system consists of LAN for interconnections among the various process control nodes with each other and with the supervisory level control. For security reasons, the networks are separated into two physically isolated LANs to handle the classified and unclassified data. Resource sharing is permitted within a commonly defined network to provide operation flexibility and redundancy.

The classified LAN extends through each of the plutonium process modules and the material handling systems and connects to the MC\&A system and the management and information system (MIS). The classified system also interfaces to the existing SRS MC\&A system via a security-classified telephone line. The control systems for ES\&H, HVAC, and utilities are connected to a separate unclassified LAN. 
The MC\&A system consists of a high-end computer with mass storage for database management of the overall SNM accountability functions. These functions include SNM measurement data management, transaction validation, assay instrument calibration records, data record auditing, inventory calculations, inventory differences analysis, and safeguards reports generation and dissemination.

The MIS performs top level plant management and information functions to provide production scheduling, data gathering, spare parts inventory, trending, statistical analysis, and report generation. It also serves as a centralized archival facility for supervisory level backup data.

The ES\&H control system provides continuous monitoring functions of the radiation monitoring system, criticality nuclear incident monitoring system, hazardous gas detection, and fire protection system. The plant overall ES\&H status is monitored at a station in the central control room. Some critical alarm signals from the ES\&H system are also hardwired to initiate independent annunciation and safe shutdown of critical equipment.

The facility HVAC, utility, and service system is controlled from a HVAC/utility control station at the utility local control room to handle switching, formatting, and energy management functions. The system normally requires little operator intervention. The status of entire plant HVAC and utilities can also be monitored from a control console in the central control room. Building physical security is controlled and monitored at the security monitoring room with an independent classified computer and surveillance CCTVs.

The control systems include a safety interlock system to maintain a safe operation environment. Interlock signals for every potential hazardous source are interfaced with safety interlock PLCs for independent safety control and protective action.

The control systems also include video cameras for remote surveillance of glovebox operations and automated material handling equipment. The video images are transmitted to the local control rooms for operator monitoring.

\subsubsection{Electrical System}

The electrical system includes feeders from the F-Area electrical system, standby generators and transformers, and motor control centers:

- One $15 \mathrm{kV}$ underground feeder from the 251-F electrical substation, feeding a double-ended unit substation located inside the PIP facility with a normally open tie breaker and two $1500 \mathrm{kVA}, 13.8 \mathrm{kV} / 480 \mathrm{~V}$ transformers, provides the normal power. These transformers have a fan rating of $1995 \mathrm{kVA}$ ( $33 \%$ increase).

- Two standby diesel generators ( $1500 \mathrm{~kW}$ each, $480 \mathrm{~V})$, feeding each bus of the normal switchgear, constitute the standby power. A 10,000 gallon diesel tank is required for storage of the fuel. A day tank for 6 hours of operation for each diesel to satisfy the daily operation needs of the generators shall be provided. 
- One pad-mounted transformer (1500 kVA, $13.8 \mathrm{kV} / 480 \mathrm{~V})$ provides an alternate source of power if both normal and standby sources were to fail. An overhead $13.8 \mathrm{kV}$ feeder from the $251-\mathrm{F}$ area substation feeds the transformer.

Table 6.2 shows the basic electrical system requirements.

Table 6.2 Electrical System Requirements.

\begin{tabular}{ll}
\hline Total connected load & $3,471 \mathrm{~kW}$ \\
Total maximum demand & $2,613 \mathrm{~kW}$ \\
Transformer maximum capacity & $1,995 \mathrm{kVA}$ \\
Diesel generator (each) & $1,500 \mathrm{~kW}$ \\
\hline
\end{tabular}

The electrical distribution is via $480 \mathrm{~V}$ substations; this equipment feeds the motor control centers, distribution panels, and chillers. The chillers will be provided with reduced voltage starters and fed directly from the $480 \mathrm{~V}$ unit substation switchgear.

Equipment sizes were calculated taking into consideration demand and diversity factors. The maximum demand $(2,613 \mathrm{~kW})$ includes the HVAC, lighting, and process loads. The two indoor transformers have a nominal rating of $1500 \mathrm{kVA}$ and fan ratings of $1995 \mathrm{kVA}$.

Motor control centers will distribute power to electrical loads rated at $480 \mathrm{~V}$. Power and lighting panel boards will be fed directly from the $480 \mathrm{~V}$ switchgear or via $480 \mathrm{~V} / 208-120 \mathrm{~V}$ transformers. Numerous transformers and associated panel boards will be provided for convenience receptacles and other small loads.

\subsubsection{Systems Engineering}

Systems engineering encompasses management of the engineering and technical effort required to transform the project objectives into an operational system. A systems analysis program will be implemented in accordance with DOE Order 430.1, Life-Cycle Asset Management, in support of the plant design, construction, and start-up. Systems are broken into distinct functional levels (plant, facility, process, and support service) to allow the systems analysis work elements to proceed in a logical manner. The program will cover the following system analysis tasks and interrelated interfaces based on the plant design requirements:

- Reliability and maintainability assessment to establish system performance requirements (reliability), system operational requirements (availability), and system repair requirements (maintainability)

- Systems modeling and simulation for material transfer system, logistic support, and configuration optimization

- Trade-off analysis of technology options and impact on cost and schedule.

The program will interact with other plant activities-including technology supporting development; design, repair and maintenance operations; safety; and testing - to ensure that problem areas and corrective actions identified by the systems analysis are incorporated into the design and plant operations. The systems analysis results will also be used to develop maintenance programs, equipment redundancy and operation automation requirements, personnel requirements, and operating procedures and training procedures. 


\subsection{Energy Conservation Approaches}

A significant amount of heating and cooling is required for the PIP because of the once-through design. Because corridors and office spaces comprise a large portion (approximately 40\%) of the processing building, a recirculation system should be considered to reduce the significant heating and cooling load requirement. The recirculation system design should comply with provisions in Regulatory Guide 3.12, General Design Guide for Ventilation Systems of Plutonium Processing and Fuel Fabrication Plants. The additional capital cost related to the recirculation system equipment and ductworks should be compared against the operating cost over the 10-year period.

\subsection{Utility Assessment}

During the Title I design, it will be necessary to conduct site-specific condition assessment of the utility systems. Site utility usage plans will need to be reviewed and the condition and age of each system will need to be established. This includes determination of existing loads on and capacities of each system. The design basis at the SRS assumes that some utility services are available and have sufficient spare capacity to support the new PIP. Existing site utilities include electrical power, medium pressure steam and condensate systems, plant and potable water systems, and a sanitary waste water treatment facility. A similar assessment of the communication needs is also to be done during Title I to ensure it has the spare capacity to support the new PIP. Other utilities will also be provided as a part of PIP.

\subsection{Environmental Considerations}

Particulate from the process is contained within the glovebox or retained by filtration systems in the glovebox exhaust system. Off-gases may be treated to remove potential hazardous gases and heat. The management of waste is performed primarily within the facility until waste is packaged for disposition. The minimization of waste in production, combined with the overall facility design to contain potential contamination, will minimize any adverse environmental impact. Provisions have been made to collect potentially contaminated fluids such as fire water or site run-off in order to test for acceptable conditions before release.

Highly reliable effluent monitoring systems provide confidence that the expected low level of environmental impact is realized.

Estimates of emissions and waste generation have been made for the PIP and applicable regulations were reviewed. Major environmental considerations are air quality, water quality waste generation, and pollution prevention.

\subsubsection{Air Quality}

The National Emission Standards for Hazardous Air Pollutants (NESHAP) are applicable to the PIP, specifically regulating emissions of radionuclides to the ambient air. Emissions of radionuclides from DOE facilities are limited so as not to cause any member of the public to receive a dose equivalent of $10 \mathrm{mrem} / \mathrm{yr}$. 
The radionuclide limitation includes all sources at the site and is determined at the site boundary. Absorbed dose to a native aquatic animal organism shall not exceed $1 \mathrm{rad}$ per day.

An application for approval of construction or modification of a facility that contains radionuclides is mandatory. However, a preconstruction approval application can be exempted if the effective dose equivalent (EDE) is less than $0.1 \mathrm{mrem} / \mathrm{yr}$. The application process for preapproval of construction under NESHAP generally takes about 3 to 6 months.

Radionuclide emissions from the PIP have been estimated and are within the 10 mrem/yr dose limit. The radionuclide emissions from the PIP should not cause any deviation from the limit at SRS. Monitoring of radionuclides emissions from the PIP is required.

Other state and local air permits may be required to address carbon monoxide, nitrogen oxide, and sulfur dioxide emissions from the diesel powered standby generators. These permitting activities require that attention be paid to the emission potential of this equipment when it is specified. Since meeting the air quality requirements should not require any unusual pollution control equipment, obtaining the required air permits should be possible within the project schedule.

\subsubsection{Water Quality}

Very small quantities of liquid waste contaminated with radioactivity are expected from the process in the PIP and the analytical laboratory. The process liquid waste quantity is expected to be small and very sporadic and may be evaporated in a glovebox and handled as solid waste. Similarly, radioactive liquids from the analytical laboratory can be solidified.

Sanitary waste water from sinks, toilets, showers, and blowdown from the cooling tower are the major waste water sources from the PIP. These will be handled by existing waste water treatment facilities at the SRS. Releases will not cause private or public drinking water systems downstream from the facility discharge to exceed the 40 CFR 141 radiological drinking water limits.

Liquid releases will be treated by the best achievable technology to the extent that annual average concentrations at the point of discharge to surface waters prior to dilution are less than the 10 CFR 834 DCG values. Liquid releases will not result in the release of settleable solids that exceed 5 picocuries per gram of alpha-emitting radionuclides and 50 picocuries per gram of beta-gamma emitting radionuclides. Release from sanitary sewers will be treated by the best achievable technology to reduce the concentration level to less than the draft 10 CFR 834 DCG values and to not provide a dose to any member of the public in excess of 2 mrem per year.

A National Pollution Discharge Elimination System (NPDES) permit modification may be needed for the waste water. If the existing sanitary waste water treatment plant discharges under an existing NPDES permit, the permit may need to be modified by adding the PIP as a source of waste water to the treatment plant. An application to modify the permit will be submitted at least 180 days before the discharge is intended to commence. 
Best management practices as specified by 40 -CFR-122.2 will be employed to control storm runoff. Site development will address storm water runoff control. A storm water runoff permit will be obtained for the PIP, or the site permit will be modified if there is a site-wide storm water runoff permit.

\subsubsection{Waste Generation}

Minimization of waste generation is a prime consideration during design. The facility provides systems to segregate and collect waste forms and to prepare the wastes for discharge or shipment from the facility. All gaseous, liquid, and solid wastes contaminated (or having potential for contamination) by a radioactive or hazardous material are monitored prior to release. Contaminated materials are transferred from the facility to an approved storage, processing, or disposal facility on or off site that is appropriate for the waste form. The SRS has an extensive, reliable effluent monitoring system in addition to its facility monitoring systems to assure that all releases from the site are maintained within acceptable limits.

Transuranic waste will be generated and handled in accordance with DOE Order 5820.2A, Radioactive Waste Management, and packaged to comply with WSRC Manual 1S, SRS Waste Acceptance Criteria Manual. Section 6.8.4 addresses the appropriate waste handling systems in more depth. Major TRU waste includes worn parts and tools, and used glovebox gloves. Transuranic waste will be assayed at the PIP. Storage of TRU waste is limited to that needed to accumulate a sufficient volume to efficiently ship to other on-site waste management facilities.

Low-level waste will be generated at the PIP and includes general maintenance items from the process area. Low-level waste will be handled in compliance with the requirements of DOE 5820.2A and packaged to comply with SRS criteria. This waste will be assayed and packaged at the PIP. Storage of LLW is limited to that needed to allow an efficient shipment to other on-site waste management facilities.

Very small quantities of hazardous waste and mixed LLW are anticipated from the process in the PIP and analytical laboratory. Handling of hazardous waste in the facility will be limited to accumulation and storage. Accumulation and storage must meet Resource and Conservation Recovery Act (RCRA) regulations. A small accumulation area is anticipated, requiring only notification of the regulatory agency. An RCRA permit is not needed.

\subsubsection{Pollution Prevention}

Pollution prevention is required to be addressed by a number of federal regulations, executive orders, and DOE orders, including RCRA, the Pollution Prevention Act (42 USC et seq. 1310113109), and DOE 5400.1, General Environmental Protection Program. The latter requires that SRS develop a pollution prevention plan. Pollution prevention has already been considered in the design of the baseline technology, resulting in the predicted low emission rates and waste generation rates, and will continue to be considered in subsequent PIP development. Pollution prevention was formally considered in the preliminary environmental impact statement and in the SPD environmental impact statement. A pollution prevention plan covering the PIP will have to be prepared either as a separate plan or as a modification to the site-wide plan. 


\subsubsection{Permits}

A list of permits (including non-environmental, SRS utilization permits) that will, or may, be required by the facility is summarized in Table 6.3.

\subsection{Facility and Equipment Maintenance Considerations}

The PIP Process Building will allow maintenance of both contaminated and noncontaminated equipment. Both a contaminated equipment maintenance room and a non-contaminated maintenance room will provided.

As in the case of contaminated process equipment maintenance, uncontaminated process equipment maintenance will initially be attempted at the location of the equipment.

Maintenance of contaminated process equipment will initially be attempted at the equipment glovebox enclosure. Rooms housing gloveboxes have been provided with both an operating side and a maintenance side. After remote removal of nuclear material from the equipment, maintenance will be performed from the maintenance side of the glovebox by hands-on access using shielded gloves. Equipment that cannot be maintained in the process line will be manually decontaminated, bagged out of the glovebox, and transported to the contaminated equipment maintenance room. This room will be equipped with gloveboxes, hoods, special maintenance tools, and spare parts as required to repair or service failure-prone processes or contaminated laboratory equipment and components. If it is determined that the equipment cannot be repaired, it is sent to the waste management area to be appropriately packaged and disposed of.

Maintenance of material handling and transport equipment within gloveboxes and transport tunnels will be done manually through gloveports or with auxiliary handling equipment. Maintenance and operations personnel will make the decision whether to repair an item in place or move it to a separate shielded maintenance area. Cranes located in radioactive areas, which could potentially become contaminated, will be provided with adjacent but separate crane maintenance areas.

Tools and spare parts as required to maintain small non-contaminated process service and support equipment located outside of glovebox or vault enclosures (e.g., electrical/electronic equipment, building utility piping components, instrumentation, building monitoring equipment, inert gas system equipment) will be provided in the non-contaminated equipment maintenance room. Maintenance of larger utility and building service equipment, such as ventilation fans, chillers, and standby generators, will be done in the auxiliary buildings in which these components are located or at other SRS on-site maintenance facilities.

\subsection{Safety Considerations}

The PIP design will address the requirements of the following federal regulations:

- 10 CFR 830, Nuclear Safety Management 
Table 6.3. Preliminary List of Required Plutonium Immobilization Facility Permits and Plans.

\begin{tabular}{|c|c|c|c|}
\hline Permit/Plan & $\begin{array}{l}\text { Responsible } \\
\text { Organization }\end{array}$ & $\begin{array}{l}\text { Required } \\
\text { Prior to } \\
\text { Start of }\end{array}$ & $\begin{array}{c}\text { Time } \\
\text { Duration } \\
\text { for Approval' }\end{array}$ \\
\hline $\begin{array}{l}\text { Air Quality Protection } \\
\text { SCDHEC Bureau of Air Quality Construction Permit } \\
\text { NESHAP Permit }{ }^{2} \\
\text { NESHAP Alternate Calculation/Exemption }{ }^{2} \\
\text { Title V Pages for Facility }\end{array}$ & $\begin{array}{l}\text { Architect Engineer } \\
\text { Architect Engineer } \\
\text { Integrating Contractor } \\
\text { Architect Engineer }\end{array}$ & $\begin{array}{l}\text { Construction } \\
\text { Procurement } \\
\text { Procurement } \\
\text { Operational } \\
\text { Readiness } \\
\text { Review (ORR) } \\
\text { ORR } \\
\text { ORR }\end{array}$ & $\begin{array}{l}\text { 3-5 Months } \\
\text { 3-7 Months } \\
\text { 3-6 Months }\end{array}$ \\
\hline $\begin{array}{l}\text { Surface Water Protection } \\
\text { NPDES Permit Engineering Report } \\
\text { NPDES Permit Application Form I } \\
\text { NPDES Permit Application Form 2C } \\
\text { Waste Water Engineering Report } \\
\text { SCDHEC Permit to Construct Waste Water System } \\
\text { Construction Stormwater Permit } \\
\text { Pollution Prevention Plan }\end{array}$ & $\begin{array}{l}\text { Architect Engineer } \\
\text { Architect Engineer } \\
\text { Architect Engineer } \\
\text { Architect Engineer } \\
\text { Architect Engineer } \\
\text { Architect Engineer } \\
\text { Architect Engineer }\end{array}$ & $\begin{array}{l}\text { ORR } \\
\text { ORR } \\
\text { ORR } \\
\text { Construction } \\
\text { Construction } \\
\text { Construction } \\
\text { Construction }\end{array}$ & $\begin{array}{l}1-10 \text { Month } \\
1-10 \text { Month } \\
1-10 \text { Month } \\
2-4 \text { Months } \\
2-4 \text { Months } \\
1-2 \text { Month } \\
1-2 \text { Months }\end{array}$ \\
\hline $\begin{array}{l}\text { Stormwater Management } \\
\text { Sediment Reduction Plan } \\
\text { Erosion Control Plan } \\
\text { Dewatering Plan } \\
\text { Spill Prevention and Control Plan (Revision) } \\
\text { Spill Prevention and Control Best } \\
\text { Management Plan (Revision) }\end{array}$ & $\begin{array}{l}\text { Architect Engineer } \\
\text { Architect Engineer } \\
\text { Architect Engineer } \\
\text { Integrating Contractor }\end{array}$ & $\begin{array}{l}\text { Construction } \\
\text { Construction } \\
\text { Construction } \\
\text { ORR } \\
\text { ORR }\end{array}$ & $\begin{array}{l}1-2 \text { Months } \\
1-2 \text { Months } \\
1-2 \text { Months } \\
1 \text { Month } \\
1 \text { Month }\end{array}$ \\
\hline $\begin{array}{l}\text { Groundwater and Drinking Water Protection } \\
\text { Domestic Water Permit Application Package }\end{array}$ & Architect Engineer & Construction & 1-2 Months \\
\hline $\begin{array}{l}\text { Waste Management } \\
\text { RCRA Part B Permit }\end{array}$ & Architect Engineer & Construction & $2-4$ Years \\
\hline $\begin{array}{l}\text { SRS Site Utilization } \\
\text { Site Utilization Permit } \\
\text { Site Clearance Permit } \\
\text { Power Services Utilization Permit - Part A } \\
\text { Power Services Utilization Permit - Part B } \\
\text { Power Services Utilization Permit - Part C } \\
\text { Work Clearance Permit } \\
\text { Health and Safety Plan }\end{array}$ & $\begin{array}{l}\text { Architect Engineer } \\
\text { Construction Agency } \\
\text { Architect Engineer } \\
\text { Architect Engineer } \\
\text { Integrating Contractor } \\
\text { Construction Agency } \\
\text { Construction Agency }\end{array}$ & $\begin{array}{l}\text { Construction } \\
\text { Construction } \\
\text { Construction } \\
\text { Construction } \\
\text { ORR } \\
\text { Construction } \\
\text { Construction }\end{array}$ & $\begin{array}{l}1-2 \text { Months } \\
1-2 \text { Months } \\
1-2 \text { Months } \\
1-2 \text { Months } \\
1-2 \text { Months } \\
1-2 \text { Months } \\
1-2 \text { Months }\end{array}$ \\
\hline $\begin{array}{l}\text { Environmental Data Collection } \\
\text { Environmental Data Collection Plan }\end{array}$ & Integrating Contractor & ORR & $N A^{3}$ \\
\hline
\end{tabular}

Notes:

1. Based on SRS experience.

2. A NESHAP Alternate Calculation/Exemption may be provided instead of a NESHAP Permit. Both are not required.

3. May be required if refrigerants are used by the facility.

4. Assumes utilization of an existing outtall. 
- 10 CFR 835, Occupational Radiation Protection

- 29 CFR 1910, Occupational Safety and Health Standards

- 29 CRF 1926, Safety and Health Regulations for Construction.

In addition, the facility will be designed to allow operation of the facility in compliance with the following WSRC manuals:

- $4 \mathrm{Q}$, Industrial Hygiene Manual

- 5Q, Radiological Control, Article 128

- 8Q, Employee Safety Manual.

\subsection{Safeguards and Security Considerations}

\subsubsection{Physical Security}

The safeguards and security facilities in the PIP will be designed and constructed to the requirements of the following (see Section 6.7.2 for requirements related to materials control and accountability):

- WSRC Manual 7Q, Security Manual

- DOE Order 5632.1C, Protection and Control of Safeguards and Security Interests

- DOE Manual M 5632.1C-1, Manual for Protection and Control of Safeguards and Security Interests.

If a conflict is encountered between any of these and the life-safety code (NFPA$101)$, the life-safety code generally will take precedence. The A/E will notify the Integrating Contractor of all such conflicts, including potential design alternatives, to resolve or mitigate the conflict.

The design and construction of the safeguards and security systems will be treated as classified systems. Thus, the design and construction of these systems in general will be performed by security-cleared ( $Q$-clearance) personnel.

\subsubsection{Material Control and Accountability}

The MC\&A systems in the PIP will be designed and constructed to the requirements of the following:

- WSRC Manual 14Q, Material Control and Accountability

- DOE Order 5633.3B, Control and Accountability of Nuclear Materials.

The MC\&A system will be divided into three material balance areas (APSF, the PIP MAA, and DWPF). The PIP MAA will be divided into two sub-material balance areas: storage areas and processing areas. All areas, including the functional support areas (loading, unloading, accountability measurement areas, etc.) will comply with domestic safeguards requirements. In addition, interim storage areas may contain materials subject to IAEA safeguards inspections.

The MC\&A system will be capable of providing real-time tracking of all SNM and other nuclear materials in the facility such that the contents and the location 
of all containers is well-characterized at any given time. The system will monitor SNM and other nuclear materials receipt through APSF and the south dock, shipments to DWPF in can-in canisters, and the shipment of waste. The system will also be capable of allowing reliable estimates of the "hold-up" in all processing gloveboxes.

Each system in the PIP that is used to track the movements of materials and that has data indicating the quantities of SNM in any location or container will be designed as a classified system.

Portions of the MC\&A system will process classified information.

Classified processors and storage media associated with the distributed control system must be under continuous supervision by appropriate personnel $24 \mathrm{hrs}$ a day or must be installed within a vault type room. Vault type room requirements are specified in DOE Manual M 5632.1C, Chapter 9, Item 1.a.(3).

Installation of the classified equipment will comply with red/black engineering practices as described in the WSRC Manual 7Q, Security Manual and Information Technology Systems, Emissions Control Manual, Part 1, June 1994.

Installation of remote terminals will require the installation of a protected distribution system per the DOE Protected Distribution System Manual, April 1994.

\subsection{Host Site Integration}

A general overview of the external interfaces of the PIP with the SRS infrastructure is depicted in Figure 6.1.

\subsubsection{Process Consumables}

Process consumables will be delivered to the PIP using trucks or piped utilities as appropriate. Commodities procured specifically for the PIP (e.g., clean canisters with internal racks, precursor materials) will be received using commercial carriers at a commodities warehouse provided by the PIP project.

Other commodities that are also used by SRS in general, such as office supplies, general hardware, and sundry electrical supplies, will be received using commercial carriers at the SRS general warehouse facilities in N-Area (central shops). Site trucks will be used to deliver these items to the PIP facilities as requested by the facility.

Liquid process consumables such as process water will be piped to the facility from existing water mains in F-Area. (Refer to Section 6.8.2.)

\subsubsection{Utilities}

\subsubsection{Water Supplies}

The PIP will require domestic water, process well water, and fire water supplies from SRS. Supplies of these waters are not available at the specific location for 
Support

\section{Systems/Organizations}

Administrative
Environmental Monitoring
Transportation
Cafeteria
Training
Health Protection
Security
Fire Station
Receiving/Warehouse
Analytical Laboratories
MC\&A Support Systems
PSAP/Fitness For Duty
Communications
Computer Support
Calibration/Standards
Engineering Services
Laundry
Maintenance

\section{Utility Systems}

\begin{tabular}{l}
\hline Supply Systems \\
\hline Electrical \\
Normal Power \\
Secondary Power \\
Emergency Power \\
Steam \\
Ventilation Supply \\
Water \\
Cooling Water Supply \\
Domestic Water \\
Fire Water
\end{tabular}

\section{Discharge Systems}

Ventilation Exhaust Cooling Water Return

Condensate Return

Fire Water Collection

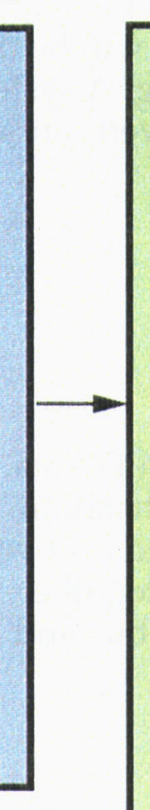

\section{Manufacturing Systems}

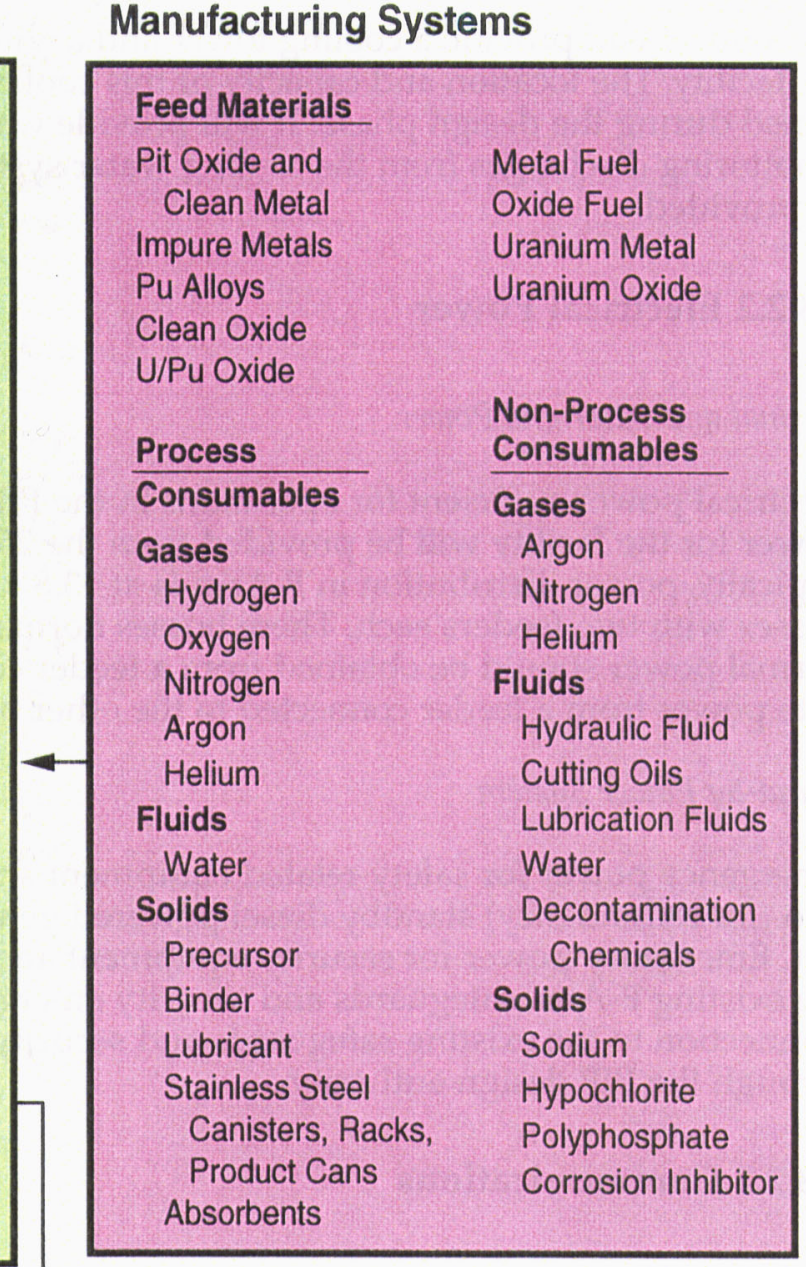

\section{Waste Handling Systems}

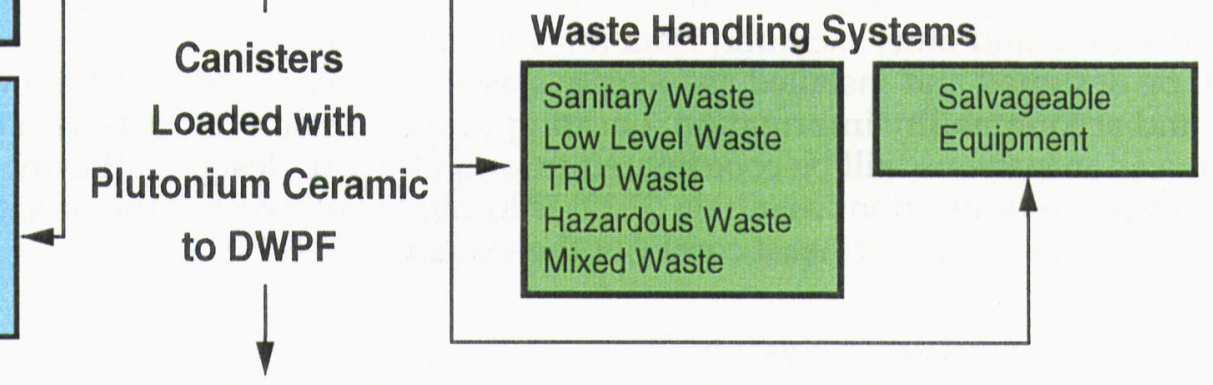

Figure 6.1. Immobilization facility interface diagram.

the proposed facility. However, an adequate supply for all water requirements can be provided for the facility from existing F-Area supply mains. These supply mains will be extended to the facility site by the project. Savannah River Site Site Map 3314, Sheet 14, shows the location of existing water lines in F-Area near the PIP site. Note that the APSF project may relocate or extend some of 
these lines.* The PIP Integrated Contractor will provide additional information during the design phase regarding potential tie-locations for these water supplies.

The project will provide a cooling tower and a chilled water system to support the facility. The location and capacity of this cooling water system will be determined during the design phase. It will provide water return piping. A system for monitoring discharges from the cooling water system to an approved outfall will be provided.

\subsubsection{Electrical Power}

Normal and Alternate Power

Electrical power sufficient for operations in the PIP are available in F-Area. Power for the facility will be provided from the $251-\mathrm{F}$ electrical substation. Typically, power distribution in F-Area is at $13.8 \mathrm{kV}$ and is supplied on two busses with two feeders each. These busses normally are not tied together; thus, normal power should be obtained from a feeder connected to one bus and alternate power from a feeder connected to the other bus.

\section{Stand-by Power System}

Emergency power for safety-related equipment and systems will be supplied by two (for redundancy) standby diesel powered generators provided by the project. Emergency power for security equipment and systems will be supplied by the existing F-Area safeguards and security emergency power system. Connection to the existing safeguards and security system will be coordinated through the PIP design authority.

\subsubsection{Communications}

\section{Telephone and Data Lines}

The PIP will require telephone and computer data line communications with the F-Area, SRS, and other facilities. Data lines connected to the SRS MC\&A system will be designed and installed as security classified lines for transmitting materials and accountability information. Locating the connection to the F-Area communication systems will be coordinated through the PIP design authority. An existing communications manhole (F-22) is located southwest of the proposed facility site near the northeast corner of the existing 235-F PIDAS.*

\subsubsection{Public Address System}

The PIP public address system will be connected to the F-Area public address system.

\footnotetext{
* A conceptual utility plan for the PIP assuming construction of the APSF is shown on drawings C-201 and C-200 in Appendix B, and indicates potential locations for connecting utilities.
} 


\subsubsection{Ventilation}

The ventilation system for the facility will require steam and chilled water.

\subsubsection{Steam}

No steam is currently provided at the specific location for the proposed facility. However, an adequate supply for the facility will be provided from existing FArea steam supply lines and piped to the facility site by the project. Locations of existing steam lines in F-Area are provided on Site Map 3313, Sheets 854 and 884.* The location of the connections to F-Area steam lines will be determined during the design phase and will be coordinated through the PIP design authority.

\subsubsection{Process Cooling Water}

Process cooling water will be provided to the PIP by the project. Construction of support facilities (such as the process cooling water system and heat exchanger with recirculating pump) is included as part of the PIP project scope of work.

\subsubsection{Process Well Water}

Process well water is available in the F Area. Drawing C-201 in Appendix B provides the location of the interface for process well water. No process well water is currently provided at the specific location for the proposed facility. However, an adequate supply for the facility can be provided from the existing F-Area and piped to the facility site by the project.

\subsubsection{Waste Handling Systems}

A variety of wastes are generated in the PIP, as discussed in Section 6.4.3, above.

\subsubsection{Solid Waste}

The SRS has existing waste disposal or long-term storage facilities for handling all waste forms generated by the PIP. Solid wastes will be packaged in appropriate incinerable boxes, drums, or metal B-25-type boxes and shipped by truck from the south loading dock to the site waste disposal or storage facility for the respective waste types.

\subsubsection{Liquid Waste}

The SRS has existing facilities for disposal or storage of all liquid waste forms generated by the PIP. Most liquid transuranic waste generated by the PIP will be from the oxide wash or laboratory waste generated in Building 772-F. The 772-F waste will be handled using existing $772-\mathrm{F}$ procedures. The small quantities of TRU generated in the PIP MAA will be associated with decontamination and will be solidified and disposed of as solid TRU.

\footnotetext{
* A conceptual utility plan for the PIP assuming construction of the APSF is shown on drawings C-201 and C-200 in Appendix B, and indicates potential locations for connecting utilities.
} 
Sanitary liquid waste will be transferred by sewer line to the existing SRS central sanitary waste water treatment facility. Connection to a sewer line can be made in F-Area. Site Map 3309, Sheet 883, provides the location of sanitary sewer lines in F-Area.

Cooling tower blowdown water will have a low potential for contamination and will be drained to a storm sewer connected to an existing NPDES monitored outfall. An existing NPDES outfall is located south of the proposed facility site at site coordinates N78977.0, E55462.0.

Fire water will be collected in the facility and monitored for contamination prior to release. Uncontaminated water will be transferred to an appropriate outfall. Contaminated water will be transferred to a portable tank or drums and shipped to an appropriate existing SRS liquid effluent treatment facility (LETF) for disposal. The PIP Integrating Contractor will identify an LETF for disposal of contaminated water during the design phase.

The ventilation systems will generate steam condensate. The steam condensate will have a low potential for contamination and will therefore be drained to a NPDES-permitted outfall. An existing NPDES outfall is located south of the proposed facility site at site coordinates N78977.0, E55462.0.

\subsubsection{Salvageable Equipment}

Salvageable equipment will be stored in existing SRS warehouses appropriate for clean or contaminated equipment. Contaminated equipment may be transferred to a central decontamination facility located in TNX for decontamination prior to being placed in storage.

\subsubsection{Support Systems and Organizations}

A number of existing SRS systems and organizations will be used to support the operations in the PIP. These systems and organizations include:

- Administrative offices and personnel

- Analytical laboratories

- Cafeteria

- Calibration/standards laboratories

- Computer support

- Site emergency response center

- Site engineering and services

- Environmental monitoring services

- Fire station/emergency medical services

- Health protection services

- Laundry services

- Maintenance shops

- MC\&A site systems

- Personal security assurance program (PSAP)/fitness for duty (security badging, etc.) 
- Site-wide safeguards and security

- Training

- Transportation infrastructure, including the fleet of trucks and cars as well as roads and bridges.

These SRS support systems and organizations currently exist and no major modification or addition to these existing systems/organizations is planned by this project.

\subsubsection{Host Site Integration Assumptions}

The following tables (Tables 6.4 through 6.6) include the site integration assumptions used to prepare the conceptual layout of the facility and to determine the LCC in this document.

\subsection{Conceptual Drawings}

Conceptual design drawings may be found in Appendix B. An index of the drawings is shown on Drawing Number A-201 (Appendix B).

\subsection{Preliminary Equipment List}

The equipment list may be found in Appendix $C$. 
Table 6.4 Integration with Site Utility Systems.

\begin{tabular}{|c|c|}
\hline System & Assumption \\
\hline Normal electrical power & $\begin{array}{l}\text { Electrical service is available at the site and can be } \\
\text { extended to the PIP }\end{array}$ \\
\hline Secondary electrical power & $\begin{array}{l}\text { Secondary power is available at the site and can be } \\
\text { extended to the PIP }\end{array}$ \\
\hline Stand-by power & The PIP will have its own stand-by generators \\
\hline UPS & The PIP has its own UPS \\
\hline Ventilation system & The PIP has its own ventilation system \\
\hline Steam & $\begin{array}{l}\text { The site steam system is adequate and will be extended } \\
\text { to serve the PIP }\end{array}$ \\
\hline Well water & $\begin{array}{l}\text { The site well water is adequate and will be extended to } \\
\text { serve the PIP }\end{array}$ \\
\hline Cooling water & The PIP has its own cooling tower \\
\hline Chilled water & The PIP has its own chilled water system \\
\hline Fire water & $\begin{array}{l}\text { The site fire water system is adequate and is extended } \\
\text { to serve the PIP }\end{array}$ \\
\hline Domestic water & $\begin{array}{l}\text { The site domestic water system is adequate and is } \\
\text { extended to serve the PIP }\end{array}$ \\
\hline Fire water collection & Fire water collection is provided as part of the PIP \\
\hline Water treatment & $\begin{array}{l}\text { Domestic water is treated as required for use in the } \\
\text { cooling tower, building heating system, and laboratory }\end{array}$ \\
\hline Vacuum systems & The PIP has its own process vacuum system \\
\hline Argon system & $\begin{array}{l}\text { The PIP has its own argon storage and distribution } \\
\text { system, which includes recycle of argon }\end{array}$ \\
\hline Nitrogen system & $\begin{array}{l}\text { The PIP has its own nitrogen storage and distribution } \\
\text { system }\end{array}$ \\
\hline Hydrogen system & $\begin{array}{l}\text { The PIP has its own hydrogen storage and distribution } \\
\text { system }\end{array}$ \\
\hline Plant/instrument/breathing air systems & The PIP has its own air systems \\
\hline Spare equipment & $\begin{array}{l}\text { An inventory of critical spare equipment is maintained at } \\
\text { the PIP }\end{array}$ \\
\hline Failed equipment & $\begin{array}{l}\text { Contaminated failed equipment is repaired in a separate } \\
\text { shop located in the PIP or handled as waste in the PIP }\end{array}$ \\
\hline
\end{tabular}


Table 6.5. Integration of Infrastructure Support.

\begin{tabular}{|c|c|}
\hline System & Assumption \\
\hline Fitness for duty programs & The PIP relies on site programs \\
\hline Environmental monitoring & $\begin{array}{l}\text { Site programs provide the overall monitoring program; } \\
\text { release points from the PIP are monitored }\end{array}$ \\
\hline Transportation & $\begin{array}{l}\text { Transportation support is provided by the site; loading } \\
\text { and unloading activities are included in the PIP }\end{array}$ \\
\hline Cafeteria & The site provides cafeteria services \\
\hline Emergency response & $\begin{array}{l}\text { Emergency response is provided by the site; first } \\
\text { response equipment is included in the PIP }\end{array}$ \\
\hline Training & Employee training is provided by the site \\
\hline Health protection & $\begin{array}{l}\text { Dosimetry programs are provided by the site; workplace } \\
\text { monitoring is provided as part of the PIP }\end{array}$ \\
\hline Security & $\begin{array}{l}\text { Guard forces are provided by the site; access control is } \\
\text { provided as part of the PIP }\end{array}$ \\
\hline Fire station & $\begin{array}{l}\text { Fire response crews and equipment are provided by the } \\
\text { site; fire alarm systems, fire protection systems, and fire } \\
\text { extinguishers are provided as part of the PIP }\end{array}$ \\
\hline Receiving/warehouse & $\begin{array}{l}\text { Receiving and warehouse services are provided by the } \\
\text { site; limited (non-nuclear materials) warehousing for } \\
\text { consumables is provided at the PIP }\end{array}$ \\
\hline Medical & $\begin{array}{l}\text { Medical services are provided by the site; first aid } \\
\text { equipment is available in the PIP }\end{array}$ \\
\hline Analytical laboratories & $\begin{array}{l}\text { Analytical laboratories are provided by the site. Samples } \\
\text { are prepared in the PIP and transported to Building } 772-F\end{array}$ \\
\hline MC\&A systems & $\begin{array}{l}\text { The PIP has its own MC\&A system that can } \\
\text { communicate with the site system }\end{array}$ \\
\hline Communications & $\begin{array}{l}\text { The PIP has internal communication systems (phones, } \\
\text { pager, and alarms) that integrate with the site }\end{array}$ \\
\hline Computer support & $\begin{array}{l}\text { The PIP maintains a core competency to maintain } \\
\text { computer systems but relies on the site for major } \\
\text { acquisitions and upgrades }\end{array}$ \\
\hline Calibration/standards & $\begin{array}{l}\text { The PIP maintains a core competency to calibrate } \\
\text { equipment but relies on the site for maintaining the } \\
\text { calibration and standards program }\end{array}$ \\
\hline Engineering services & $\begin{array}{l}\text { The PIP maintains a core competency to follow the } \\
\text { process and maintain the facility but relies on the site for } \\
\text { major design efforts }\end{array}$ \\
\hline Laundry & Laundry is handled by the site external to the PIP \\
\hline Maintenance shop & $\begin{array}{l}\text { The PIP has a maintenance shop for both contaminated } \\
\text { and non-contaminated items; craftsmen and major shop } \\
\text { efforts are provided by the site }\end{array}$ \\
\hline
\end{tabular}


UCRL-ID-131617 Rev.1

PIP-98-115

Table 6.6 Integration of Waste Handling.

\begin{tabular}{ll}
\hline System & Assumption \\
\hline Sanitary waste & $\begin{array}{l}\text { Sanitary waste is handled by the site in existing } \\
\text { facilities }\end{array}$
\end{tabular}

LLW

LLW is assayed, packaged, certified, and accumulated in the PIP, then moved to site waste management facilities for long-term storage and/or disposal

TRU waste

TRU waste is assayed, packaged, certified, and accumulated in the PIP, then moved to site waste management facilities for long-term storage and loading for transport to WIPP; final certification procedures for TRU, including gas testing and gas venting, are done at site waste management facilities

Mixed LLW

Mixed LLW is assayed, packaged, and accumulated in the PIP, then moved to site waste management facilities for long-term storage and/or disposal

Hazardous waste

Hazardous waste is accumulated in the PIP, then moved to site waste management facilities for packaging, long-term storage, and/or disposal 


\section{Project Management and Implementation}

Project Management during the design phase of the project involves establishing a baseline and managing performance of design activities to the baseline. The baseline will have three elements:

- A technical basis, to ensure that the design meets the technical requirements established in the development phase

- A cost basis, to establish cost goals and variance thresholds for each element of the design

- A schedule basis, to establish schedule and milestones for the performance of design activities.

\subsection{Project Management Team and Responsibilities}

The Project Management Team will be responsible for providing the detailed planning, organization, direction, and control for all activities leading to the successful execution of the design activities.

\subsubsection{The DOE Office of Fissile Materials Disposition Project Manager}

The overall responsibility for the project lies with the Director, DOE Office of Fissile Materials Disposition (DOE-MD). The DOE-MD Project Manager designated by the Office Director has overall responsibility for overseeing the preparation of facility design, acting as the main link between the Operations Office and Headquarters, and reporting to the Office Director on project performance. The DOE-MD Project Manager is responsible for defining programmatic requirements of the DOE-MD, ensuring that these requirements are included in the project scope and that the programmatic requirements are satisfied. The Operations Office Project Manager will have the day-to-day oversight responsibility for project activities.

The DOE-MD Project Office, through the Savannah River DOE Project Office, also provides the interface with state, area, and site infrastructure.

\subsubsection{Contracting Officer}

The Contracting Officer (CO) is responsible for procurement, contracting, and contract administration of the A/E contract.

\subsubsection{Contracting Officer's Representative}

The Contracting Officer's Representative (COR) is responsible for providing the necessary liaison between the $\mathrm{A} / \mathrm{E}$ project manager or the construction manager and the $\mathrm{CO}$ on technical, cost, and schedule matters. The COR reviews invoices submitted by the contractor, recommends payments based on performance, conducts inspections and acceptance of performance and deliverables, and recommends corrective actions on any noted deficiencies to the $\mathrm{CO}$. 


\subsubsection{The Project Leader}

The Integrating Contractor is the Management and Operating Contractor for the Savannah River Site. The Integrating Contractor Project Leader will have the responsibility of directing the successful execution of the project as defined in the project baseline.

The Project Leader has the responsibility to provide site infrastructure and site interface information necessary to integrate the new plant design effort and manages the operator training, turnover, commissioning, and startup for continuous operation of the facility.

\subsubsection{Architect/Engineer Project Manager}

The A/E Project Manager manages the A/E design and engineering team responsible for preliminary and detailed design of the facility, process equipment, and process support equipment for the $\bar{P} \overline{\mathrm{P}}$ and associated interfaces with supporting facilities.

\subsubsection{Construction Manager}

The Construction Manager manages the field work, equipment installation and fabrication, and turnover operations of the PIP.

\subsubsection{Laboratory Technical Leader}

Lawrence Livermore National Laboratory is the lead laboratory responsible for providing expert advise and guidance on the compliance with the technical, functional, and environment, safety, and health requirements of the plutonium conversion and immobilization processes to the DOE-MD Project Manager.

\subsection{Project Management System}

A project management system will be developed that is in compliance with DOE Order 430.1 based on the risk assessed in the performance of design activities. Elements of the system include technical, cost, and schedule controls graded to the assessed risk of each of these elements during the design phase. AWBS will be used for the definition of work elements containing individual work scope, cost, and schedule units for planning and performance measurement.

\subsubsection{Work Scope and Technical Baseline Management}

A system engineering process will be used to develop and approve tasks/work packages to meet technical objectives. Change control for work scope will be managed by the project team and reviewed by a change control board. 


\subsubsection{Cost Control}

Cost controls will involve the development of individual WBS elements or task budgets and the preparation of cost management reports detailing planned costs for each element. Actual costs reported by the A/E in each element will be reviewed based on an earned value system or an appropriate and equivalent assessment of work performed in terms of deliverables and completion milestones.

\subsubsection{Schedule Control}

Schedules for the accomplishment of design milestones and deliverable products will be established in each design WBS element. Activity progress will be assessed for each milestone/product based on completion or a percentage completion of the activity progress.

\subsection{Project Execution}

During the conceptual phase, the program office, using a graded approach, will ensure development of the initial project execution plan (PEP). The initial planning shall include the information identified in the Joint Program Office Direction on Project Management, a companion document to DOE Order 430.1. Over the course of the project, the PEP will be updated.

\subsection{Procurement Strategy}

It is anticipated that the engineering and design procurement will be a costplus contract awarded on the basis of best evaluated qualifications and cost. However, DOE reserves the option of awarding a fixed price contract.

It is anticipated that the construction procurement will be a fixed price contract awarded on the basis of competitive bidding.

\subsection{Risk Assessment}

A preliminary technical risk assessment and a preliminary hazard analysis have been prepared for the PIP. The risk assessment was prepared as part of the technical evaluation in support of the down selection of immobilization alternatives. The risk assessment identified issues to be resolved but found no technical problems that presented major concern for the technical viability of the PIP's deployment. The results of the risk assessment may be found in the Technical Evaluation Panel Summary Report: Ceramic and Glass Immobilization Options (UCRL-ID-129315).

The hazards analysis was prepared for the EIS data call, which was updated for this DOCDR. The hazards analysis also did not identified any probable concerns, accident scenarios, or design issues which might cause unsafe operation of the PIP.

There may be some risks associated with the procurement of gloveboxes that may impact the successful deployment of the PIP. Initial discussions with glovebox fabricators have indicated that if all three plutonium disposition facilities go forwand 
in roughly the same time frame, fabricating capacity may be exceeded. Careful planning, scheduling, and budgeting providing the longest lead time possible may be required to successfully deploy these initiatives.

\subsection{Quality Assurance}

All SSCs provided by this project with a safety classification of "Safety-Class" or "Safety-Significant" or with a Functional Performance Classification of PC-3 shall be designed and procured under a quality assurance program that conforms to the DOE-MD Quality Assurance Requirements Document (QARD), January, 1999.

The QARD incorporates and amplifies DOE 0414.1, Quality Assurance, and10CFR 830.120, Quality Assurance Requirements, as the fundamental QA standards for the program. In some situations, basic criteria and supplementary requirements will be adopted from the latest revisions of the following:

- DOE/RW-0333P, Office of Civilian Radioactive Waste Management (OCRWM) Quality Assurance Requirements and Description

- ASME NQA-1-1997, Quality Assurance Requirements for Nuclear Facility Applications

The QARD clarifies and augments the regulatory requirements of the DOE/RW0333P. Each participating organization will develop a QA plan, implementing procedures, and a cross reference matrix of requirements and implementing procedures.

Systems, structures, and components with a safety classification of "Production Support" or "General Service" or with a functional classification of PC-1 or PC-2 will be designed and procured to commercial-type practices with the following additional provisions. The A/E shall specify functional and quality requirements for specific items or services based on their importance to operation in the facility (e.g., CAMs, ventilation exhaust flow monitors, process control computer codes). The A/E shall also verify compliance with these requirements for all subcontracted services and procurements.

\subsection{Work Breakdown Structure}

Figure 7.1 is the proposed DOCDR WBS for the PIP. It is to be integrated with the other disposition projects, the MOX Fuel Fabrication Facility (MFFF), and the Pit Disassembly and Conversion Facility (PDCF). Accordingly, the Level 1 tasks are PDCF, MFFF, and the PIP.

Level 2 tasks similarly include:

- Project Management - Site management and operations (M\&O) contractor who has overall responsibility for defining and managing subcontracts for the engineering and design, procurement, and construction. Project management will provide design and budget for D\&D activities. 


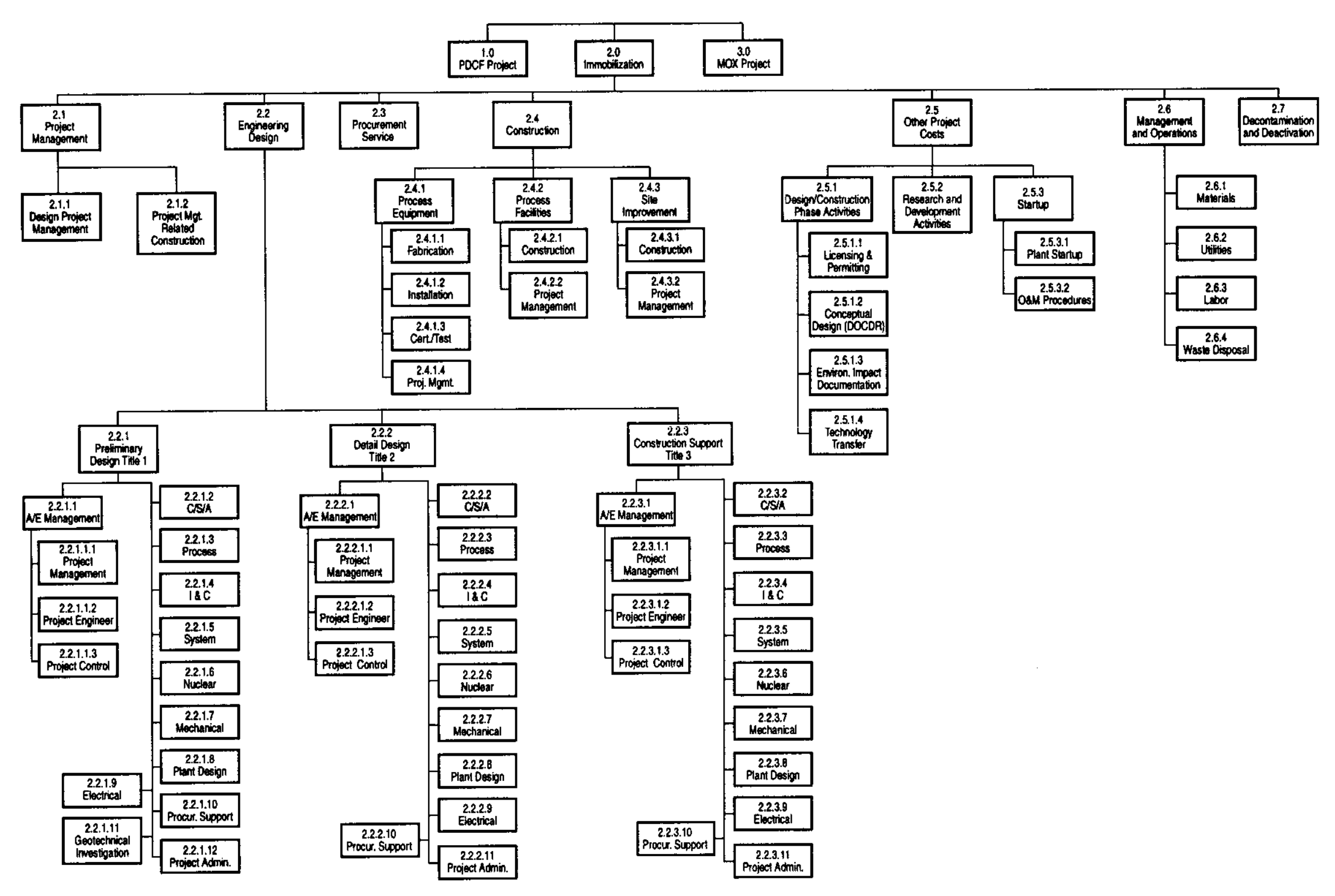


- Engineering Design - A/E subcontractor for the facility design and construction support (Titles I, II, \& III).

- Procurement - Procurement of special facilities equipment.

- Construction.

- Other project costs - Design/construction phase activities, research and development activities and start-up activities.

- Management and Operations.

- Decontamination and Deactivation.

Level 3 tasks include:

- Preliminary Design (Title I) - includes A/E project management and control; preliminary civil/structural/architectural process; instrumentation and control; systems; nuclear; mechanical; plant design; and electrical design of systems, structures and components; support for early procurements; geotechnical investigations; and administration.

- Detailed Design (Title II) - includes A/E management, control, and administration; the detailed design of process facilities, process equipment, and site improvements and support facilities from all disciplines; and procurement support.

- Construction Support (Title III) - includes engineering support during construction. 


\section{Schedule Basis}

\subsection{Engineering Schedule}

The project engineering schedule is based on the labor estimate required for specific activity durations. The schedule covers the period from the start of Preliminary Design (Title I), through Detailed Design (Title II), and ends with the completion of Construction Support (Title III), which coincides with the end of construction. The schedule is presented with major DOE milestones and permitting and licensing activities.

\subsection{Construction Schedule}

The construction schedule is a preliminary view of the major construction activities and sequences for the PIP baseline case. The construction schedule is integrated with the engineering schedule and procurement activities. It starts with mobilization and ends with system turnover and pre-startup activities.

The integrated engineering and construction schedule is provided in Appendix D. 
UCRL-ID-131617 Rev. 1

PIP-98-115 


\section{Engineering and Life-Cycle Cost Summary}

This section provides an estimate of the engineering costs and a rough order of magnitude LCC for the Immobilization Project for a new aboveground facility at SRS.

\subsection{Engineering Estimate}

The engineering and design costs for Title I and Title II are based on a bottomsup conceptual design estimate. A breakdown of the engineering costs are shown in Table 9.1. Appendix E (Tables E.1 and E.2) provides the summary estimate. Title III, engineering support for construction, is found in Section 9.2 and Appendix F as part of the LCC estimate. The engineering estimate is developed by identifying the specific time frame, required staffing, and related engineering salary levels for each engineering phase (i.e., for Titles I and II). Other direct costs (ODCs) are included for each work discipline and were calculated based on labor hours using in-house historical data for similar DOE projects. These include office supplies and miscellaneous material, computer, and automation costs. The costs of business travel are also included for each work discipline for each engineering phase. The cost of geotechnical investigation was provided by WSRC (NMP-PLS-980058, May 19, 1998). It is assumed that all personnel will be from local resources.

Table 9.1. Engineering Cost and Contingency (in first quarter FY00 dollars).

\begin{tabular}{|c|c|c|c|}
\hline Description & $\begin{array}{l}\text { Estimated Cost } \\
(\$ K)\end{array}$ & $\begin{array}{c}\text { Contingency } \\
(\$ \mathrm{~K})\end{array}$ & $\begin{array}{c}\text { Total Cost } \\
(\$ K)\end{array}$ \\
\hline $\begin{array}{l}\text { AVE Design Phase Cost: } \\
\text { Preliminary Design, Title I } \\
\text { Detailed Design, Title II } \\
\text { Project Management, Design Phase } \\
\text { Total Estimated AE Design Cost }\end{array}$ & $\begin{array}{r}10,974 \\
34,821 \\
\mathbf{9 . 9 0 9} \\
\mathbf{5 5 , 7 0 4}\end{array}$ & $\begin{array}{r}2,754 \\
8,740 \\
2.487 \\
13,981\end{array}$ & $\begin{array}{l}13,728 \\
43,561 \\
12,396 \\
69,685\end{array}$ \\
\hline
\end{tabular}

Title I engineering is based on a 12-month schedule from October 1999 to September 2000 . It was developed and summarized by management functions and engineering discipline (e.g., architect/engineer $(A / E)$ management; civil/structural/architectural (C/S/A) design; process design, instrument and control; systems engineering; nuclear, mechanical, plant design/layout; geotechnical investigations; and electrical design).

Title II engineering is based on a 24-month schedule from October 2000 to September 2002. It was developed and summarized by management functions and engineering discipline (e.g., A/E management; C/S/A design; process design, instrument and control; systems engineering; nuclear, mechanical, plant design/layout; electrical design; and project administation). 


\subsubsection{General Assumptions}

The following general assumptions have been made:

- This is a bottoms-up, budget/conceptual design estimate based on management and graduated engineering manpower, deliverables, studies, tasks, meetings, and personnel travel.

- All engineering design costs are based on first quarter FY00 dollars. Cost of escalation beyond first quarter of FY00 is excluded.

- All engineering documentation quantities are determined from new design parameters and new facility layouts.

- A/E engineering includes costs for facility design, glovebox system integration engineering, glovebox installation procedures, and procurement support.

- Glovebox fabrication design and shop drawings are considered as part of vendor cost in glovebox procurement and are not included in $\mathrm{A} / \mathrm{E}$ design cost.

- Special process equipment design, and robotics, software and unit controls are assumed to be designed by LLNL and SRS. Implementation of these systems with associated facility control is by the A/E.

- Nuclear design basis is assumed to be completed by LLNL and SRS and implemented by the $\mathrm{A} / \mathrm{E}$.

- Costs are based on the schedule in Appendix D.

- Engineering and design will be executed by an A/E firm under a separate subcontract to the DOE.

\subsubsection{Exclusions}

The following costs are not included:

- DOE program management

- A/E employee site relocation expenses

- Escalation beyond first quarter of FYD0.

\subsubsection{Engineering Cost Contingency}

The risk analysis program used to evaluate the contingency for this project is BecRAC, a Bechtel proprietary computer program that uses Monte-Carlo-based methodology combined with technical judgement to evaluate the collective uncertainty of the engineering and design variables associated with each cost element in the cost estimate.

The contingency analysis result for the engineering cost is shown in Table 9.2. A $25.1 \%$ contingency is incorporated into the engineering cost estimate. This contingency factor is based on a 30\% probability of overrun, which is typically used for a project at this level of the design. The engineering and design contingency is computed on all phases of the engineering effort, including Title III.

\subsection{Life-Cycle Costs}

This section presents the rough order of magnitude LCC of the PIP. All costs are expressed in first quarter FY00 dollars. This estimate is based on the design for a 50 MT aboveground PIP at a new site at Savannah River. Management and operations costs based on 18.2 MT throughput are also included. The cost scope 
Table 9.2. Design Phase Engineering Design Cost Estimate Summary

(Title I and Title II, in the 1st Q/FYO0 dollars

\begin{tabular}{|c|c|c|c|c|c|}
\hline & & Title I & Title II & $\begin{array}{c}\text { Contingency } \\
25.1 \% \\
\end{array}$ & TOTAL \\
\hline 2.2 & \multirow{2}{*}{$\begin{array}{l}\text { A/E Project Engineering Management } \\
\text { Project Management } \\
\text { Project Engineering } \\
\text { Project Controls } \\
\text { A/E Engineering } \\
\text { C/S/A } \\
\text { Process } \\
\text { Electrical//\&C } \\
\text { Systems Engineering } \\
\text { Nuclear } \\
\text { Mechanical/Plant Design } \\
\text { Procurement Support } \\
\text { Geotechnical Investigation } \\
\text { Project Admin. }\end{array}$} & $\begin{array}{l}537,331 \\
981,471 \\
831,958\end{array}$ & $\begin{array}{l}1,913,479 \\
3,200,843 \\
2,444,311\end{array}$ & & $\begin{array}{l}2,450,810 \\
4,182,314 \\
3,276,269\end{array}$ \\
\hline \multirow[t]{4}{*}{2.2} & & $\begin{array}{r}2,350,760 \\
1,218,573 \\
954,528 \\
1,223,323 \\
1,672,530 \\
626,897 \\
3,263,031 \\
773,982 \\
519,000 \\
721,647\end{array}$ & $\begin{array}{r}7,558,633 \\
4,764,867 \\
1,067,192 \\
8,985,319 \\
304,230 \\
1,572,592 \\
12,090,487 \\
3,696,451 \\
2,339,587\end{array}$ & $2,487,258$ & $\begin{array}{r}12,396,651 \\
5,983,440 \\
2,021,720 \\
10,208,642 \\
1,976,760 \\
2,199,489 \\
15,353,518 \\
4,470,433 \\
519,000 \\
3,061,234\end{array}$ \\
\hline & Subtotal & $10,973,511 \mid$ & $34,820,725$ & $11,494,353$ & $57,288,589$ \\
\hline & TOTAL & $13,324,271$ & $42,379,358$ & $13,981,611$ & $69,685,240$ \\
\hline & & & \multicolumn{2}{|c|}{ A/E Design Phase Grand Total } & $69,685,240$ \\
\hline
\end{tabular}


presents the LCC developed for a 10-year operating period. The LCC includes the Integrating Contractor project management cost; the engineering and design costs for Titles I, II, and III; the cost for procurement services provided to the project, the construction captial cost; the M\&O (management and operation) cost; and D\&D (decontamination and deactivation) cost.

The work breakdown structure developed for the PIP is used as the basis for the LCC estimate. A cost breakdown of the LCC is shown in Table 9.3. Appendix F provides the LCC estimate and basis.

The costs for integration project management are built up from SRS wage rates and an assumed staffing level.

The other project cost (OPC) is composed of costs for design/construction phase support activities, research and development activities, and start-up support activities.

The Title I and Title II engineering and design includes the preliminary and detailed design during the design phase. The basis of engineering and design costs for Title I and Title II has been described in Section 9.1. Title III engineering includes the field engineering support during the construction. Title III engineering design cost is based on a 30-month schedule from October 2002 to March 2005. It was developed and summarized by management functions and engineering disciplines (e.g., A/E management; C/S/A design; process design, instrument, and control; systems engineering; nuclear, mechanical, plant design/layout; electrical design; and project administration). 
Table 9.3. Life Cycle Cost and Contingency for Aboveground Facility (in 1st Quarter FYOO dollars).

\begin{tabular}{|c|c|c|c|c|c|}
\hline WBS No. & Discipline & $\begin{array}{l}\text { Estimated } \\
(\$ K)\end{array}$ & $\begin{array}{l}\text { Contingency } \\
(\text { (SK) }\end{array}$ & $\begin{array}{c}50 \mathrm{MT} \\
\text { TotalCost } \\
(\$ \mathrm{~K})\end{array}$ & $\begin{array}{l}18.2 \mathrm{MT}^{\star *} \\
\text { Total Cost } \\
\text { (SK) }\end{array}$ \\
\hline 2.1 & $\begin{array}{l}\text { Integrating Contractor } \\
\text { Project Management }\end{array}$ & 11,333 & 2,845 & 14,178 & 14,178 \\
\hline 2.2 & Engineering Design* & & & & \\
\hline 2.2 .1 & Preliminary Design (Title I) & 13,324 & 3,344 & 16,668 & 16,668 \\
\hline 2.2 .2 & Detailed Design (Title II) & 42,380 & 10,637 & 53,017 & 53,017 \\
\hline \multirow[t]{2}{*}{2.2 .3} & Construction Support (Title III) & 11,672 & 2,930 & 14,602 & 14,602 \\
\hline & Subtotal 2.2 & 67,376 & 16,911 & 84,287 & 84,287 \\
\hline 2.3 & Procurement Service ${ }^{\star \star}$ & 0 & 0 & 0 & \\
\hline 2.4 & Construction & & & & \\
\hline 2.4 .1 & Process Equipment & 150,935 & 51,469 & 202,404 & 202,404 \\
\hline 2.4 .2 & Process Facilities & 136,640 & 46,594 & 183,234 & 183,234 \\
\hline \multirow[t]{2}{*}{2.4 .3} & Site Improvements & 46,992 & 16,024 & 63,016 & 63,016 \\
\hline & Subtotal 2.4 & 334,567 & 114,087 & 448,654 & 448,654 \\
\hline 2.5 & Other Project Costs & & & & \\
\hline 2.5 .1 & Design/Construction Activities & & & & \\
\hline 2.5.1.1 & Licensing \& Permitting & 4,474 & 929 & 5,403 & 5,403 \\
\hline 2.5.1.2 & Conceptual Design (DOCDR) & 1,915 & 0 & 1,915 & 1,915 \\
\hline \multirow[t]{2}{*}{2.5 .1 .3} & Environmental Impact & & & & \\
\hline & Documentation (NEPA) & 662 & 0 & 662 & 662 \\
\hline \multirow[t]{2}{*}{ 2.5.1.4 } & Technology Transfer & 10,022 & 2,515 & 12,537 & 12,537 \\
\hline & Subtotal 2.5.1 & 17,073 & 3,444 & 20,517 & 20,517 \\
\hline 2.5 .2 & Research \& Development & 177,987 & 0 & 177,987 & 177,987 \\
\hline 2.5 .3 & Startup & & & & \\
\hline 2.5.3.1 & Plant Startup & 37,238 & 0 & 37,238 & 35,629 \\
\hline \multirow[t]{3}{*}{ 2.5.3.2 } & O\&M Procedures & 1,386 & 348 & 1,734 & 1,734 \\
\hline & Subtotal 2.5.3 & 38,684 & 348 & 38,972 & 37,363 \\
\hline & Subtotal 2.5 & 233,684 & 3,792 & 237,476 & 235,867 \\
\hline 2.6 & Management and Operations & & & & \\
\hline 2.6 .1 & Materials & 102,513 & 0 & 102,513 & 52,186 \\
\hline 2.6 .2 & Utilities & 16,009 & 0 & 16,009 & 16,009 \\
\hline 2.6 .3 & Labor & 310,316 & 0 & 310,316 & 296,906 \\
\hline \multirow[t]{2}{*}{2.6 .4} & Waste Disposal & 33,392 & 0 & 33,392 & 26,944 \\
\hline & Subtotal 2.6 & 462,230 & 0 & 462,230 & 392,045 \\
\hline \multirow[t]{2}{*}{2.7} & Decontamination and Deactivation & 33,457 & 11,409 & 44,865 & 44,865 \\
\hline & Total Life Cycle & $1,142,647$ & 149,043 & $1,291,690$ & $1,219,896$ \\
\hline
\end{tabular}

"Includes Title I and Title II A/E engineering management.

**Support to Procurement Services (\$7.3 million with contingency) is included in Engineering Design, WBS 2.2. **18.2 MT case is based on the same operating assumptions as the $50 \mathrm{MT}$ case but with reduced throughput. 
UCRL-ID-131617 Rev. 1

PIP-98-1 15 


\section{References}

Baxter, R.G. (1986), "Design and Construction of the Defense Waste Processing Facility Project at the Savannah River Plant," Waste Management '86, vol. 2, High Level Waste, p. 449.

Boersma, M.D. (1984), "Process Technology for the Vitrification of Defense High Level Waste at the Savannah River Plant," Am. Nucl. Soc.-Fuel Reprocessing and Waste Management Proc. 1, pp. 131-147.

Calculation Number N-CLC-G00053, Neutron and Gamma Source Terms for Plutonium Ceramic Batches (U) May 20, 1997.

Department of Energy (1982), Environmental Assessment-Waste Form Selection for SRP High Level Waste, U.S Department of Energy, Washington, DC, DOE/EA-0179.

Department of Energy (1996), Criteria for Preparing and Packaging Plutonium Metals and Oxides for Long-Term Storage, U.S. Department of Energy, Washington, DC, DOE STD-3013-96.

Department of Energy (December 1996), Storage and Disposition of Weapons-Usable Fissile Materials Programmatic Environmental Statement, U.S. Department of Energy, Washington, DC, DOE/EIS-0229.

Federal Register, "Record of Decision for the Storage and Disposition of Weapons."

Lawrence Livermore National Laboratory (December 1997), Fissile Materials Disposition Program, Preliminary Cost Estimate for Immobilization of $50 \mathrm{MT}$ of Plutonium Using New Facilities at the Savannah River Site: Alternative 12A, Preliminary Draft, Lawrence Livermore National Laboratory, Livermore, CA.

Lawrence Livermore National Laboratory (June 1998), Plutonium Immobilization Plant Using Ceramic in Existing Facility at Hanford, Lawrence Livermore National Laboratory, Livermore, CA, UCRL-ID-128275.

Lawrence Livermore National Laboratory (June 1998), Plutonium Immobilization Plant Using Ceramic in Existing Facilities at the Savannah River Site, Lawrence Livermore National Laboratory, Livermore, CA, UCRL-ID128274.

Lawrence Livermore National Laboratory (June 1998), Plutonium Immobilization Plant Using Ceramic in New Facilities at the Savannah River Site, Lawrence Livermore National Laboratory, Livermore, CA, UCRL-ID-128273.

Lawrence Livermore National Laboratory (June 1998), Plutonium Immobilization Plant Using Glass in Existing Facilities at Hanford, Lawrence Livermore National Laboratory, Livermore, CA, UCRL-ID-128276. 
Lawrence Livermore National Laboratory (June 1998), Plutonium Immobilization Plant Using Glass in Existing Facilities at the Savannah River Site, Lawrence Livermore National Laboratory, Livermore, CA, UCRL-ID-128272.

Lawrence Livermore National Laboratory (June 1998), Plutonium Immobilization Plant Using Glass in New Facilities at the Savannah River Site, Lawrence Livermore National Laboratory, Livermore, CA, UCRL-ID-128271.

Lawrence Livermore National Laboratory (July 1998), Integrated Development and Testing Plan for Plutonium Immobilization Plan, Lawrence Livermore National Laboratory, Livermore, CA, PIP-98-064.

Maher, R., L.F. Shafranek, J.A. Kelley, and R.W. Zeyfang (1981), "Solidification of the Savannah River Plant High Level Waste," Am. Nucl. Soc. Trans. 39, 228.

Specification for procurement of DWPF canisters, Procurement Specification Number OPS-DTE-910008, Revision Number 4, November 7, 1992.

Westinghouse Savannah River Company (April 1997), Remote Can-In-Canister Loading Operations, Westinghouse Savannah River Company, Aiken, SC, NMP-PLS-970034.

Westinghouse Savannah River Company (1998), Preconceptual Study of HVAC Requirements for the Plutonium Immobilization Plant Design-Only Conceptual Design Report, Westinghouse Savannah River Company, Aiken, SC, NMPPLS-980047.

Westinghouse Savannah River Company (1998), Preconceptual Study of Analytical Laboratory Requirements for the Plutonium Immobilization Plant Design-Only Conceptual Design Report, Westinghouse Savannah River Company, Aiken, SC, NMP-PLS-980052.

Westinghouse Savannah River Company (1998), Preconceptual Study of Computer System Requirements for the Plutonium Immobilization Plant Design-Only Conceptual Design Report, Westinghouse Savannah River Company, Aiken, SC, NMP-PLS-980048.

Westinghouse Savannah River Company (1998), Preconceptual Study of Electrical Requirements for the Plutonium Immobilization Plant Design-Only Conceptual Design Report, Westinghouse Savannah River Company, Aiken, SC, NMPPLS-980049.

Westinghouse Savannah River Company (1998), Preconceptual Study of Fire Protection and Life Safety Requirements for the Plutonium Immobilization Plant Design-Only Conceptual Design Report, Westinghouse Savannah River Company, Aiken, SC, NMP-PLS-980051.

Westinghouse Savannah River Company (1998), Preconceptual Study of Geotechnical Requirements for the Plutonium Immobilization Plant DesignOnly Conceptual Design Report, Westinghouse Savannah River Company, Aiken, SC, NMP-PLS-980054. 
Westinghouse Savannah River Company (1998), Preconceptual Study of Radiological Control and Criticality Requirements for the Plutonium Immobilization Plant Design-Only Conceptual Design Report, Westinghouse Savannah River Company, Aiken, SC, NMP-PLS-980056.

Westinghouse Savannah River Company (1998), Preconceptual Study of Safeguards and Security Requirements for the Plutonium Immobilization Plant DesignOnly Conceptual Design Report, Westinghouse Savannah River Company, Aiken, SC, NMP-PLS-980055.

Westinghouse Savannah River Company (1998), Preconceptual Study of Structural Requirements for the Plutonium Immobilization Plant Design-Only Conceptual Design Report, Westinghouse Savannah River Company, Aiken, SC, NMPPLS-980053. 


\section{Appendix A \\ Major Codes, Orders, Standards, and Regulations}

The following list is a compilation of only the major governing codes, orders, standards, and regulations. Standard building codes and accepted industry standards that are imposed by the applicable DOE orders are not referenced here. Additionally, both the old and new series DOE orders are listed because the SRS has not fully moved to implementing the requirements of the new series orders and the old series orders are still listed as current by DOE.

The PIP is to be designed and constructed NRC licensing standards. The DOE and the NRC are currently reviewing how and which NRC regulations will apply to DOE facilities.

10 CFR 20

10 CFR 70

10 CFR 71

10 CFR 74

10 CFR 75

10 CFR 710

10 CFR 820

10 CFR 830

10 CFR 834 (Draft)

10 CFR 835

10 CFR 1021

29 CFR 1910

29 CFR 1926

40 CFR 60

40 CFR 61

40 CFR 101

40 CFR 110-122

40 CFR 125

40 CFR 136

40 CFR 141

40 CFR 142
Standards for Protection Against Radiation

Domestic Licensing of Special Nuclear Materials

Packaging and Transportation of Radioactive Material

Material Control and Accounting of Special Nuclear Material

Safeguards on Nuclear Material: Implementation of US/IAEA Agreement

Criteria and Procedures for Determining Eligibility for Access to Classified Matter or Special Nuclear Materials

Procedural Rules for DOE Nuclear Activities

Nuclear Safety Management

Radiation Protection for the Public and Environment: Proposed Rules

Occupational Radiation Protection

National Environmental Policy Act Implementation

Occupational Safety and Health Act: Operations

Occupational Safety and Health Act: Construction

Standards for Performance for New Stationary Sources

National Emission Standards for Hazardous Air Pollutants

Federal Property Management Regulations

EPA Administered Permit Programs: The National Pollution Discharge Elimination System

Criteria and Standards for NPDES (National Pollutant

Discharge Elimination System)

Guidelines for Establishing Test Procedures for the Analysis of Pollutants

National Primary Drinking Water Regulations

National Primary Drinking Water Regulations

Implementation 
40 CFR 191

DOE O 420.1, Chg. 2

DOE O 430.1

DOE O 430.2

DOE O 440.1

DOE O 451.1 A

DOE O $460.1 \mathrm{~A}$

DOE O 460.2, Chg. 1

DOE O470.1

DOE O 471.2A

DOE O 472.1 B

DOE-1270.2B

DOE-1300.2A

DOE-1360.2B

DOE-1324.2B

DOE-1540.2

DOE- 1540.3A

DOE-4700.1

DOE-5300.4D

DOE-5400.1

DOE-5400.5

DOE-5440.1E

DOE 5480.1B

DOE-5480.3

DOE-5481.1B

DOE-5483.1A

DOE-5484.1

DOE-5500.1B

DOE-5500.2B
Environmental Radiation Protection Health Reporting

Facility Safety

Life Cycle Asset Management

In-House Energy Management

Worker Protection Management for DOE Federal and Contractor Employees

National Environmental Policy Act Compliance Program

Packaging and Transportation Safety

Department Material Transportation and Packaging Management

Safeguards and Security Program

Information Security Program

Personnel Security Activities

Safeguards Agreement with the International Atomic Energy Agency

Department of Energy Technical Standards Program

Unclassified Computer Security Program

Records Management

Hazardous Material Packaging for Transport-Administrative Procedures

Base Technology for Radioactive Material Transportation Packaging Systems

Project Management Systems

Telecommunications: Protected Distribution System

General Environmental Protection Program

Radiation Protection of the Public and Environment

National Environmental Policy Act Compliance Program

Environmental, Safety, and Health Program for DOE Operations

Safety Requirements for the Packaging and Transportation of Hazardous Materials, Hazardous Hazards Mitigation

Safety Analysis and Review System

Occupational Safety and Health Program for Department of Energy Contractor Employees at Government-Owned, Contractor-Operated Facilities

Environmental Protection Safety and Health Protection Information Reporting Requirements

Emergency Management System

Emergency Categories, Classes, and Notification and Reporting Requirements 
DOE-5500.3A

DOE-5500.4A

DOE-5500.7B

DOE-5610.14

DOE-5630.12A

DOE 5632.1C

DOE-5633.3B

DOE-5637.1

DOE 5639.1

DOE-5639.5

DOE-5639.6A

DOE-5639.7

DOE-5660.1B

DOE $5700.6 \mathrm{C}$

DOE Activities:

DOE P 450.1

DOE-STD-1020-94

DOE-STD-1021-93

DOE-STD-1022-94

DOE-STD-1023-95

DOE-STD-1024-92

DOE-STD-1027-92

DOE-STD-1066-97

DOE-STD-1090-96

DOE-STD-3009-94

DOE-STD-3011-94

DOE-STD-3013-96

DOE-STD-3020-97
Planning and Preparedness for Operational Emergencies

Public Affairs Policy and Planning Requirements for Emergencies

Emergency Operating Records Protection Program

Transportation Safeguards System Program Operations

Safeguards and Security Inspection and Assessment Program

Protection and Control of Safeguards and Security Interests

Control and Accountability of Nuclear Materials

Classified Computer Security Program

Information Security Program

Technical Surveillance Countermeasures

Classified Automated Information System Security Program

Operations Security Program

Management of Nuclear Materials

Quality Assurance

Environment, Safety, and Health Policy for the DOE Complex

Natural Phenomena Hazards Design and Evaluation Criteria for DOE Facilities

Natural Phenomena Hazards Performance Categorization Guidelines for Structures, Systems, and Components

Natural Phenomena Characterization Criteria

Natural Phenomena Hazards Assessment Criteria

Guidelines for Use of Probabilistic Seismic Hazard Curves at Department of Energy Sites, December 1992

Guidance on Preliminary Hazards Classification and Accident Analysis Techniques for Compliance with DOE 5480.23, Safety Analysis Reports

Fire Protection Design Criteria

Hoisting and Rigging

Preparation Guide for U.S. Department of Energy Nonreactor Nuclear Facility Safety Analysis Reports

Guidance for Preparation of DOE 5480.22 (TSR) and DOE 5480.23 (SAR) Implementation Plans

Criteria for Preparing and Packaging Plutonium Metal and Oxide for Long-term Storage

Specification for HEPA Filters Used by DOE Contractors

DOE-EM-STD-5502-94 Hazards Baseline Documentation 
DOE/EH-0256T

INFCIRC 153

INFRCIRC288

TID-7016

IEEE 493

NFPA 70

NFPA 72

NFPA 101

\section{DOE Radiological Control Manual}

The Structure and Content of Agreements Between the Agency (IAEA) and States Required in Connection with the Treaty on the Non-Proliferation of Nuclear Weapons

Agreement Between the United States of America and the International Atomic Energy Agency for the Application of Safeguards in the United States of America

Nuclear Safety Guide

IEEE Recommended Practice for the Design of Industrial and Commercial Power Systems

National Electric Code

National Fire Alarm Code

Code for Safety to Life from Fire in Buildings and Structures

\section{South Carolina Regulations:}

R.61-58

R.61-62

R.61-70

R.61-86

R.61-92

R.72-300

WSRC Documents:

Manual 1Q

Manual 2Q

Manual 3Q

Manual 4Q

Manual 5Q

Manual 7Q

Manual 8Q

Manual 100

Manual 14Q

Manual $18 \mathrm{Q}$

Manual $19 Q$

Manual 20Q

WSRC Manual 1D

Manual 1S

WSRC-RP-92-631
South Carolina Primary Drinking Water Regulations

South Carolina Air Pollution and Control Regulations and Standards

South Carolina Hazardous Waste Management

Land Disposal Restrictions

South Carolina Underground Tank Control Regulations

South Carolina Standards for Stormwater Management and Sediment Reduction Regulations

Quality Assurance

Fire Protection

Environmental Compliance Manual

Industrial Hygiene Manual

Radiological Control Manual

Security Manual

Employee Safety Manual

Computer Security Manual

Material Control and Accountability

Safe Electrical Practices and Procedures Manual

Transportation Safety Manual

Health and Safety for Hazardous Waste Operations

Site Infrastructure and Services Manual, Site Real Property Configuration Control

SRS Waste Acceptance Criteria Manual

SRS Waste Minimization Plan 


$\begin{array}{ll}\text { WSRC-IM-92-43 } & \text { Process Ventilation Guide } \\ \text { WSRC-IM-90-48 } & \text { F-Area Spill Prevention Plan } \\ \text { WSRC-IM-90-90 } & \text { SRS "Smarts" Program } \\ \text { WSRC-IM-91-60 } & \begin{array}{l}\text { National Emission Standards for Hazardous Air Pollutants } \\ \text { Quality Assurance Plan }\end{array} \\ \text { WSRC-IM-91-69 } & \begin{array}{l}\text { SRS Environmental Permitting "HOW" Manual } \\ \text { WSRC-IM-94-53 }\end{array} \\ \text { Savannah River Site Title V Air Permitting Compliance } \\ \text { Wanual } \\ \text { WSRC-TR-94-0236 } & \text { CAM and Stack Air Sampler Design Guide } \\ & \text { SRS Engineering Standards Manual }\end{array}$


UCRL-ID-131617 Rev. 1

PIP-98-115 


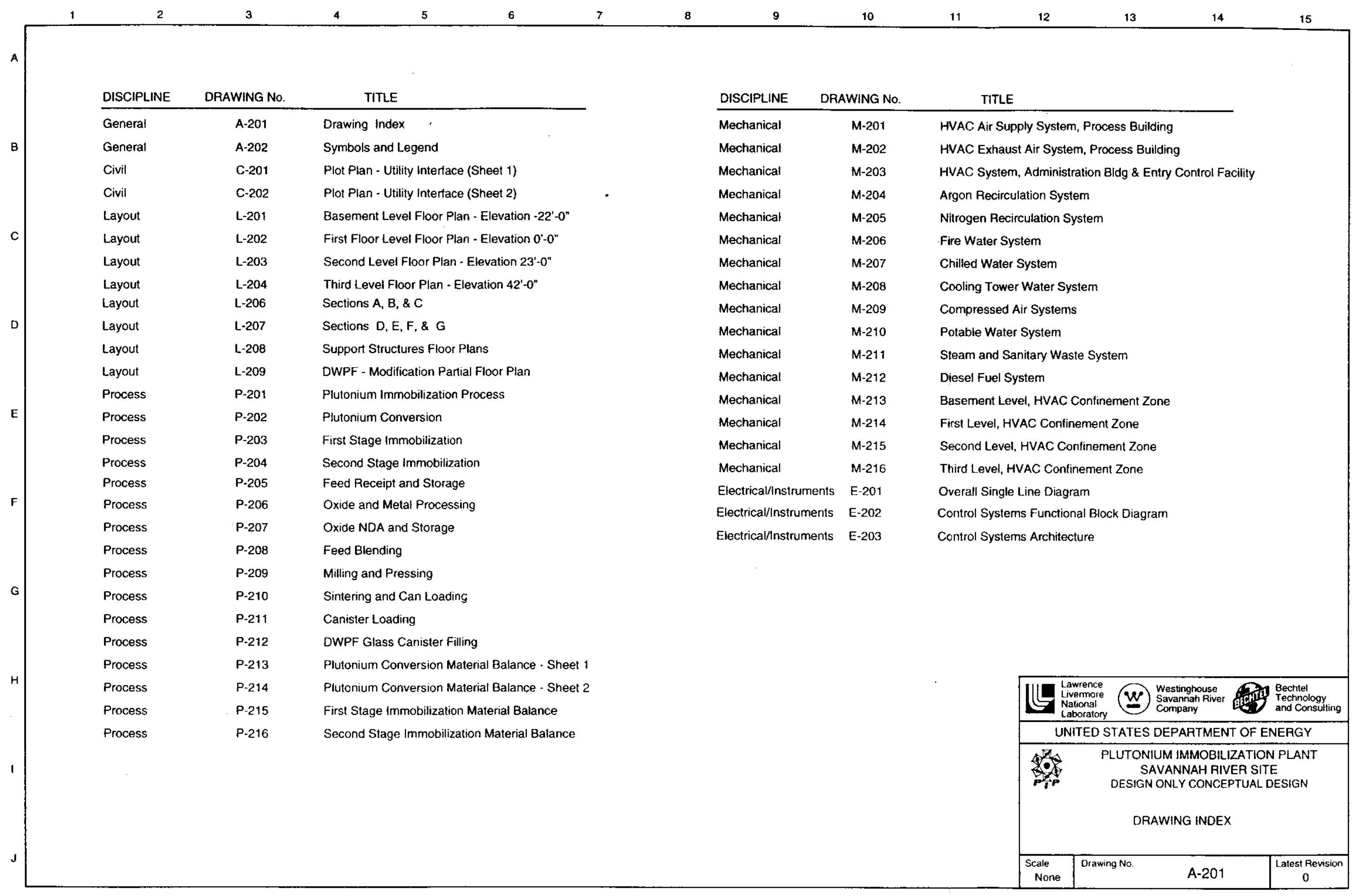




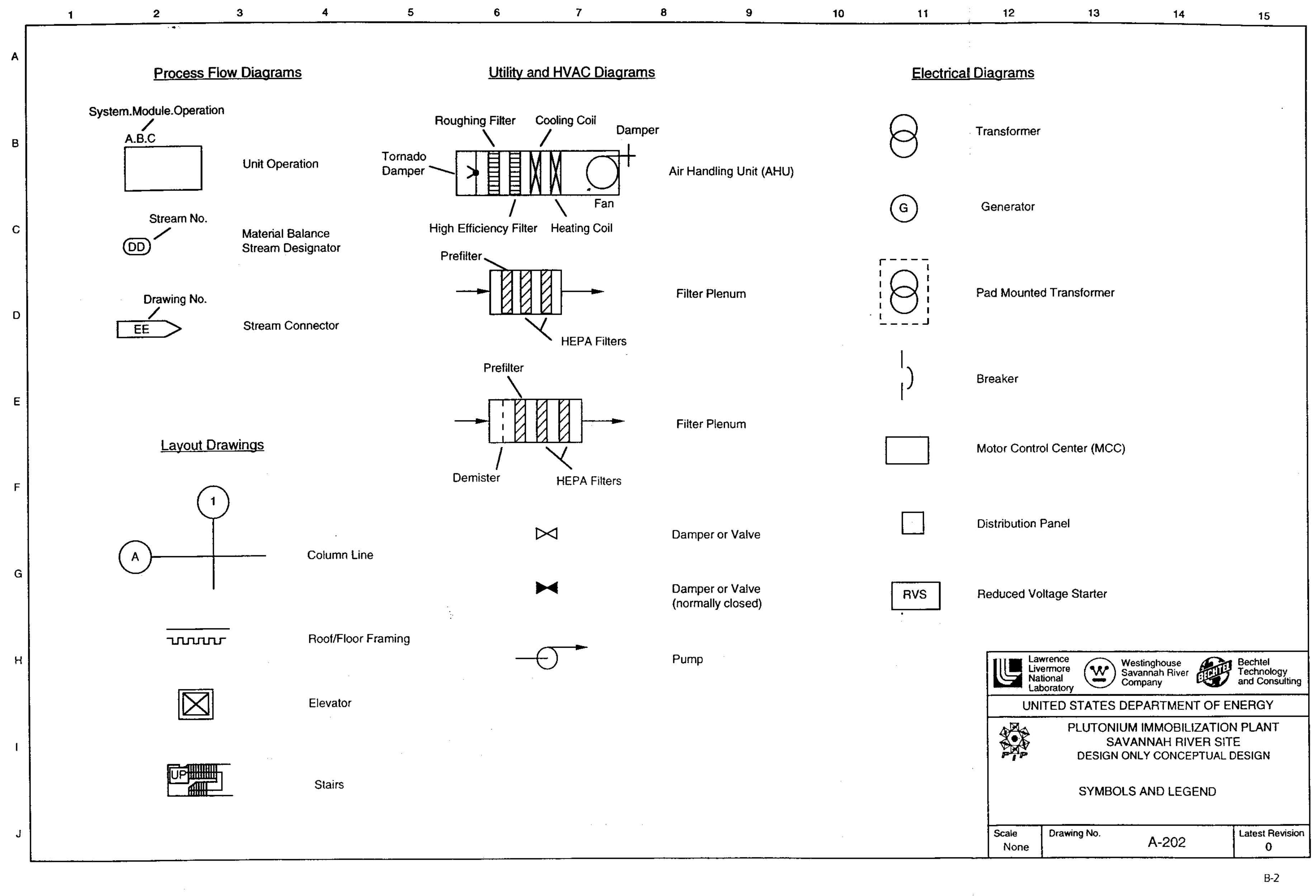




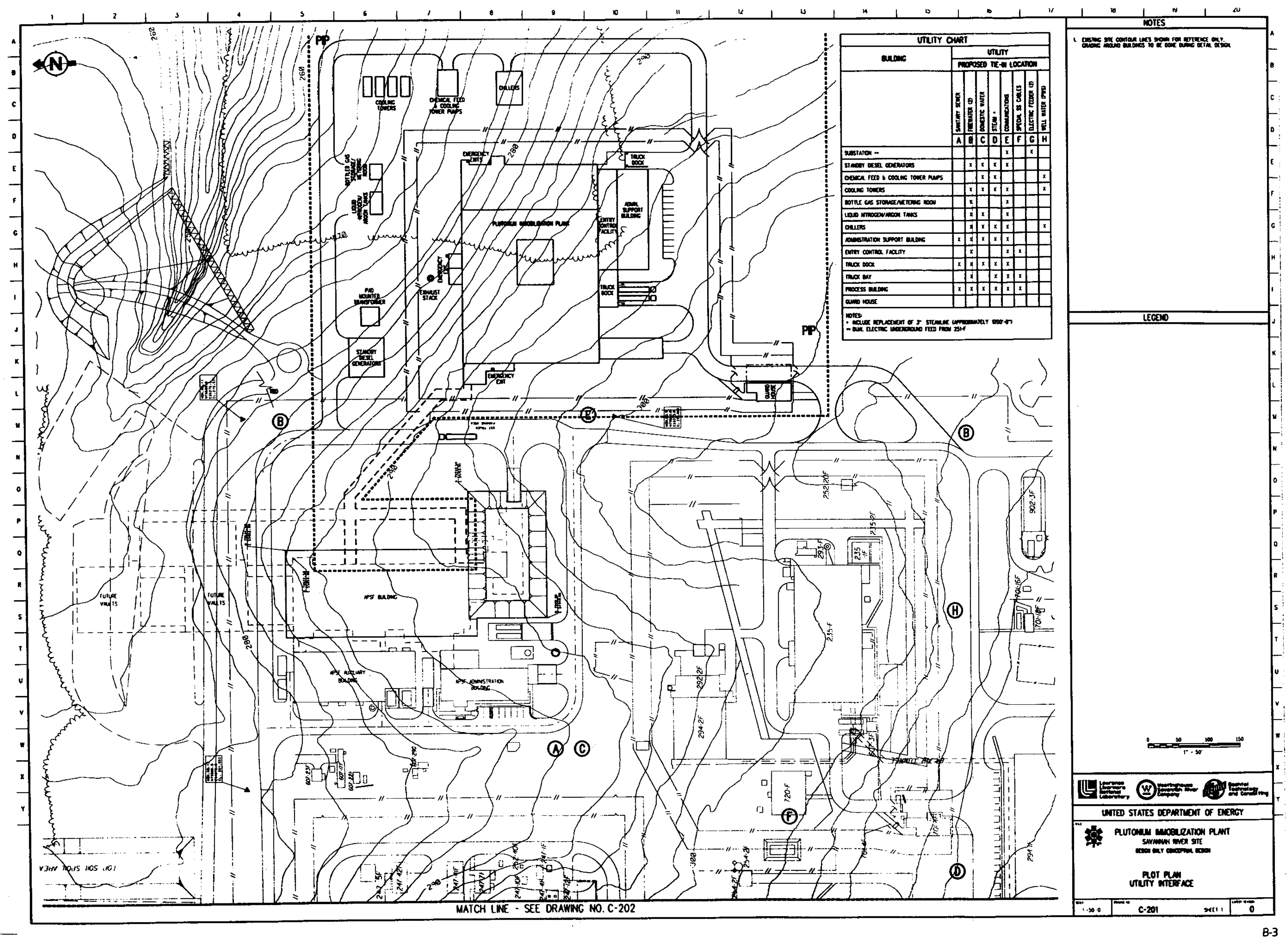


MATCH LNE - SEE DRAFING NO. C-201
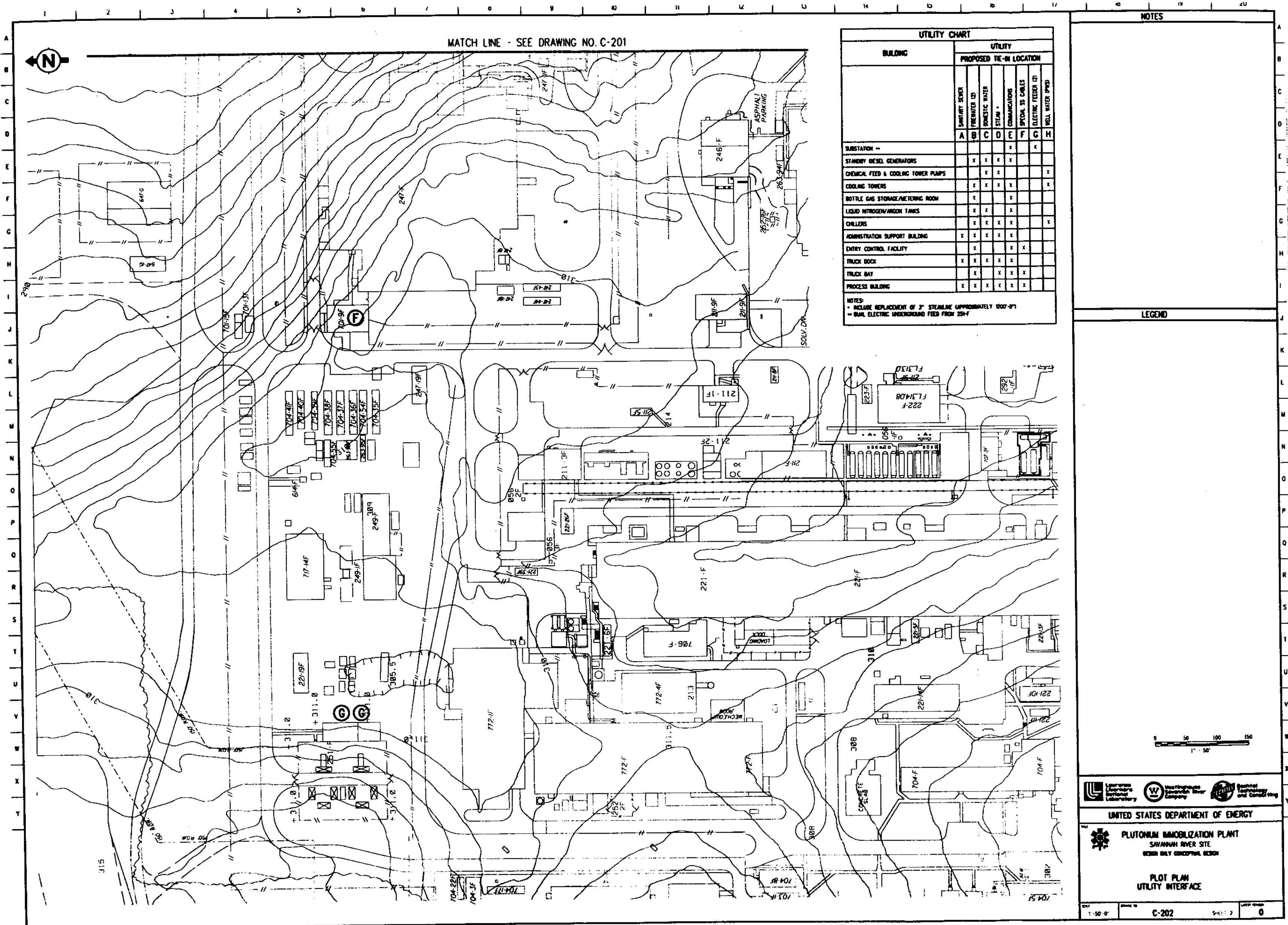


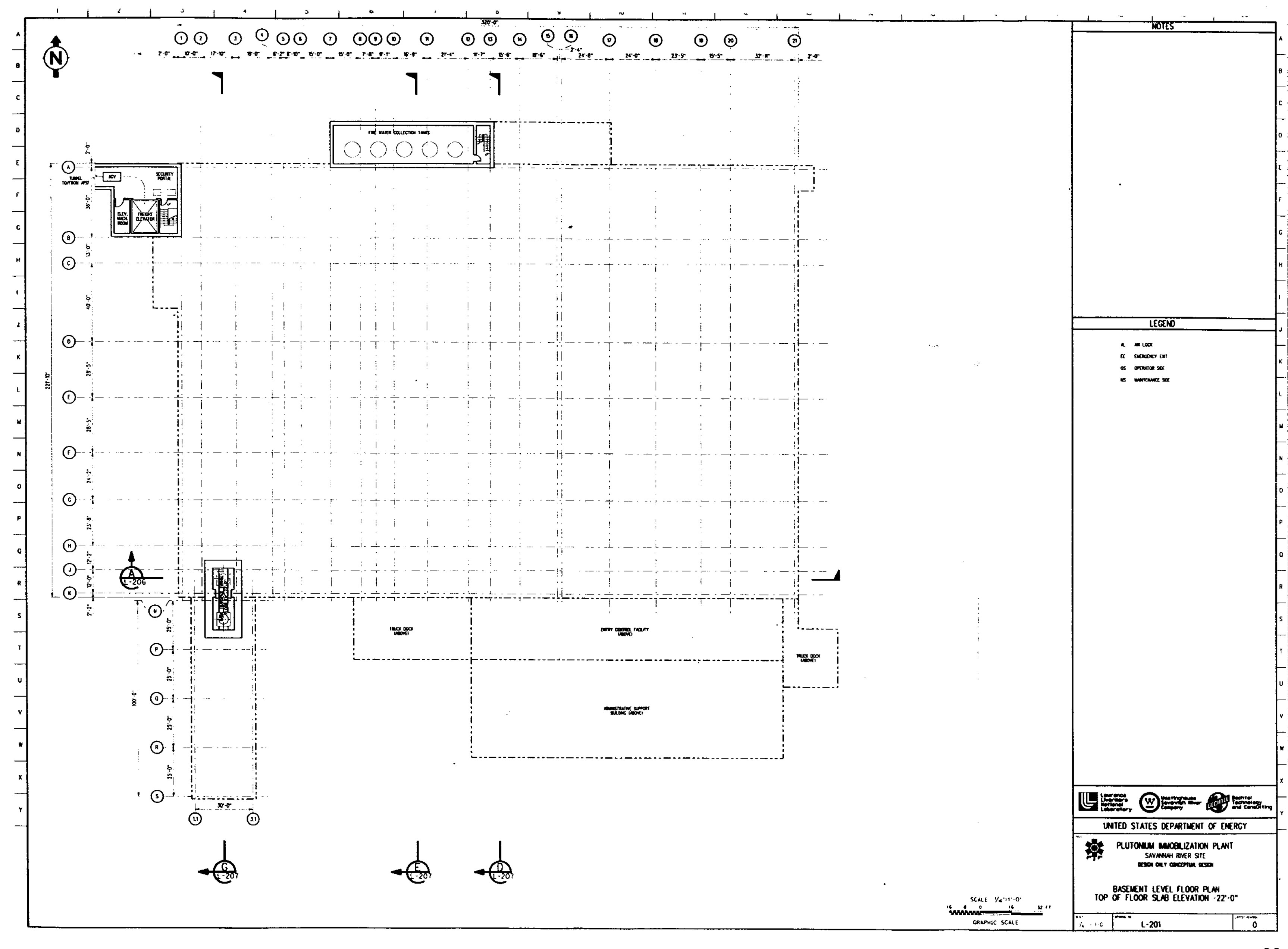




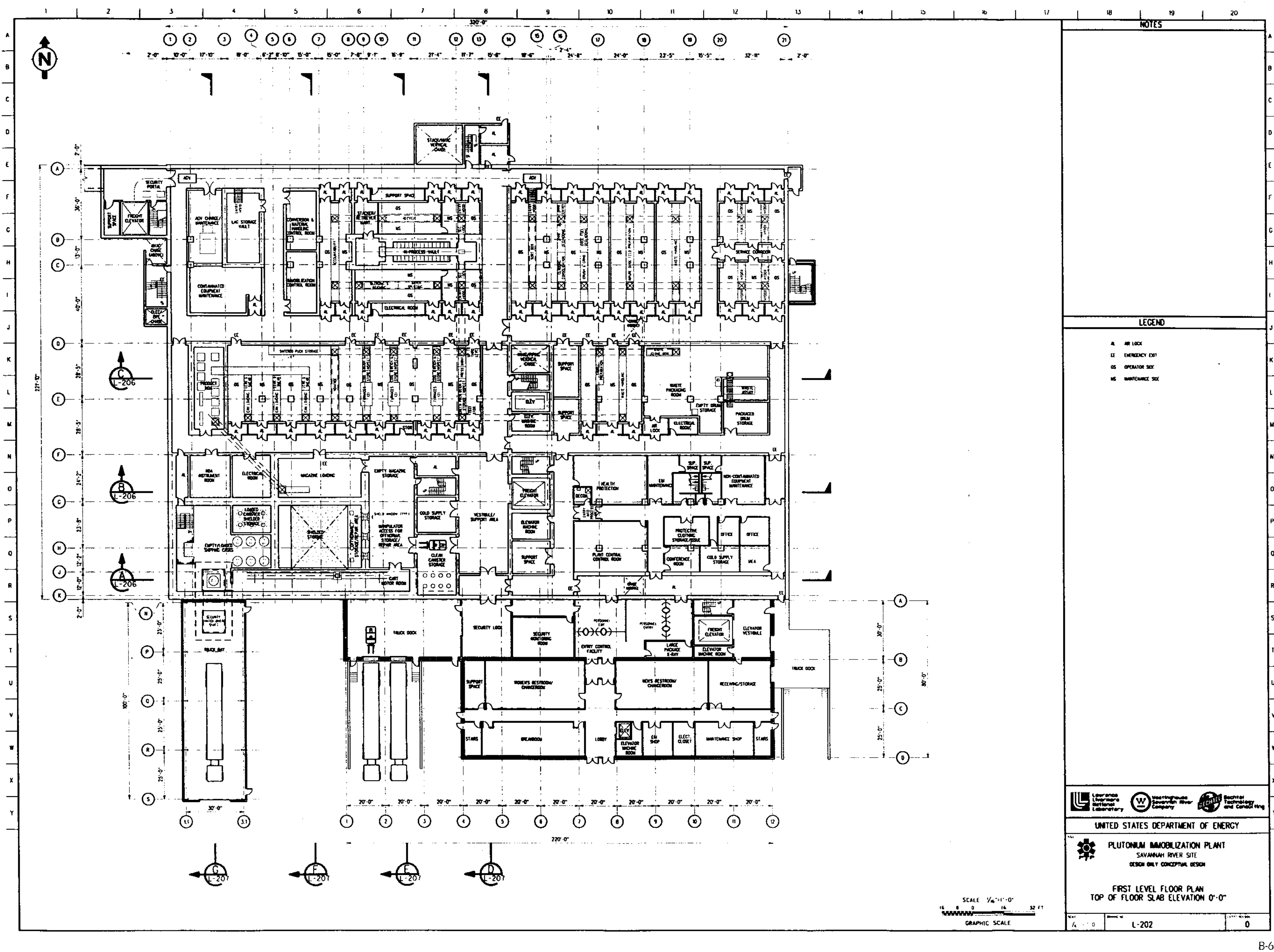




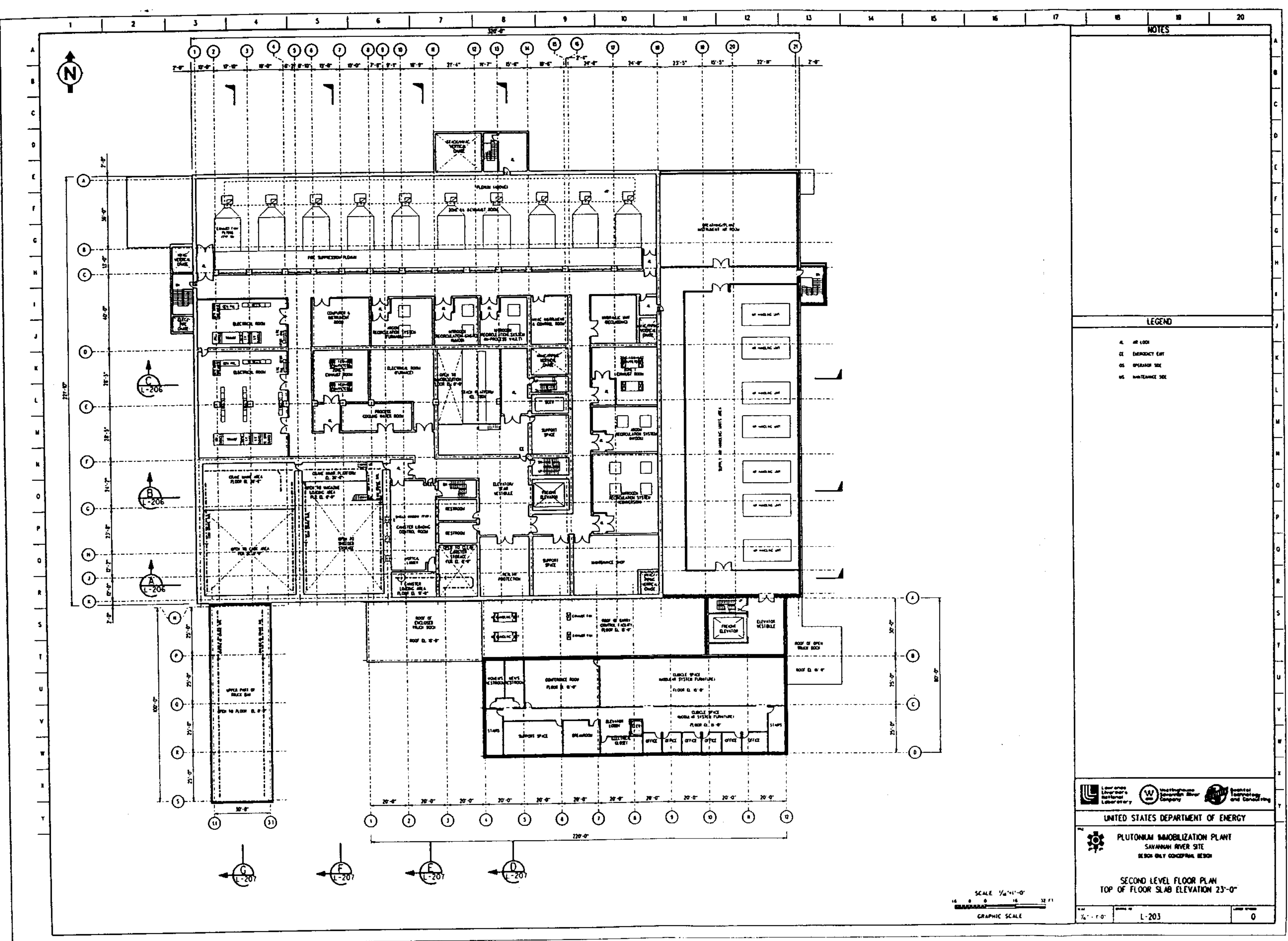




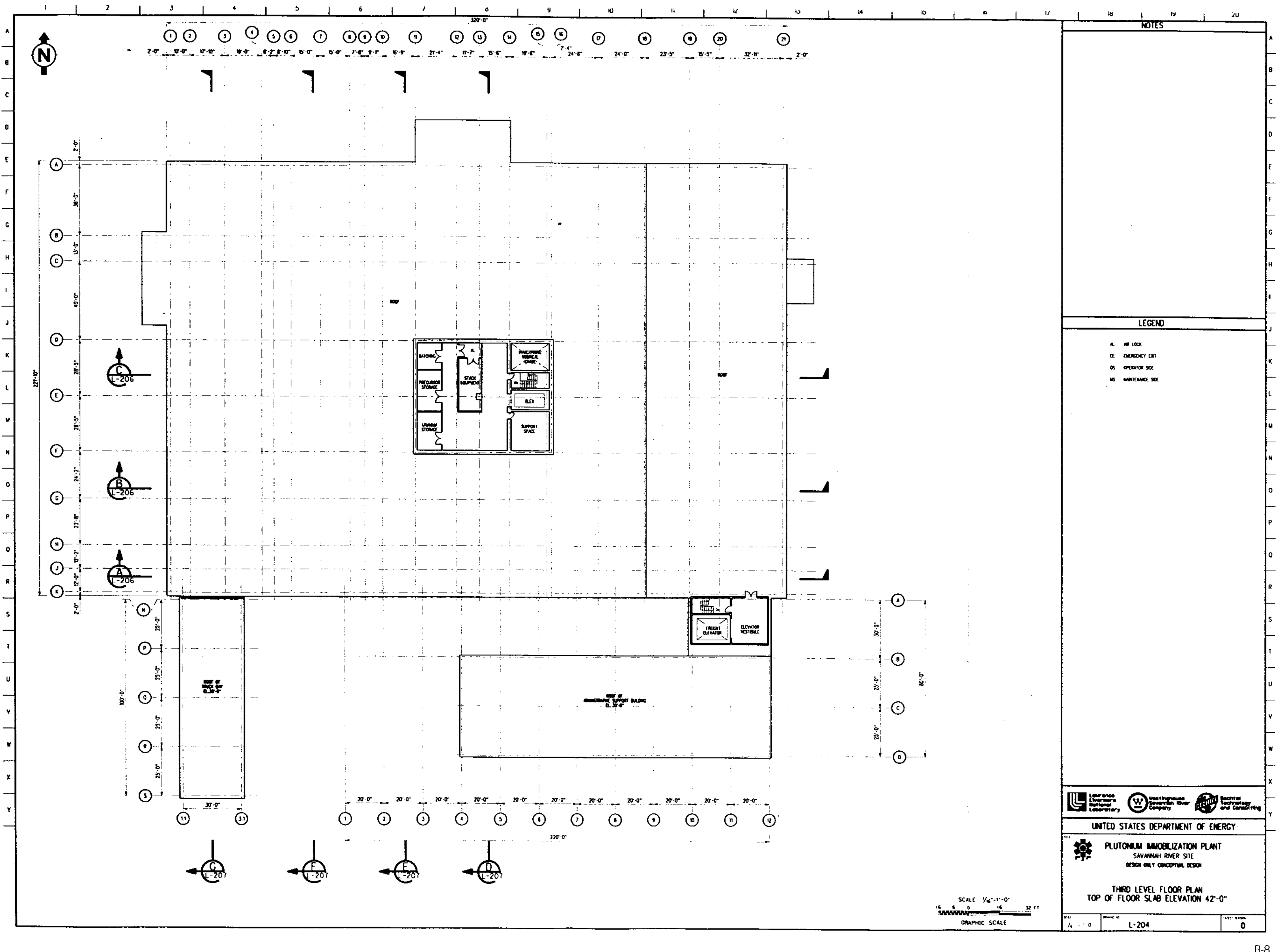




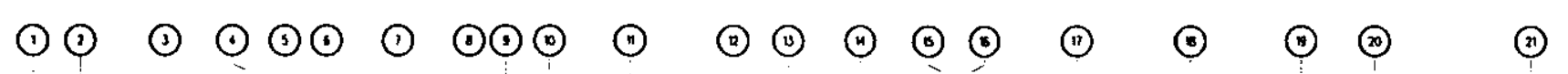

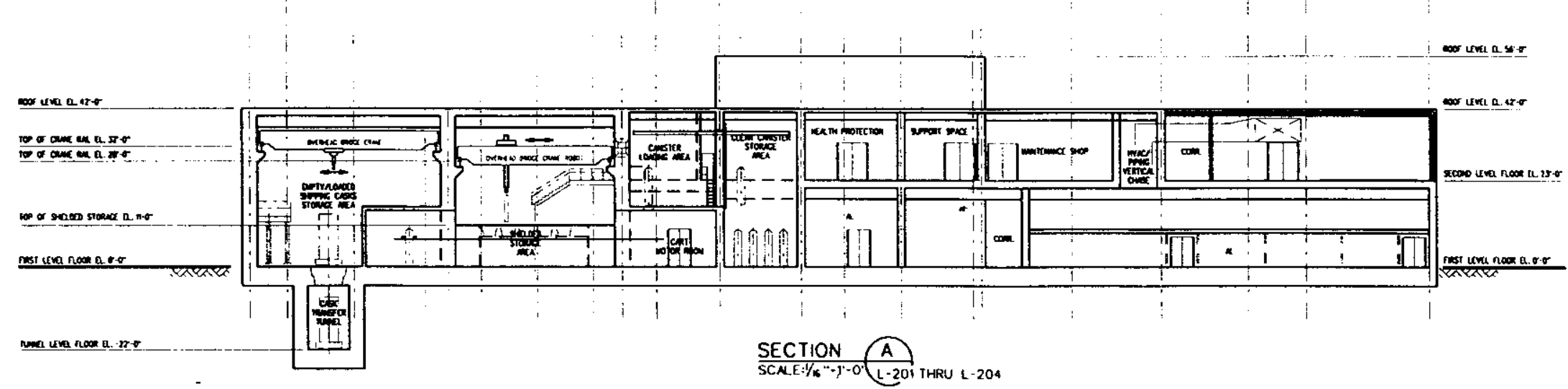

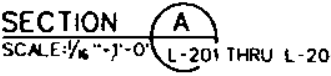

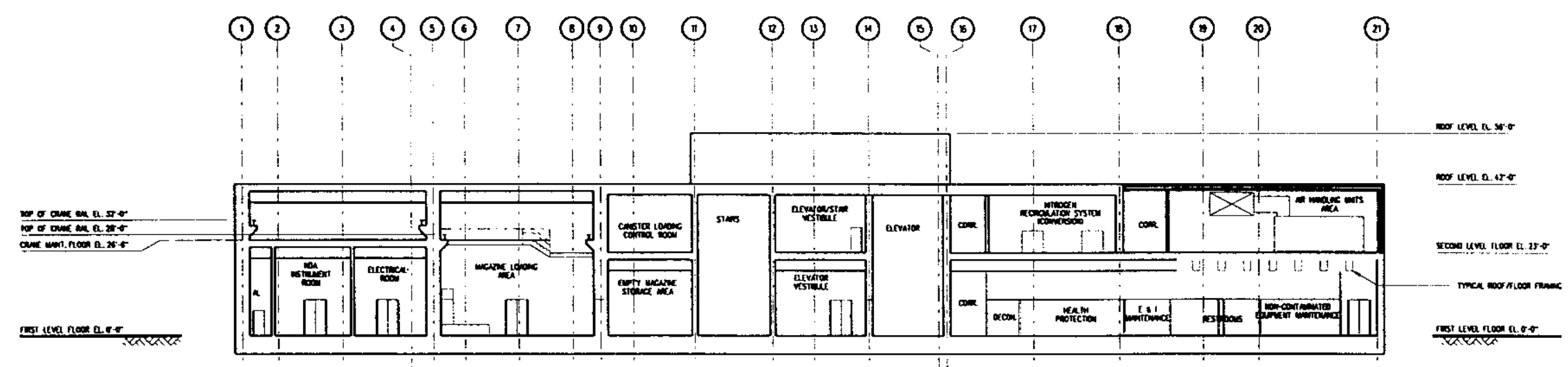

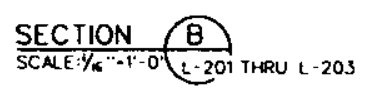

(1) (2)
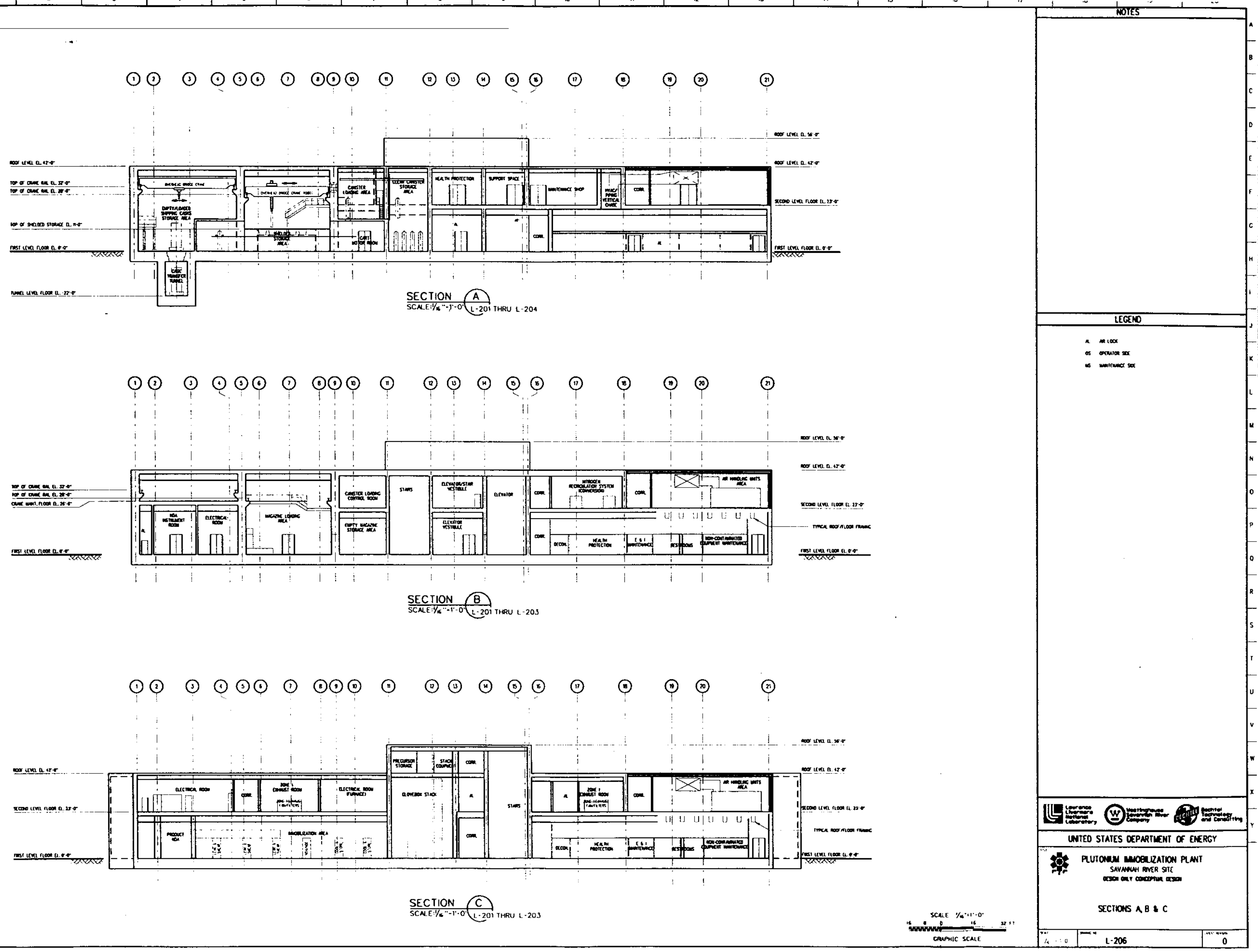

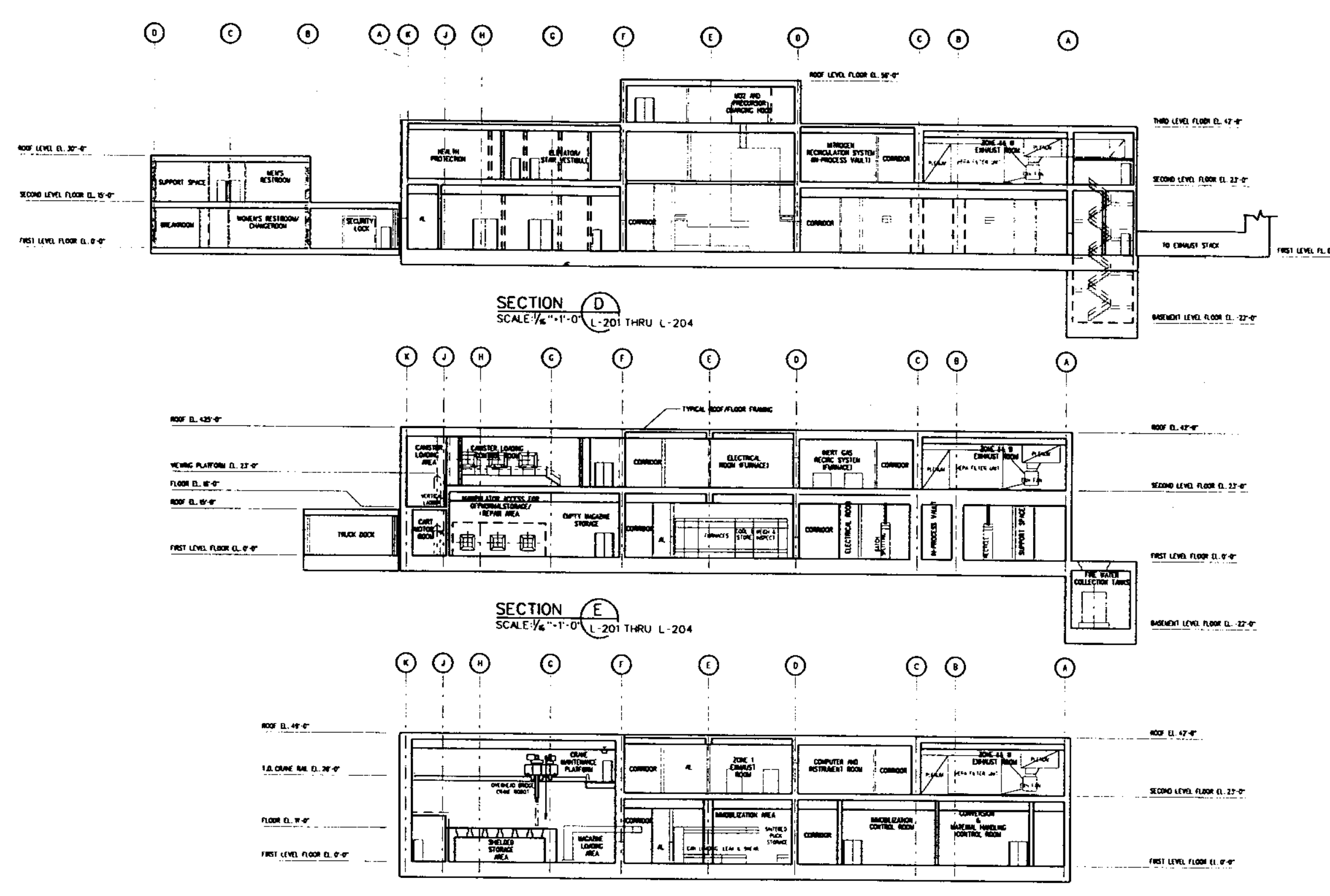

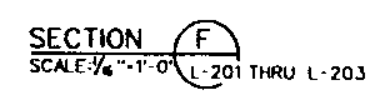

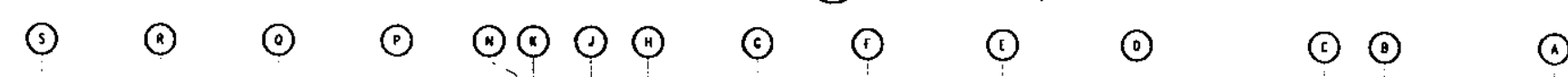
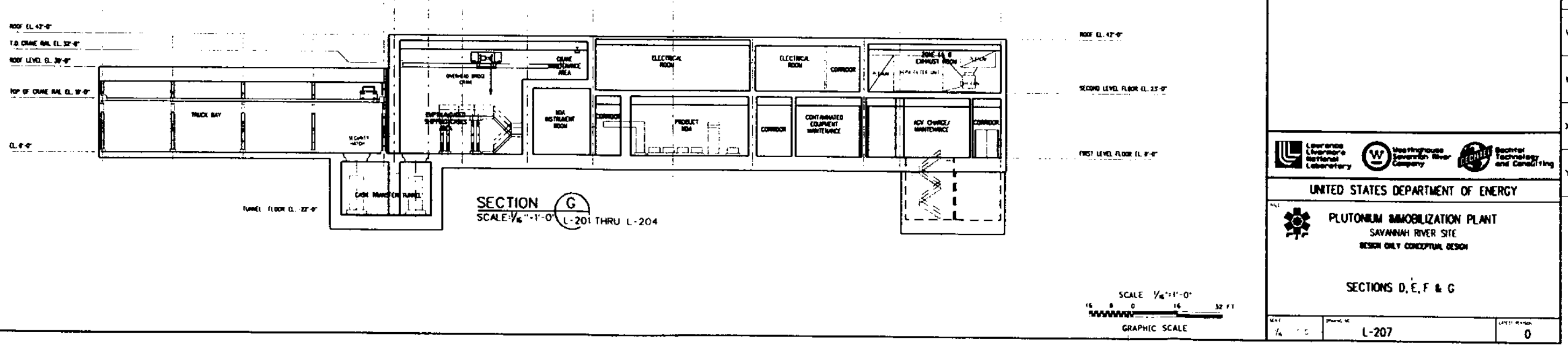


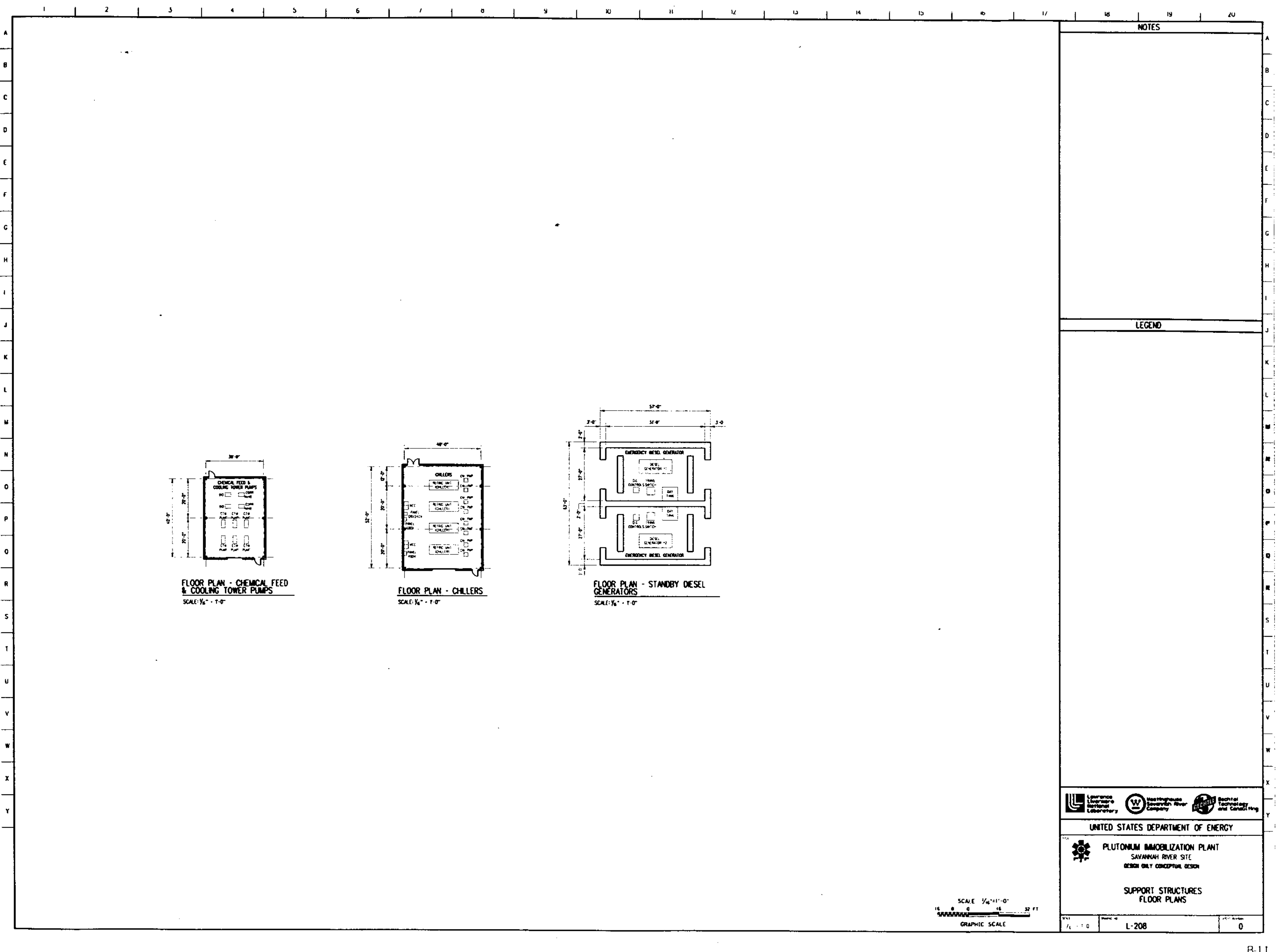




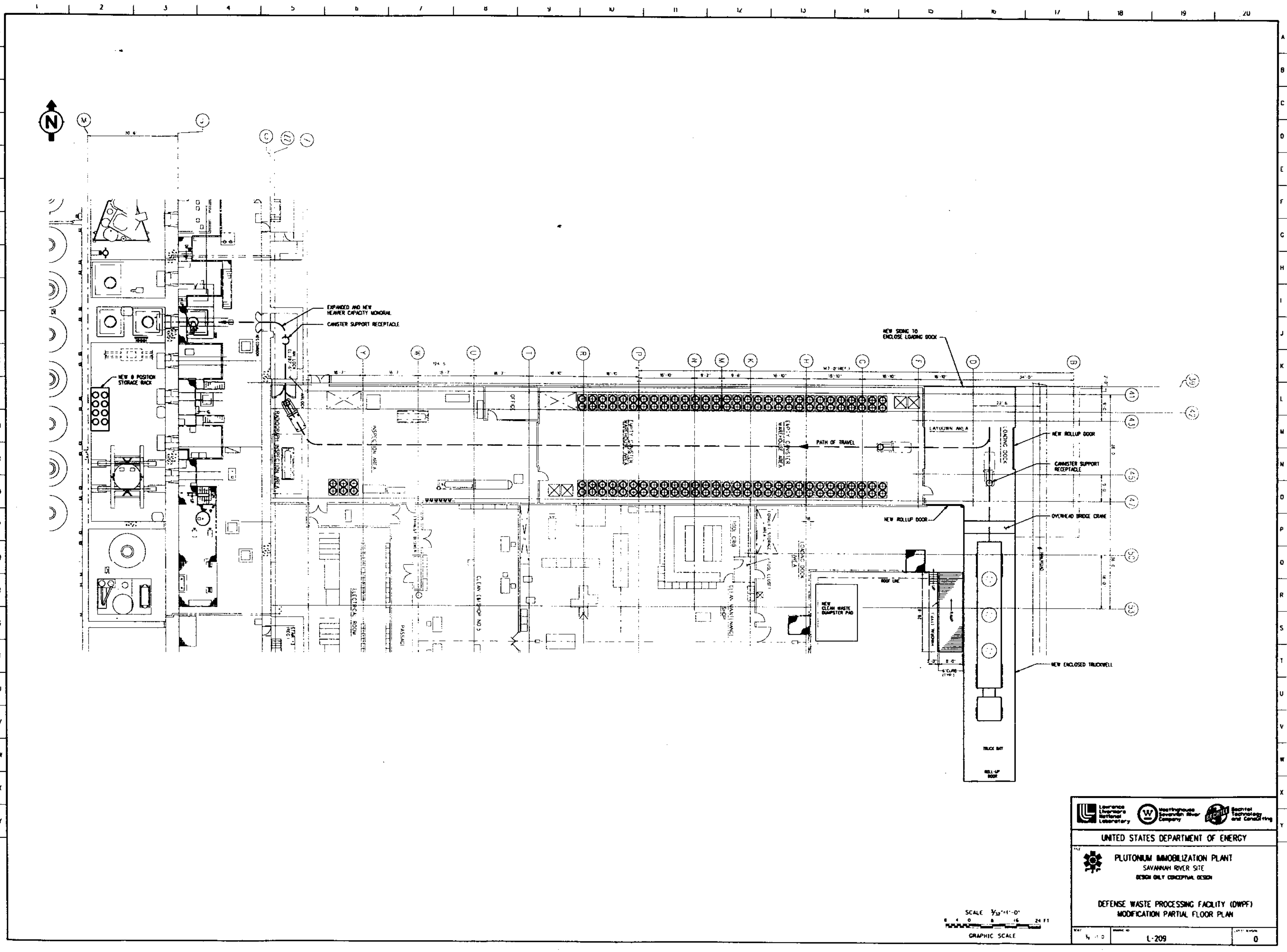




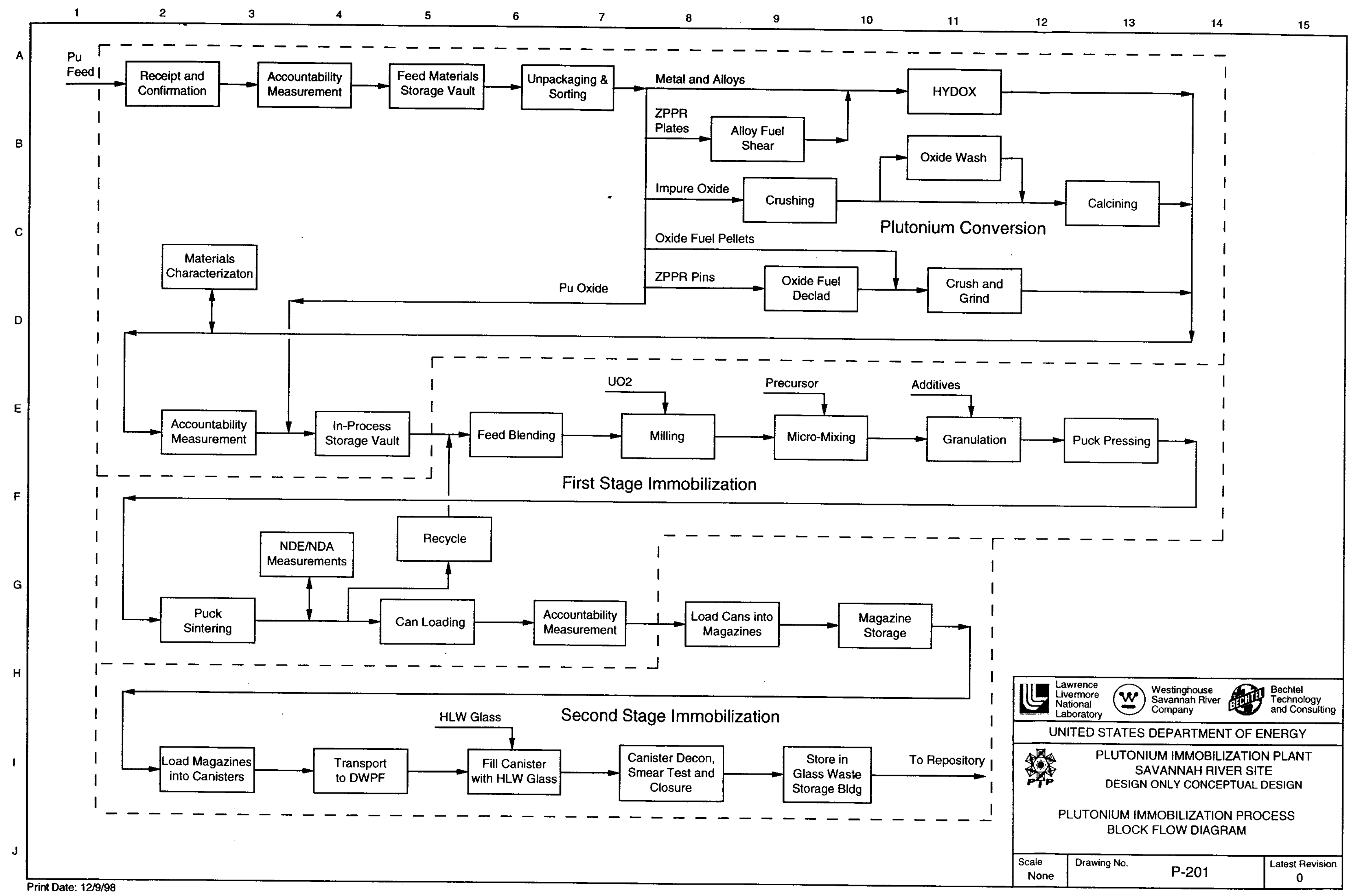




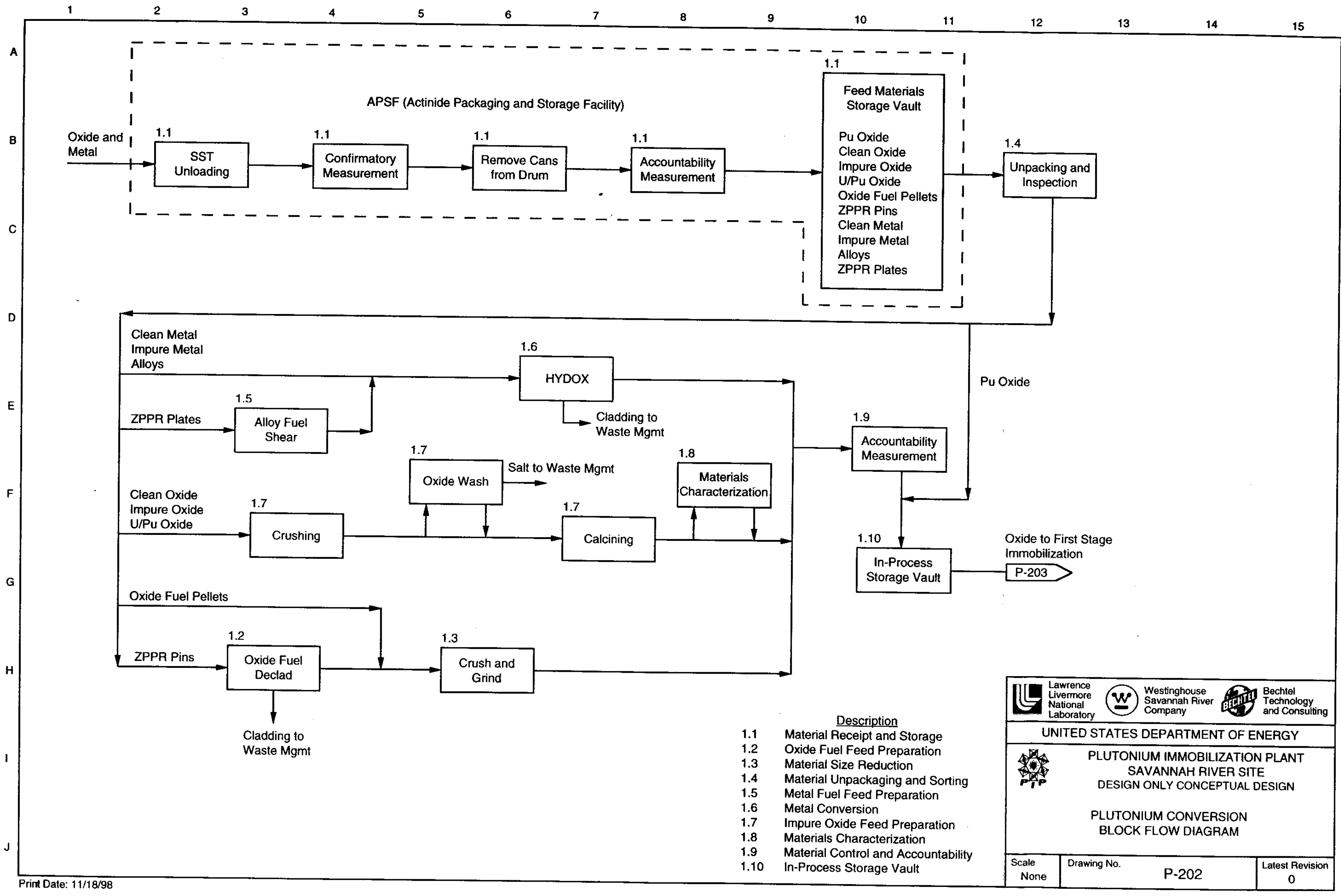




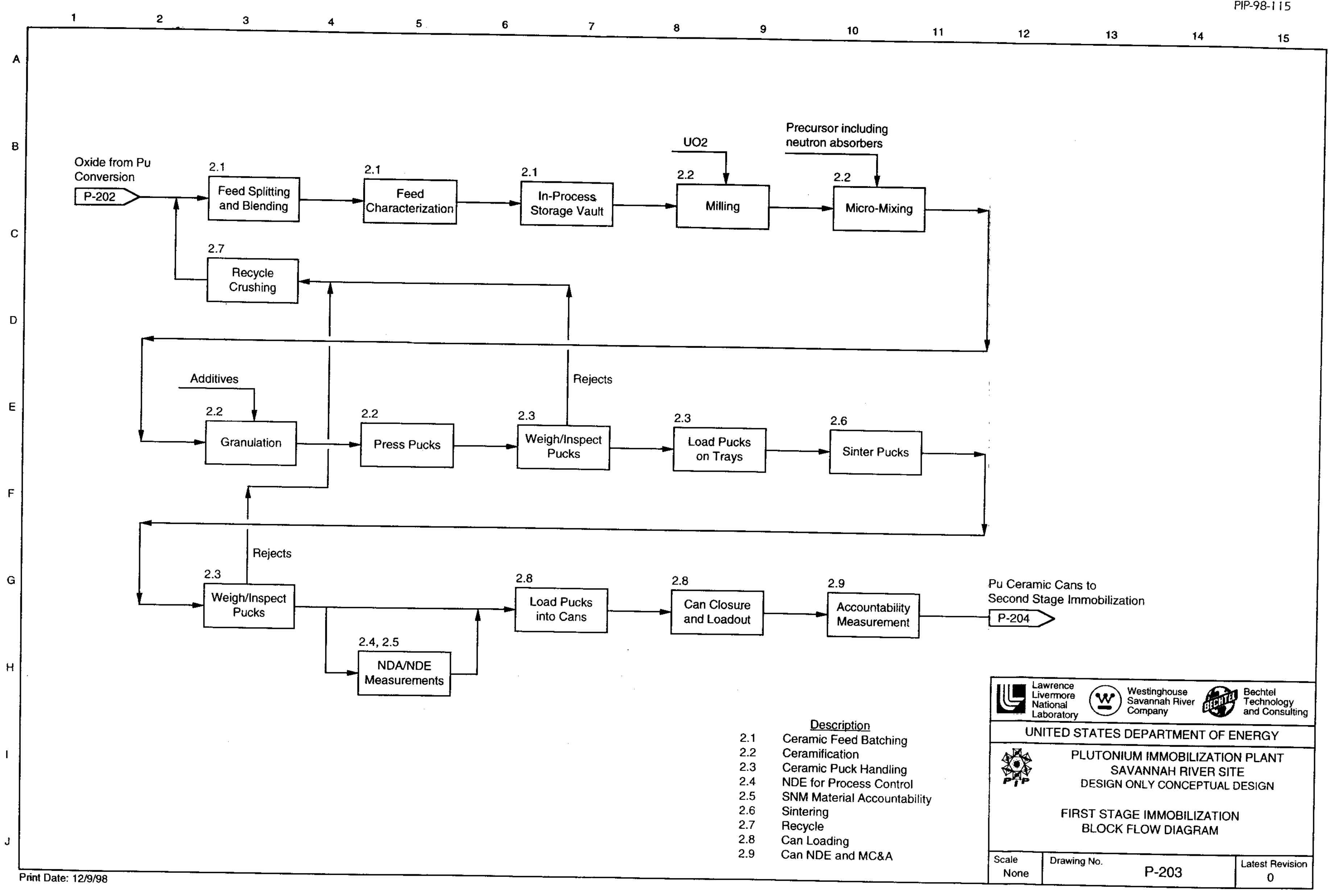




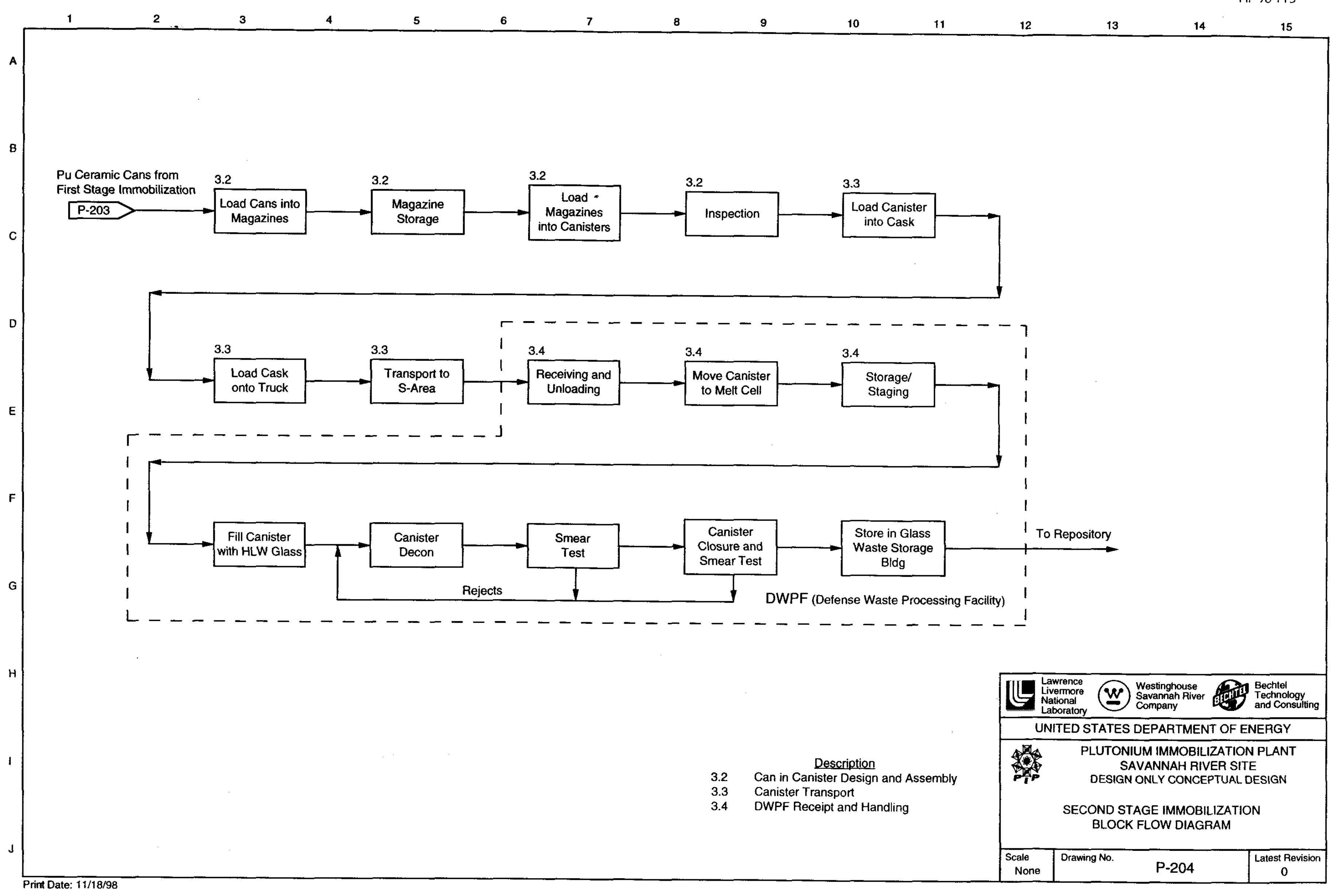




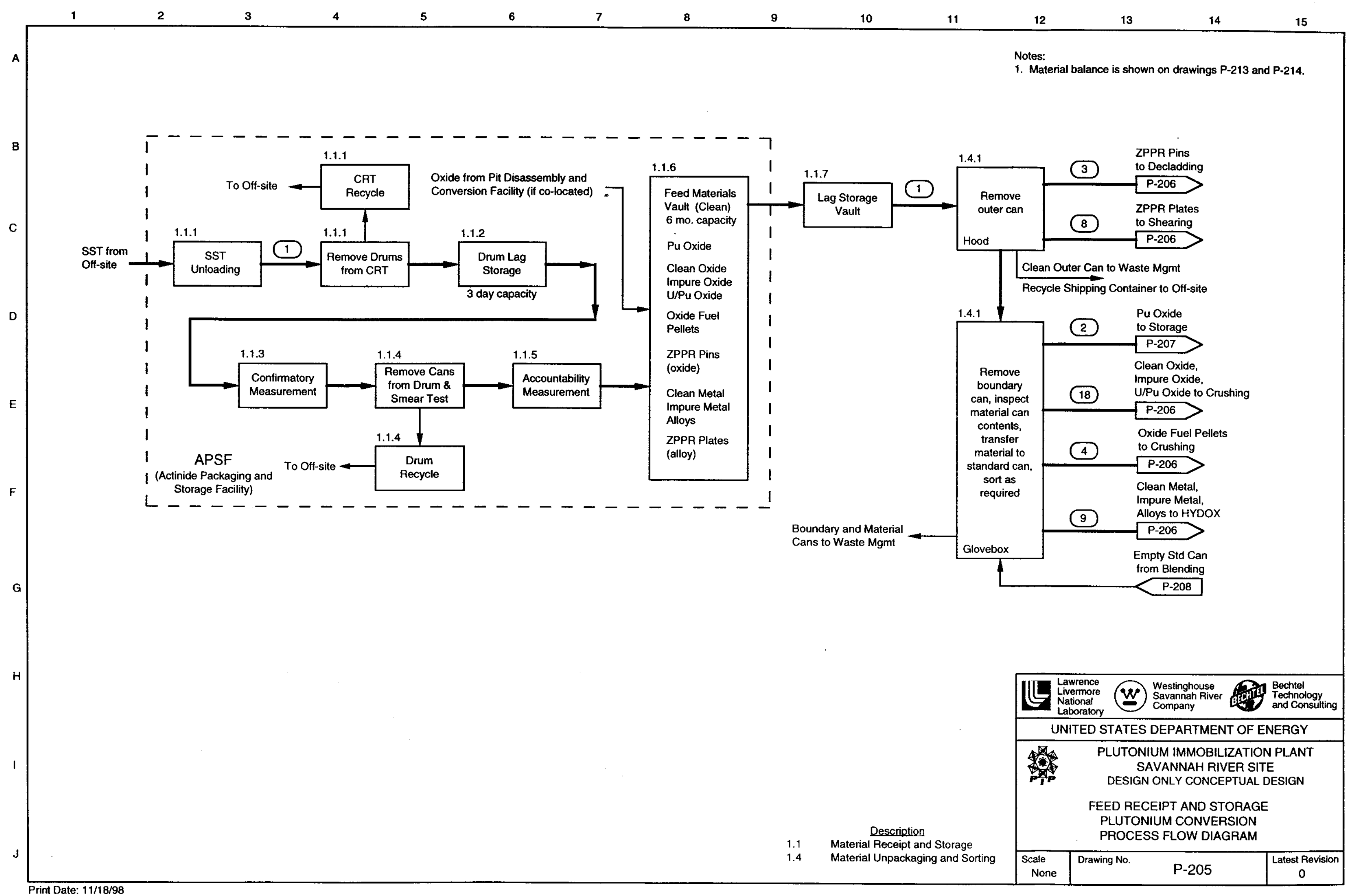




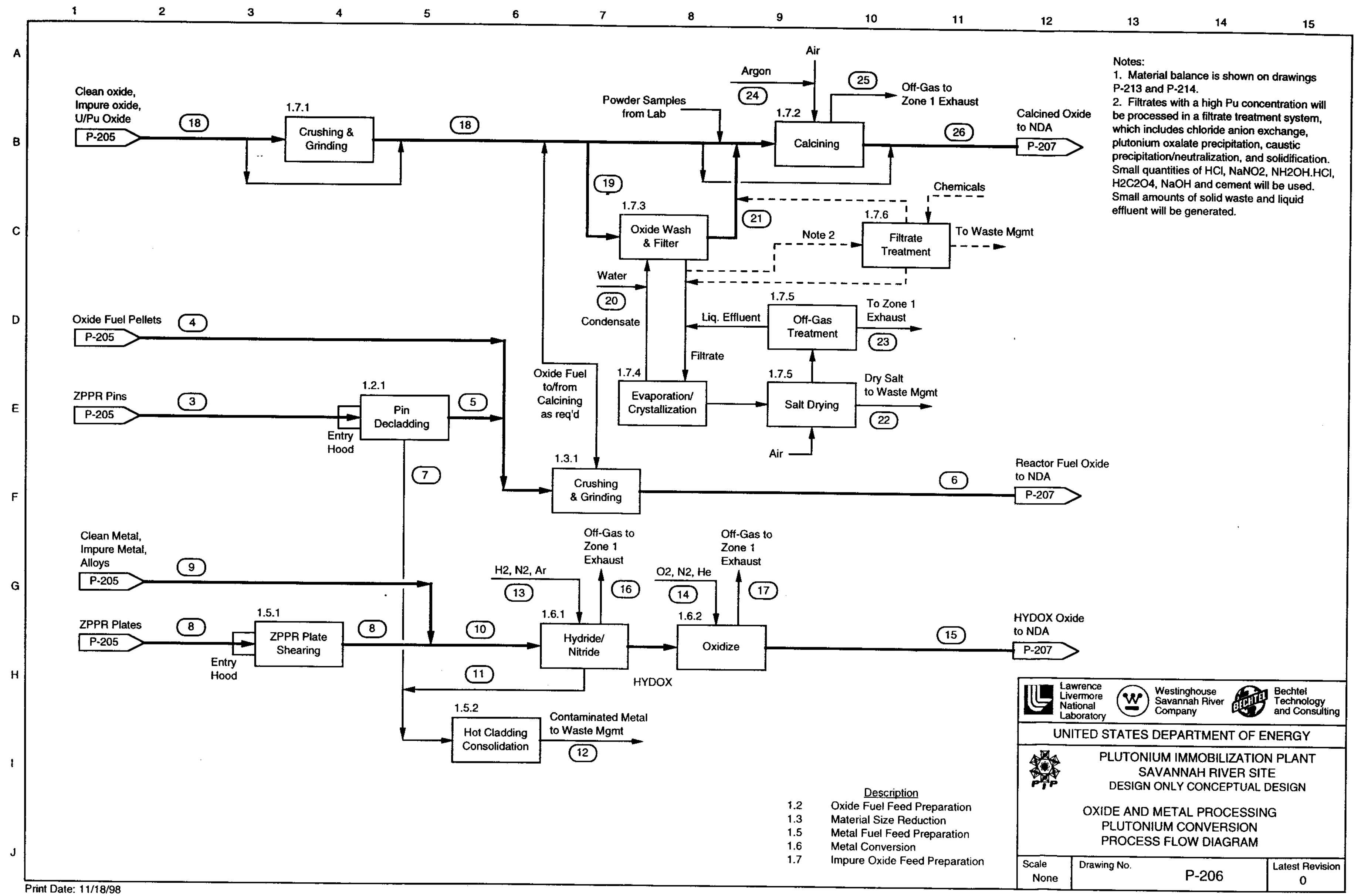




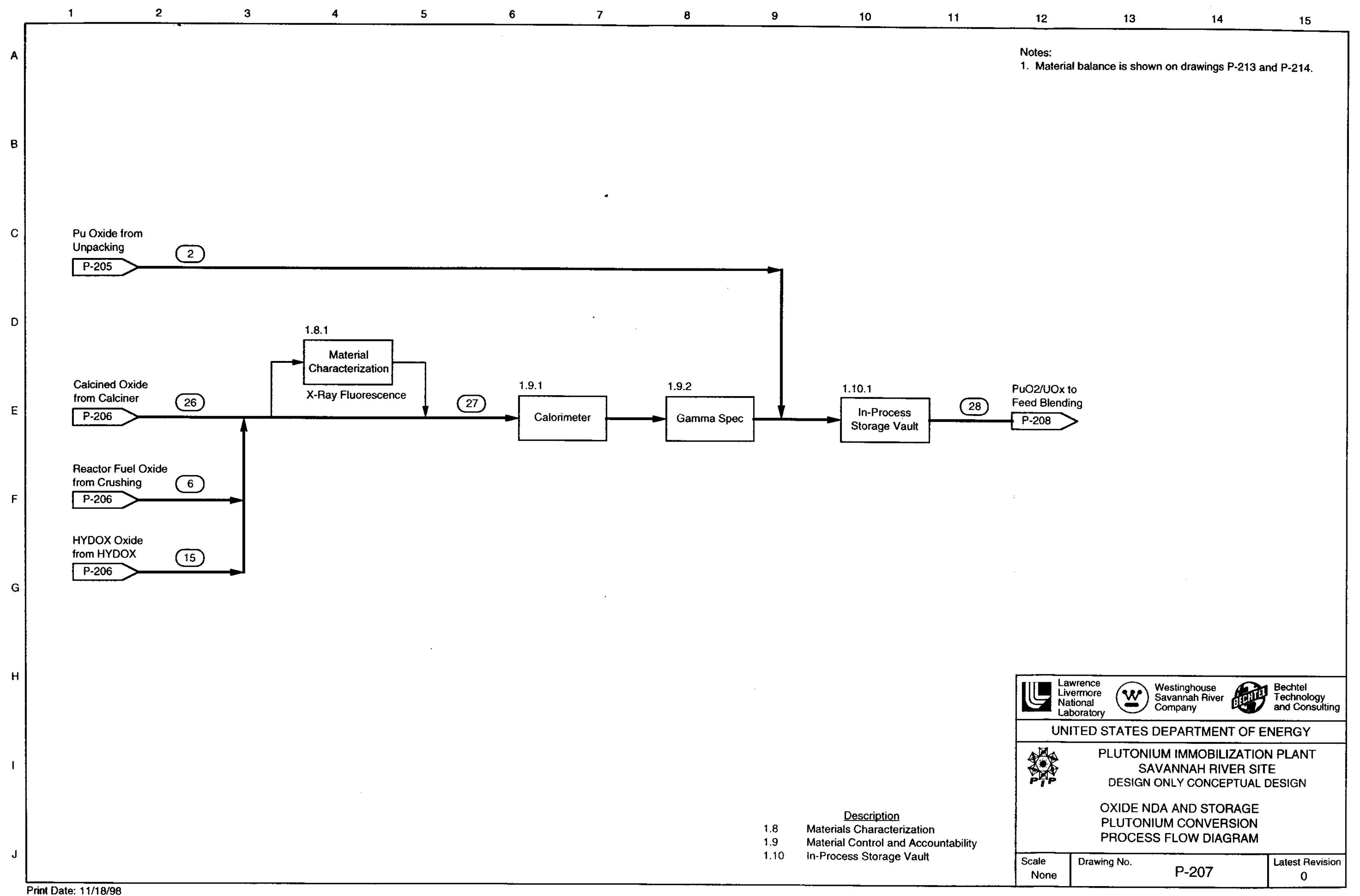

了 


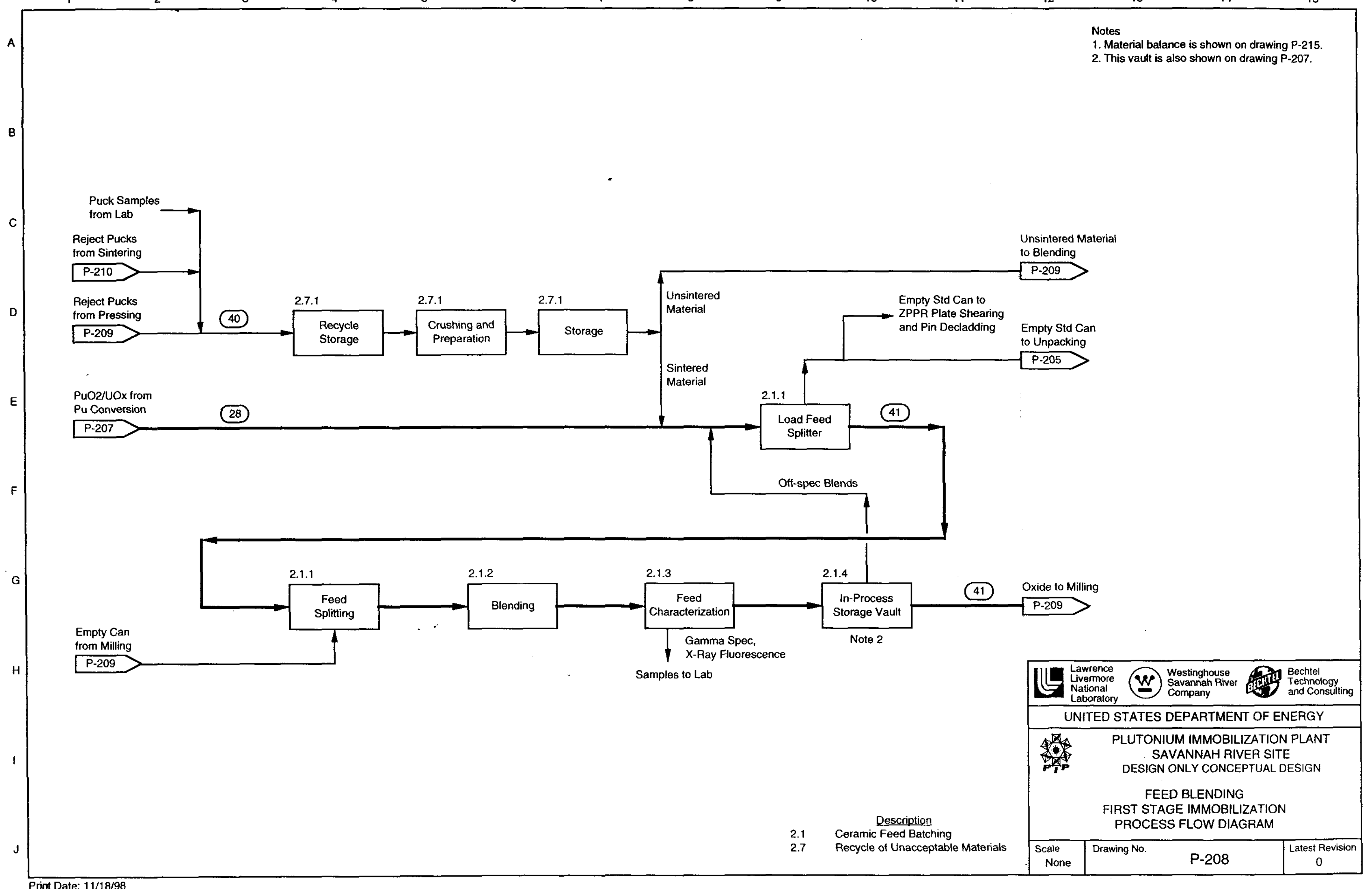




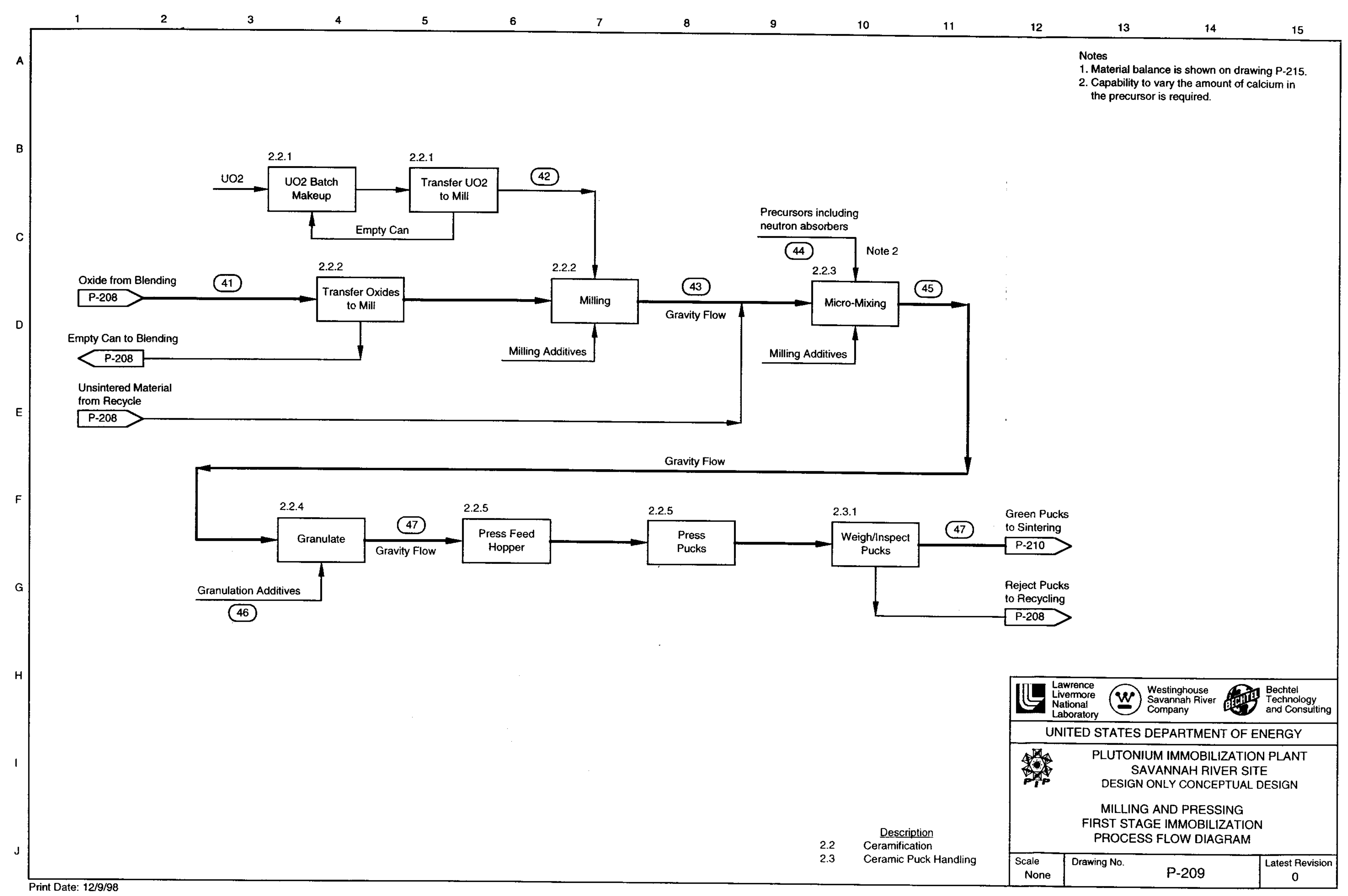




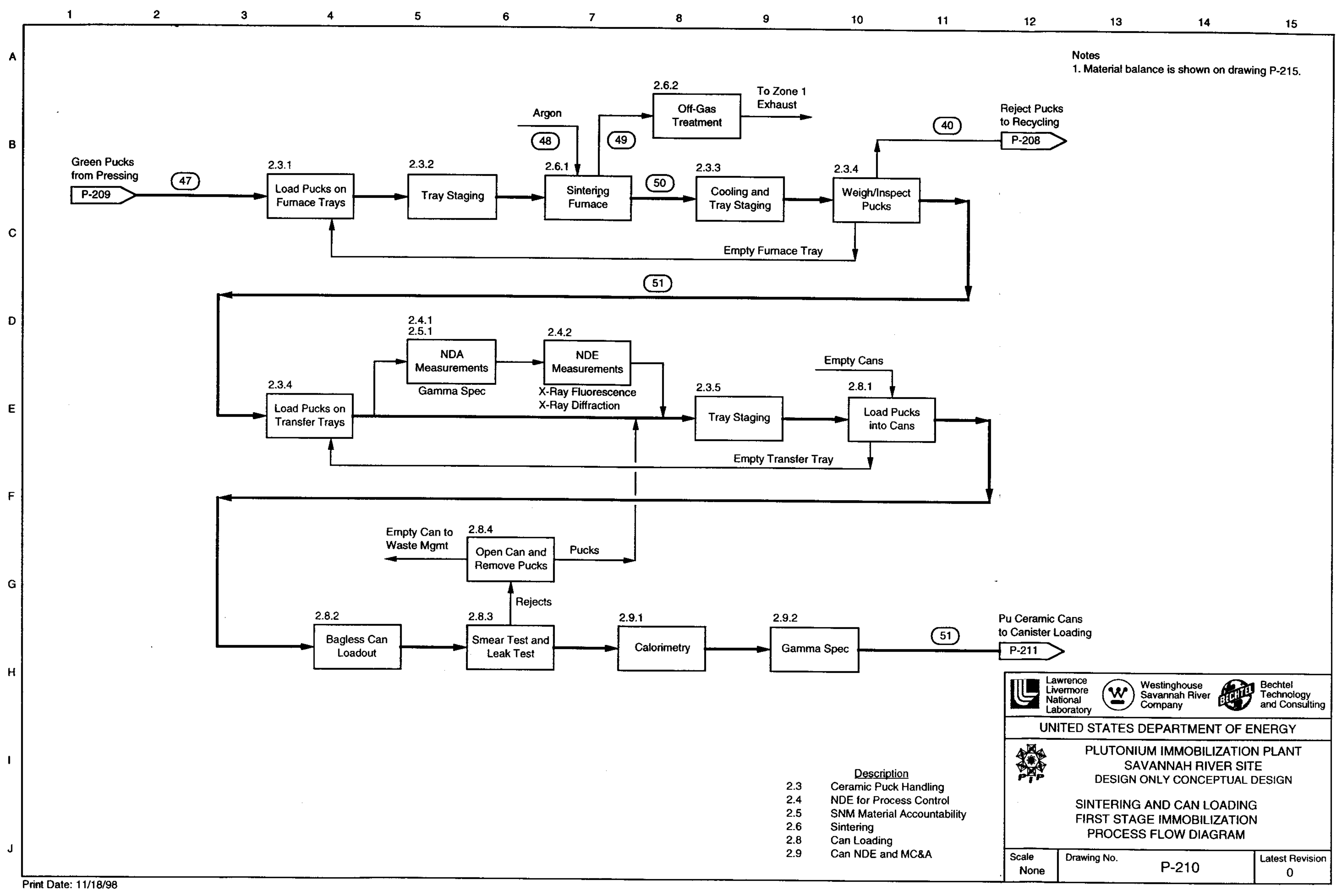




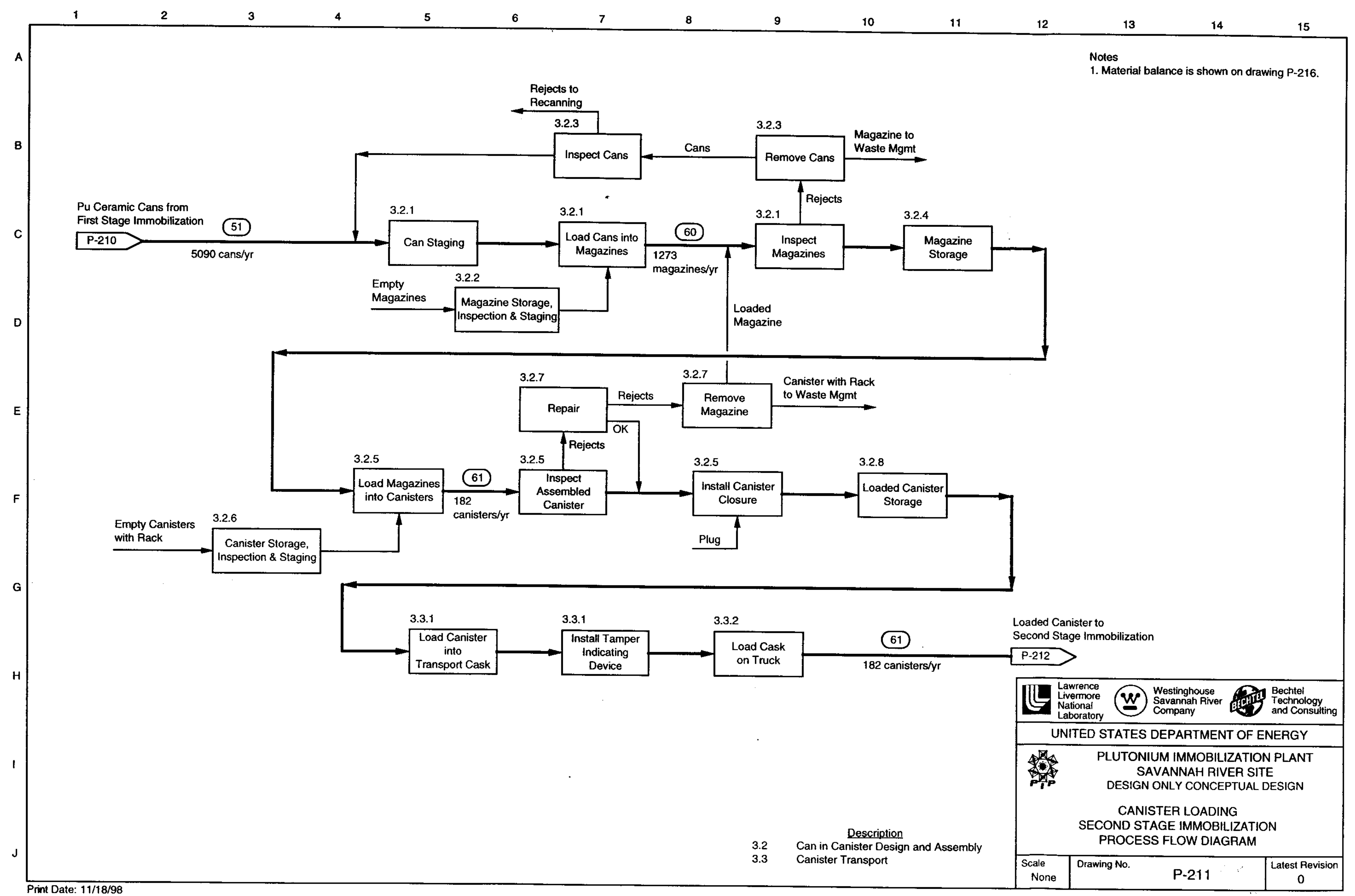




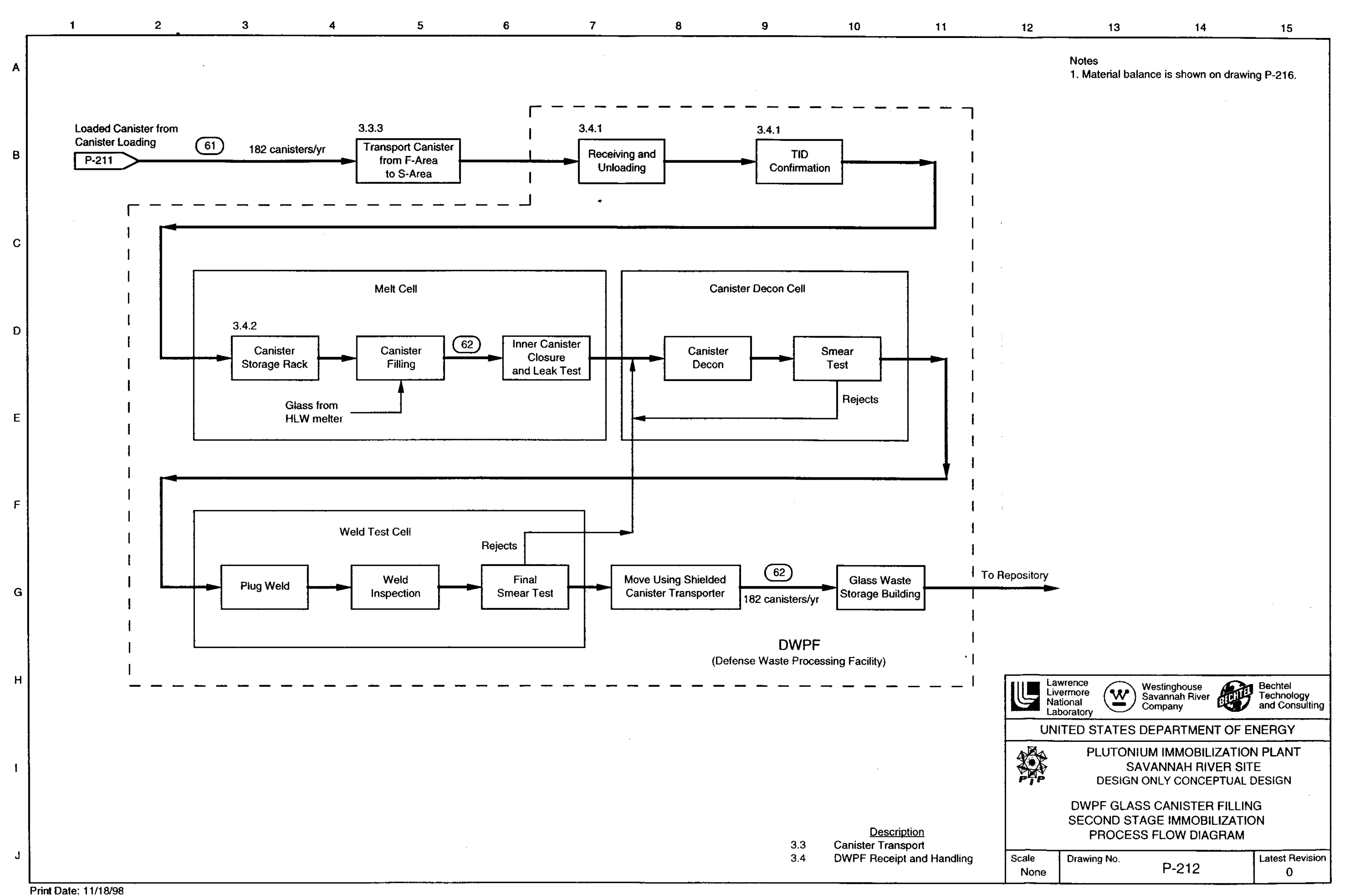




I

Notes

1. Plutonium conversion process is shown on drawings P-205 to P-207.

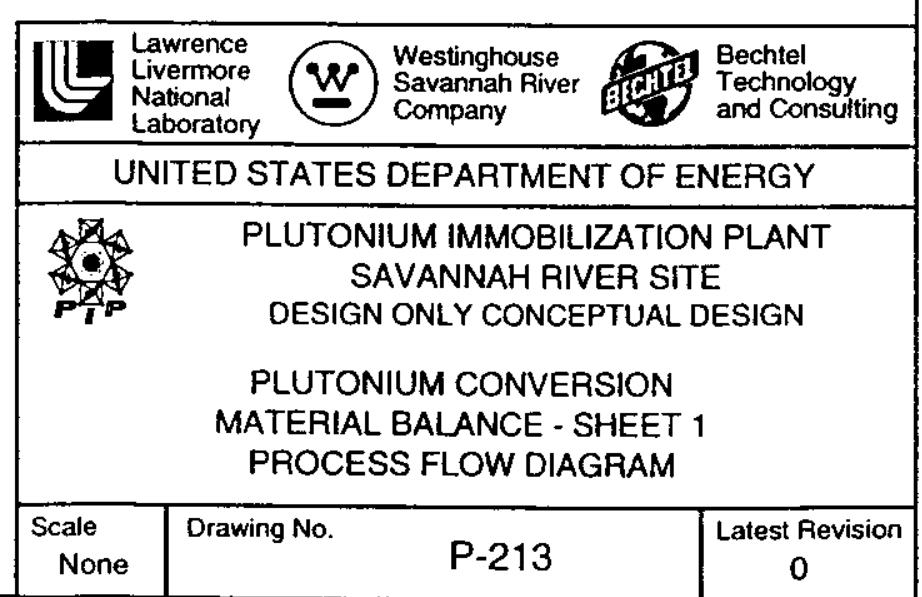




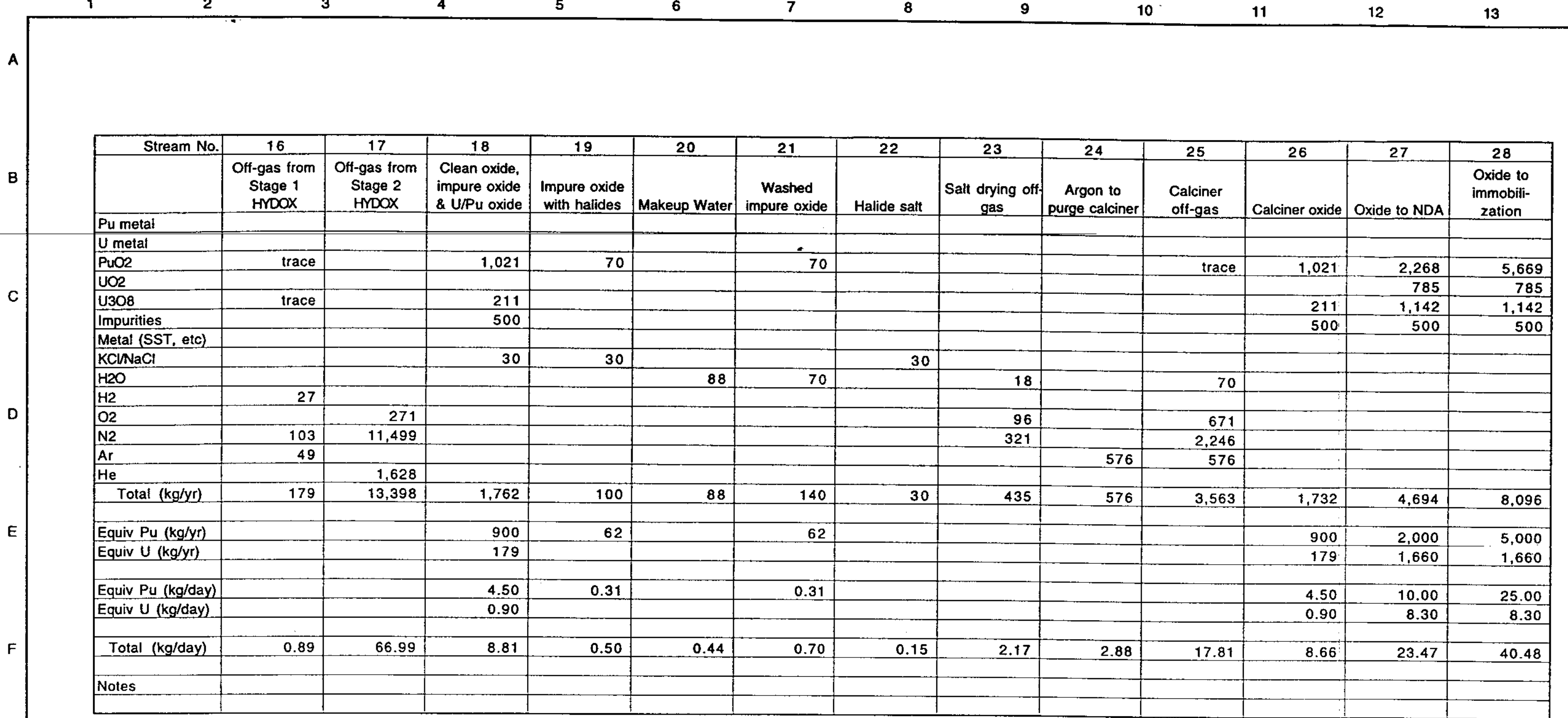

Notes
Plutonium conversion process is shown on drawings $\mathrm{P}-205$ to $\mathrm{P}-207$

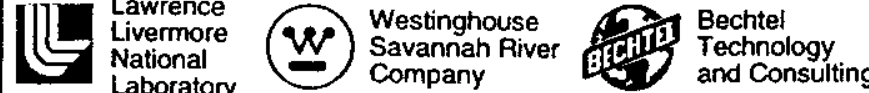
UNITED STATES DEPARTMENT OF ENERGY PLUTONIUM IMMOBILIZATION PLANT SAVANNAH RIVER SITE
DESIGN ONLY CONCEPTUAL DESIGN

PLUTONIUM CONVERSION MATERIAL BALANCE - SHEET PROCESS FLOW DIAGRAM

\begin{tabular}{l|lr}
\hline $\begin{array}{c}\text { Scale } \\
\text { None }\end{array}$ & Drawing No. & P-214
\end{tabular}




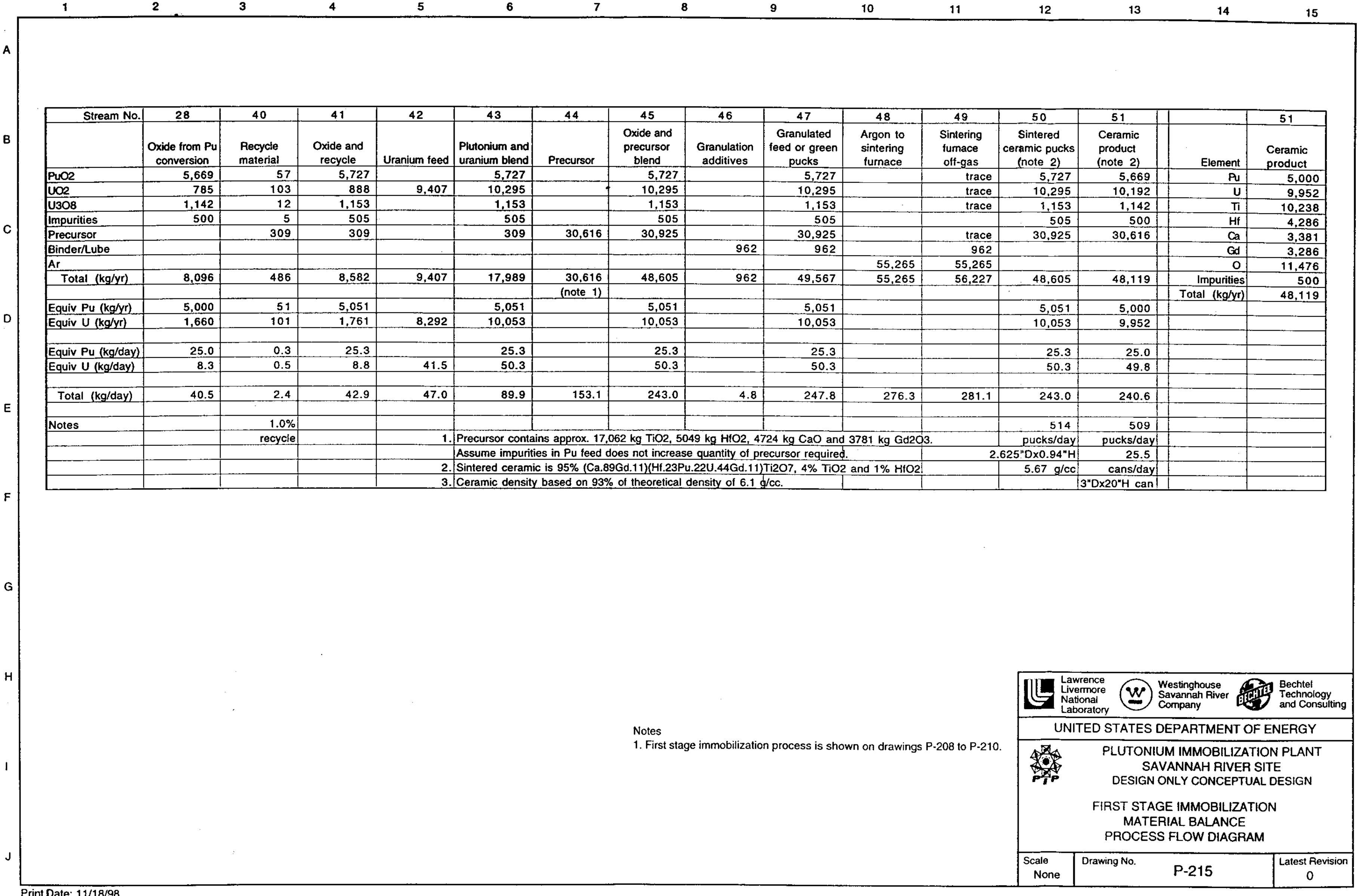




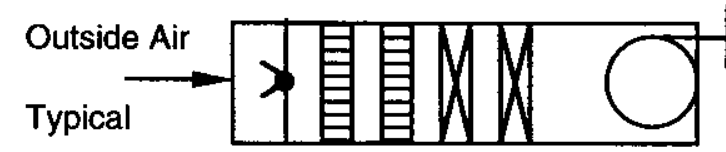

$85,000 \mathrm{cfm}$
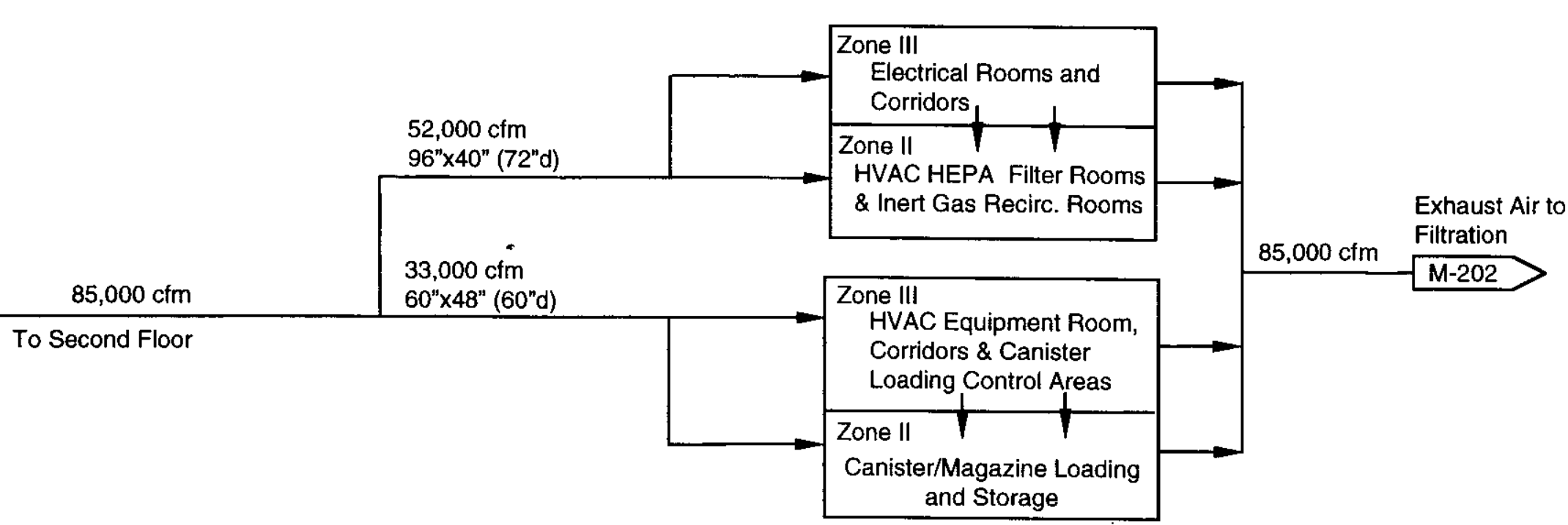

$\rightarrow$ 并目目WM
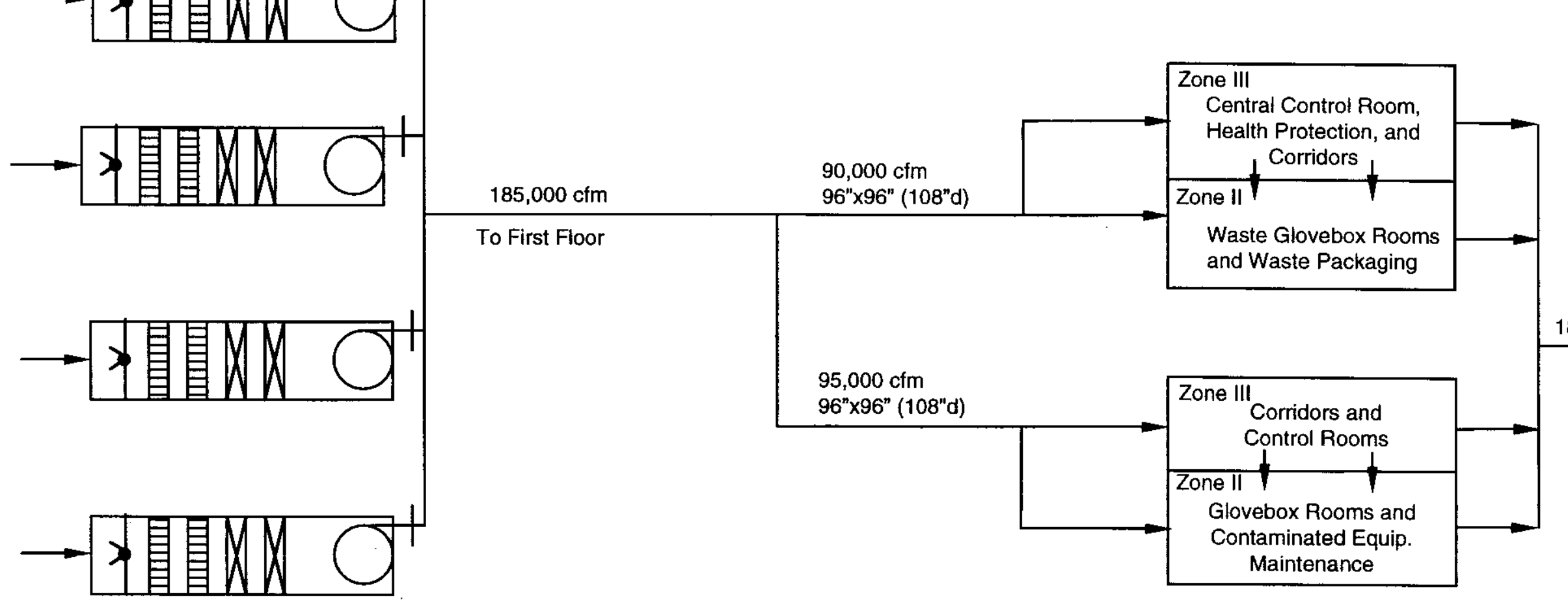

\begin{tabular}{|c|c|c|c|}
\hline \multirow{2}{*}{\multicolumn{4}{|c|}{ 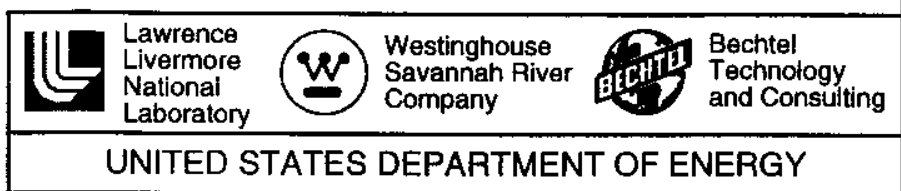 }} \\
\hline & & & \\
\hline 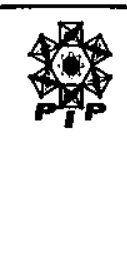 & \multicolumn{3}{|c|}{$\begin{array}{c}\text { PLUTONIUM IMMOBILIZATION PLANT } \\
\text { SAVANNAH RIVER SITE } \\
\text { DESIGN ONLY CONCEPTUAL DESIGN }\end{array}$} \\
\hline $\begin{array}{c}\text { Scale } \\
\text { None }\end{array}$ & Drawing No. & M-201 & $\begin{array}{c}\text { Latest Revision } \\
0\end{array}$ \\
\hline
\end{tabular}

Exhaust Air to $185,000 \mathrm{cfm}$ Filtration $M-202$ 


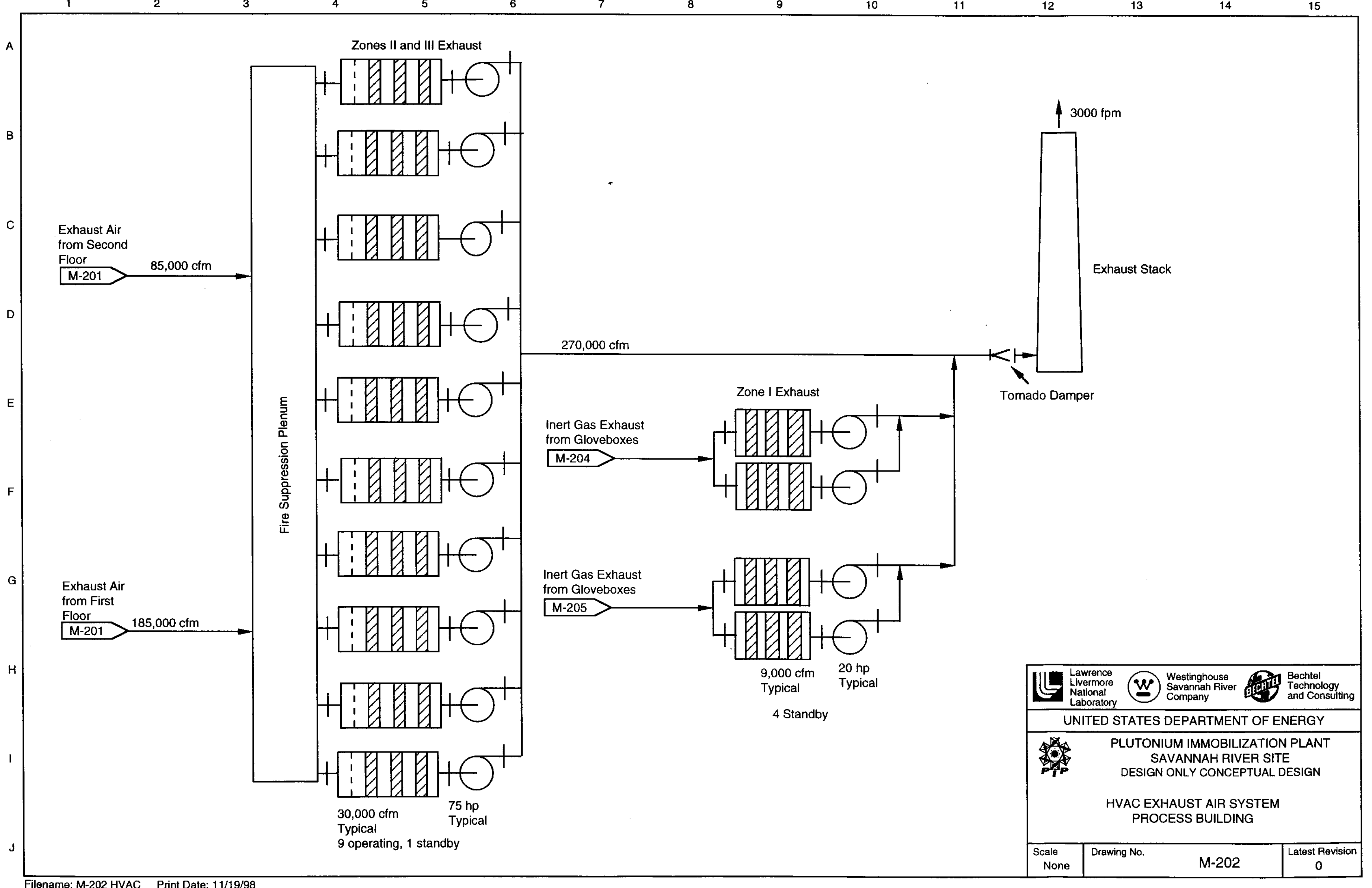




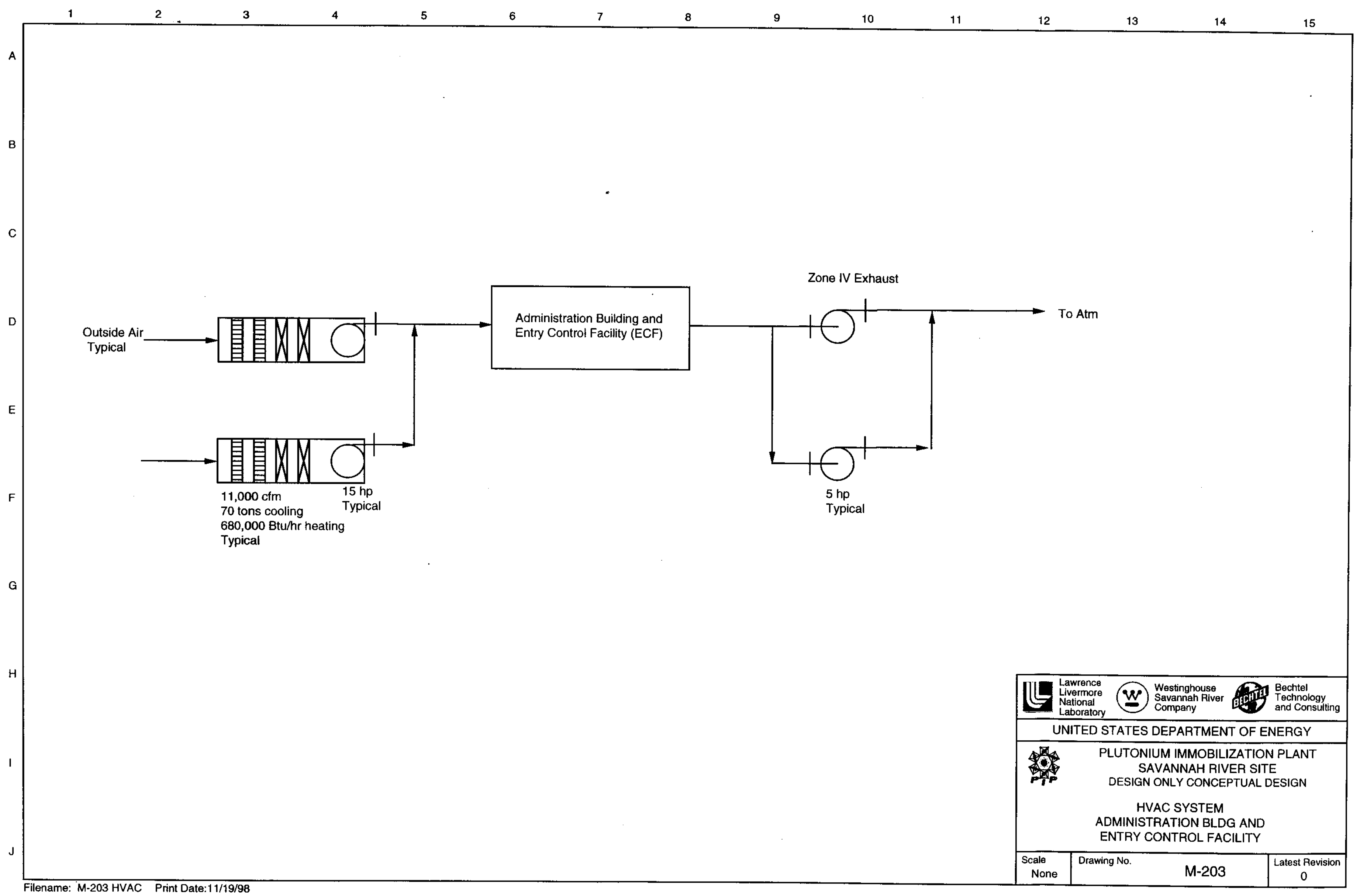




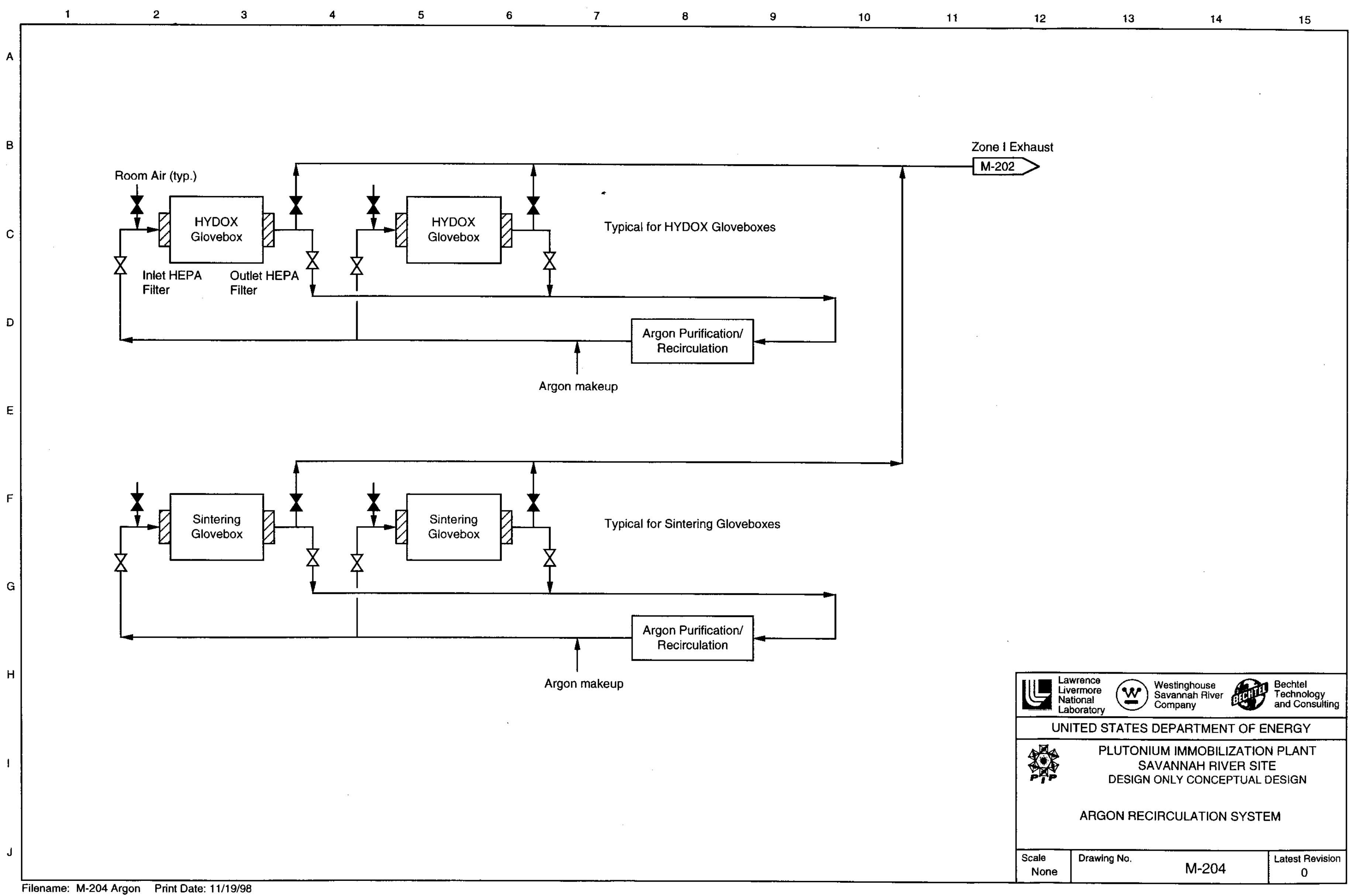




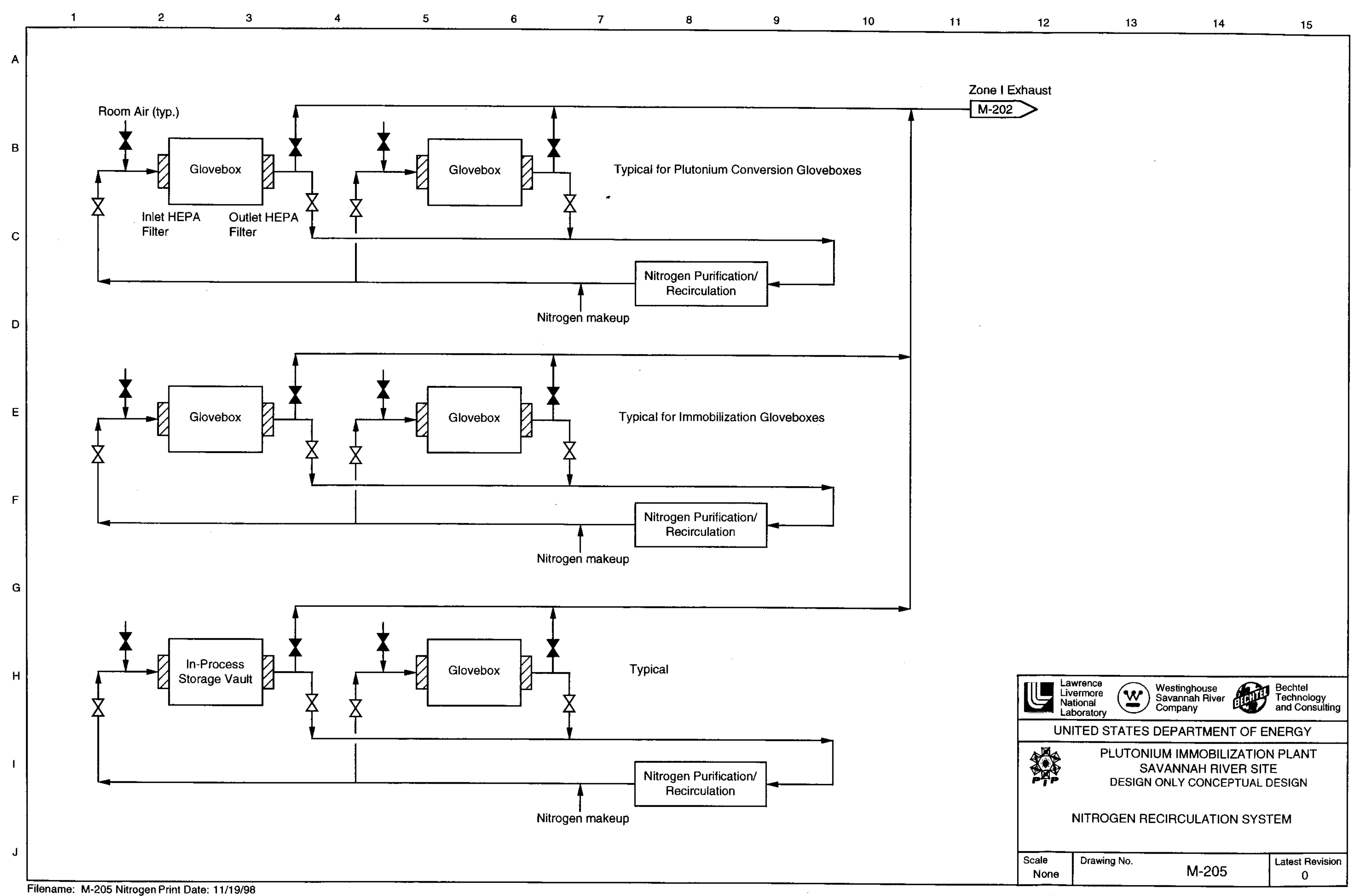




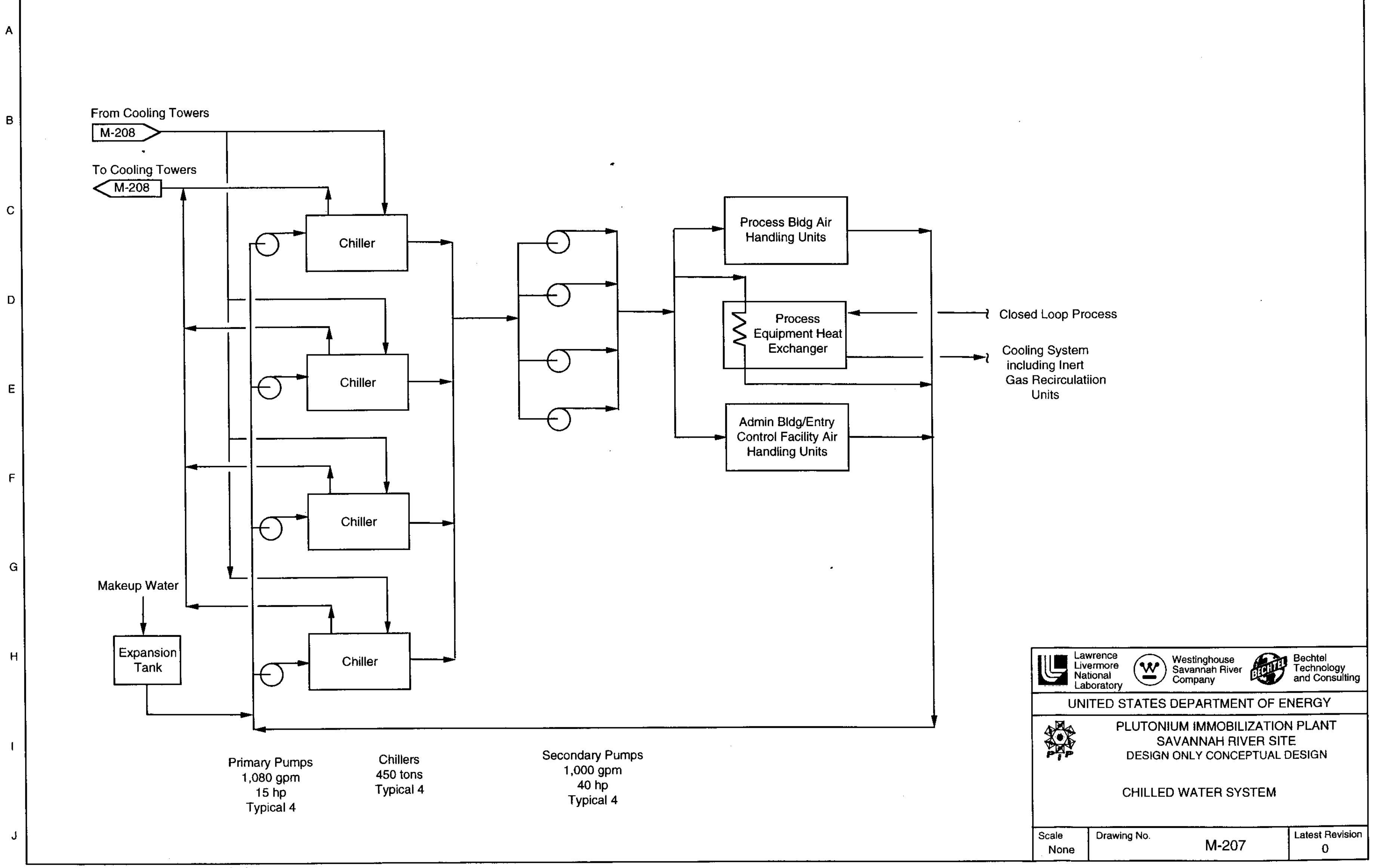




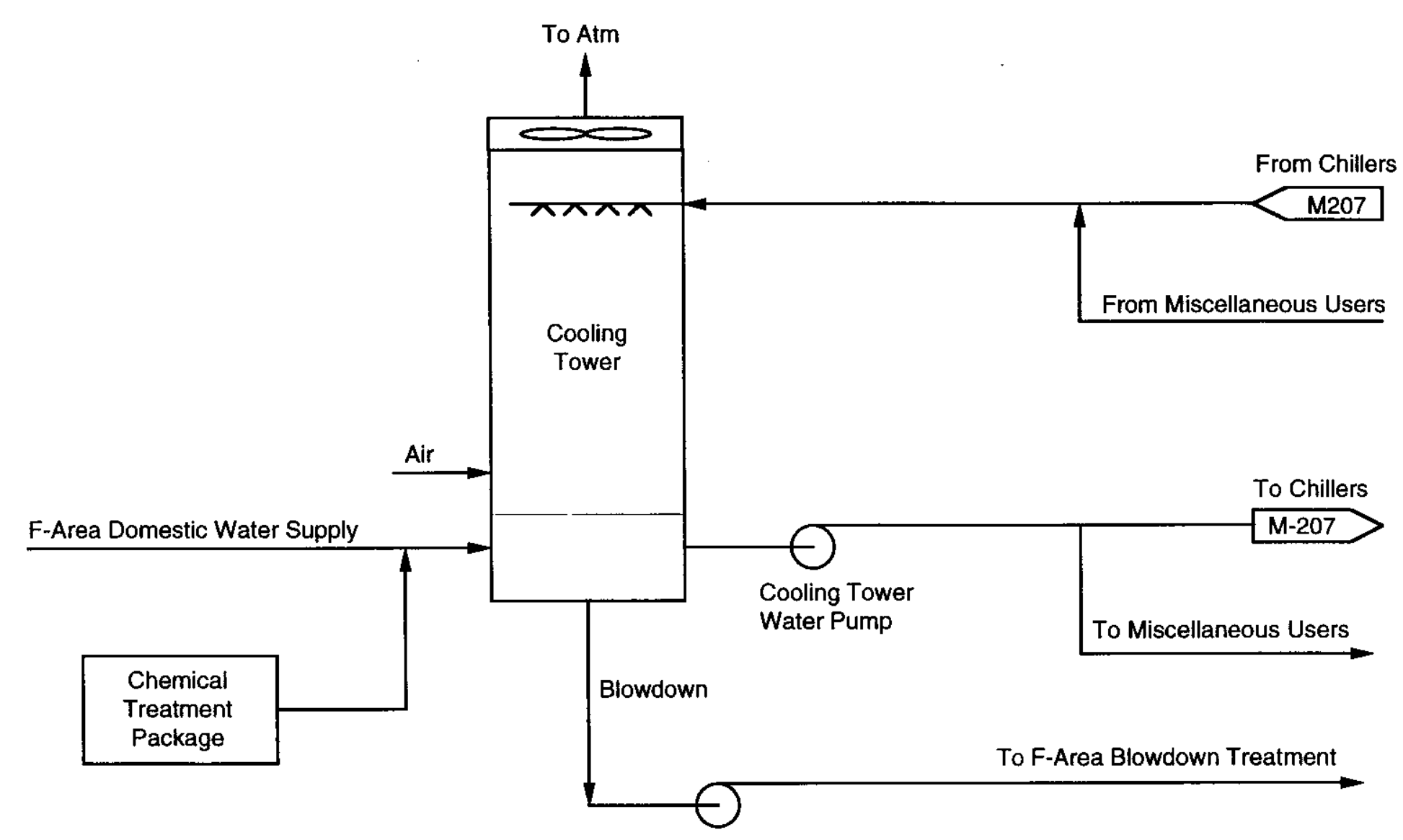

Cooling Towers

450 tons

Cooling Tower

Water Pumps

$1,350 \mathrm{gpm}, 30 \mathrm{~h}$
Typical 4

\begin{tabular}{|c|c|c|c|}
\hline \multirow{2}{*}{\multicolumn{4}{|c|}{ 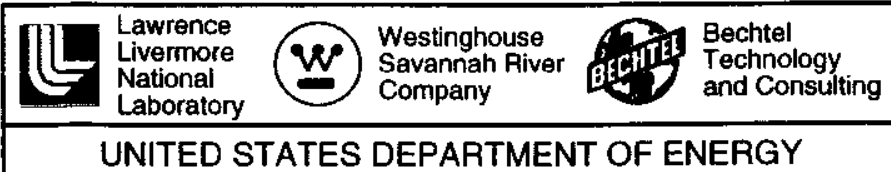 }} \\
\hline & & & \\
\hline 模 & \multicolumn{3}{|c|}{$\begin{array}{c}\text { PLUTONIUM IMMOBILIZATION PLANT } \\
\text { SAAVANNAH RIVER SITE } \\
\text { DESIGN ONLY CONCEPTUAL DESIGN }\end{array}$} \\
\hline $\begin{array}{c}\text { Scale } \\
\text { None }\end{array}$ & Drawing No. & M-208 & $\begin{array}{c}\text { Latest Revision } \\
0\end{array}$ \\
\hline
\end{tabular}




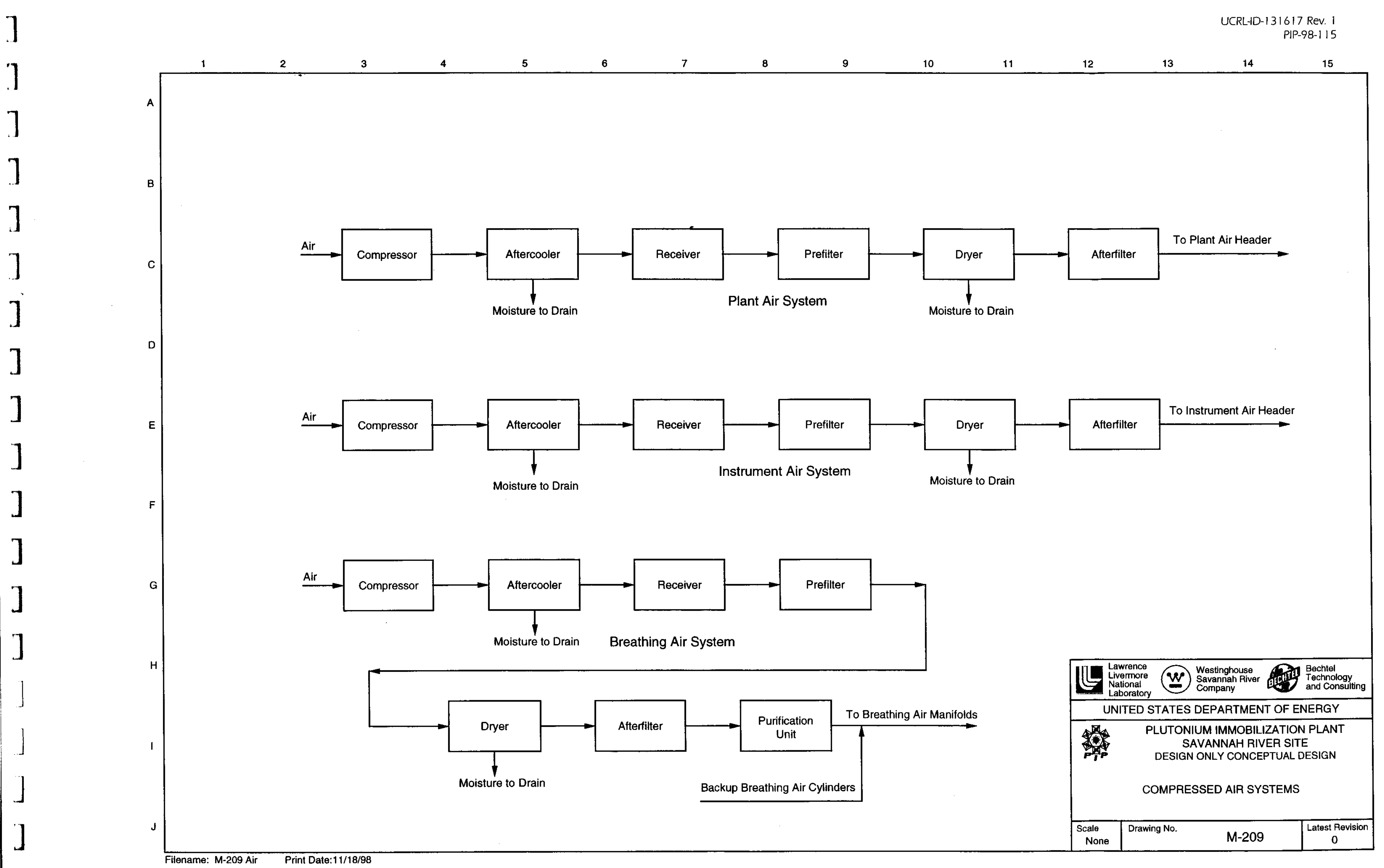




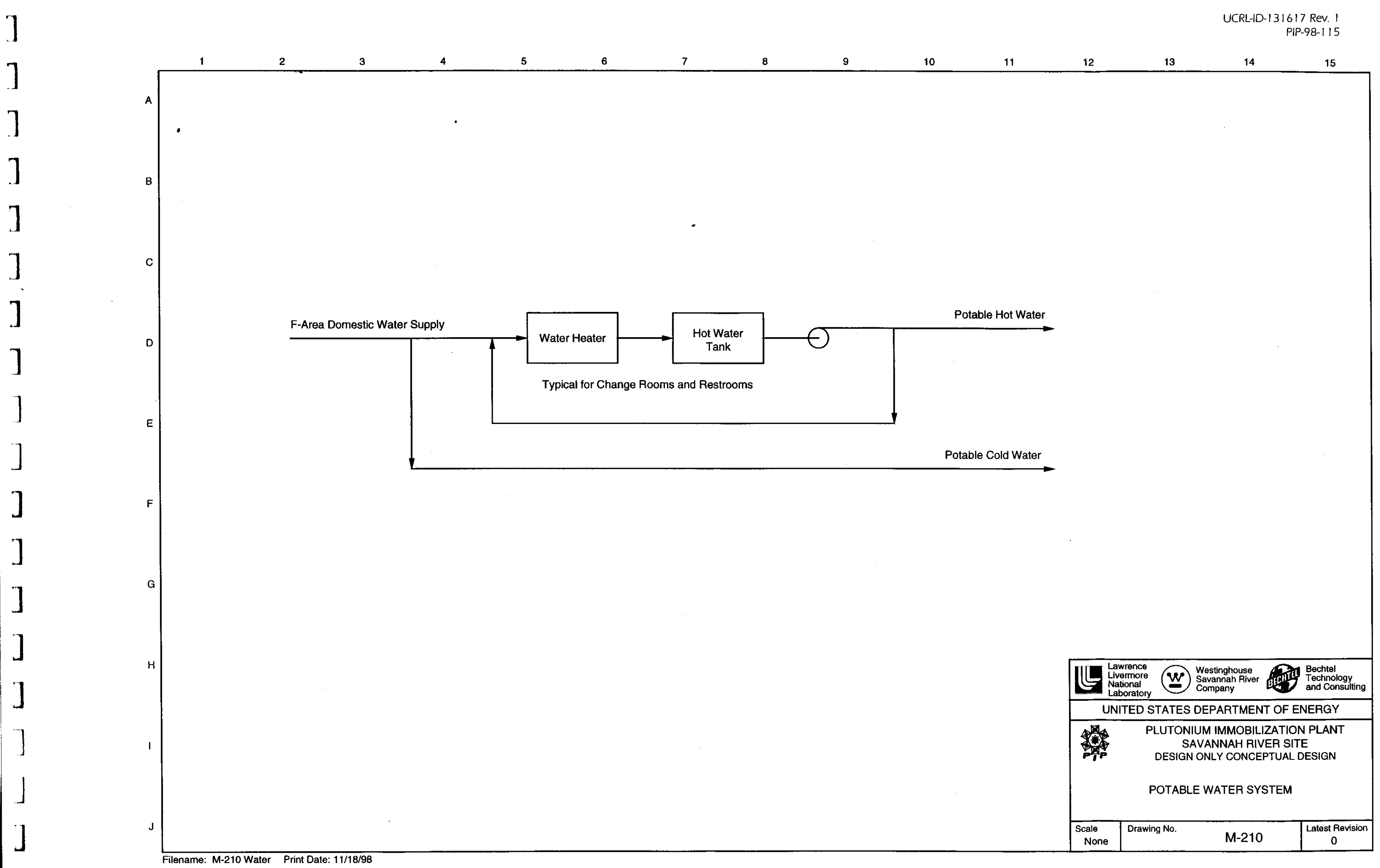




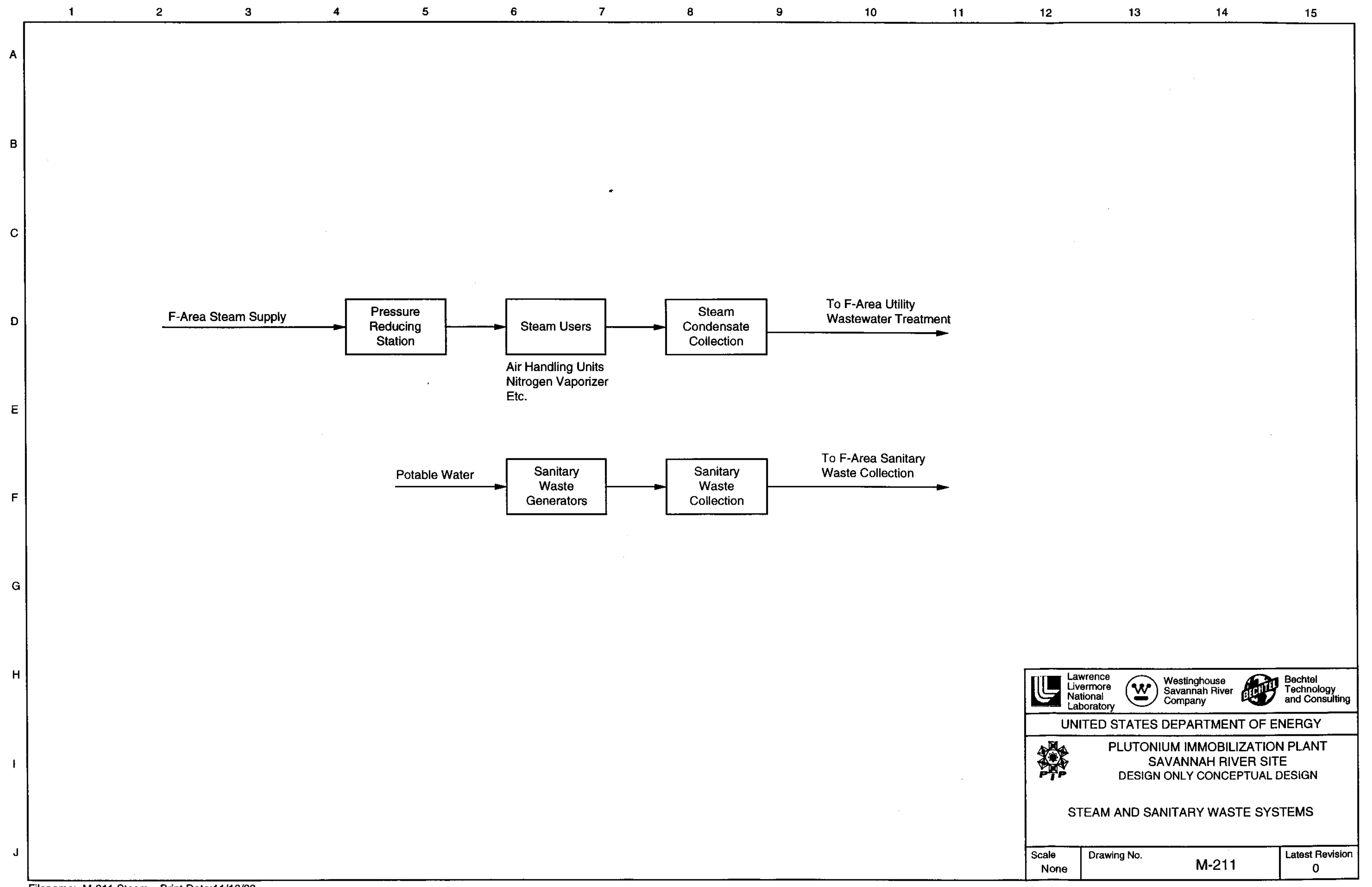




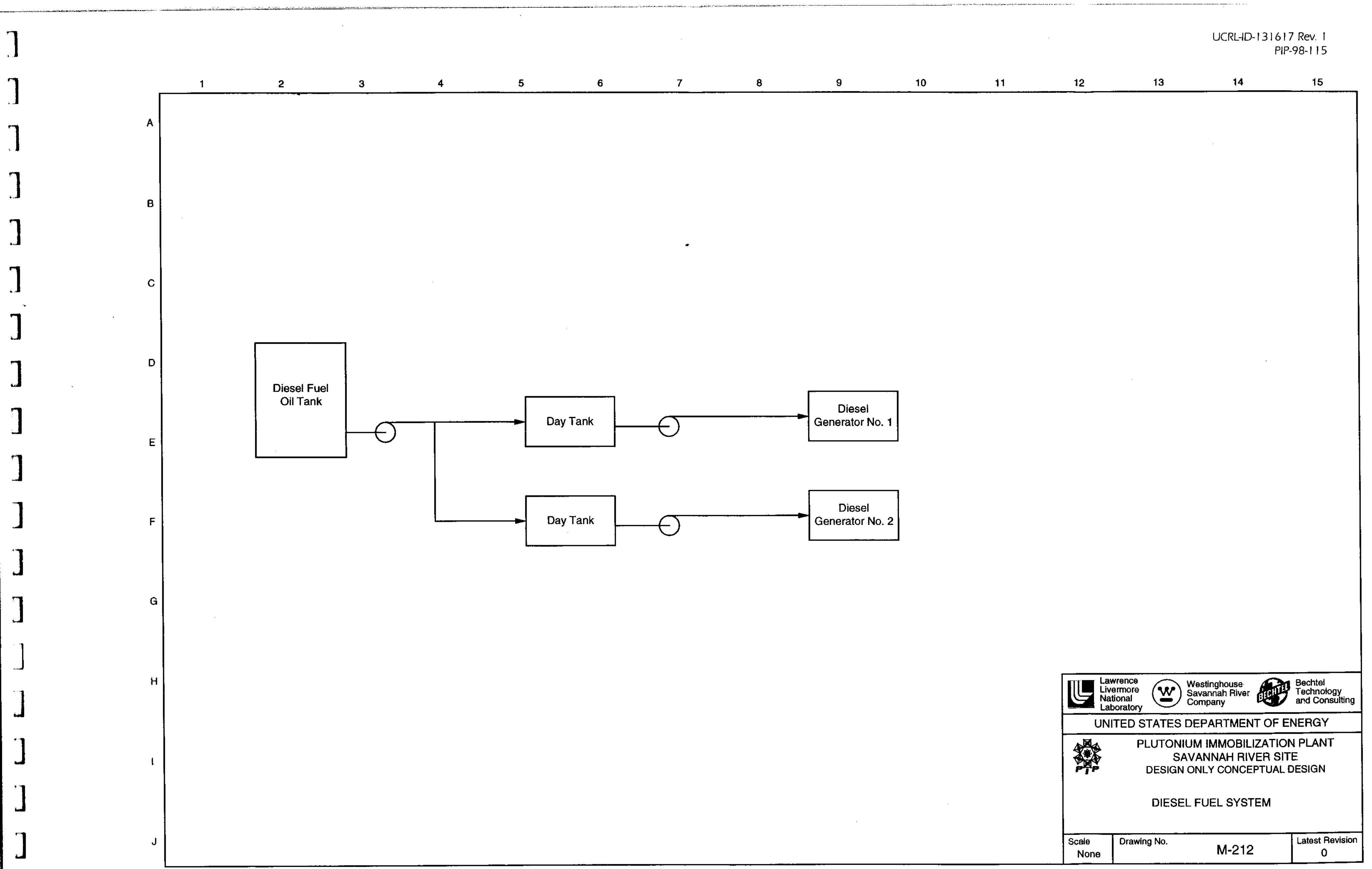

] 


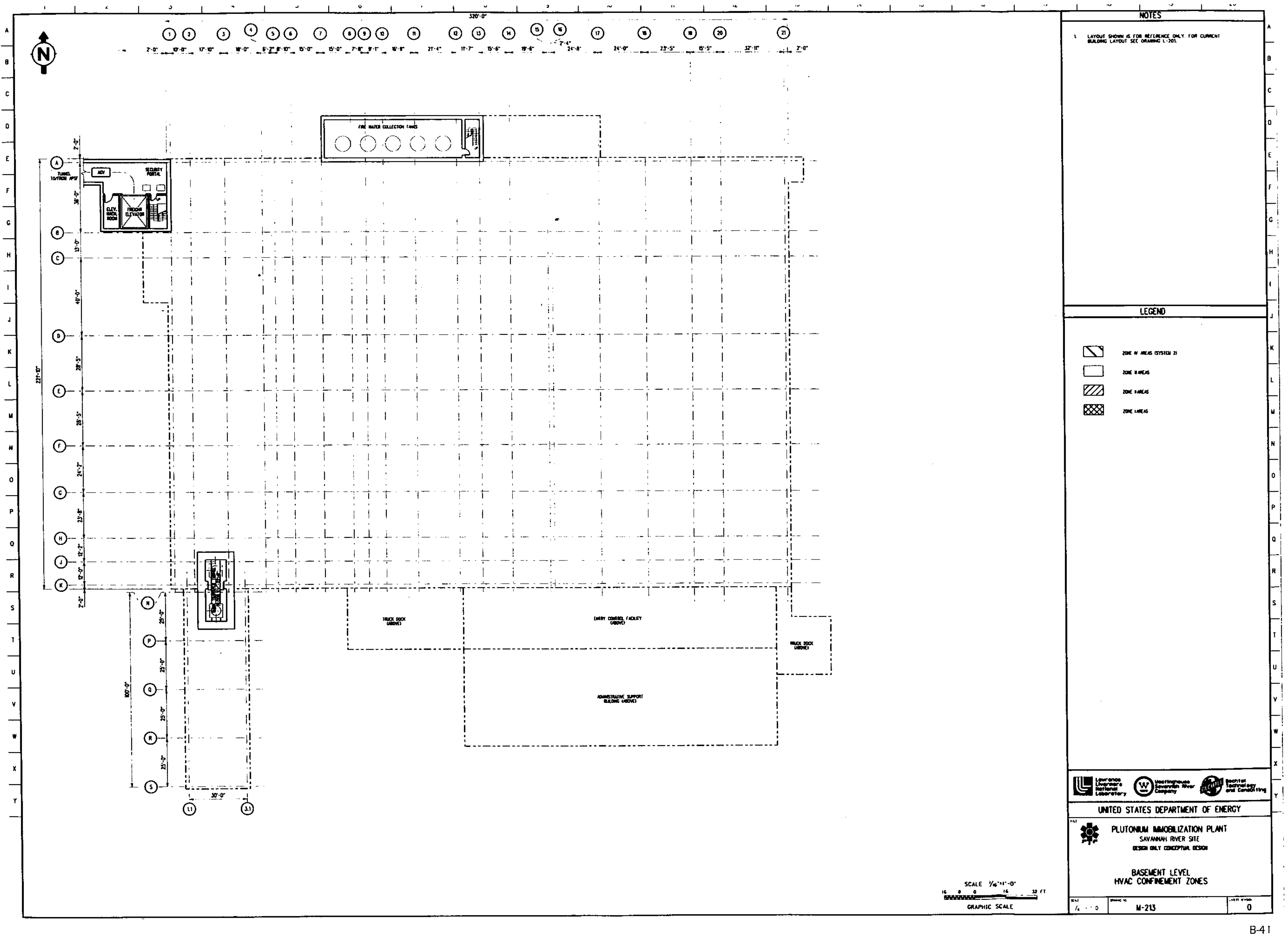




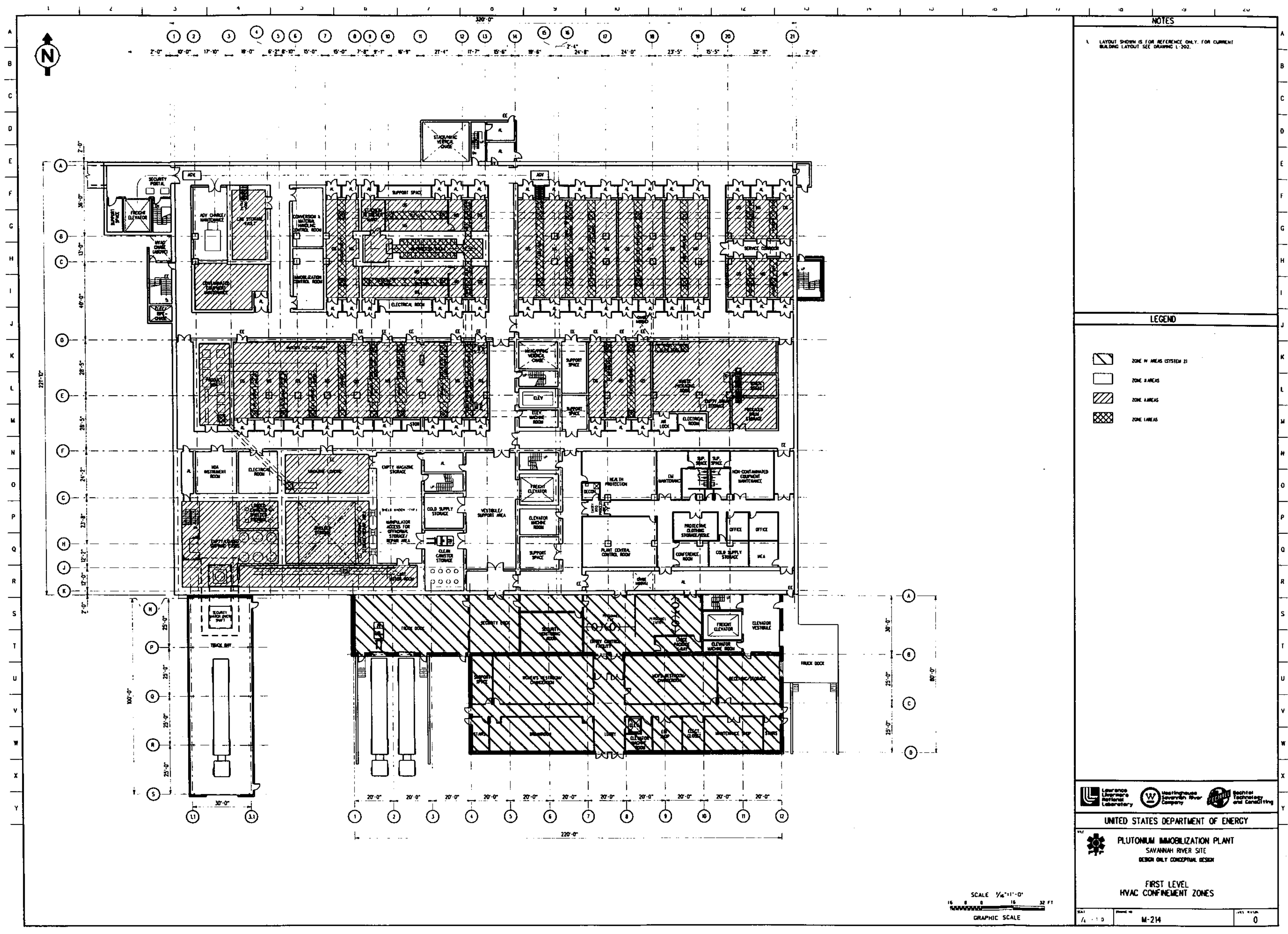




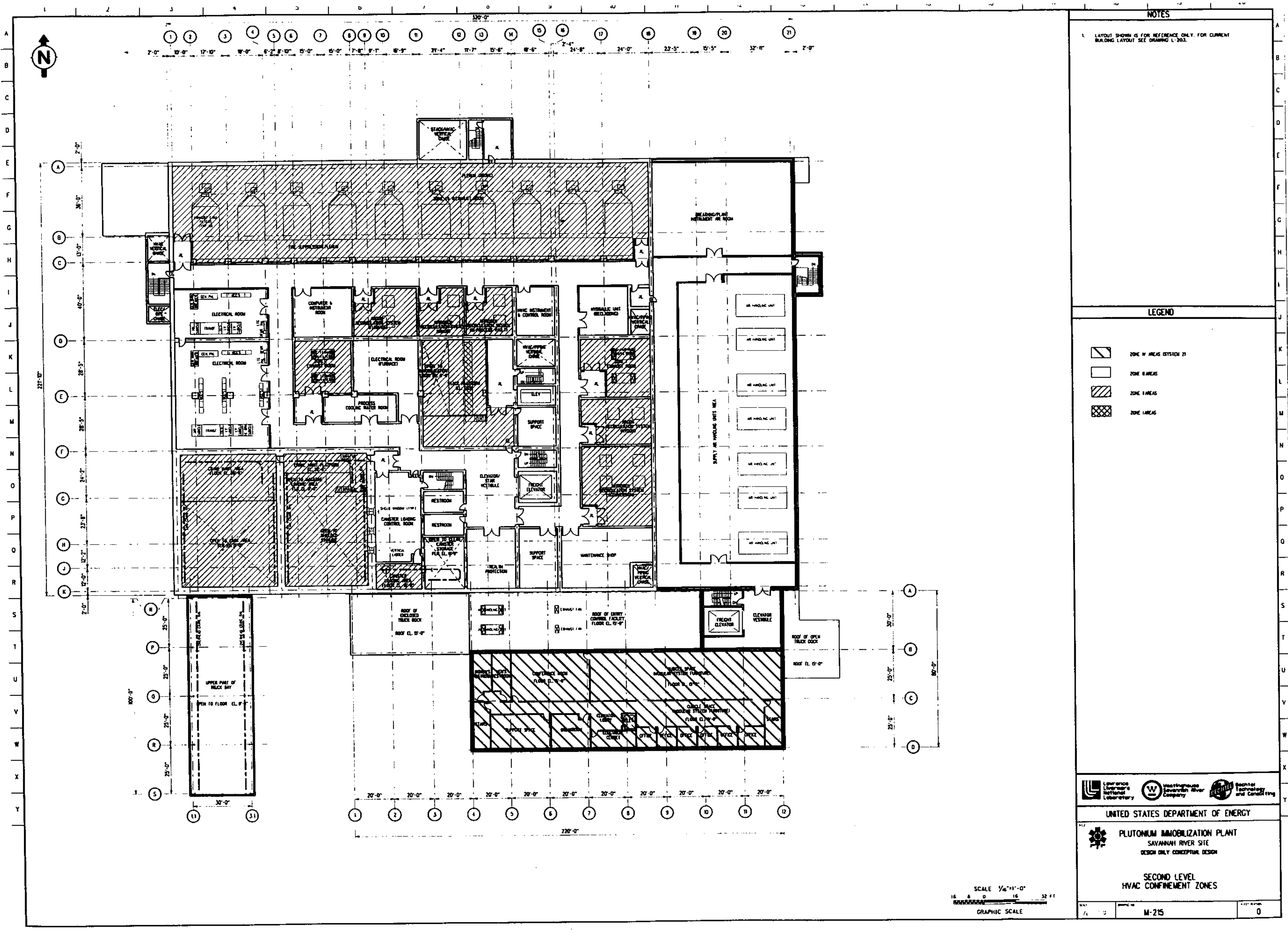




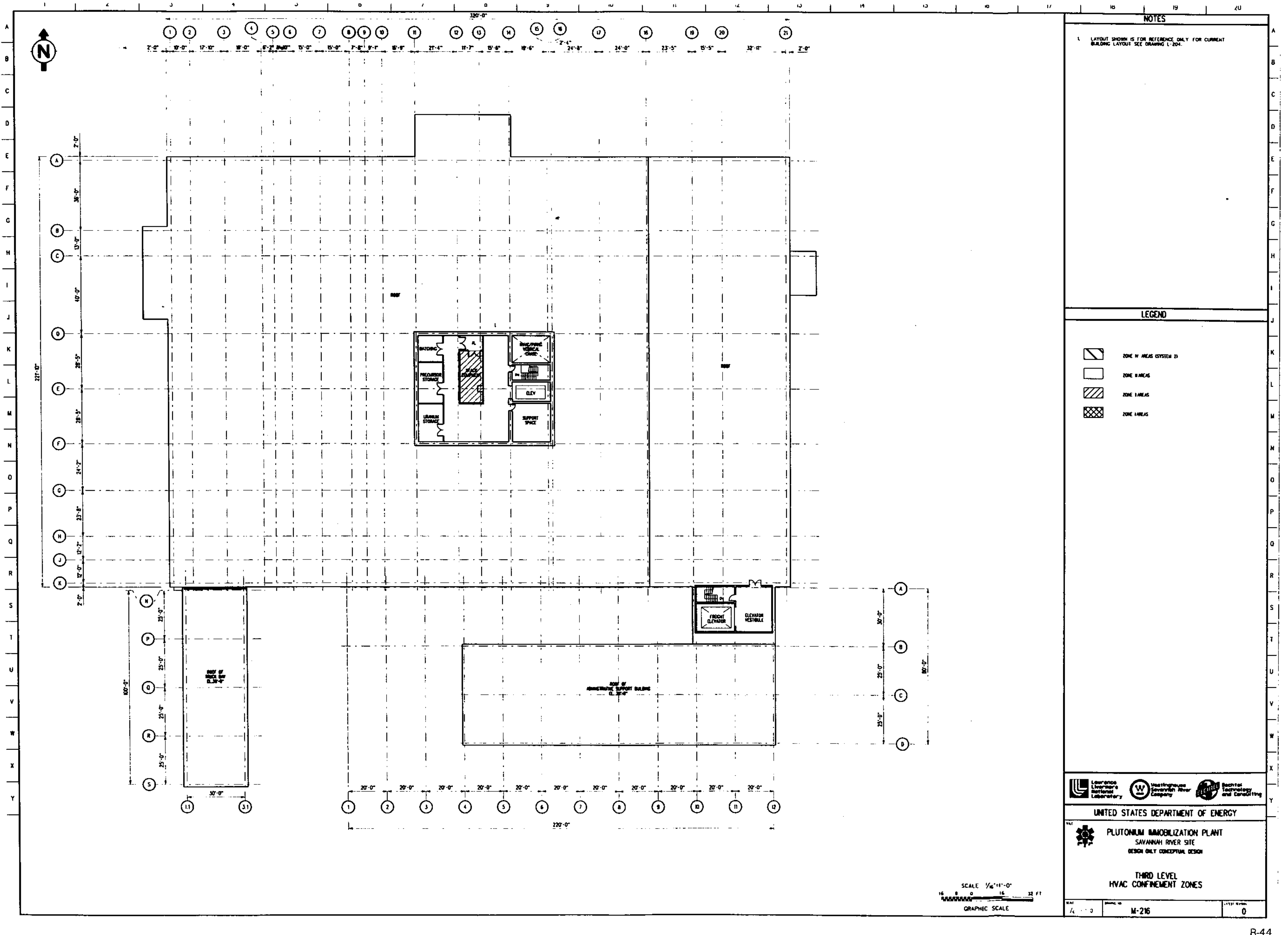




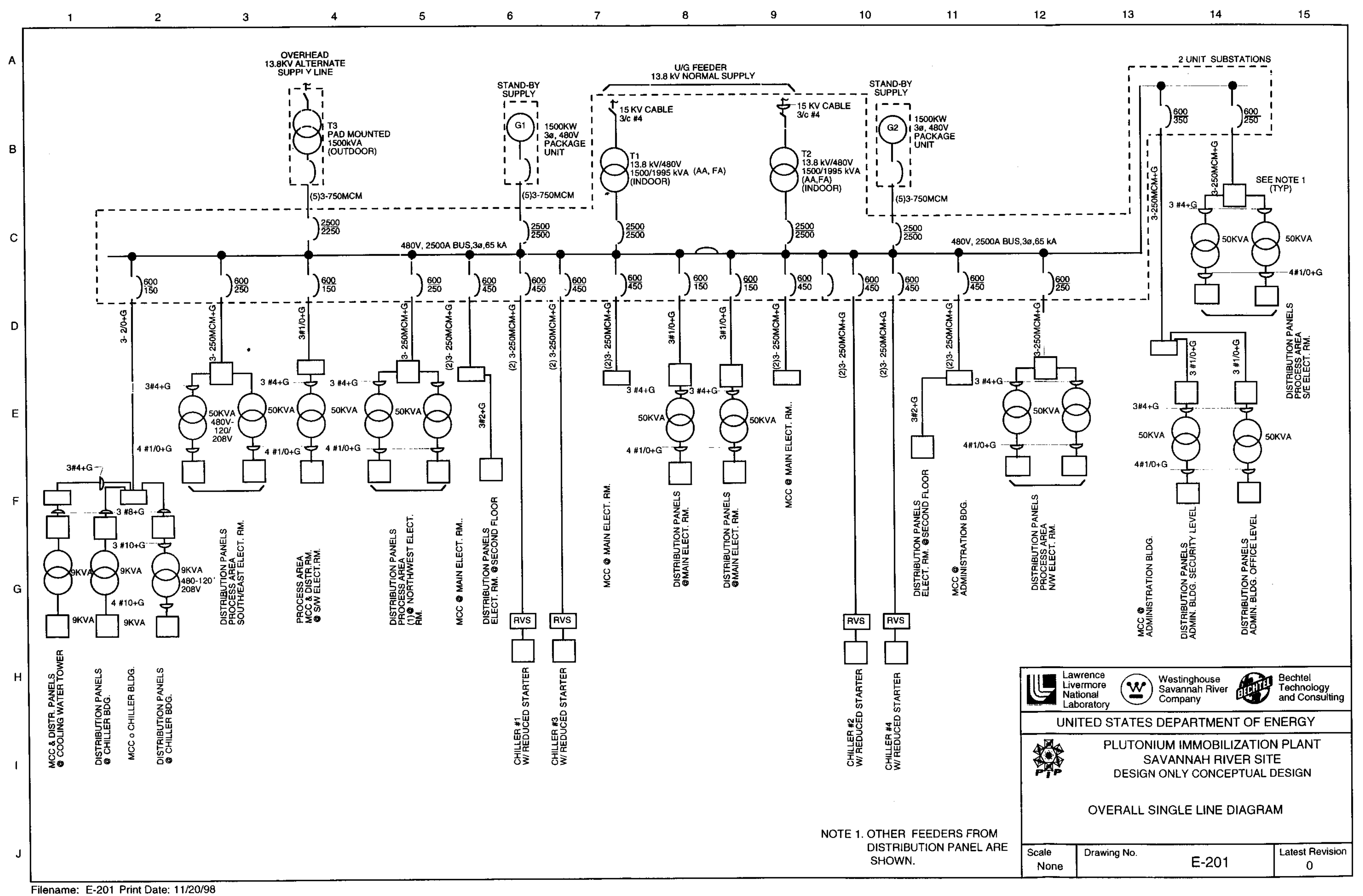




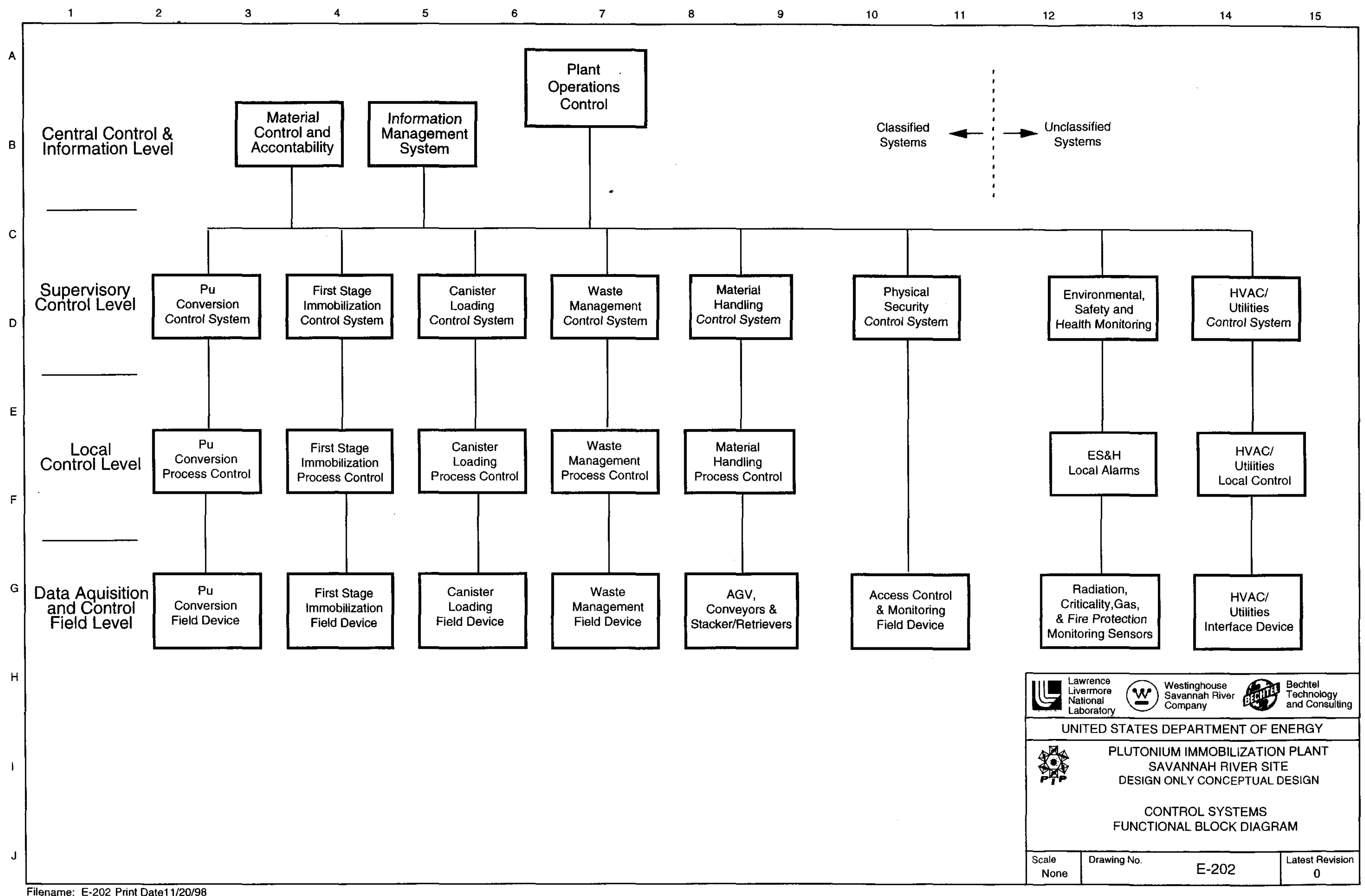




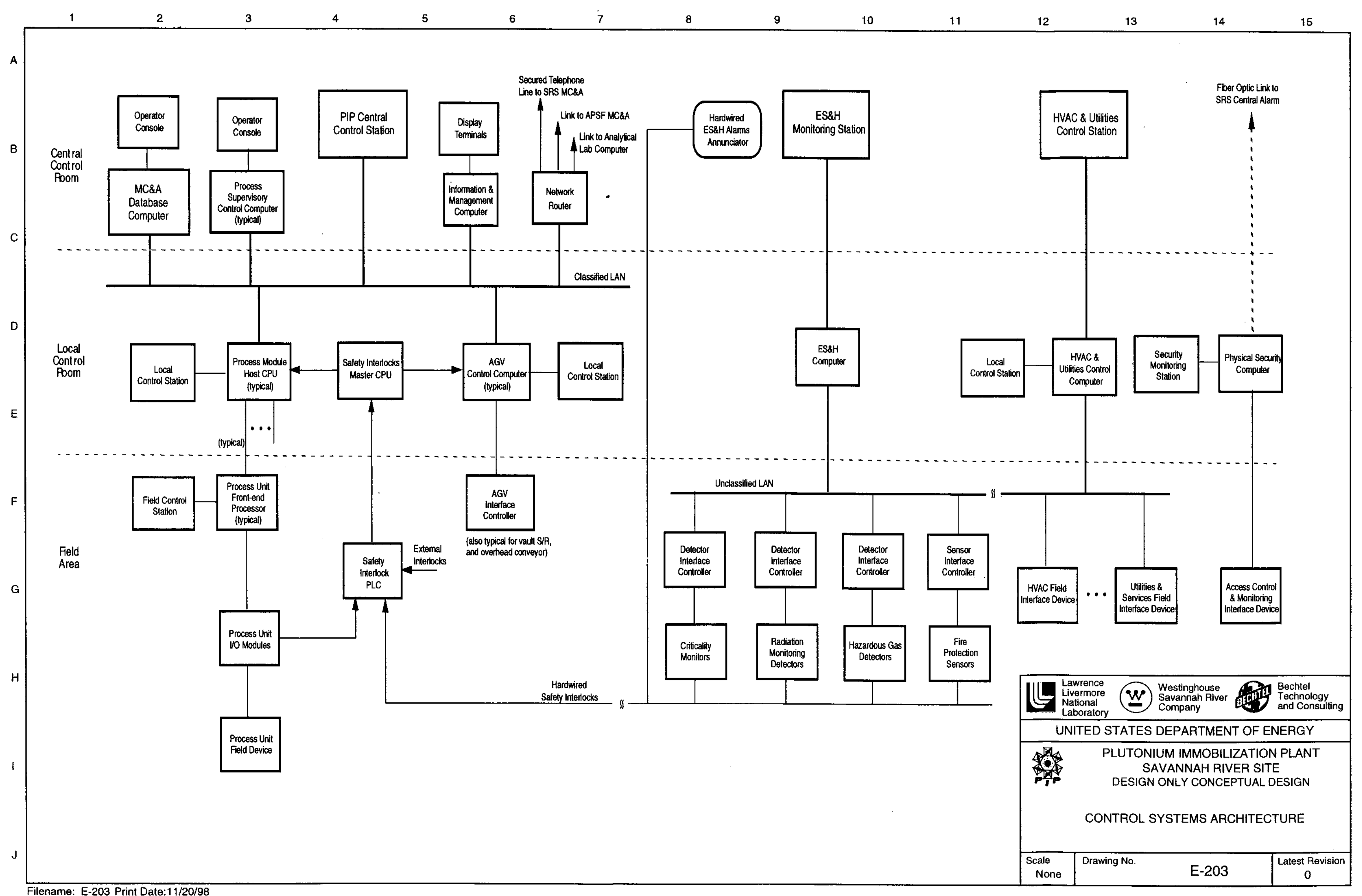




\section{Appendix $C$ Equipment List}

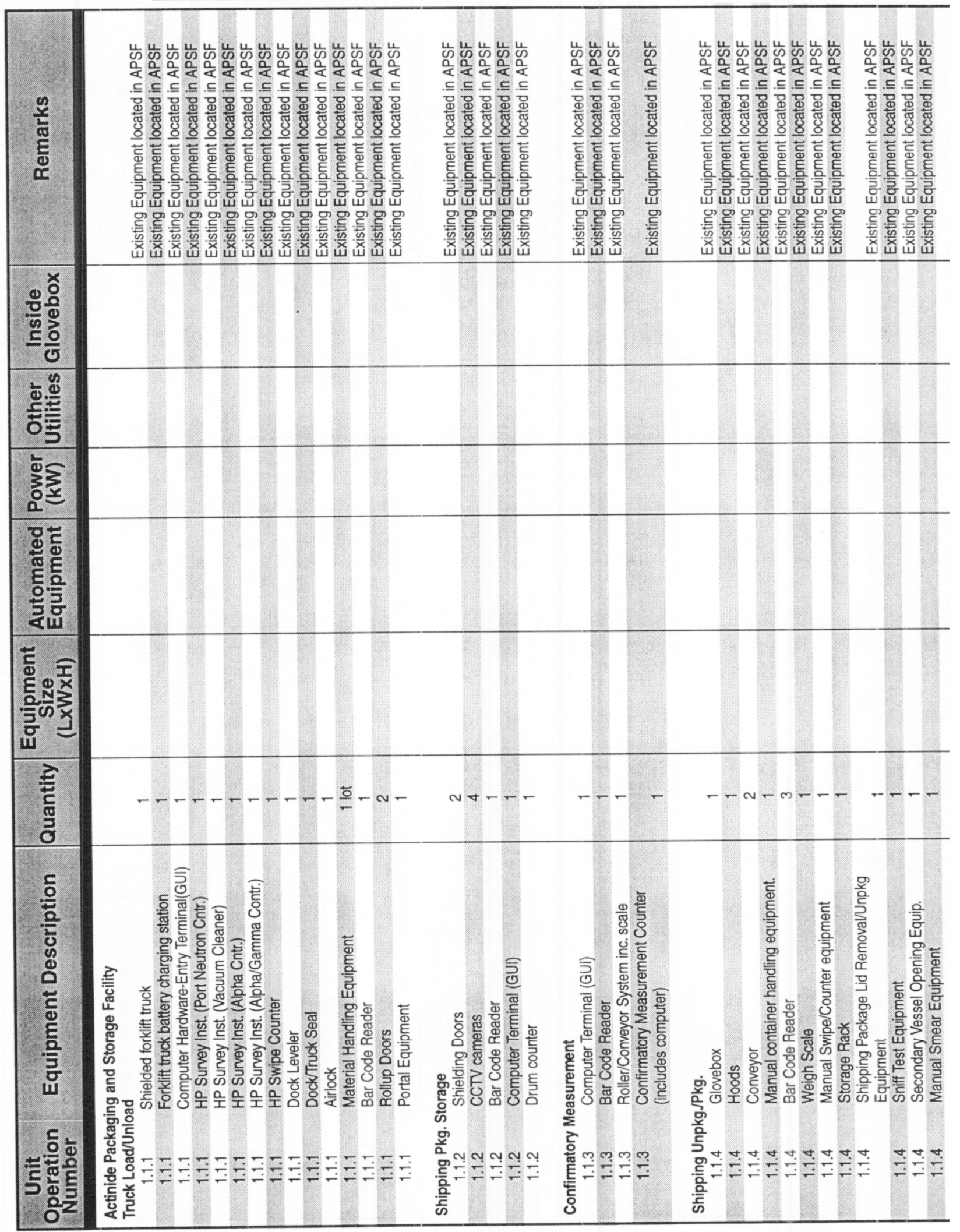


UCRL-ID-131617 Rev. I

PIP-98-115

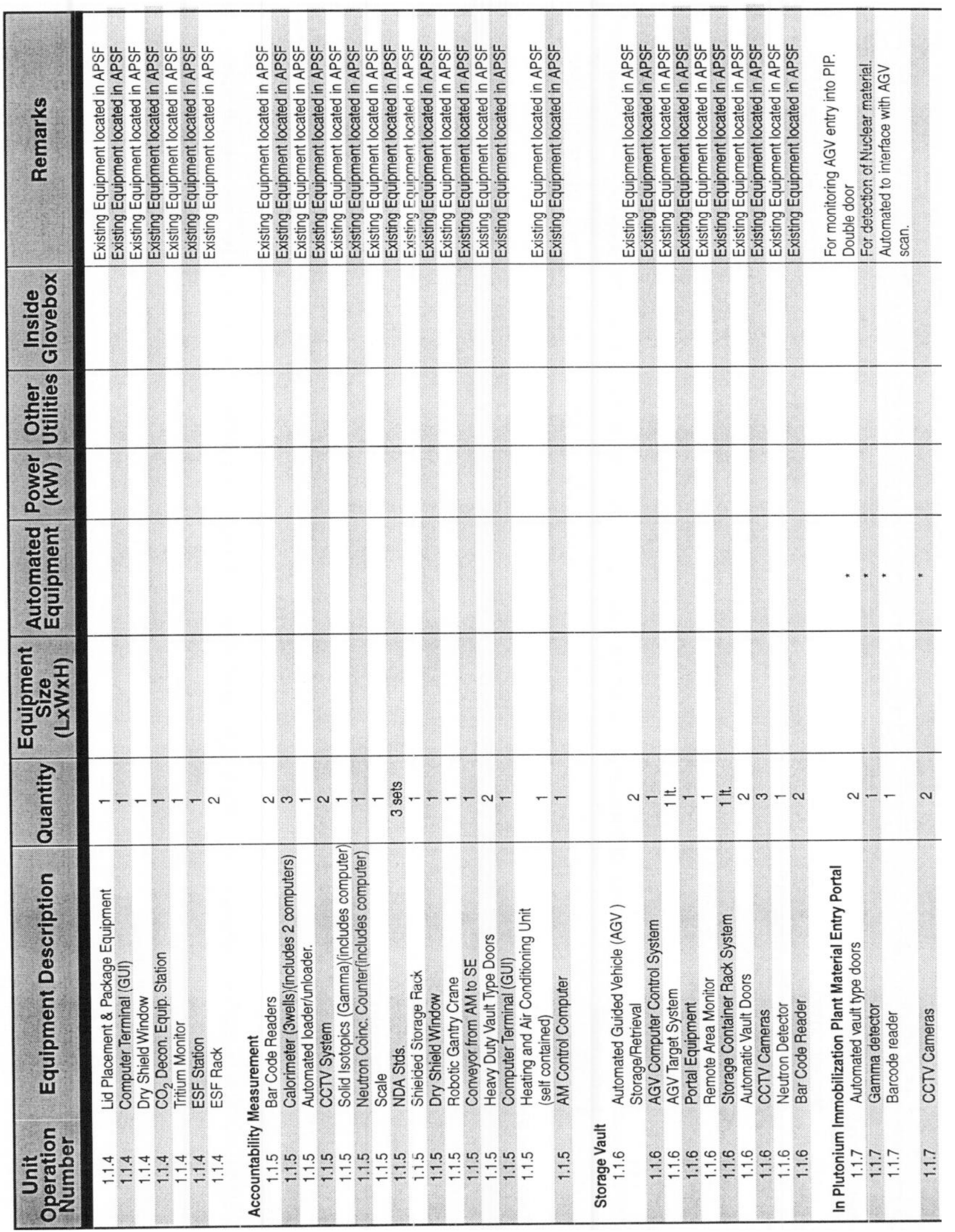




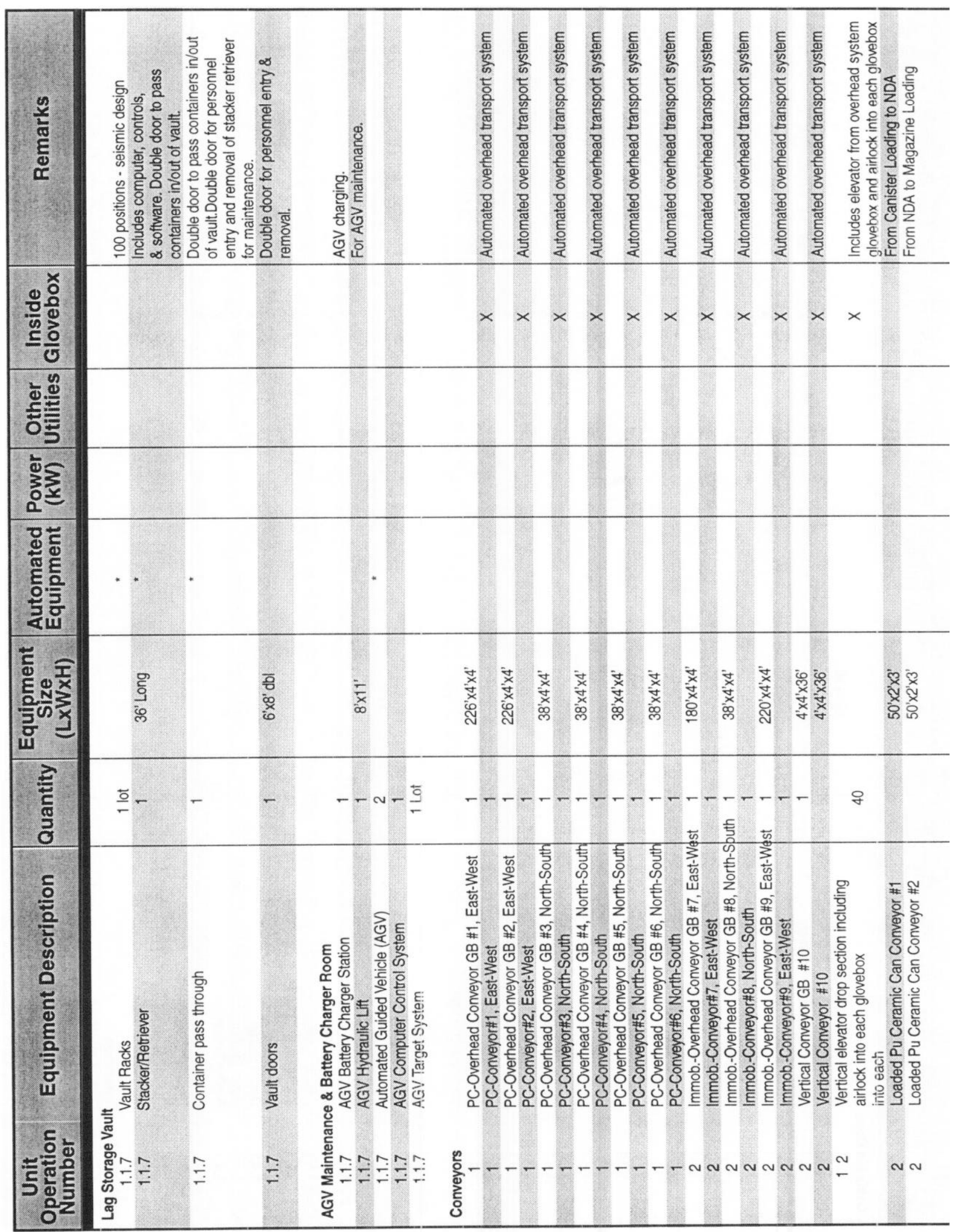


UCRL-ID-131617 Rev. I

PIP-98-I I5

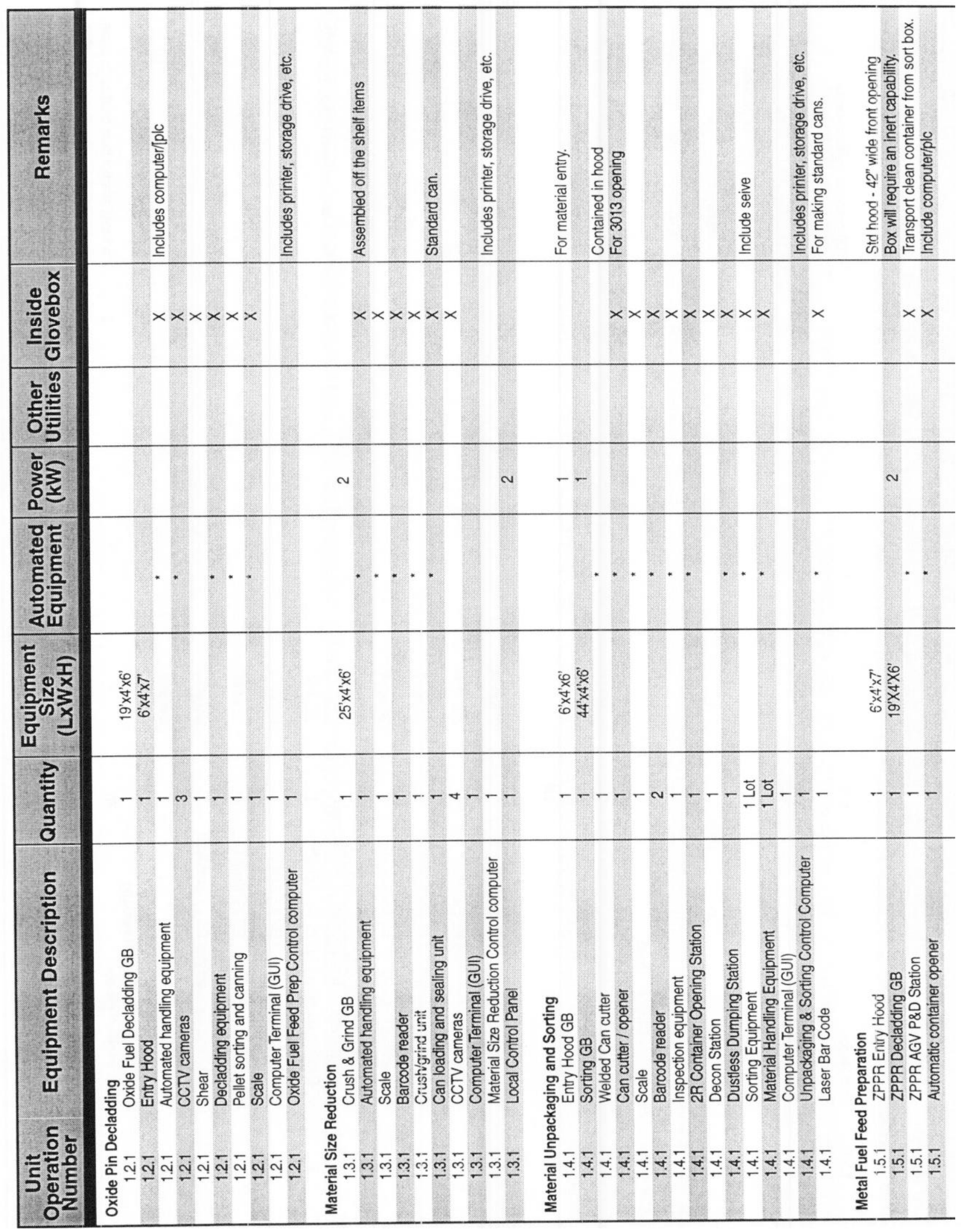




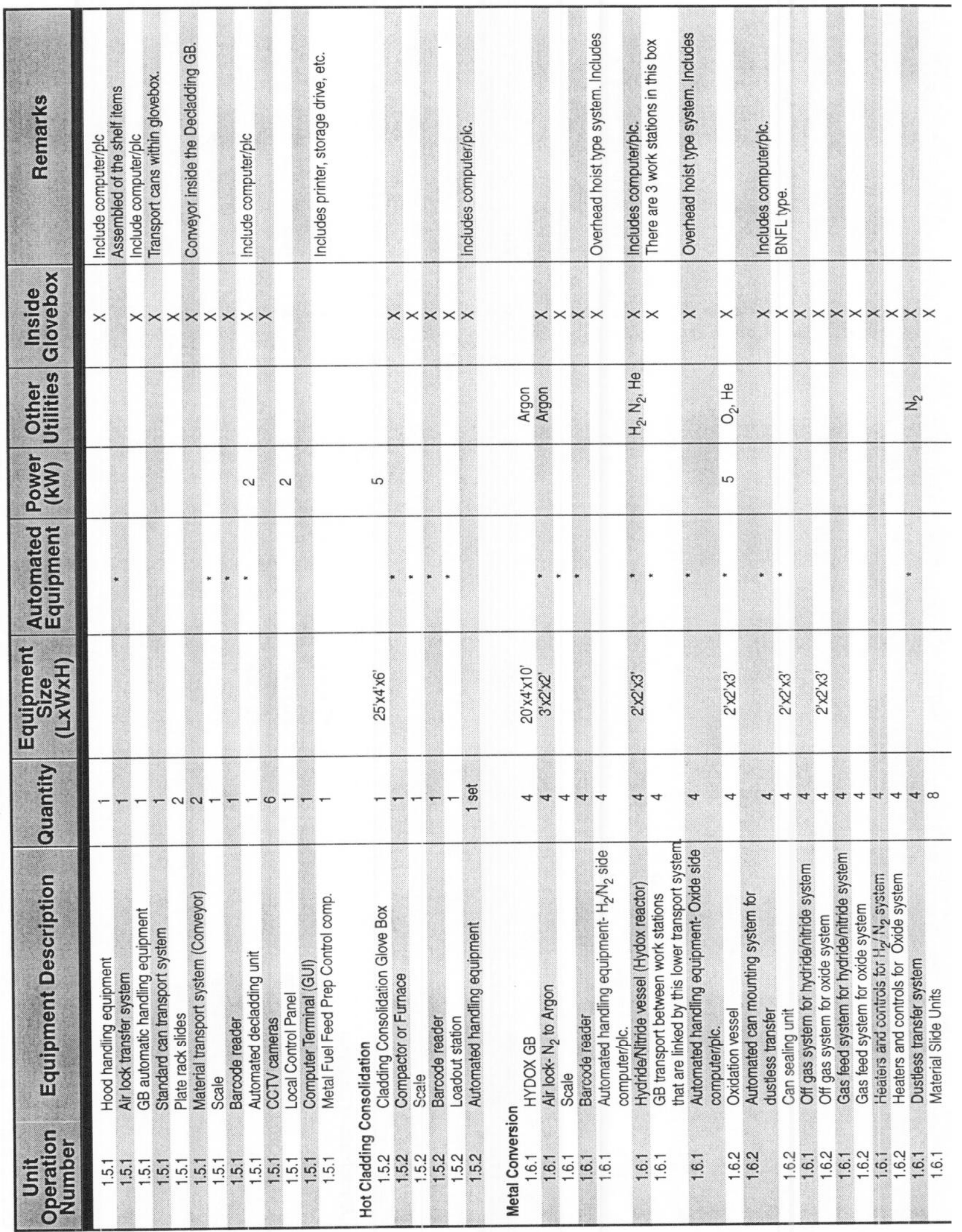


UCRL-ID-131617 Rev. 1

PIP-98-115

\begin{tabular}{|c|c|c|c|c|c|c|c|}
\hline$\frac{g}{\frac{g}{2}}$ & 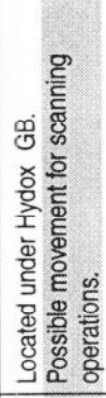 & 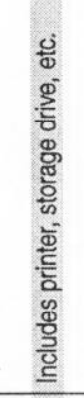 & 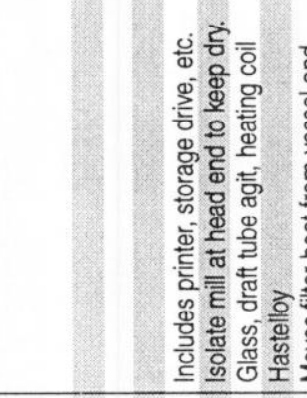 & 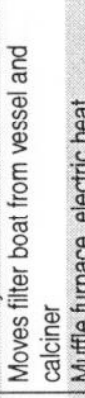 & 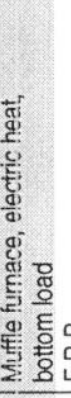 & 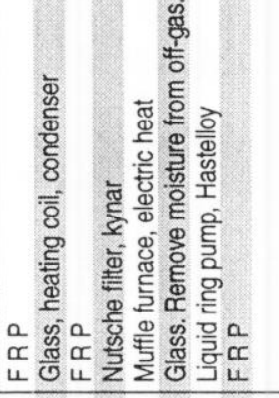 & 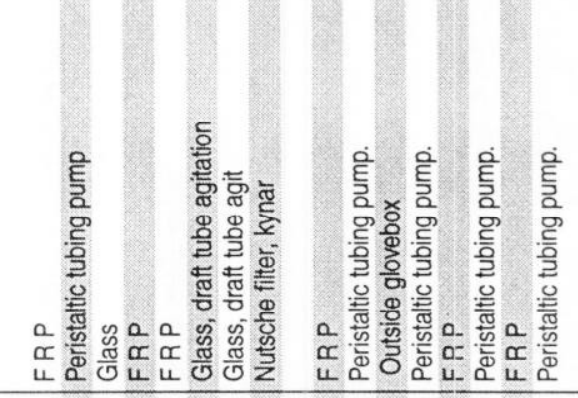 \\
\hline 등ㅇํㅇ & $\times x$ & & $x \times x>$ & & & $\times \times \times \times \times \times \times \times$ & $\times \times \times \times \times \times \times \times \times$ \\
\hline & & & & & & & \\
\hline 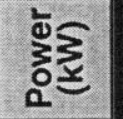 & & & & & & & \\
\hline 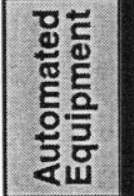 & & & & & & & \\
\hline 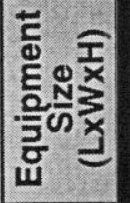 & & & 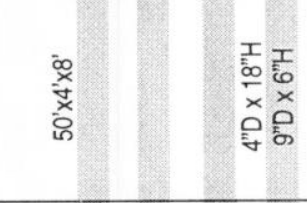 & & & 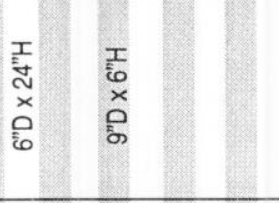 & 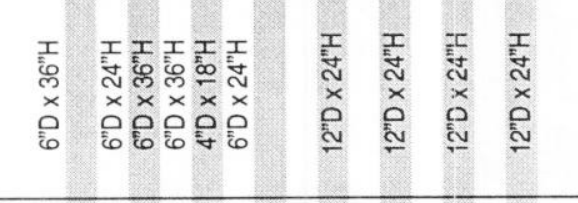 \\
\hline$\frac{\sum^{\frac{2}{c}}}{\frac{\pi}{0}}$ & $\nabla \widetilde{ల}$ & $\theta \theta$ & - & & -- & & - \\
\hline 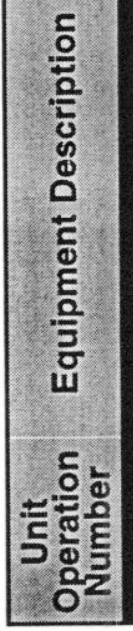 & 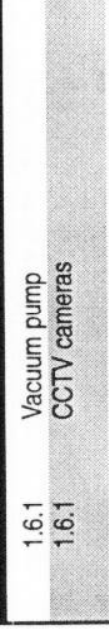 & 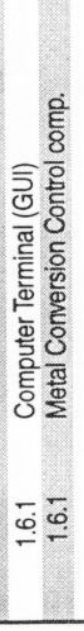 & 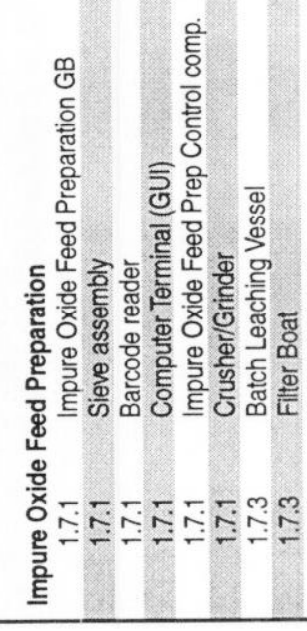 & 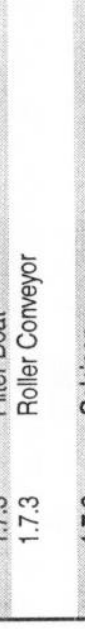 & $\frac{\frac{5}{5}}{D_{5}^{5}}$ & 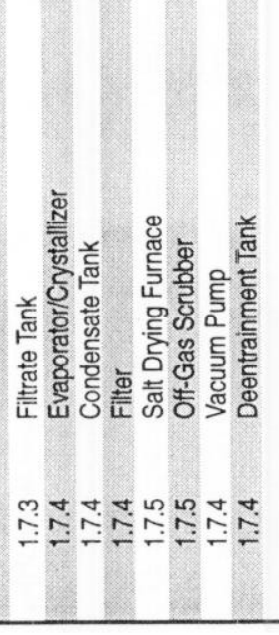 & 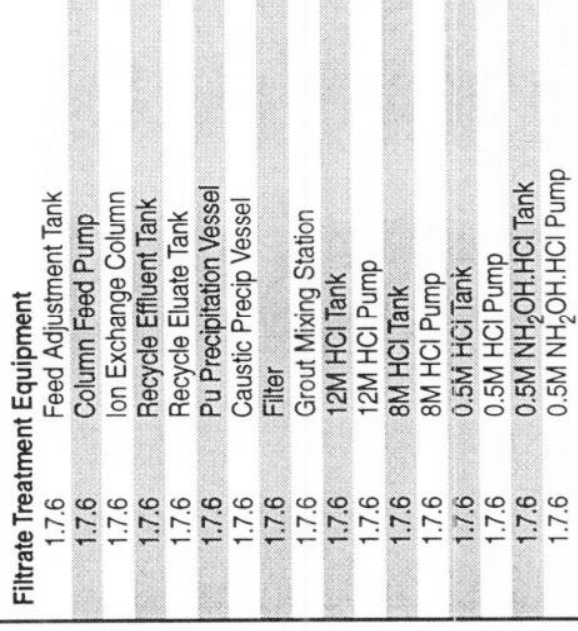 \\
\hline
\end{tabular}




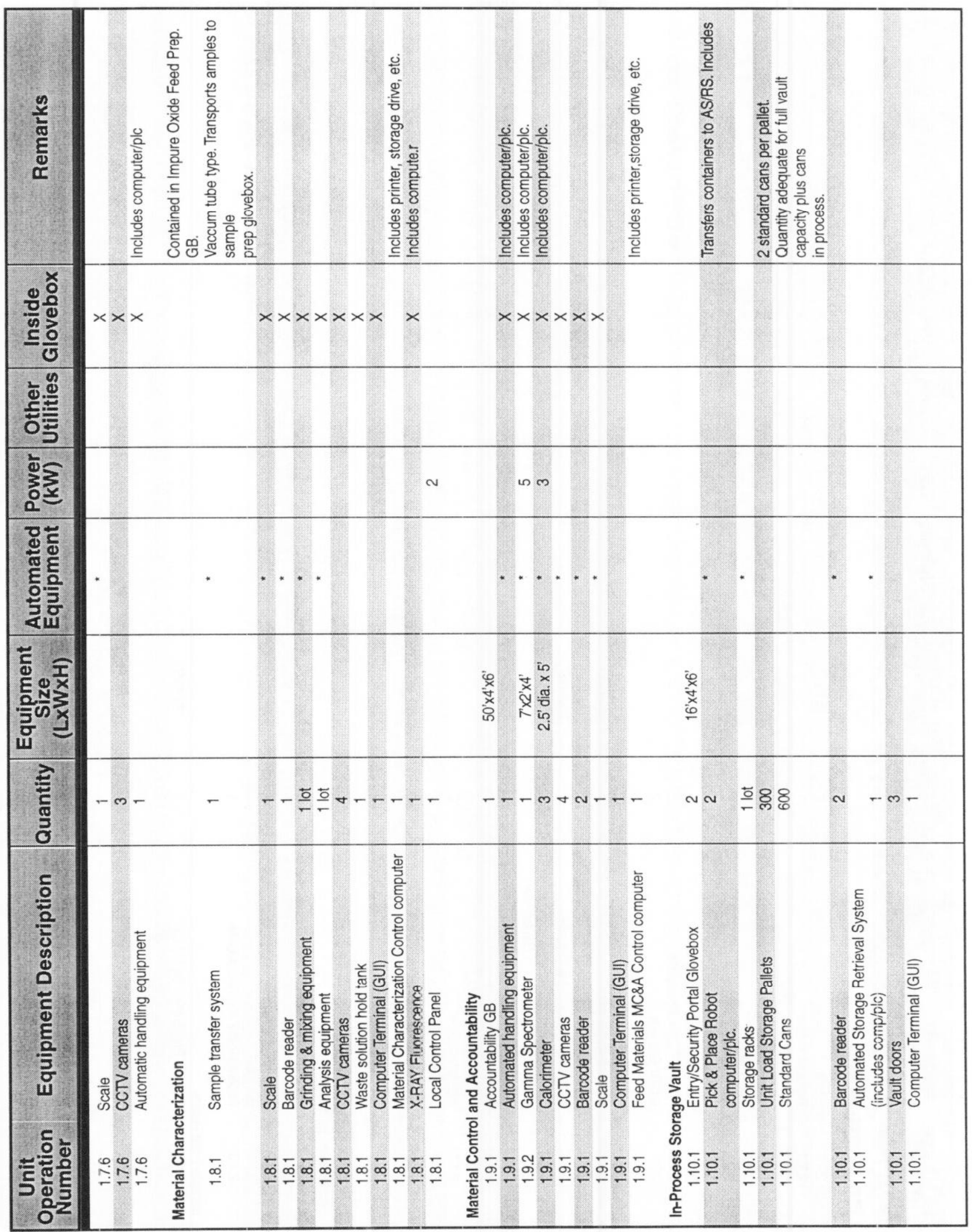


UCRL-ID-131617 Rev. 1

PIP-98-1 15

\begin{tabular}{|c|c|c|c|c|c|}
\hline 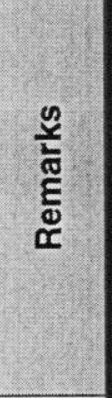 & 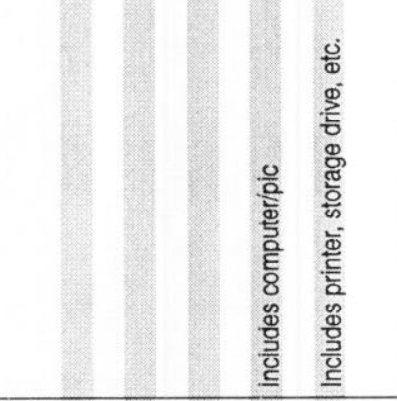 & & 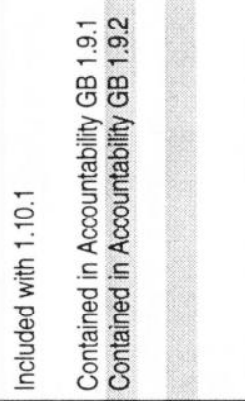 & & 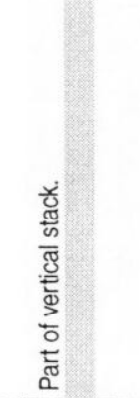 \\
\hline $\begin{array}{l}\text { 응ㅇํㅇ } \\
\text { 드은 }\end{array}$ & $x \times \times \times \times \times \times$ & $\times \times \times \times \times \times \times \times$ & $\times \times \times \times$ & $\times \times$ & $x \times$ \\
\hline 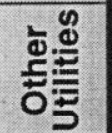 & & & & & 密 \\
\hline 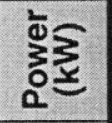 & & & m & & \\
\hline 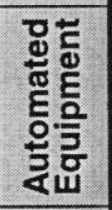 & $* * *$ & $\cdots$ & $\cdots$ & & \\
\hline 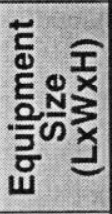 & 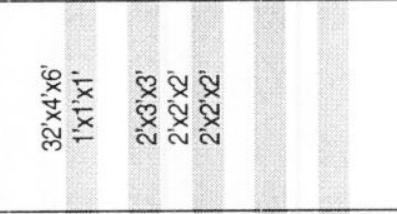 & 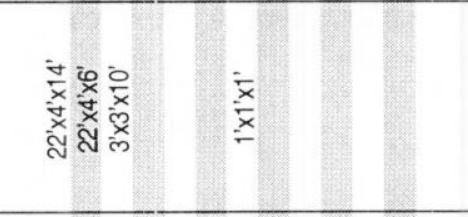 & 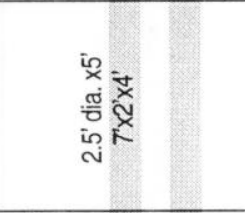 & $\begin{array}{l}0 \\
x \\
\forall \\
\dot{x} \\
0 \\
0\end{array}$ & 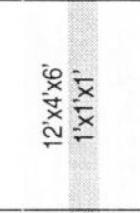 \\
\hline 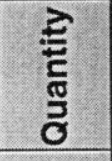 & $-------\frac{\bar{t}}{-}-\cdots$ & $-----n$ n $-m$ & ---- & $-\frac{\bar{\sigma}}{-} \sim-$ & $--\omega$ \\
\hline 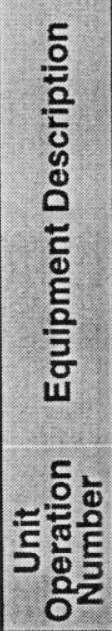 & 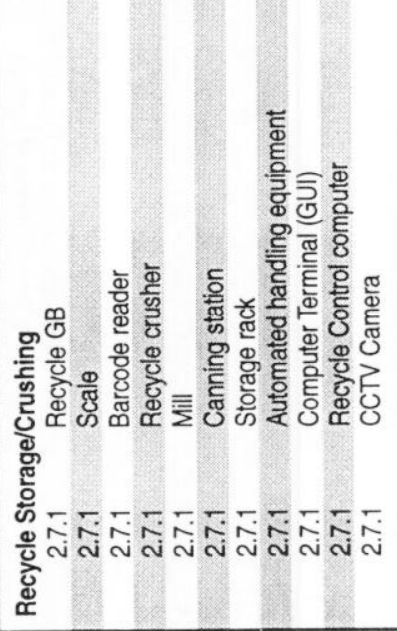 & 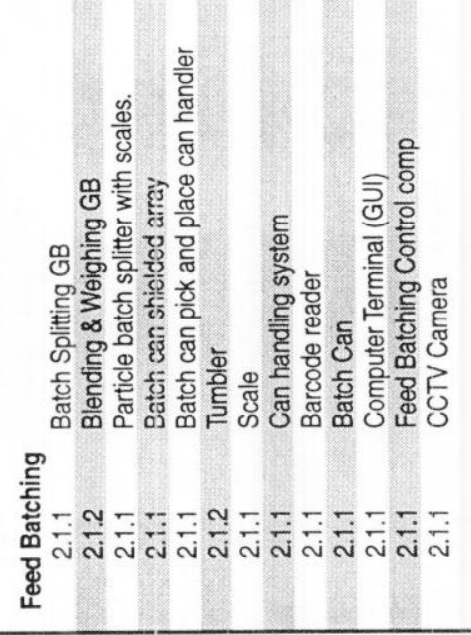 & 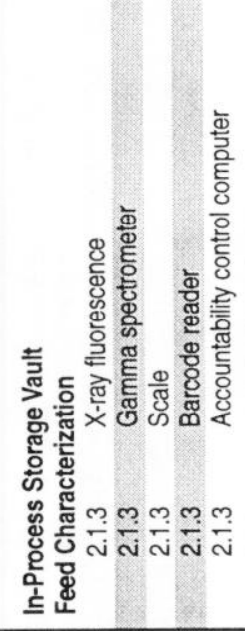 & 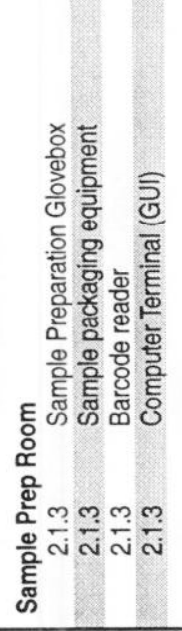 & 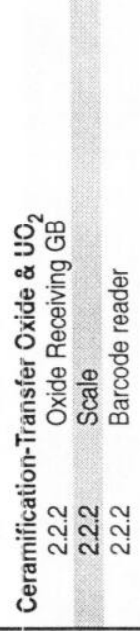 \\
\hline
\end{tabular}




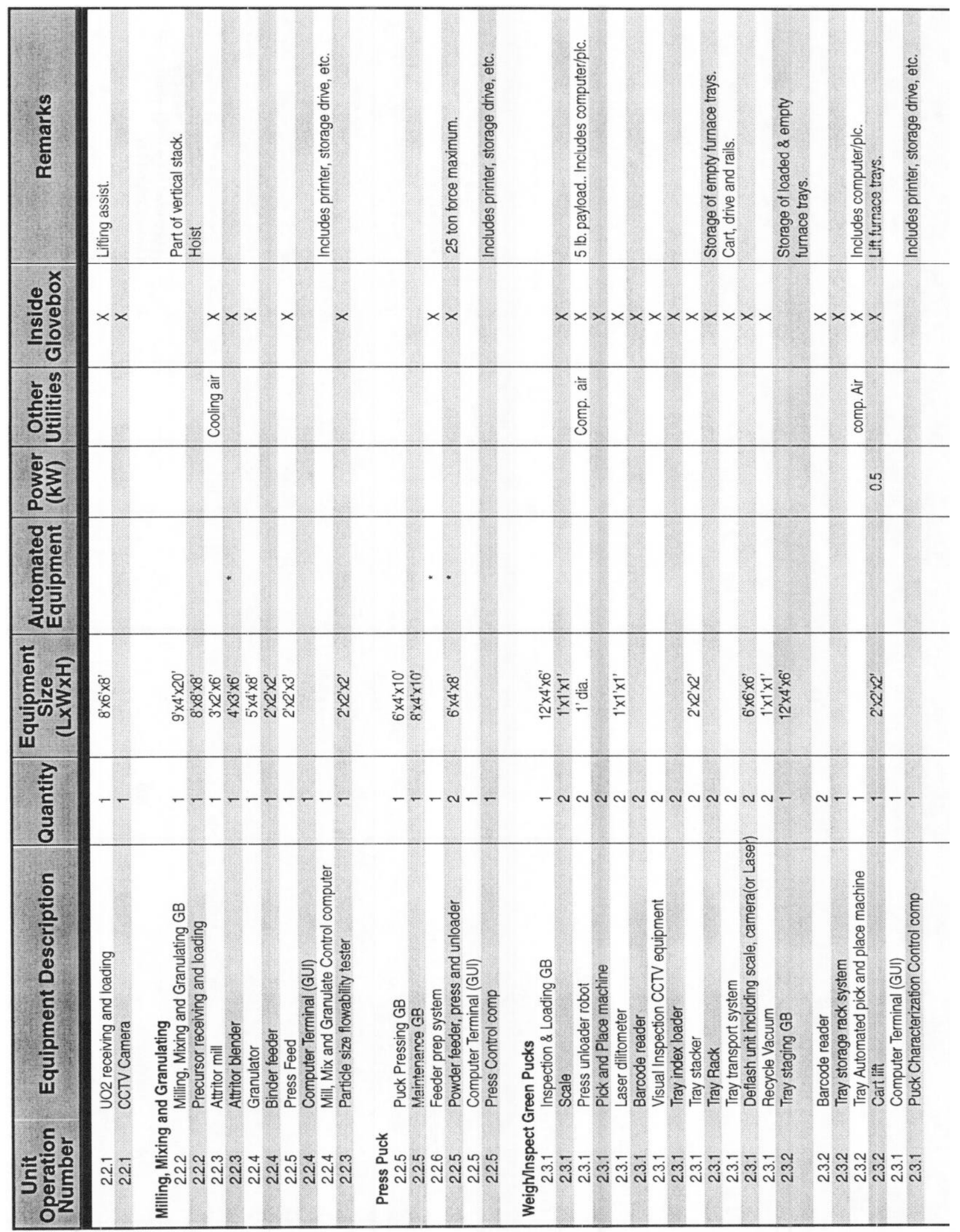


UCRL-ID-131617 Rev. 1

PIP-98-115

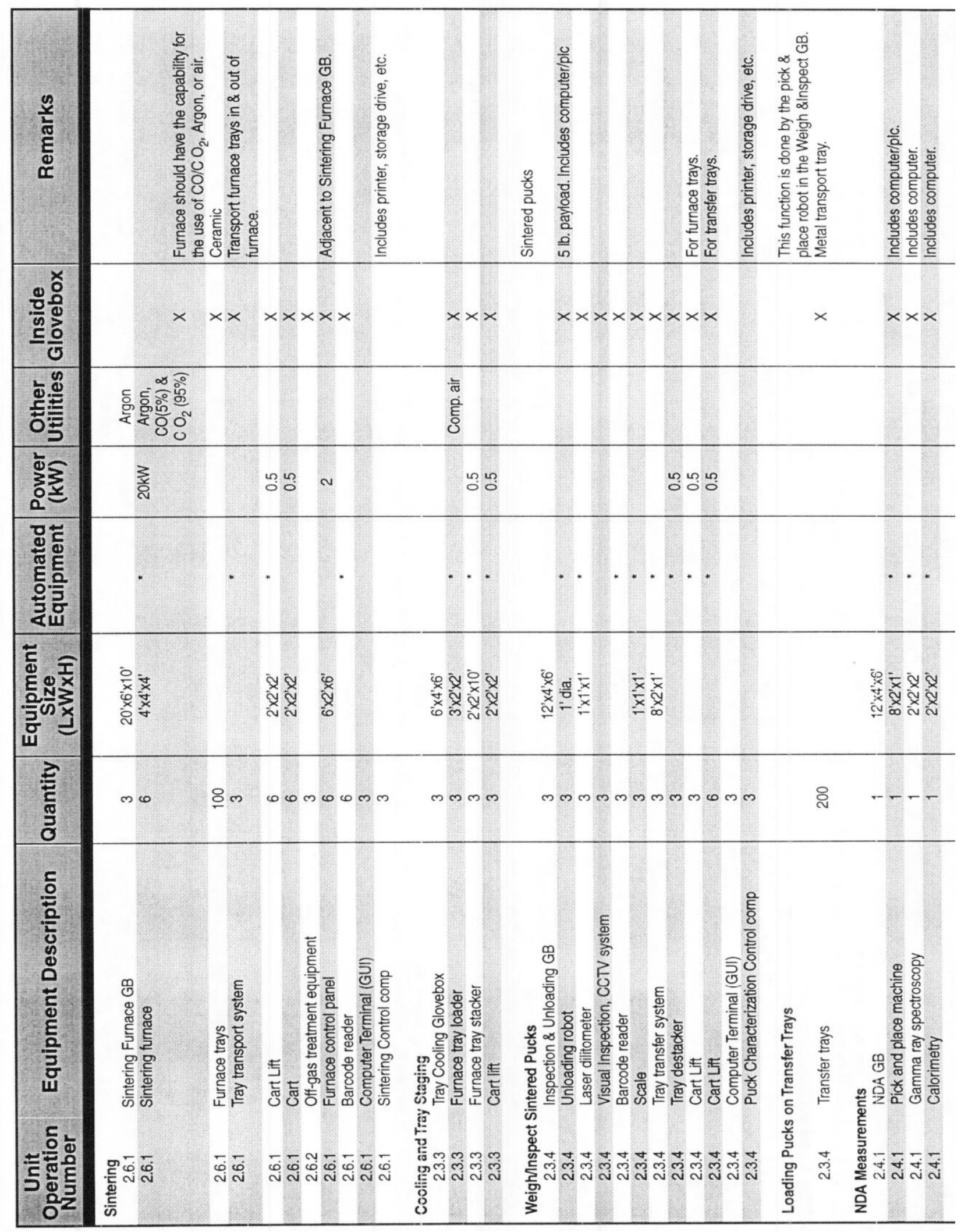




\begin{tabular}{|c|c|c|c|c|c|c|c|c|}
\hline 童 & 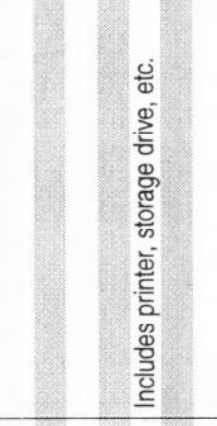 & 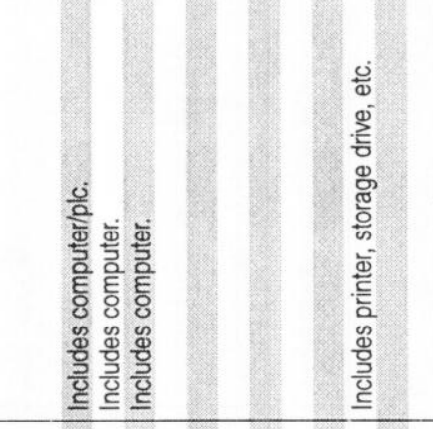 & 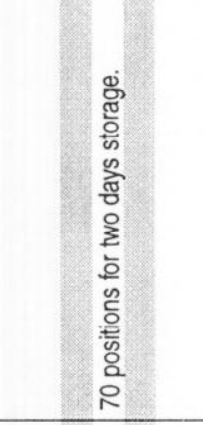 & 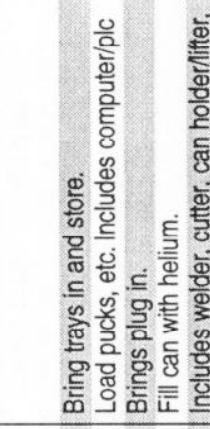 & 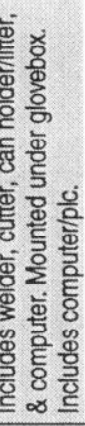 & 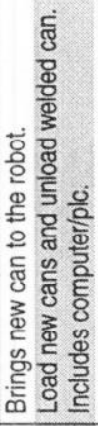 & 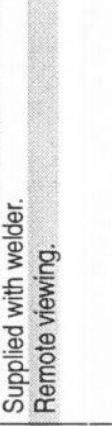 & \\
\hline 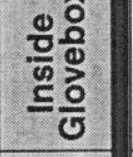 & $x \times x \quad x$ & $\times \times \times \times \times \times \times$ & $x \times x$ & $x \times x \times$ & & & & \\
\hline 递总 & & & & 安 & & & & 家 \\
\hline 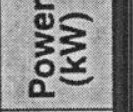 & & & & $\sim$ & N & & స్ & - \\
\hline 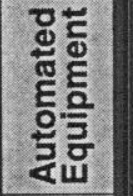 & & $* * * *^{*}$ & * & * & & * & . & * \\
\hline 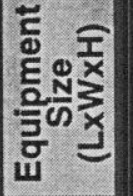 & 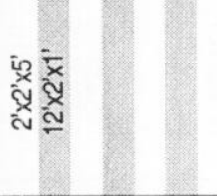 & 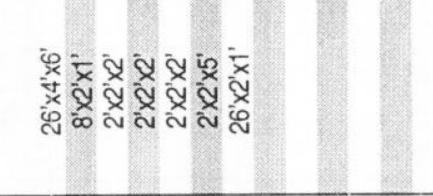 & 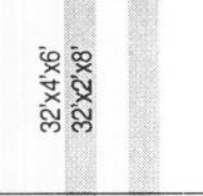 & 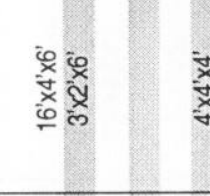 & $\begin{array}{l}\text { 䒝 } \\
\text { 妾 } \\
\text { a }\end{array}$ & & $\begin{array}{l}\text { ix } \\
\text { w. } \\
\text { w }\end{array}$ & $\begin{array}{l}\frac{\pi}{0} \\
=\end{array}$ \\
\hline 䒕 & & & $--\underline{\bar{s}}-$ & लмलмल & & mल & $m \simeq 0$ & $m$ \\
\hline 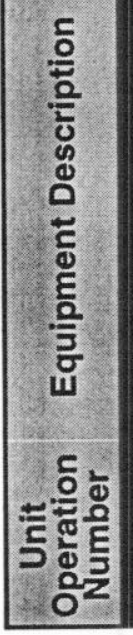 & 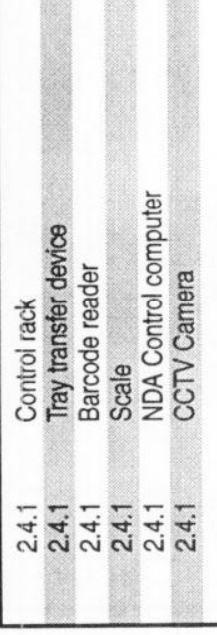 & 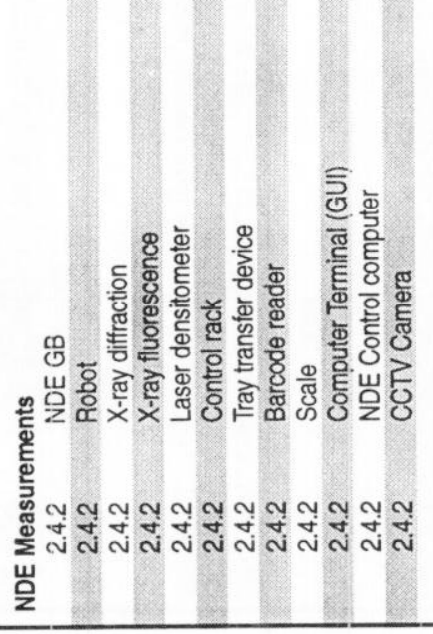 & 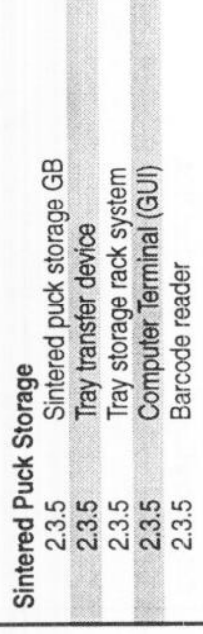 & 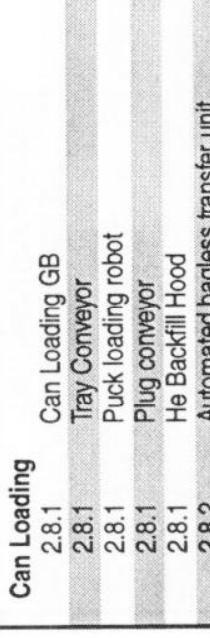 & & 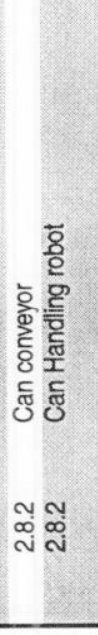 & 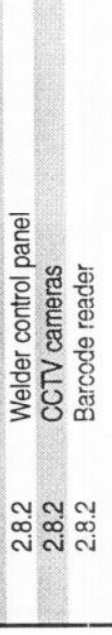 & 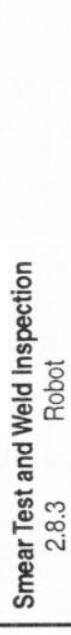 \\
\hline
\end{tabular}




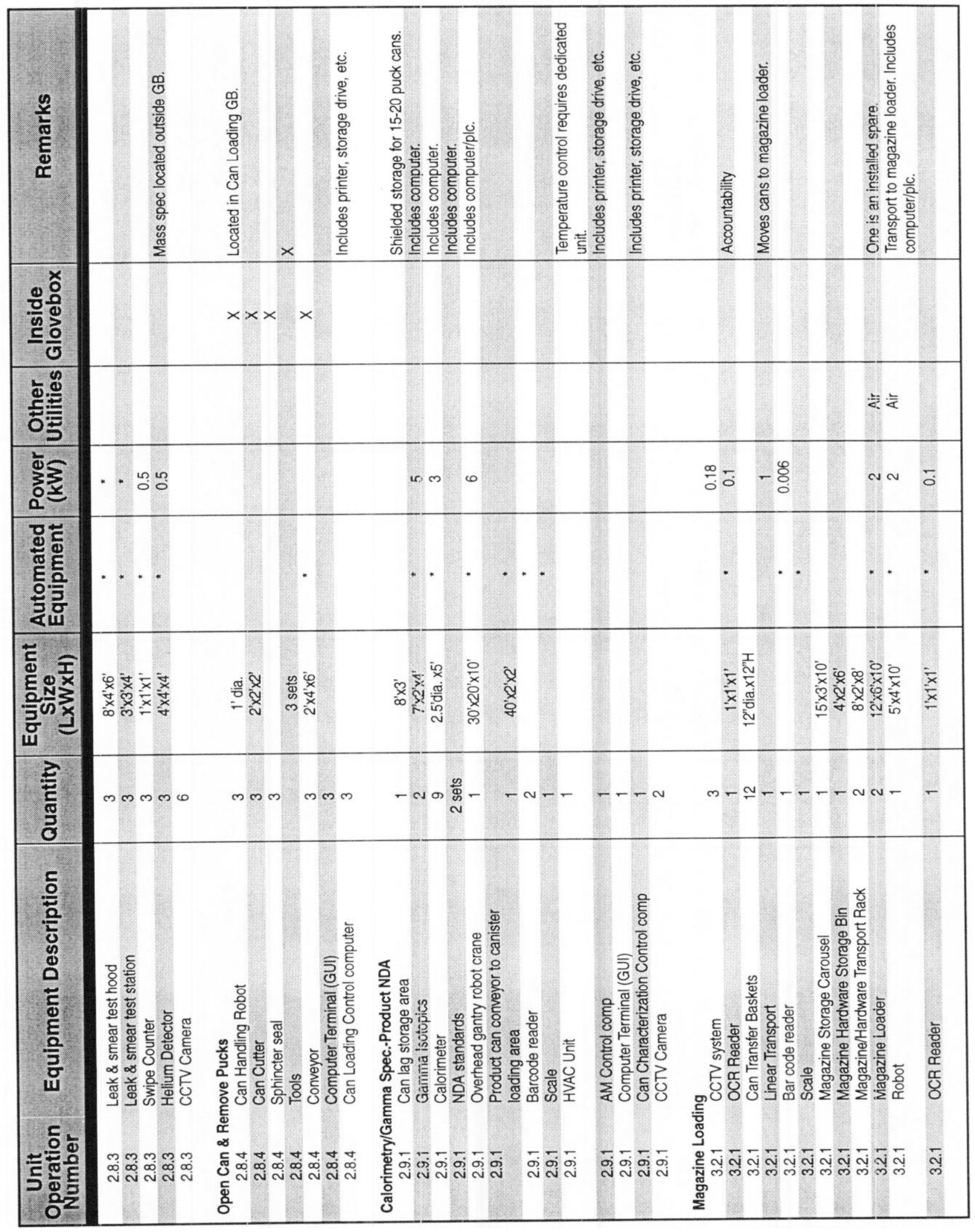




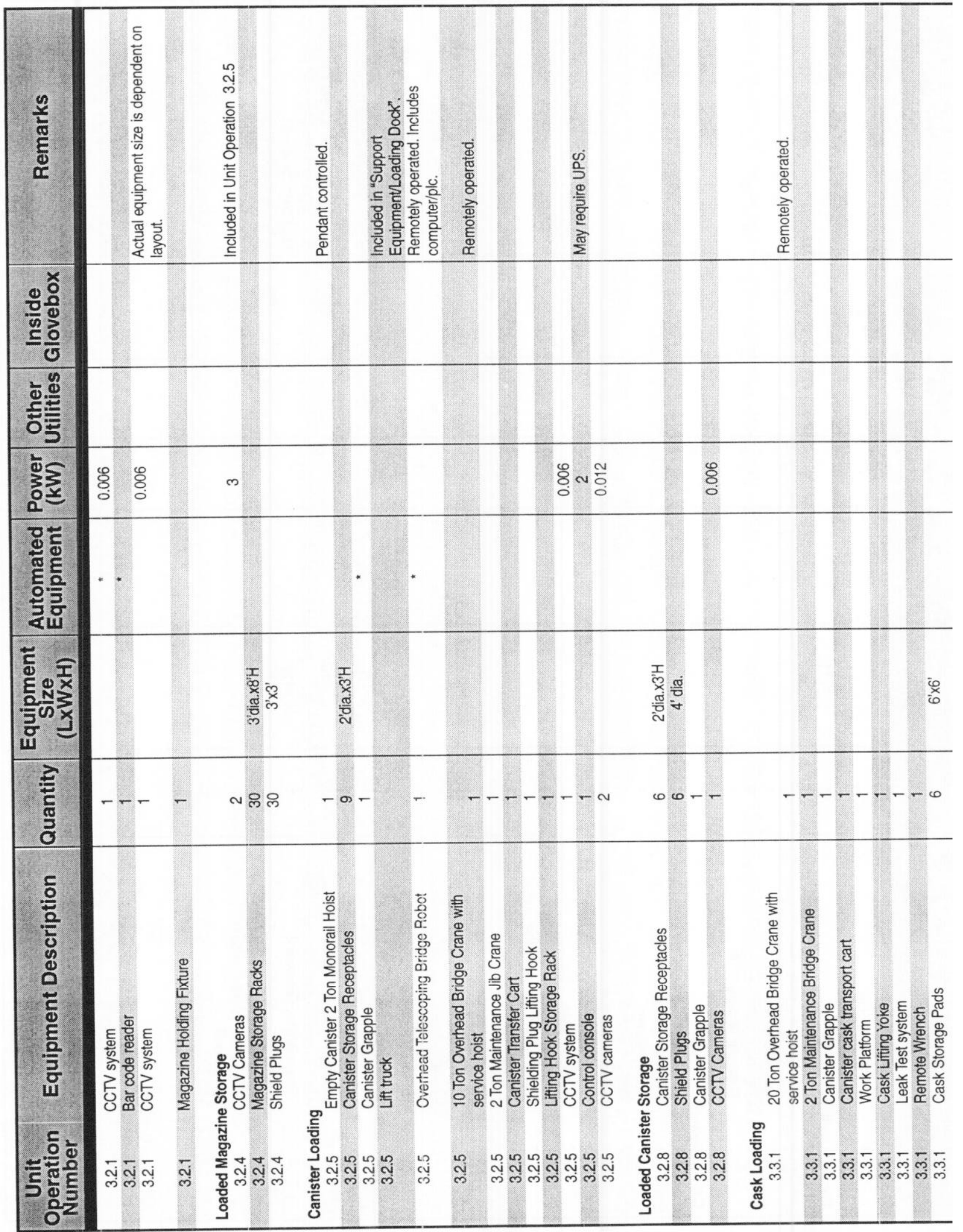




\begin{tabular}{|c|c|c|c|c|c|c|c|c|}
\hline$\frac{y}{\frac{y}{2}}$ & 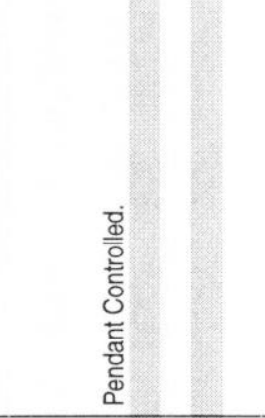 & & 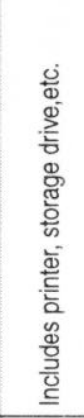 & 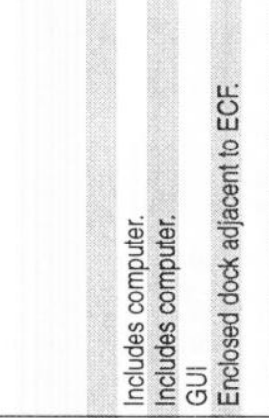 & 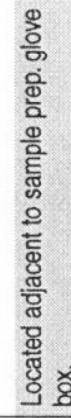 & 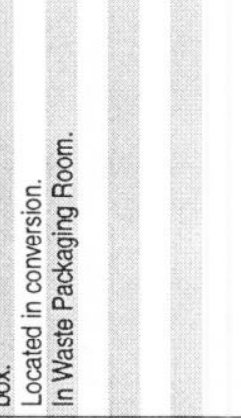 & 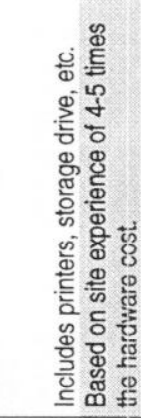 & 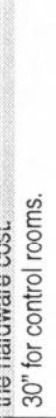 \\
\hline $\begin{array}{l}\text { 응유 } \\
\text { 드은 }\end{array}$ & & & & & & $x \times x \times$ & & \\
\hline 㐫. & & & & & & & & \\
\hline 这 & & \& & & & & & & \\
\hline 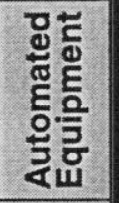 & & & & & & & & \\
\hline 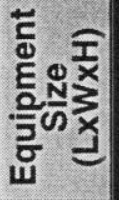 & 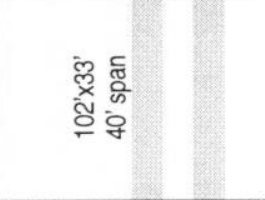 & & & $\begin{array}{l}\overline{\bar{x}} \\
\text { o. } \\
\stackrel{\sim}{N}\end{array}$ & 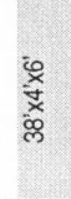 & 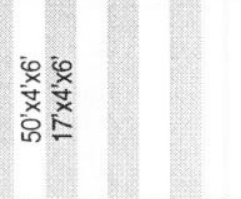 & & \\
\hline 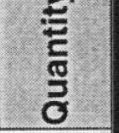 & $-----\omega-$ & $\theta--m-m$ & - & $\underline{\underline{\mathrm{o}}}-----$ & -- & $--\frac{\bar{t}}{-}---\sim$ & $n-$ & $\simeq$ \\
\hline 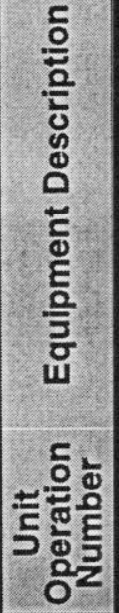 & 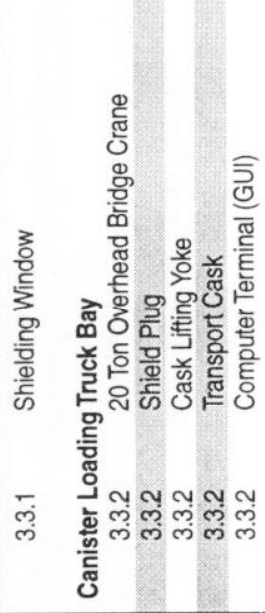 & 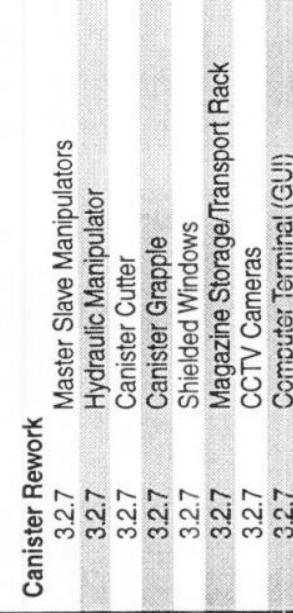 & 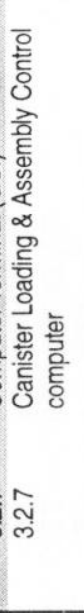 & 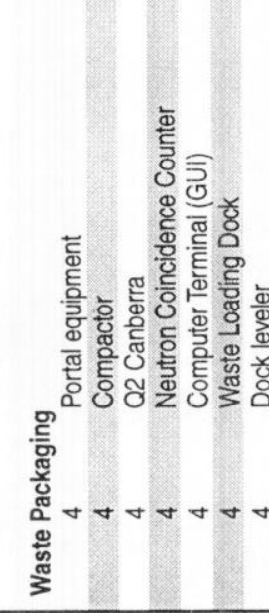 & 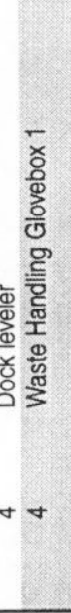 & 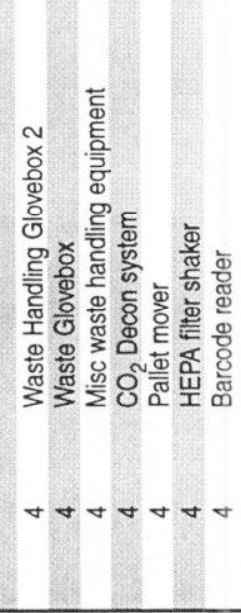 & 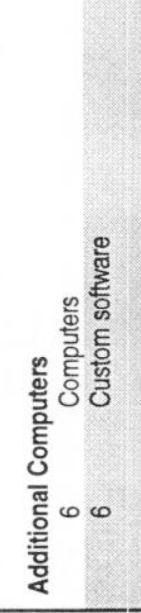 & 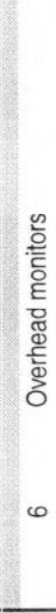 \\
\hline
\end{tabular}




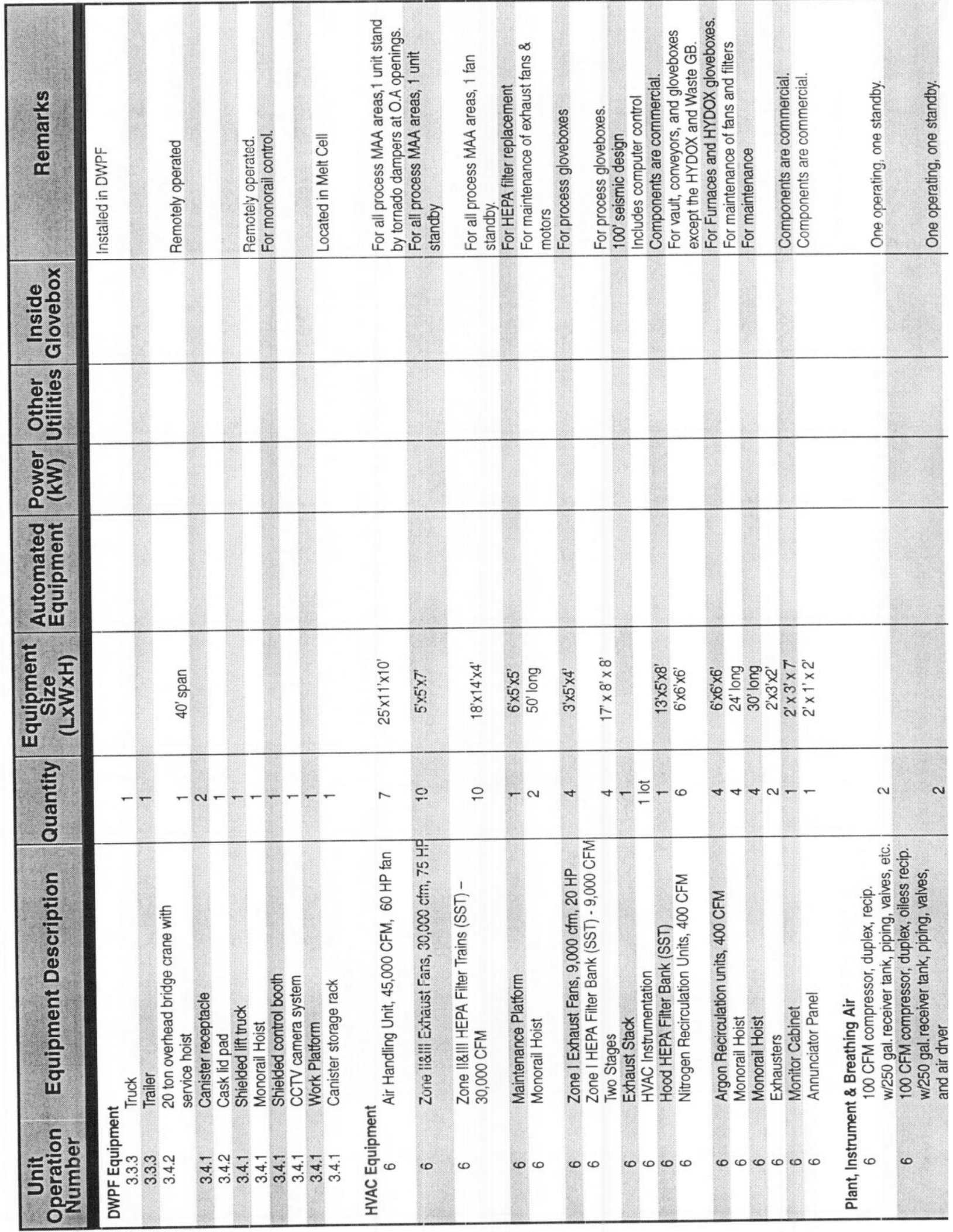




\begin{tabular}{|c|c|c|c|c|c|c|c|c|c|c|c|}
\hline$\frac{\frac{n}{2}}{\frac{2}{\pi}}$ & 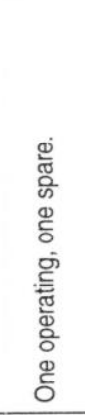 & 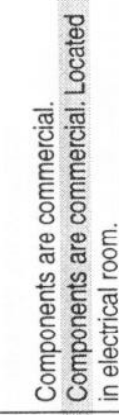 & & 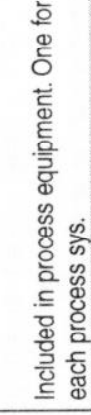 & 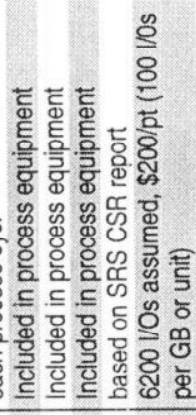 & 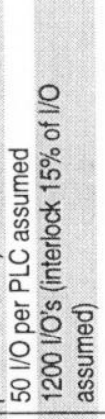 & 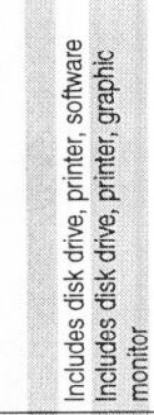 & 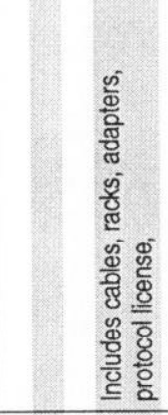 & 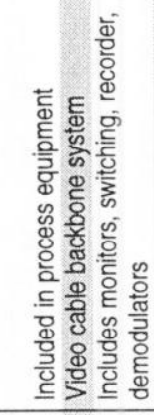 & 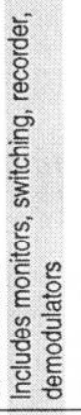 & 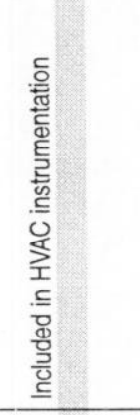 \\
\hline 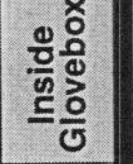 & & & & & & & & & & & \\
\hline 氙. & & & & & & & & & & & \\
\hline 递 & & & & & & & & & & & \\
\hline 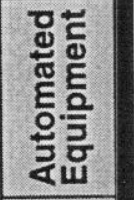 & & & & & & & & & & & \\
\hline 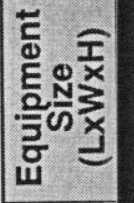 & & 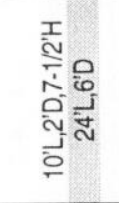 & & & & & & & & & \\
\hline 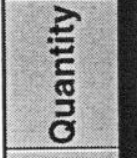 & $\sim$ & ON & $\infty \forall \sim$ & 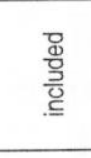 & 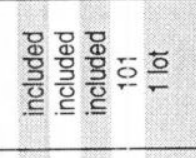 & $\stackrel{t}{\underline{0}}$ & & $---\frac{\bar{t}}{t}$ & $\frac{\bar{g}}{\frac{\mathrm{g}}{\mathrm{g}}}-\frac{\mathrm{t}}{\underline{\underline{b}}}$ & $\underline{\underline{\underline{\sigma}}}$ & 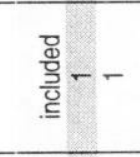 \\
\hline 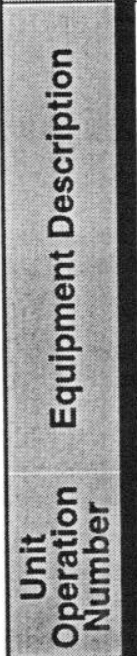 & 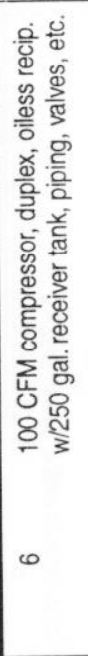 & 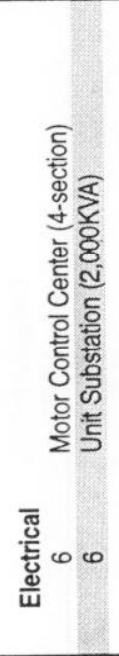 & 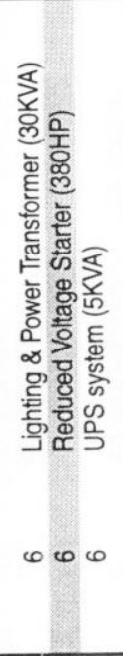 & 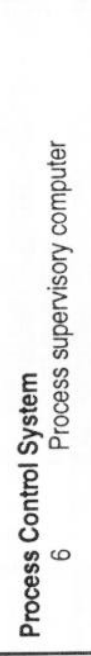 & 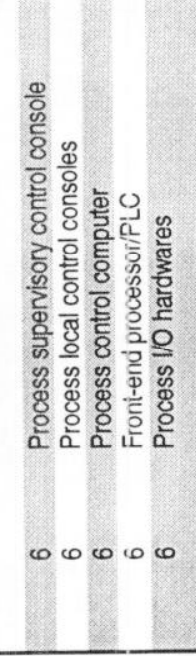 & 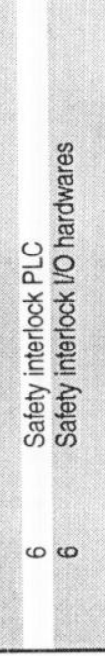 & 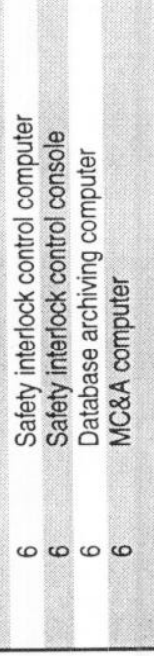 & 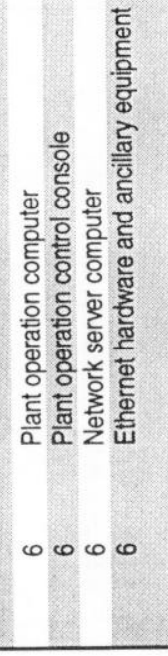 & 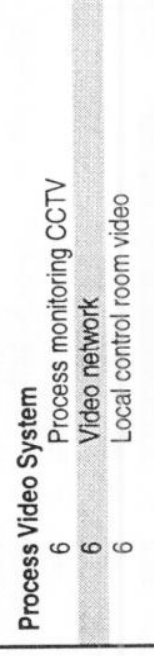 & 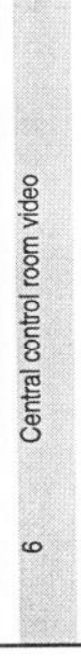 & 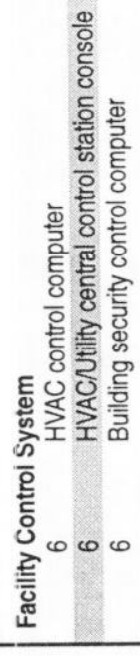 \\
\hline
\end{tabular}




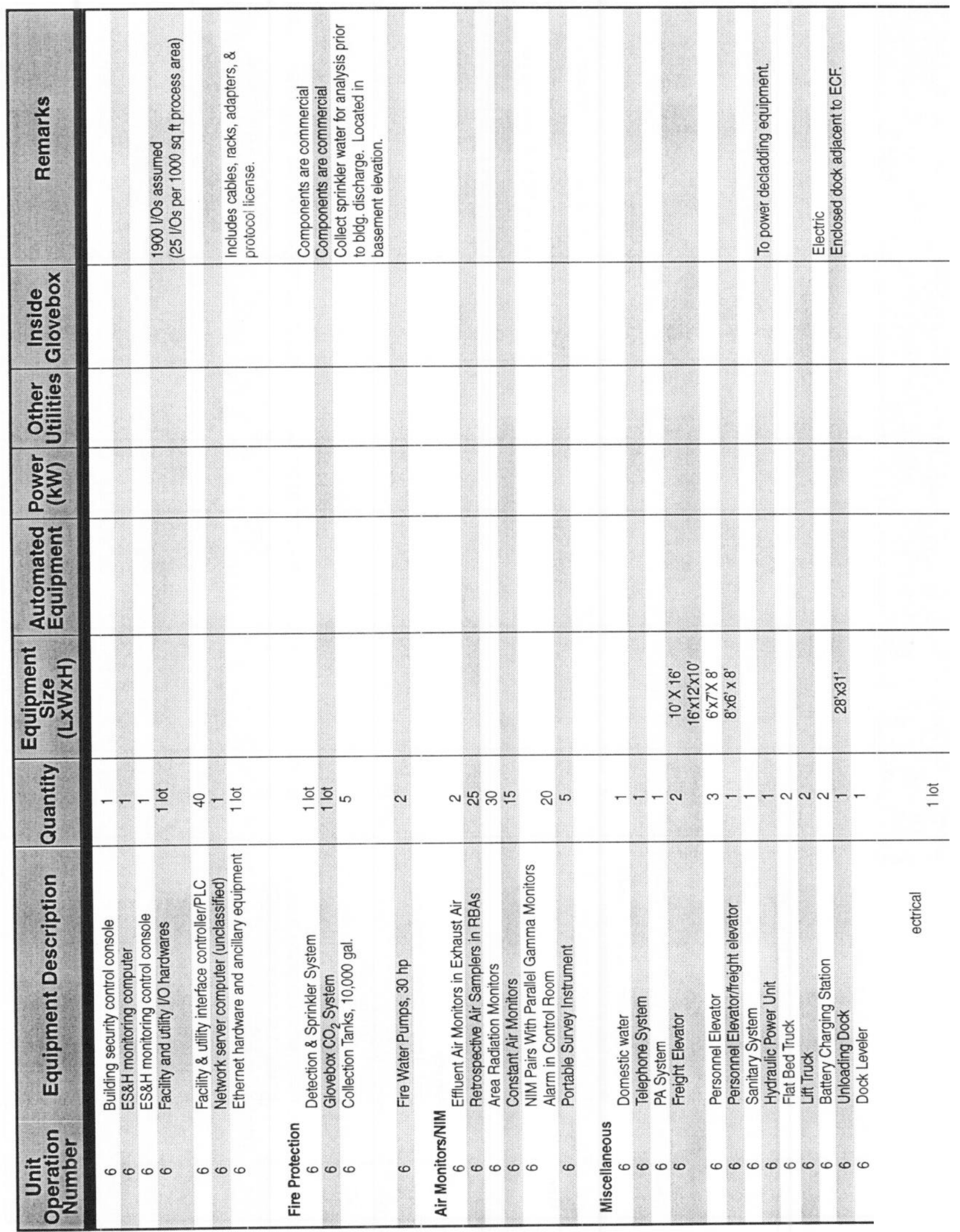




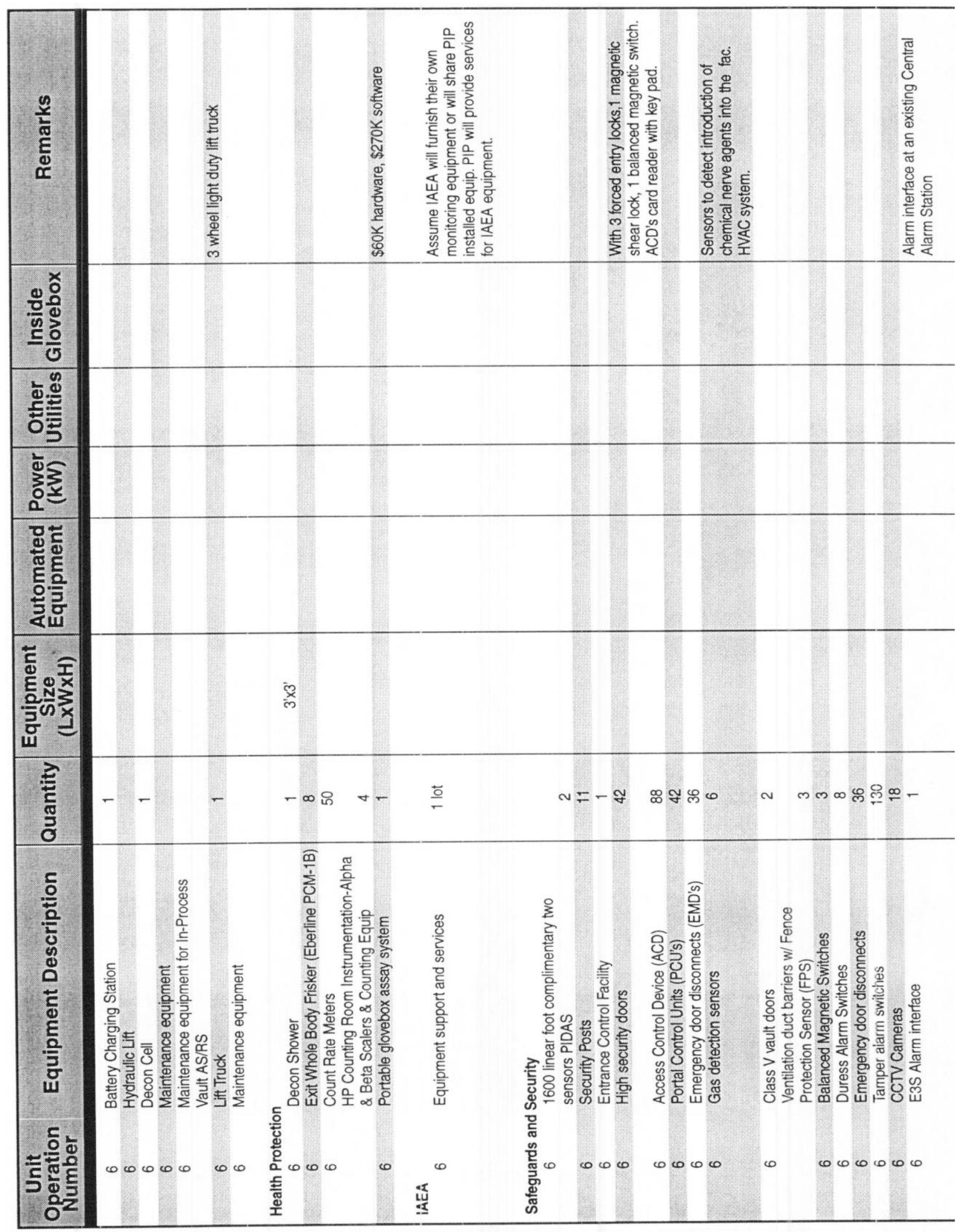




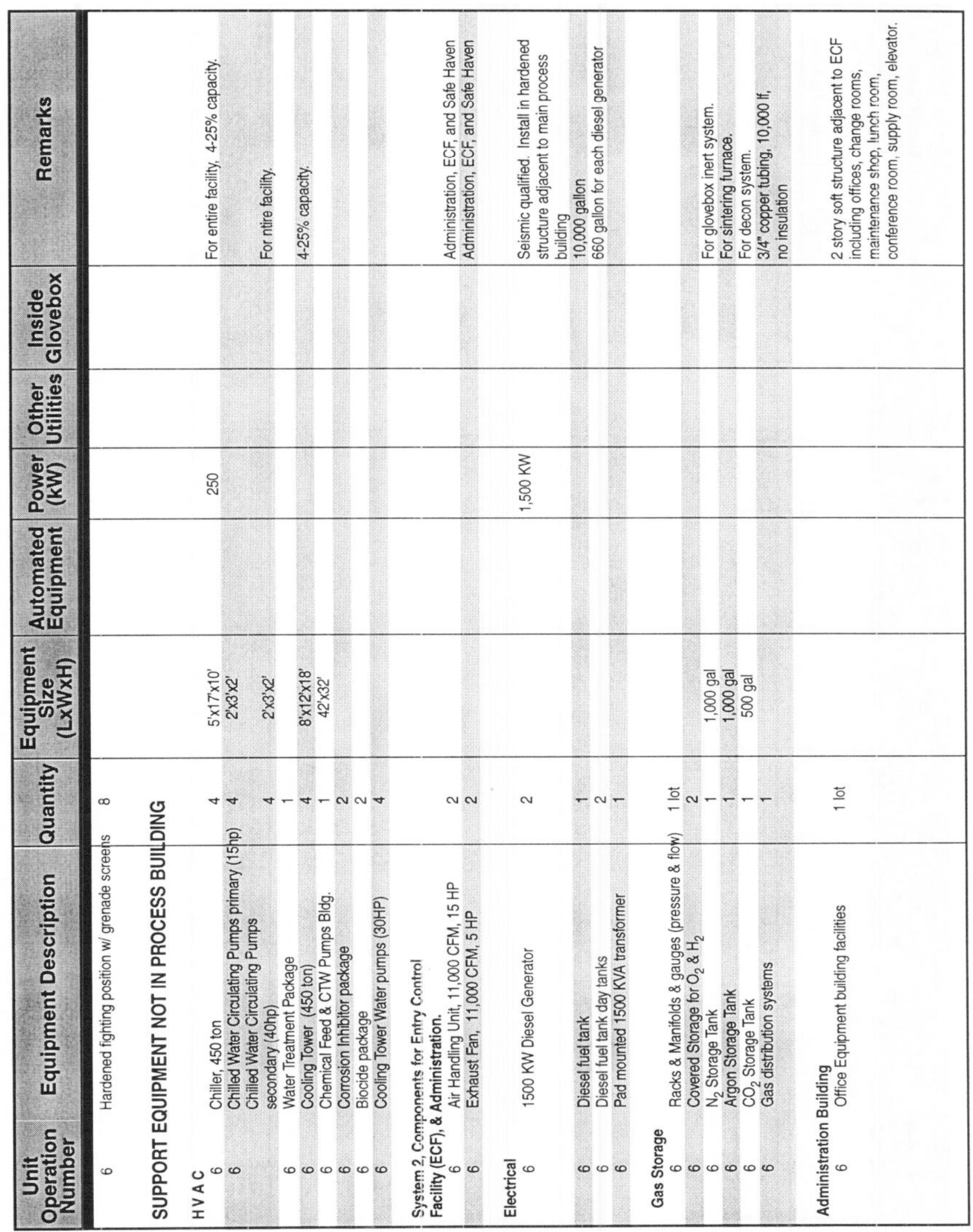




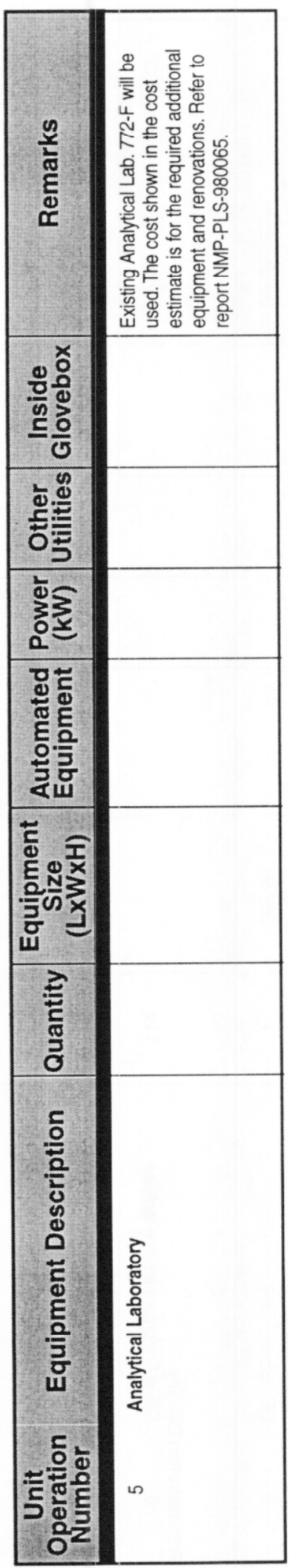

C-20 


1

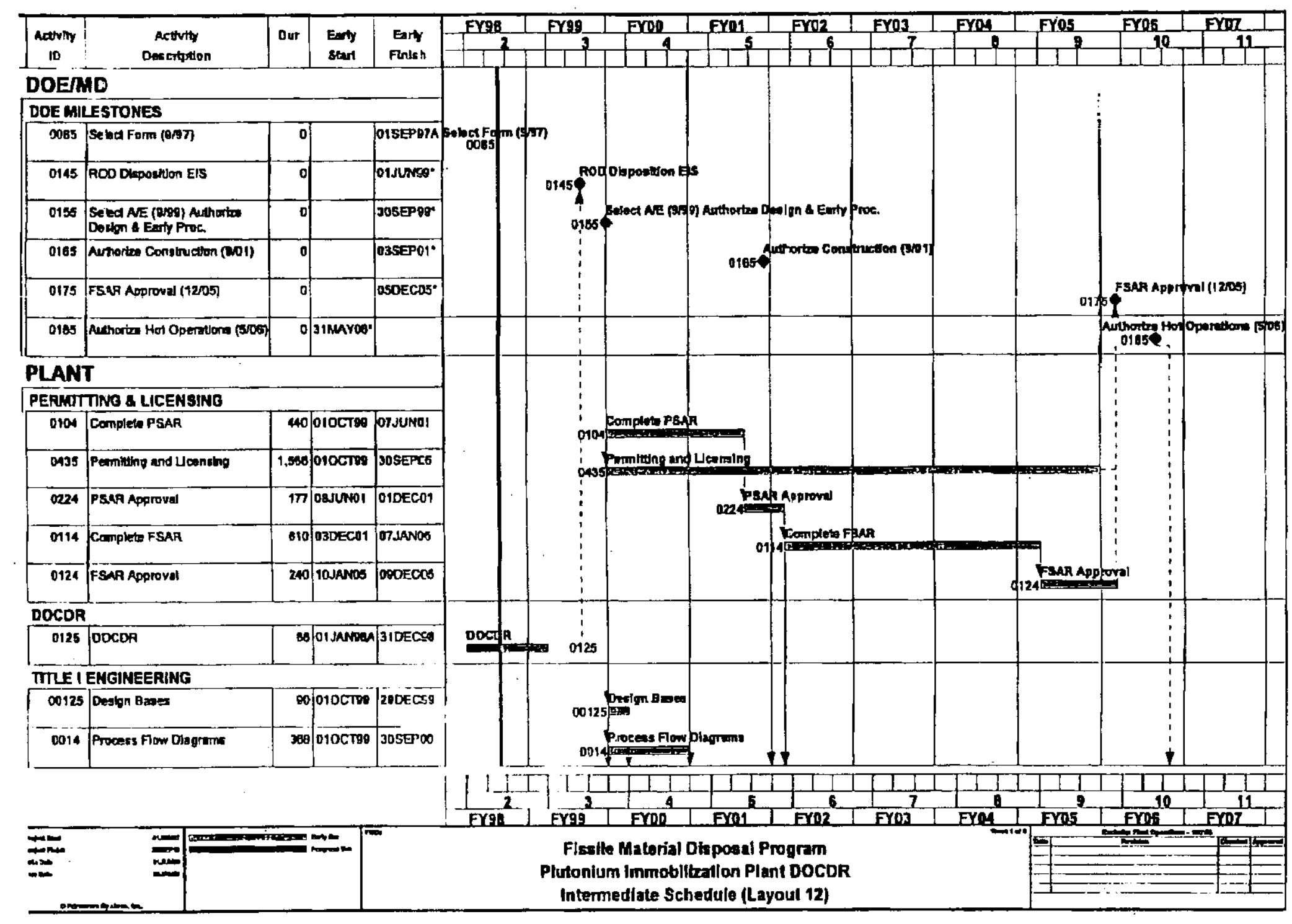




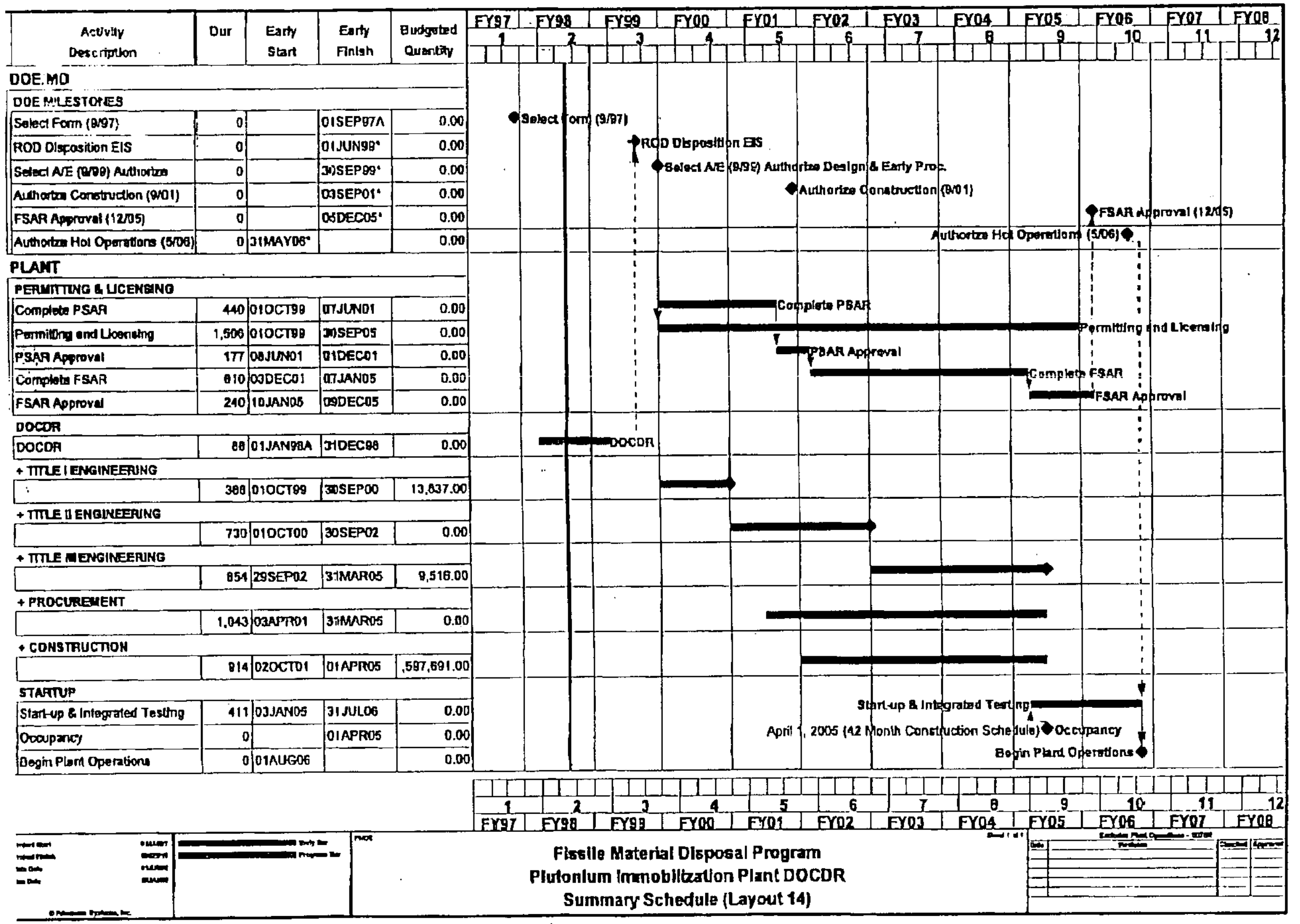




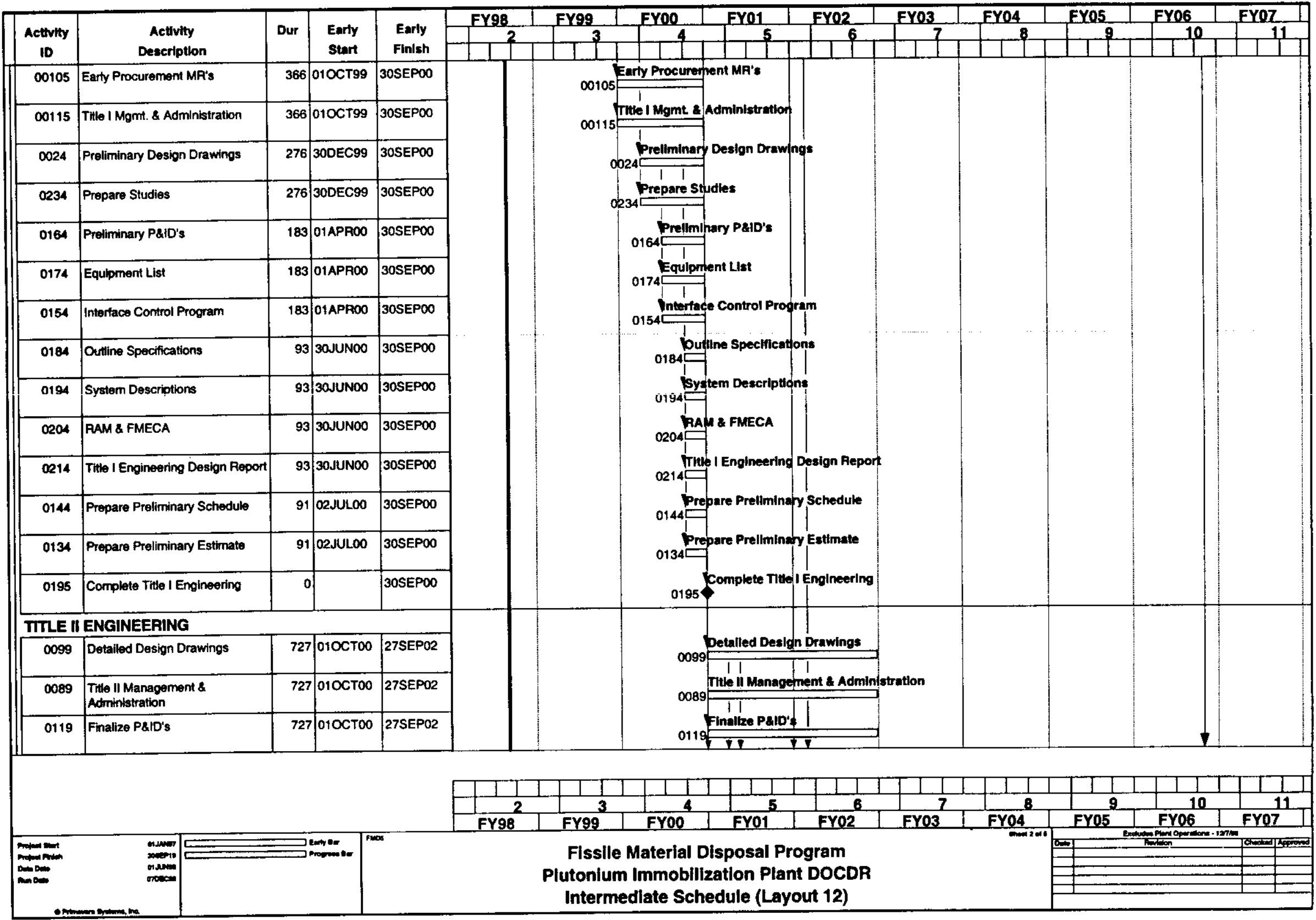




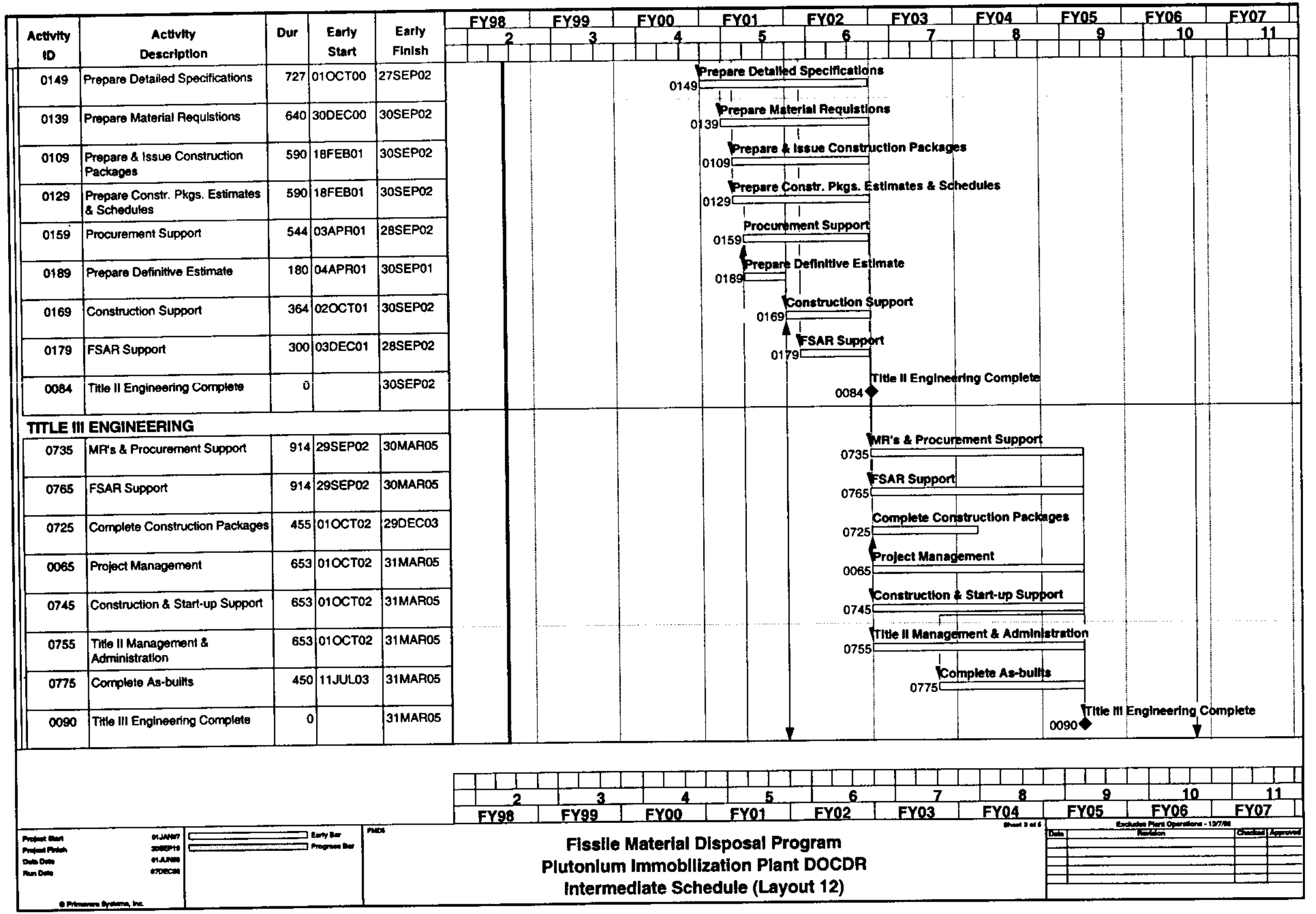

1




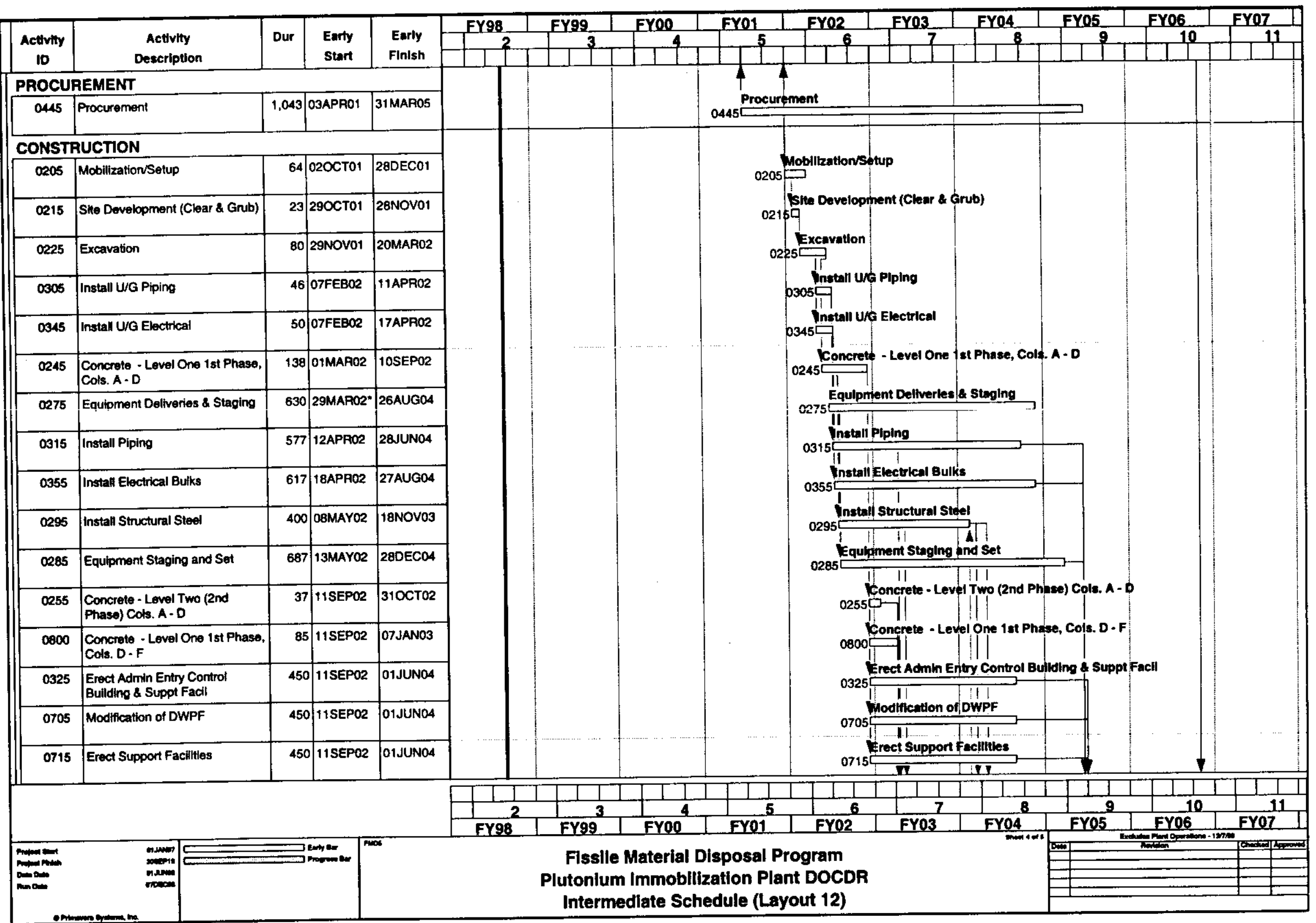




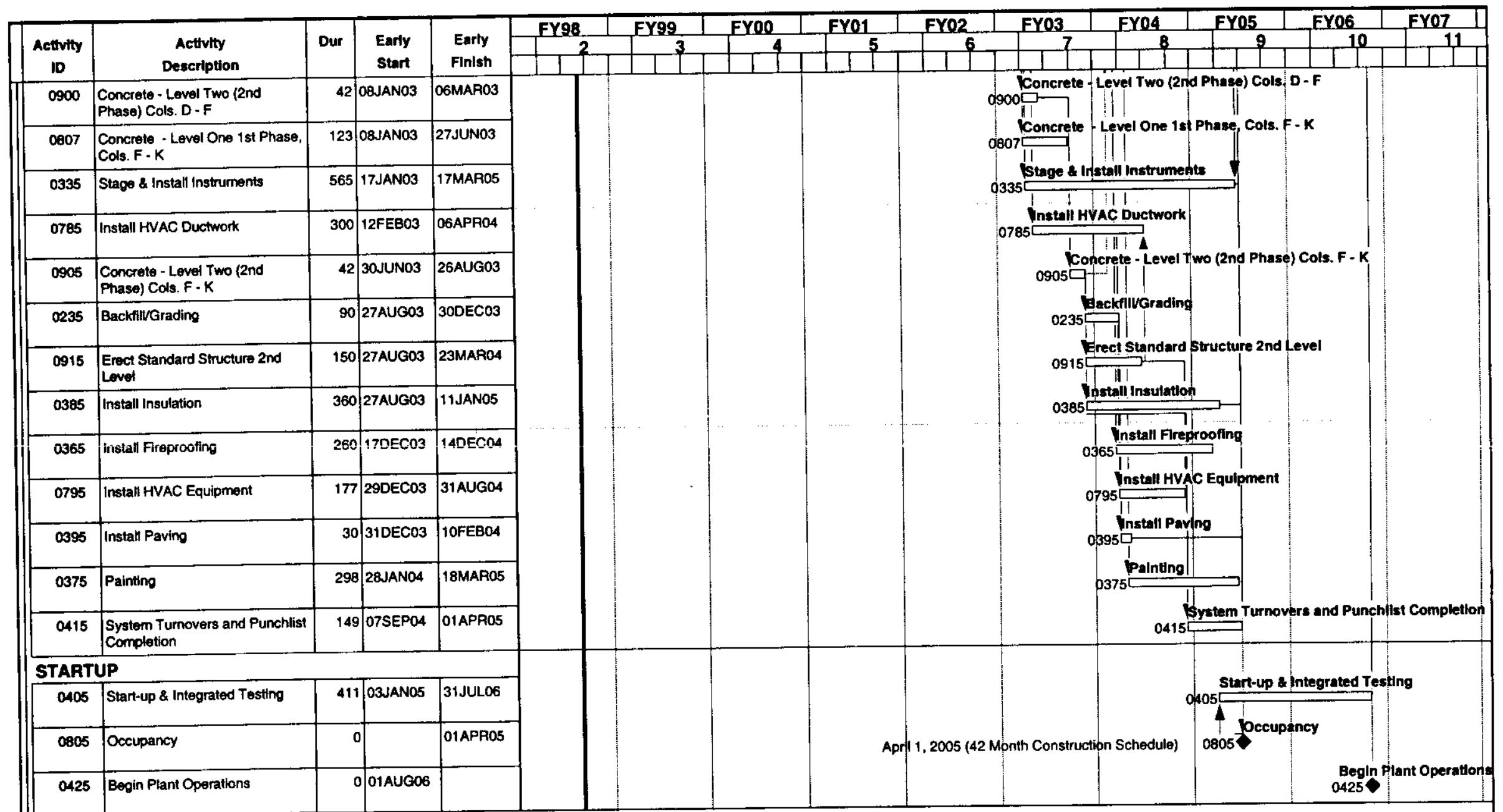

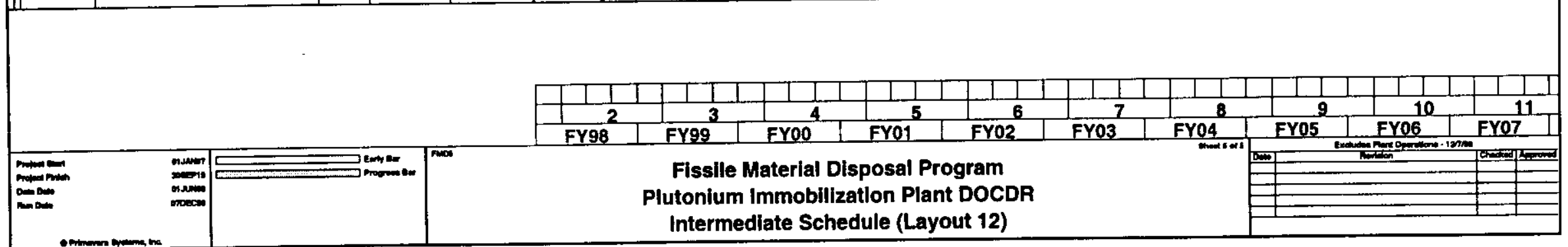




1

1

Table E.1. Design Phase Engineering Design Cost Estimate Summary

(Title $\mathrm{I}$ and Title 11 , in 1st Q/FYOO dollars)

\begin{tabular}{|c|c|c|c|c|c|}
\hline & & Title 1 & Title II & $\begin{array}{c}\text { Contingency } \\
25.1 \% \\
\end{array}$ & TOTAL \\
\hline 2.2 & $\begin{array}{l}\text { AVE Project Engineering Management } \\
\text { Project Management } \\
\text { Project Engineering } \\
\text { Project Controls }\end{array}$ & $\begin{array}{l}537,331 \\
981,471 \\
831,958\end{array}$ & $\begin{array}{l}1,913,479 \\
3,200,843 \\
2,444,311\end{array}$ & & $\begin{array}{l}2,450,810 \\
4,182,314 \\
3,276,269\end{array}$ \\
\hline \multirow[t]{4}{*}{2.2} & $\begin{array}{l}\text { A/E Engineering } \\
\text { C/S/A } \\
\text { Process } \\
\text { Electrical/I\&C } \\
\text { Systems Engineering } \\
\text { Nuclear } \\
\text { Mechanical/Plant Design } \\
\text { Procurement Support } \\
\text { Geotechnical Investigation } \\
\text { Project Admin. }\end{array}$ & $\begin{array}{r}2,350,760 \\
1,218,573 \\
954,528 \\
1,223,323 \\
1,672,530 \\
626,897 \\
3,263,031 \\
773,982 \\
519,000 \\
721,647\end{array}$ & \begin{tabular}{r|}
$7,558,633$ \\
$4,764,867$ \\
$1,067,192$ \\
$8,985,319$ \\
304,230 \\
$1,572,592$ \\
$12,090,487$ \\
$3,696,451$ \\
$2,339,587$
\end{tabular} & $2,487,258$ & $\begin{array}{r}12,396,651 \\
5,983,440 \\
2,021,720 \\
10,208,642 \\
1,976,760 \\
2,199,489 \\
15,353,518 \\
4,470,433 \\
519,000 \\
3,061,234\end{array}$ \\
\hline & Subtotal & $10,973,511$ & $34,820,725$ & $11,494,353$ & $57,288,589$ \\
\hline & TOTAL & $13,324,271$ & $42,379,358$ & $13,981,611$ & $69,685,240$ \\
\hline & & & A/E Design Phas & se Grand Total & $69,685,240$ \\
\hline
\end{tabular}


Table E.2. Engineering Design Costs

(1st Q/FYOO dollar)

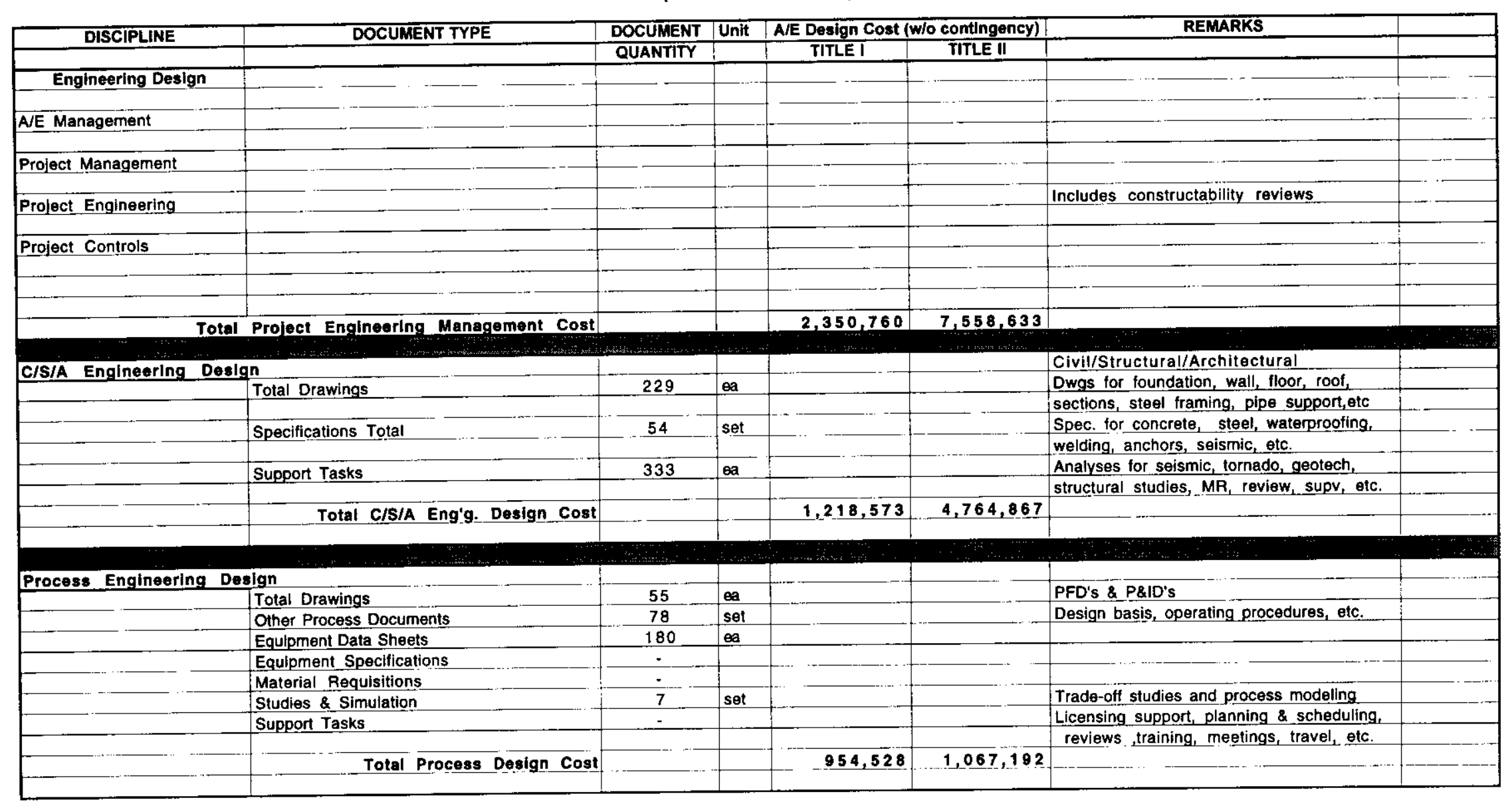




1

I

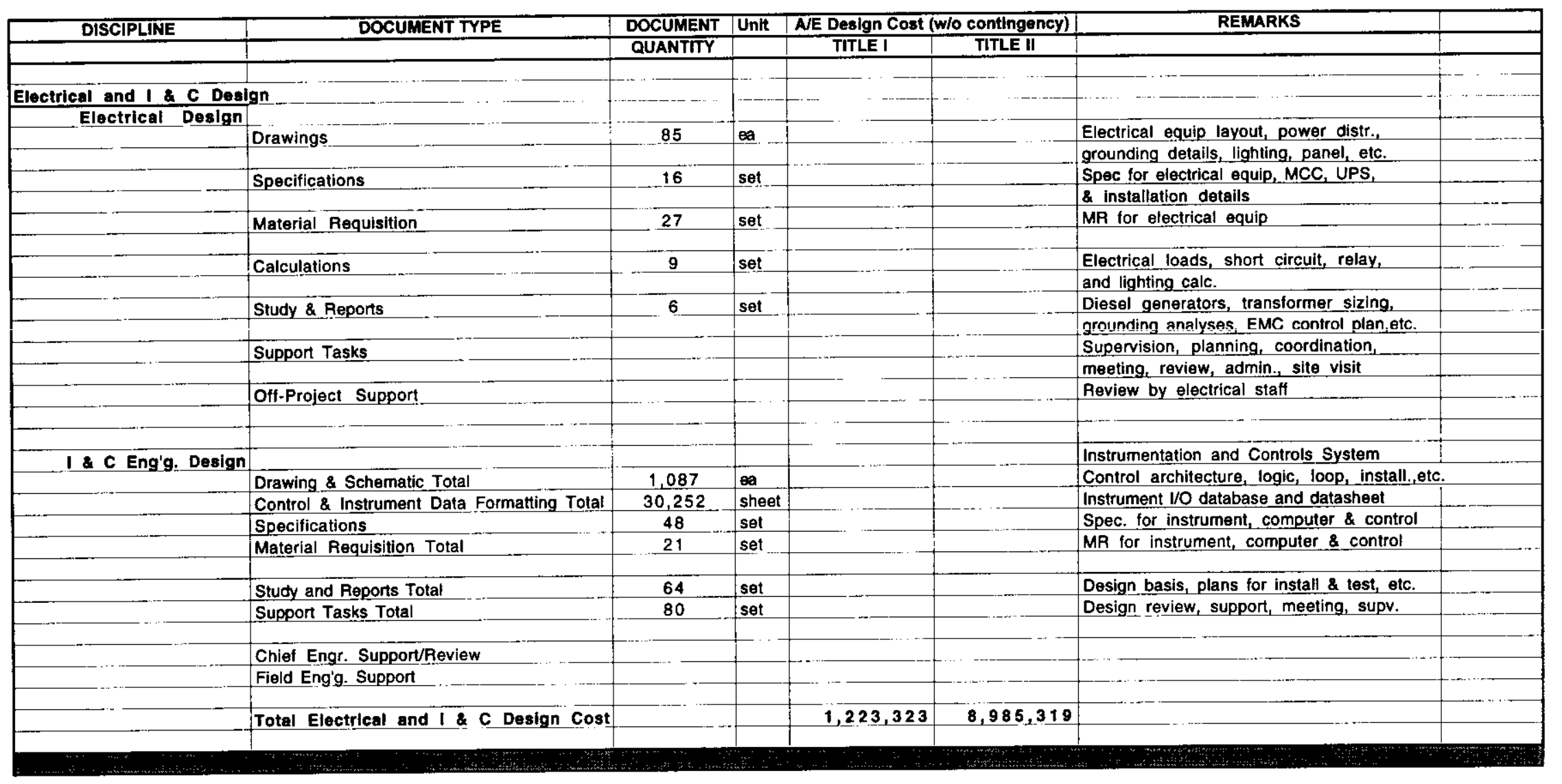




\begin{tabular}{|c|c|c|c|c|c|c|c|}
\hline DISCIPLINE & DOCUMENT TYPE & DOCUMENT & Unit & AIE Design Cost (I) & w/o contingency) & REMARKS & \\
\hline & & QUANTITY & & TITLEI & TITLE II & & \\
\hline \multirow{2}{*}{\multicolumn{8}{|c|}{ Systems Engineering Design }} \\
\hline & & 33 & ng & & & RAM/FMEA special assessment value & \\
\hline & System Eng'g. Design Total & 33 & (ad & & & engineering, trade-off studies, modeling & \\
\hline & Chlef Engr. Support/Review & & ea & & & & \\
\hline & Total Systems Engineering Design Cost & & & $1,672,530$ & 304,230 & & \\
\hline \multirow{2}{*}{\multicolumn{8}{|c|}{ Iuclear Engineering Design }} \\
\hline & Drawling \& Schematic Total & 24 & $\infty$ & & & Radiation zoning, shielding, MBA, rad. & \\
\hline & & & & & & monitoring, waste \& decon systems & \\
\hline & Specifications- Nuclear Total & 10 & set & & & Review construction package equip spec & -.... \\
\hline & Material Requisition Total_ & 10 & set & -.... & & Review nuclear equip MR & \\
\hline & Study \& Beports Total & 20 & 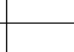 & & & Radiological protection, criticality & \\
\hline & & & & & & MC\&A, hazard, waste, shielding studies & \\
\hline & Support Tasks Total & 130 & set & & & Design review, meeting, supv. etc. & \\
\hline & Chief Engr. Support/Review & & {$[\ldots$} & - & & 20 & \\
\hline & & & & & & & \\
\hline - n & Field Eng'g. Support Total. & -4 & ea & & & Operation procedures and support & \\
\hline & Total Nuclear Engineering Design Cost & & & 626,897 & $1,572,592$ & & \\
\hline
\end{tabular}

1




\section{1}

\begin{tabular}{|c|c|c|c|c|c|c|c|}
\hline DISCIPLINE & DOCUMENT TYPE & DOCUMENT & Unit & AVE Design Cost & (w/o contingency) & REMARKS & \\
\hline & & QUANTITY & & TITLE I & TITLE II & & \\
\hline & & & -... & & & & ..... \\
\hline \multirow{2}{*}{\multicolumn{8}{|c|}{ Mechanical/Plant Deslgn }} \\
\hline & & & & & & & \\
\hline & Total Drawings & 78 & ea & & & Dwgs. for HVAC, fire suppresion, & \\
\hline & & & & & & air/gas and utilities system & \\
\hline & Design Documents & 29 & set & & ....... & Design Basis, Data Sheets, system & \\
\hline & & & & & & description, etc. & \\
\hline & Calculations & 17 & set & & & System sizing, design calculations & \\
\hline & & & & & & & \\
\hline & Specifications & 31 & set & & & Specs. for HVAC, fire suppresion, & \\
\hline & & & & & & air/gas and utilities system & \\
\hline & Management Hour (Group Supervisor) & & & & & & \\
\hline & & & & & & & \\
\hline & Material Requisition & & & & & & \\
\hline & & & & & & & \\
\hline & Study \& Reports & 4 & set & & & Design report and NEPA \& SAE support & \\
\hline & Supoort Tasks & & & & & & \\
\hline & Support Tasks & 20 & set & & & Review, meeting, modeling support, etc. & \\
\hline & Field Enginearing Support & & & & & & \\
\hline & & & & & & & \\
\hline Process Mechanlcal & & & & & & & \\
\hline & Total Drawings & 235 & ea & & & Dwgs. for glovebox \& equip arrangement, & \\
\hline & & & & & & automated handling equip, install details & \\
\hline & Supervision & & & & & & \\
\hline & Planning Schoduling & & & & & & \\
\hline & Off Project Support & & & & & -. & \\
\hline & Site Visits & & & & & & \\
\hline & Review Meetings & & & & & & \\
\hline 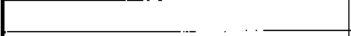 & Vendor Visits & & & . & -..._............. & t_-__.... & \\
\hline & Equipment List & 1 & ea. & & & & \\
\hline & Specifications & -53 & set & & & Data Sheet included in Specs. & \\
\hline & Material Requisition & 78 & set & & & MR for glovebox and equipment & \\
\hline & Study and Reports & & $\ldots$ & & & & \\
\hline & Field \& Engineering Support & & & & & & \\
\hline & & & & & & & \\
\hline
\end{tabular}




\begin{tabular}{|c|c|c|c|c|c|c|c|}
\hline \multirow[t]{2}{*}{ DISCIPLINE } & \multirow[t]{2}{*}{ DOCUMENT TYPE } & \multirow{2}{*}{$\begin{array}{l}\text { DOCUMENT } \\
\text { QUANTITY }\end{array}$} & \multirow[t]{2}{*}{ Unit } & \multicolumn{2}{|c|}{ A/E Design Cost (w/o contingency) } & \multirow[t]{2}{*}{ REMARKS } & \\
\hline & & & & TITLE I & TITLE II & & \\
\hline \multirow{2}{*}{\multicolumn{8}{|c|}{ Plant Design/Layout }} \\
\hline & & & & & & & \\
\hline & Total Drawings & 299 & $\Leftrightarrow a$ & & - _..... & $\begin{array}{l}\text { General arrangement, piping, equip } \\
\text { location, duct routing, hanger details, etc. }\end{array}$ & \\
\hline & Detail/Isometrics etc & 500 & $\infty$ & & & & \\
\hline & & & & & & & \\
\hline & Material Requsition Total & -5 & set & ...._____....... & & Pipes and valves MR. & \\
\hline & Specifications & 30 & set & & & Spec. for pipes and valves, field welds & \\
\hline & & & & & & & \\
\hline & Special Studies/Reports & 16 & set & & & Piping, seismic, stress analysis & \\
\hline & & & & & & & \\
\hline & Indices/Logs List & 5 & $\infty$ & & & Drawing and model control logs & \\
\hline & Support Tasks & 2 & set & & & Design review, coordination & \\
\hline & & & & & & & \\
\hline 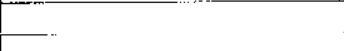 & Supervision \& Administration & & & & & 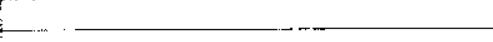 & \\
\hline Total & Mechanical Eng. and Plant Design Cost & & & $3,263,031$ & $12,090,487$ & & \\
\hline & & & & & & & \\
\hline & & & & & & & \\
\hline Procurement Support & Total Procurement Supports Cost & & & 773,982 & $3,696,451$ & & \\
\hline & & & & & & & \\
\hline $\begin{array}{l}\text { Ceotechnical } \\
\text { Investlagation }\end{array}$ & & & & & & & \\
\hline & Total Geotechnical Investigation & & & 519,000 & & & \\
\hline & & & & & & & \\
\hline Project Administration & Total Project Administration & & & 721,647 & $2,339,587$ & & \\
\hline & & & & & & & \\
\hline & & & & & & & \\
\hline & TOTAL ENGINEERING DESIGN COST & & & $13,324,271$ & $42,379,358$ & & \\
\hline
\end{tabular}


Figure E.1. Engineering and Design Cost Contingency.

(Including Title I, II, and III)

BECHTEL NATIONAL, INC.

RISK ANALYSIS/CONTINGENCY EVALUATION PROGRAM
Job No.: 23386
Plutonium Immobitization Plant, Aboveground w/ R. Protection
Project: DOE/LLNL
Location: SRS, SC.
Date: $\quad 1203 / 98$

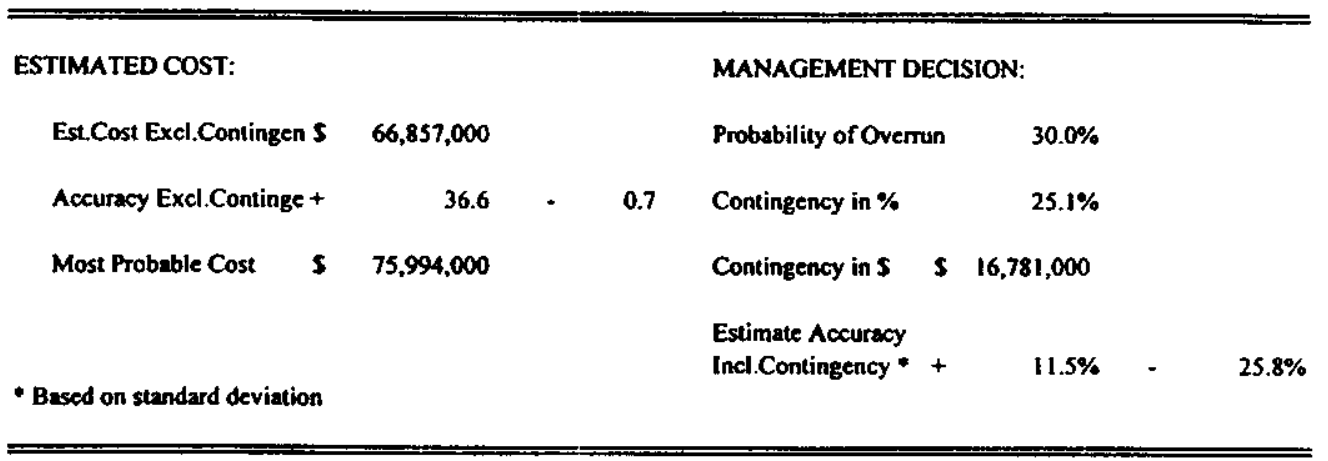

ANAL.YSIS OF RISK

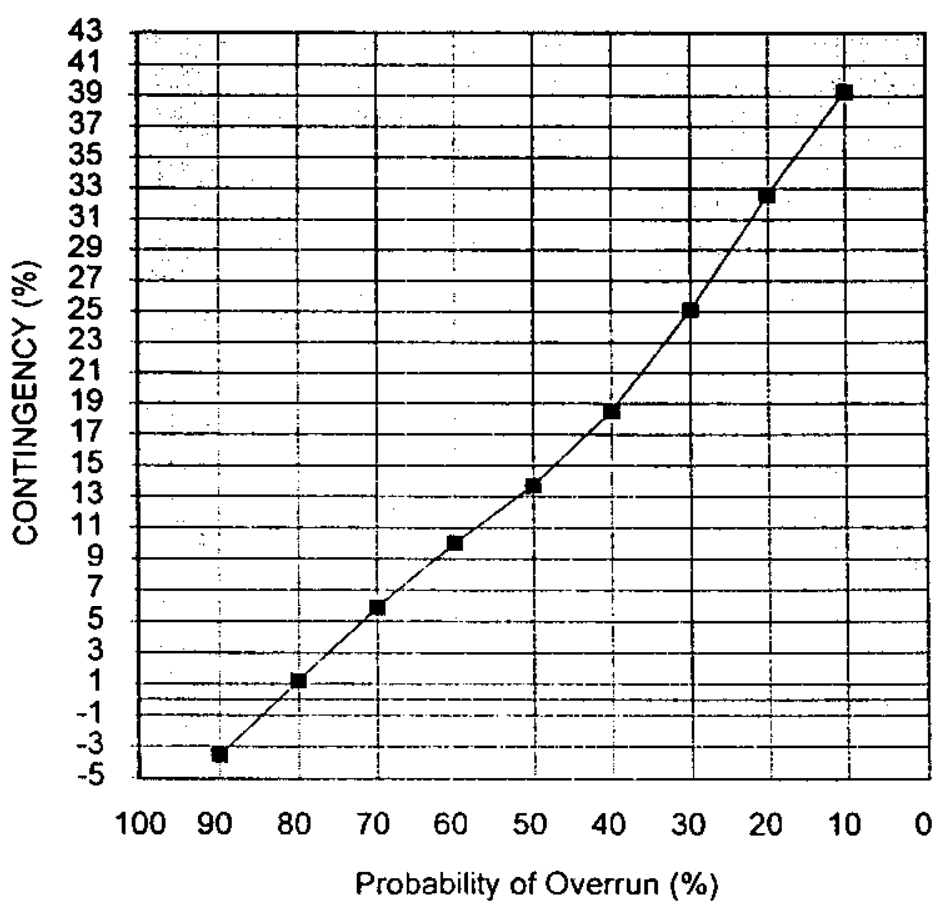

Note: Geotechnical Investigation cost is a subcontract and not included in contingency analysis. The contingency of $\mathbf{2 5 . 1} \%$ was applied to estimated cost. 
UCRL-ID-131617 Rev. 1

PIP-98-1 15 


\section{Appendix $F$ \\ Life Cycle Cost Estimate Summary and Bases}

This appendix provides the basis for the Life Cycle Cost Estimate. It includes the:

- Integrating Contractor Project Management costs

- The Engineering Design costs for construction support (Title III). Title I and Title II, Engineering Design bases, are found in Section 9.1 and Appendix E.

- Procurement Services

- Construction capital costs

- Other project costs

- Management and Operations costs

- Decontamination and Deactivation costs

based on a new $50 \mathrm{MT}$ aboveground facility at the Savannah River Site.

Management and operations costs based on an 18.2 MT throughput are also included.

\section{F.1. Integrating Contractor Project Management}

The costs for integration project management include project management, project engineering cost and schedule control, and clerical/secretarial support. The costs are built up from SRS wage rates and an assumed staffing level over the 66 months of design and construction.

\section{F.2. Engineering Design, Construction Support, Title III}

Table F.1 presents the cost estimate summary of the engineering design for construction support, Title III.

Table F.1. Construction Support Title III Engineering Design Cost Estimate Summary (1st Q/FY00 Dollars).

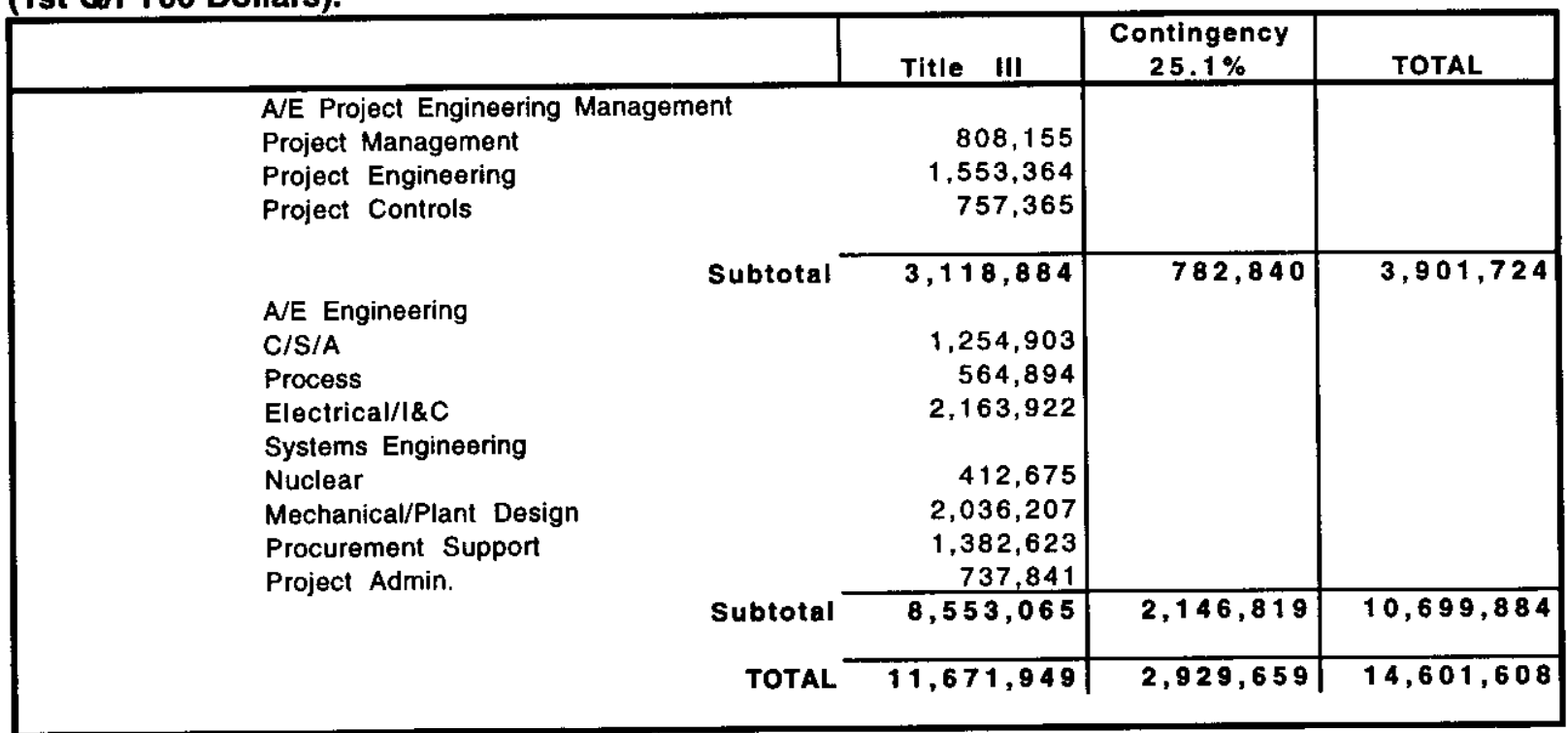




\section{F.3. Procurement Services}

The costs for support to Procurement Services are included in the engineering design costs.

\section{F.4 Construction Capital Cost Estimate}

The construction capital costs (Tables F.2, F.3, F.4, and F.5) include construction field direct and indirect costs, construction management, and A/E project management. The technical scope used for this estimate includes conceptual drawings, sketches, equipment lists, and studies. The general qualifications, assumptions, exclusions, and cost factors are described below.

\section{F.4.1 General Qualifications and Assumptions}

General qualifications and assumptions include the following:

- A bottoms-up budget/conceptual design estimate for a single case, not a comparative estimate.

- All costs based on first quarter FY00 dollars. Cost of escalation beyond FY00 is excluded.

- All construction quantities determined from new design parameters and new facility layouts contained in the DOCDR.

- Gloveboxes based on SRS specifications.

- The following costs based on cost factors from a review by Bechtel:

-Distributable (general conditions) and costs for contractor's overhead and profit

-Contractor's bond

-Construction management

-Project management (excluding DOE administration).

- Contingencies determined by Bechtel's contingency simulation program (BecRAC) which is based on input to a Monte-Carlo program.

- Labor wages based on Davis Bacon rates for the South Carolina area as reviewed by WSRC. These rates include base wage rate, fringe benefits, workman's compensation, social security, and payroll insurance.

- The construction site assumed to be clean of any underground and aboveground obstruction.

- All works for support and service facilities within 5 feet of the construction site unless otherwise specified.

\section{F.4.2 Exclusions}

The following costs are not included in the construction capital cost:

- Cost of land provided by the government

- Costs of NEPA, licensing, and permitting (in OPC)

- DNFSB/DOE oversight costs

- Escalation beyond the first quarter of FY00

- Regulatory compliance documentation (Licensing and Permitting are included in the OPC) 
Table F.2. Total Construction Capital Cost.

$$
\text { Job 23386, Fissile Material Disposition Program }
$$

Immobilization of 50 MT of Plutonium Using New Facilities (Above Ground = AG) with Radiation Protection At the Savannah River Site (DOCDR)

\section{Total Construction Capital Cost}

(in $1^{\text {st } Q}$ / FYOO Dollars)

\begin{tabular}{lrrr} 
Facility / Cost Items & \multicolumn{1}{c}{ Subtotal } & \multicolumn{1}{c}{ Contingency } & Total \\
\cline { 2 - 3 } Process Equipment & $150,935,000$ & $51,469,000$ & $202,404,000$ \\
Process Facilities & $136,640,000$ & $46,594,000$ & $183,234,000$ \\
Site Improvement \& Support Facilities & $46,992,000$ & $16,024,000$ & $63,016,000$ \\
& & & \\
Total & $\mathbf{3 3 4 , 5 6 7 , 0 0 0}$ & $\mathbf{1 1 4 , 0 8 7 , 0 0 0}$ & $\mathbf{4 4 8 , 6 5 4 , 0 0 0}$
\end{tabular}


Table F.3. Construction Capital Cost, Process Equipment.

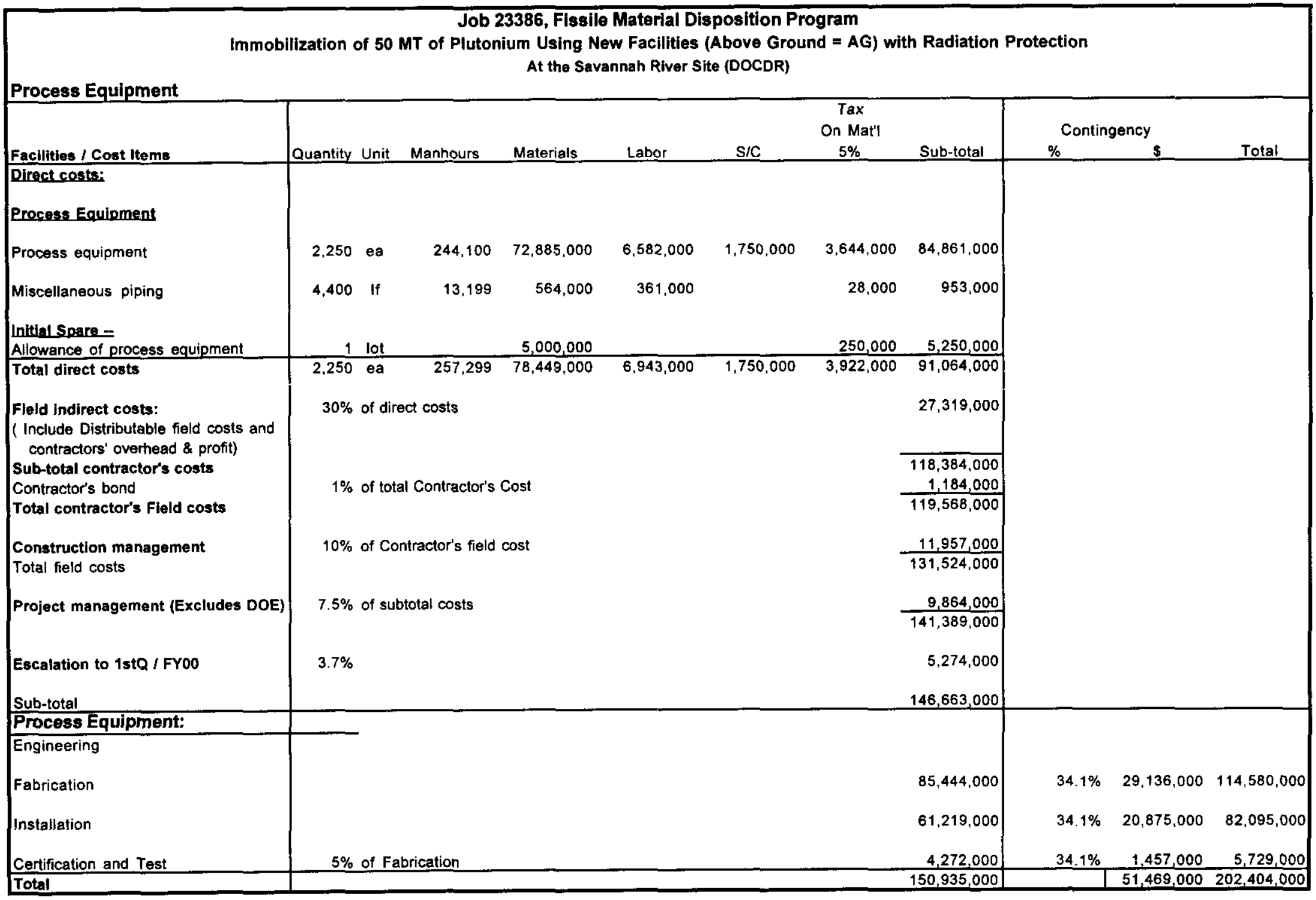




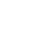

Table F.4. Construction Capital Cost, Process Facilities.

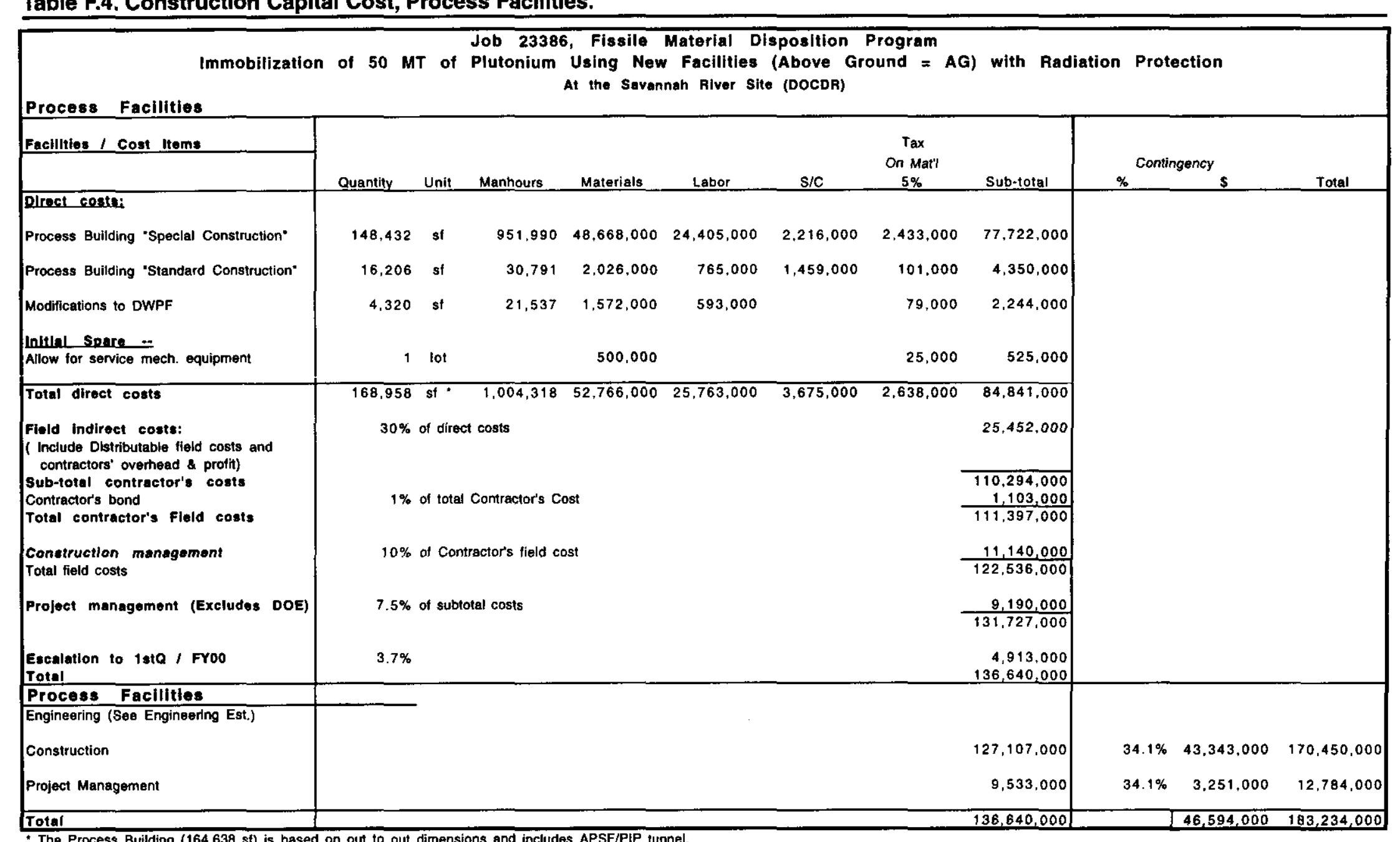


Table F.5. Construction Capital Cost, Site Improvement and Support Facilities.

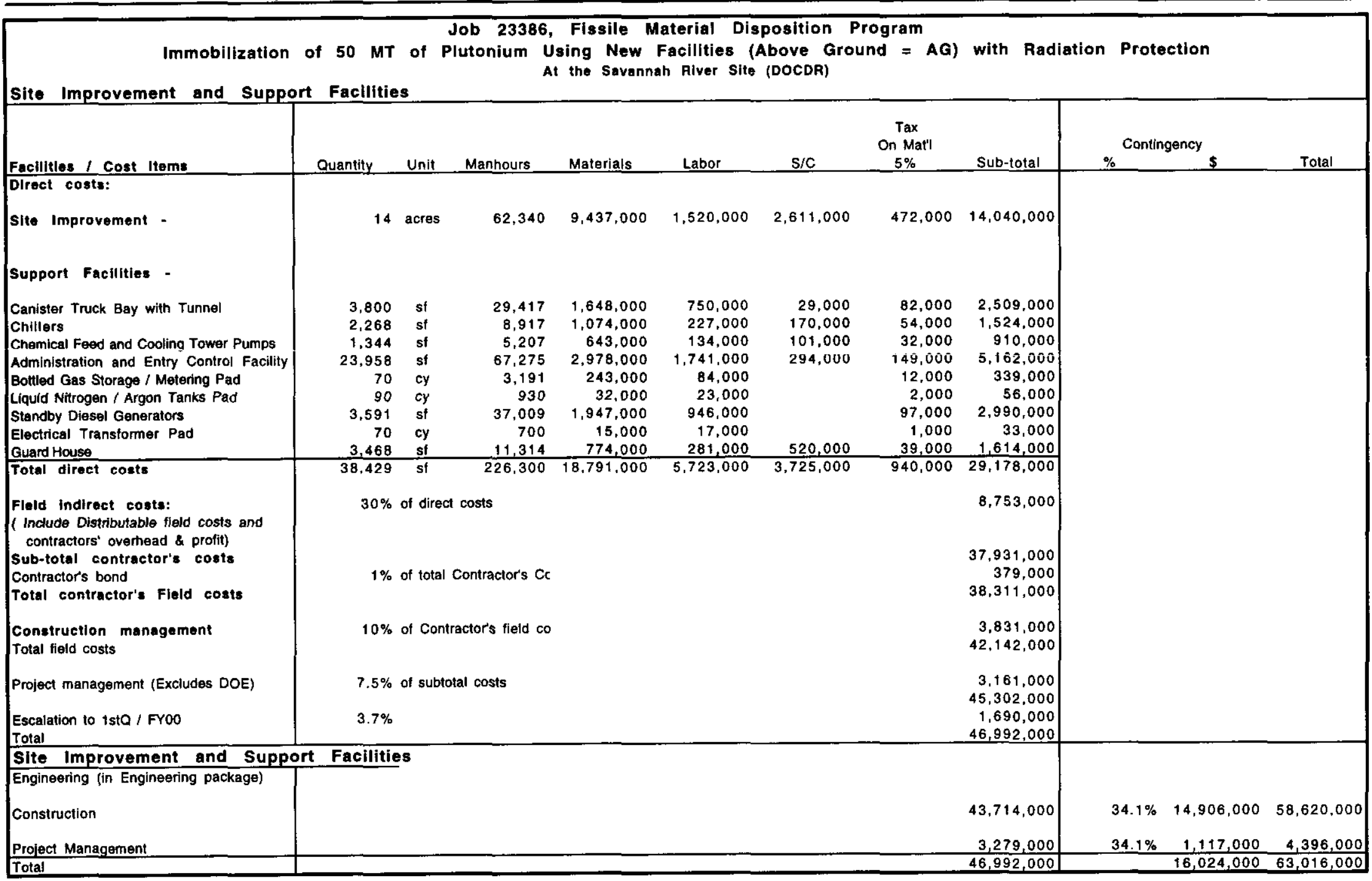

1


- Payments-in-lieu-of-taxes to local communities

- Government fees to privately owned facilities

- Waste management facilities

- APSF construction and operation

- Asbestos and hazardous material removal, if any.

\section{F.4.3 Construction Wage Rates}

The construction base rate and fringes' sources are based on Davis Bacon rates for South Carolina and the U.S. Department of Labor, Wage and Hour Division, Davis Bacon National Office Specialists. The burdened construction wage rates include base rate, fringe benefits, compensation, social security, and payroll insurance. The craft wage rates are listed in Table F.6.

The crew rates by trades are a composite of craft rates. These rates are shown in Table F.7.

Table F.6. Craft burdened wage rates.

\begin{tabular}{lc}
\hline Craft & $\begin{array}{c}\text { Wage Rates } \\
\text { (\$/Hour) }\end{array}$ \\
\hline Boiler Maker (BM) & 32.10 \\
Carpenter (CA) & 25.86 \\
Cement Finishers (CM) & 19.91 \\
Electrician (EL) & 28.27 \\
Struct. Steel Worker (IW) & 29.40 \\
Labor (LA) & 17.70 \\
Millwright (MW) & 26.68 \\
Operator (OE) & 26.53 \\
Painter (PA) & 24.29 \\
Pipefitter (PF) & 27.92 \\
Sheetmetal Worker (SM) & 28.71 \\
Teamster (TM) & 23.21 \\
\hline
\end{tabular}

Table F.7. Crew rates (by trades).

\begin{tabular}{lc}
\hline Basic Crew & $\begin{array}{c}\text { Composite Wage Rates } \\
\text { (\$/Man-hour) }\end{array}$ \\
\hline Civil Work & 19.36 \\
Concrete, all-in & 24.65 \\
Structural steel & 28.73 \\
Architectural finish & 24.05 \\
HVAC & 26.72 \\
Mechanical & 26.93 \\
Piping & 27.36 \\
Electrical equipment & 28.10 \\
Electrical bulks & 28.15 \\
Instrumentation & 27.97 \\
Temp. construction facilities & 25.89 \\
Misc. construction services & 22.45 \\
\hline
\end{tabular}




\section{F.4.4 Indirect Costs and Taxes}

The field indirect costs (FICs), which include field distributable costs and contractors' overhead and profit, are derived from the field direct costs (FDCs). The FDCs include material, equipment, labor, and subcontract (SC) costs. The FICs are based on $30 \%$ of FDCs. The state sales taxes are calculated to be $5 \%$ of material costs. The state sales taxes are included in the FDCs. Contractors' bond is calculated to be $1 \%$ of the combining total costs of FDCs and FICs. The construction management cost is at $10 \%$ of the sum of FDCs, FICs, and contractors' bond.

The project management cost (excluding administration costs of DOE) in the construction phase is at $7.5 \%$ of total field costs (the sum of FDCs, FICs, contractors' bond, and construction management costs).

\section{F.4.5 Estimate Methodology}

The capital cost estimate is performed using a unit cost approach with construction quantities estimated from the site plan, building layout and facility sizing, process flow diagrams, and major equipment. The estimated capital cost includes construction, procurement, equipment staging and installation, and testing. The cost components include sitework and site support facilities, process equipment, and process facilities.

\section{F.4.6 Process Equipment}

The major equipment and gloveboxes are based on the engineering specifications and drawings. Glovebox costs are derived from an estimate of the fabrication cost of individual gloveboxes according to SRS specifications. Equipment unit prices are based on prices provided from WSRC or derived from vendors' quotes and in-house historical data for similar projects.

\section{F.4.7 Process Facilities}

The major quantities of earthwork, concrete, structural steel, architectural, HVAC, mechanical, piping, fire protection, electrical and instrumentation are developed from drawings provided by the Bechtel engineering group. The unit costs for the process buildings are based on the in-house historical data and informal vendors' quotes for similar projects.

\section{F.4.8 Sitework and Site Support Facilities}

Sitework includes the following site improvement and utility scope:

\section{Site improvement}

- Minimal clearing and grubbing (acres)

- Mass earthwork for excavation, backfill, and grading (CY)

- Earthwork for utility foundations, equipment foundations, etc. (CY)

- Roads, accesses, and pavement (LF) 
- Parking areas (SF)

- Storm sewer (LF)

- Security fence (LF)

- Landscaping (acres)

- Yard piping (LF)

- Yard electrical (LS)

- Allowance for utility tie-ins (LS).

Site utility equipment

- Cooling tower

- Chillers

- Substation.

Yard mobile equipment

- Canister cask transporter.

The estimate is based on the engineering developed quantities with units indicated in parenthesis. The unit costs for sitework are based on the in-house historical data bases and informal vendors' quotes.

Site support facilities include the following support buildings

- Administration and entry control facility

- Chemical feed and cooling tower pumps

- Chiller building

- Bottled gas storage/metering pad

- Liquid nitrogen/argon tanks pad

- Standby diesel generators building

- Electrical substation pad

- Guard house

The unit costs for site support facilities are based on the in-house historical data bases and informal vendors' quotes.

\section{F.5 Other Project Costs}

The OPCs are divided into three cost components corresponding to costs for the design/construction phase, research and development activities, and startup phase. The OPC design/construction phase activities comprise all engineering efforts prior to validation and approval of title designs. These include conceptual design, licensing and permitting, environmental impact documentation, research and development, and technology transfer. Design phase activities (licensing and permitting and technology transfer) and research and development which continue beyond the design phase are included.

Environmental documentation, conceptual design, and research and development costs were taken from the LLNL Integrated Development and Testing Plan for Plutonium Immobilization Project, December 1998. Licensing costs and technology transfer costs are built up from SRS wage rates and assumed staffing levels. 
The OPC startup phase activities comprise all support efforts prior to operation of the facility. The startup cost covers the operation cost prior to plant normal operation. The startup cost is based on a factor of 1.2 of the annual normal operation labor cost. These include activities required after facility completion to prepare for the operational readiness review. The operations and maintenance procedures development is based on the SRS wages rates, assumed staffing level, and a one-year development time.

Repository costs are excluded. However, the estimated cost for disposal of the immobilized waste forms in a repository, based upon information contained in the Federal Register notice (52 FR 31508) published by the Department of Energy on August 20, 1987, entitled Civilian Radicactive Waste Management: Calculating Nuclear Fund Disposal Fees for DOE Defense Program Waste, is $\$ 910 \mathrm{M}$ for $50 \mathrm{MT}$ and $\$ 335 \mathrm{M}$ for $18.2 \mathrm{MT}$.

In this notice, DOE identified a preferred cost sharing approach between defense and civilian wastes according to the formula. The repository cost per canister of DHLW is approximately $\$ 500 \mathrm{~K}$ based on a total life cycle cost analysis completed in September 1995, "Analysis of the Total Life Cycle Cost of the Civilian Radioactive Waste Management Program, "DOR/RW-0479, U.S. Department of Energy, Office of Civilian Radioactive Waste Management, September 1995."

\section{F.6. Management and Operation Costs}

The operations costs, Table F.8, are defined for this estimate as the operation and maintenance costs of the plant over its expected life of 10 years. The operation and maintenance cost for the PIP includes operating personnel wages, utilities, consumables, operation material and maintenance expenditures, and waste management and disposal. The transportation or storage of plutonium form and wastes out of the facility is excluded from the estimate.

\section{F.6.1. Labor Costs}

Operation costs for personnel are based on the facility operating manpower requirements as provided by WSRC. The rate for the non-manual labor employee including updated burden rates are based on DOE wage rates for South Carolina. DWPF and APSF operating costs are excluded.

\section{F.6.2. Consumable Material Costs}

Consumable material costs for process operations such as chemicals and additives are based on quoted costs in Chemical Marketing Prices Report magazine. Cooling tower water system treatment chemical costs are based on a preliminary quote from Nalco Chemical Company for treating the required gallons of makeup water. Product canisters are based on pricing from DWPF. Other operating material costs include the supply of waste containers and standard waste drums. The cost for the facilities' equipment maintenance is based on an allowance of $1 \%$ of total equipment capital cost plus $1 \%$ of total facility direct operation and maintenance labor costs. The cost for major capital replacement is based on an allowance of $2 \%$ of total facility equipment costs. 
Table F.8. Management and Operations Cost Estimate Summary (in 1st Q/FY00 dollars).

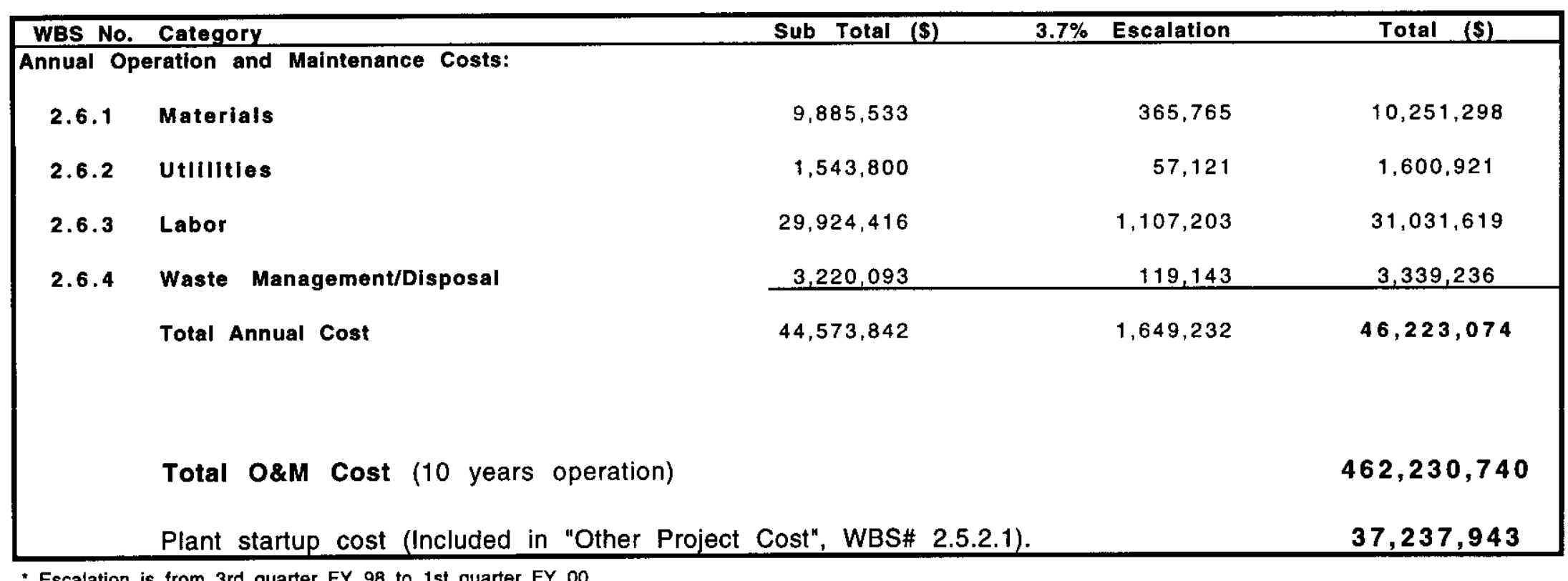




\section{F.6.3 Utility Costs}

The cost for utilities and services (including material, safety, environmental and security) are based on the current kilowatt hour, water usage, estimated fuel consumption, and telephone services costs in the South Carolina area. The utility rates used are:

- Electricity

- Diesel fuel $\$ 0.039 / \mathrm{kwh}$

- Gasoline fuel $\$ 1.50 / \mathrm{gal}$

- Coal $\$ 1.50 / \mathrm{gal}$

- Raw water $\$ 250.00 /$ ton $\$ 0.0014 / \mathrm{gal}$.

\section{F.6.4. Waste Management and Disposal Costs}

Waste management and disposal costs are estimated based on waste disposal costs for disposal of TRU waste to the WIPP in New Mexico and LLW to shallow land burial site. The waste disposal rates are:

- TRU $\$ 696.00 / \mathrm{ft}^{3}$

- LLW $\$ 31.00 / \mathrm{ft}^{3}$

- Mixed LLW $\$ 31.00 / \mathrm{ft}^{3}$

- Hazardous waste $\$ 20.00 / \mathrm{ft}^{3}$.

\section{F.7. Decontamination and Deactivation Cost Estimate}

The D\&D costs are based on the assumption that a DOE M\&O contractor or $\mathrm{A} / \mathrm{E}$ will shut down, decontaminate, and remove contaminated or other surplus equipment from the PIP facility. The D\&D cost estimate is assumed to be $10 \%$ of the total facility construction capital cost. Dismantling and removal of existing facilities or equipment to restore land to the greenfield condition are excluded from this estimate.

\section{F.8. Capital Cost Contingency}

The risk analysis program used to evaluate the contingency for this project is BecRAC, a Bechtel proprietary computer program that uses Monte-Carlo-based methodology. The input for this program consists of terms, variables, and the integration of the terms and variable as discussed below:

- Terms. This program requires that the individual cost elements ("terms" in this programming language) be identified. In order to identify the terms, weights have to be calculated. ("Weight" in this program language means the estimate for each of the identified terms). The sum of the weights of the terms equals the total project cost excluding contingency.

- Variables. Variables that affect the cost accuracy of the terms were identified. For each variable, a probability curve was developed by estimating the variance for five probability points $-10 \%, 25 \%, 50 \%, 75 \%$, and $90 \%$. The values were entered into the code as percentages of the estimated term costs in the process of system simulation. 
- Integration of Terms and Variables. The BecRAC program calculates a single value of the total project cost without contingency for each iteration by randomly choosing points on the probability curve for each variable. Two thousand iterations were used for each. run for this project. The total iterations were summarized to give the probability of an overrun as a function of percentage of the estimated total cost. The results are presented as a curve of probability of overrun versus contingency percentage. The choice of a specific contingency is then determined by the willingness to assume risk. Typically, a $30 \%$ probability of overrun is used for a project at this level of the design.

The contingency evaluation for capital cost is performed using a Monte Carlo risk analysis with terms and variables for construction cost elements. The analysis result is shown in Figure F.1. A 34.1\% contingency is incorporated into the capital cost estimate. This contingency factor is based on a $30 \%$ probability of overrun, which is typically used for a project at this level of the design. 
UCRL-ID-131617 Rev. 1

PIP-98-1 15

Figure F.1. ROM Capital Cost Estimate Contingency.

BECHTEL NATIONAL, INC.

RISK ANALYSIS/CONTINGENCY EVALUATION PROGRAM

Job No.: 23386

Project: DOERLNL
Client: Plutonium Immobilization Plant (PIP), Aboveground w/ R. Protection Location: SRS, SC.

Datc:

$12 / 02 / 98$

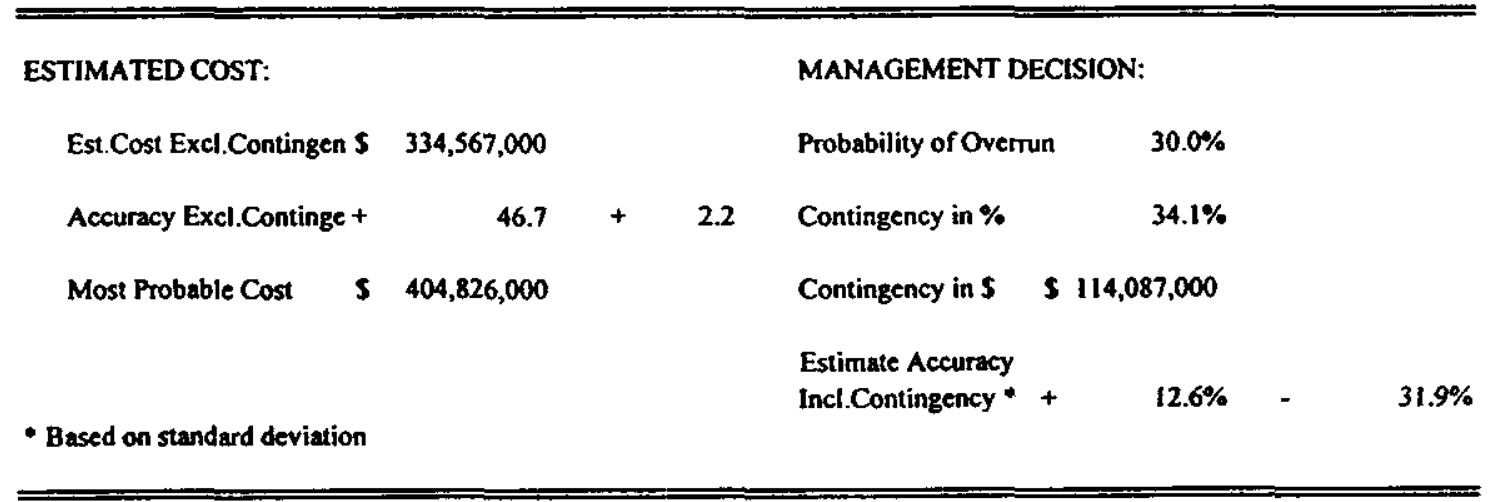

ANALYSIS OF RISK

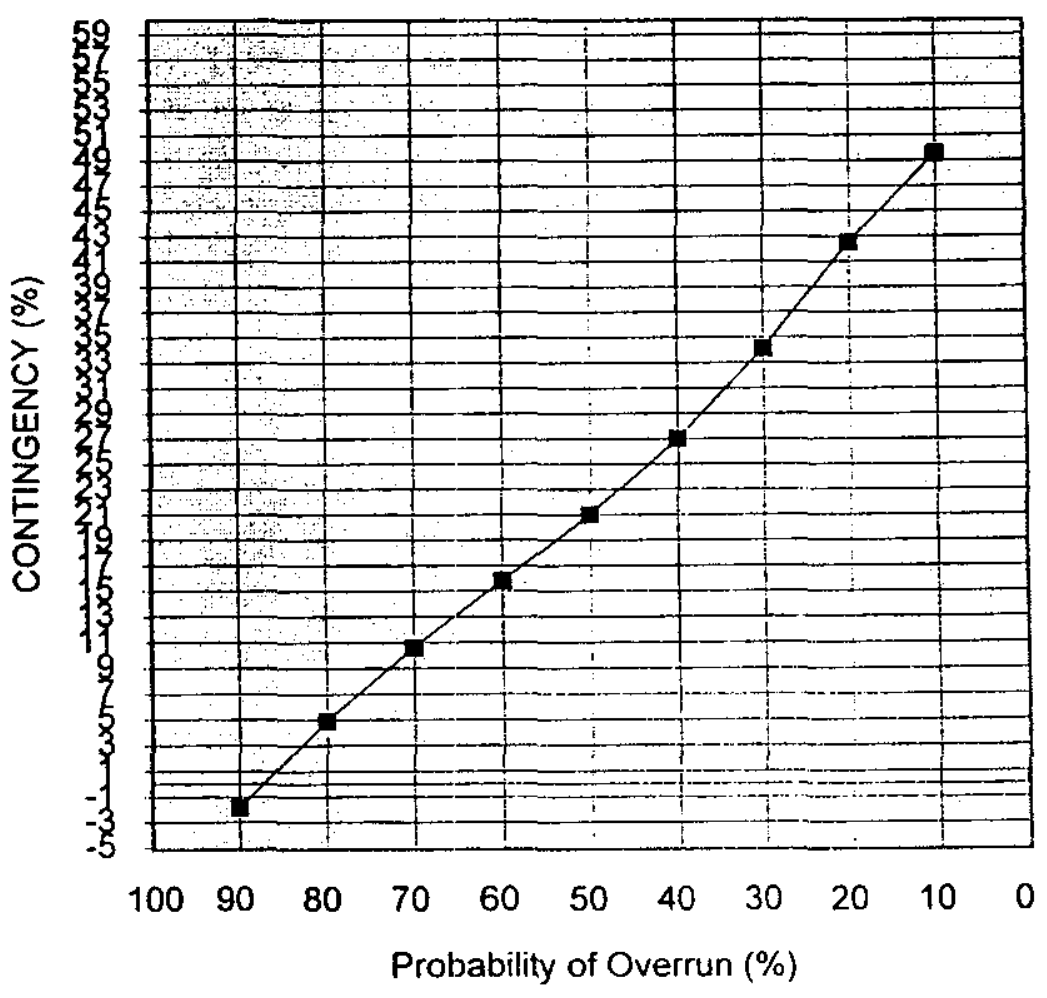




\section{Appendix G List of Measures}

\begin{tabular}{|c|c|}
\hline Btu & British thermal unit \\
\hline C & coulomb \\
\hline $\mathrm{cfm}$ & cubic feet per minute \\
\hline cm & centimeters \\
\hline fpm & feet per minute \\
\hline $\mathbf{f t}$ & foot \\
\hline gpd & gallons per day \\
\hline gpm & gallons per minute \\
\hline GWh & gigawatt hours \\
\hline $\mathbf{h}$ & hour \\
\hline in & inch \\
\hline keff & effective neutron multiplication factor \\
\hline kg & kilogram \\
\hline $\mathbf{l b}$ & pound \\
\hline $\mathbf{k V}$ & kilovolt \\
\hline Lpd & liters per day \\
\hline Lpm & liters per minute \\
\hline m & meter \\
\hline $\mathbf{M P a}$ & megapascals \\
\hline mrem & milli-Roentgen equivalent man \\
\hline $\mathrm{mSv}$ & milli-Sievert \\
\hline MT & metric ton (tonne) \\
\hline MW & megawatt \\
\hline psi & pounds per square inch \\
\hline psig & pounds per square inch gauge \\
\hline $\mathbf{R}$ & roentgen \\
\hline $\mathbf{s}$ & second \\
\hline $\operatorname{scf}$ & standard cubic feet \\
\hline $\mathbf{t}$ & tonne (metric ton, $103 \mathrm{~kg}$ ) \\
\hline VAC & volts alternating current \\
\hline $\mathbf{y}$ & year \\
\hline
\end{tabular}


UCRL-ID-131617 Rev. 1

PIP-98-115 


\section{Appendix $\mathrm{H}$ \\ List of Acronyms and Abbreviations}

A/E

AED

AGV

AHU

ALARA

ALI

ANL-W

ANSI

APSF

ARM

AS/RS

ASHRAE

BMP

CAM

CCTV

CFR

CIF

CO

COR

CRT

D\&D

DAC

DBA

DBF

DNFSB

DOCDR

DOE

DOE-MD

DOE-RW

DWPF

E\&I

ECF

EDE

EIS architect/engineer

aerodynamic equivalent diameter

automatic guided vehicle

air handling unit

as low as reasonably achievable

annual limit of intake

Argonne National Laboratory-West

American National Standards Institute

Actinide Packaging and Storage Facility

area radiation monitor

automated storage and retrieval system

American Society of Heating, Refrigeration, and Air-

Conditioning Engineers

best management practice

continuous air monitor

closed-circuit television

Code of Federal Regulations

consolidated incineration facility

contracting officer

contracting officer's representative

container restraint transport

decontamination and deactivation

derived air concentration

design basis accident

design basis flood

Defense Nuclear Facilities Safety Board

design-only conceptual design report

Department of Energy

The DOE Office of Fissile Materials Disposition

The DOE Office of Civilian Radioactive Waste Marnagement

Defense Waste Processing Facility

electrical and instrumentation

entry control facility

effective dose equivalent

Environment Impact Statement 
ES\&H

FDC

FFTF

FIC

FMEF

FTP

GWSB

HEPA

HEU

HLW

HP

HVAC

HYDOX

I\&C

I/O

IAEA

ICRP

IES

INEEL

IPWF

ISA

IWPF

KMP

LaBS

LAN

LANL

LCC

LETF

LLNL

LLW

$\mathrm{M} \& \mathrm{O}$

MAA

MC\&A

MCC

MFFF

MIS

MOI environment, safety and health

field direct cost

Fast Flux Test Facility

field indirect cost

Fuels Material and Examination Facility

File Transfer Protocol

Glass Waste Storage Building

high-efficiency particulate air

highly enriched uranium

high-level waste

health protection

heating, ventilation, and air conditioning

hydride oxidation

instrumentation and controls

input/output

International Atomic Energy Agency

International Committee on Radiological Protection

Illuminating Engineering Society of North America

Idaho National Engineering and Environmental

Laboratory

immobilized plutonium waste form

Instrument Society of America

Immobilization Waste Processing Facility

key measurement point

lanthanide borosilicate

local area network

Los Alamos National Laboratory

life-cycle cost

liquid effluent treatment facility

Lawrence Livermore National Laboratory

low level waste

management and operations

material access area

material control and accountability

motor control center

MOX Fuel Fabrication Facility

management and information system

maximally exposed offsite individual 


\begin{tabular}{|c|c|}
\hline MOX & mixe:d oxide (fuel) \\
\hline MT & tonne (metric ton) \\
\hline NDA & nondestructive assay \\
\hline NDE & nondestructive examination \\
\hline NESHAP & $\begin{array}{l}\text { National Emissions Standards for Hazardous Air } \\
\text { Pollutants }\end{array}$ \\
\hline NFPA & National Fire Protection Association \\
\hline NIM & nuclear incident monitor \\
\hline NO & nitrous oxides \\
\hline NPDES & National Pollution Discharge Elimination System \\
\hline NPH & natural phenomena hazard \\
\hline NRC & Nuclear Regulatory Commission \\
\hline NSR & New Special Recovery Facility \\
\hline OPC & other project cost \\
\hline ORR & Operational Readiness Review \\
\hline PA & public address \\
\hline PC & performance category \\
\hline PCM & personal contamination monitors \\
\hline PDCF & Pit Dissassembly and Conversion Facility \\
\hline PEP & project execution plan \\
\hline PIDAS & perimeter intrusion detection and assessment system \\
\hline PIP & Plutonium Immobilization Plant \\
\hline PLC & programmable logic controller \\
\hline PSAP & personal security assurance program \\
\hline PSF & Plutonium Storage Facility \\
\hline $\mathbf{P u}$ & plutonium \\
\hline QA & quality assurance \\
\hline QARD & quality assurance requirements document \\
\hline RCRA & Rescurce Conservation and Recovery Act \\
\hline RFETS & Rocky Flats Environmental Technology Site \\
\hline ROM & rough order of magnitude \\
\hline RWP & radiological work permit \\
\hline SBC & standard building code \\
\hline SNM & special nuclear material \\
\hline SRS & Savannah River Site \\
\hline SSC & systems, structures, and components \\
\hline SST & safe secure transport \\
\hline SYNROC & synthetic rock \\
\hline
\end{tabular}


TCP/IP

TEC

TPC

TRU

$\mathbf{U}$

UBC

UL

UPS

VFD

WAC

WBS

WIPP

WSRC

ZPPR
Transmission Control Protocol/Internet Protocol

total estimated cost

total project cost

transuranic

uranium

uniform building code

Underwriters Laboratory

uninterruptible power supply

variable frequency drive

waste acceptance criteria

work breakdown structure

Waste Isolation Pilot Plant

Westinghouse Savannah River Company

Zero Power Physics Reactor 